\title{
WestVirginiaUniversity
}

THE RESEARCH REPOSITORY @ WVU

Graduate Theses, Dissertations, and Problem Reports

2003

\section{Modeling of an aluminum reduction cell for the development of a state estimator}

Philip Biedler

West Virginia University

Follow this and additional works at: https://researchrepository.wvu.edu/etd

\section{Recommended Citation}

Biedler, Philip, "Modeling of an aluminum reduction cell for the development of a state estimator" (2003). Graduate Theses, Dissertations, and Problem Reports. 2475.

https://researchrepository.wvu.edu/etd/2475

This Dissertation is protected by copyright and/or related rights. It has been brought to you by the The Research Repository @ WVU with permission from the rights-holder(s). You are free to use this Dissertation in any way that is permitted by the copyright and related rights legislation that applies to your use. For other uses you must obtain permission from the rights-holder(s) directly, unless additional rights are indicated by a Creative Commons license in the record and/ or on the work itself. This Dissertation has been accepted for inclusion in WVU Graduate Theses, Dissertations, and Problem Reports collection by an authorized administrator of The Research Repository @ WVU.

For more information, please contact researchrepository@mail.wvu.edu. 


\title{
Modeling of an Aluminum Reduction Cell for the Development of a State Estimator
}

\author{
Philip Biedler
}

\author{
Dissertation submitted to the \\ College of Engineering and Mineral Resources \\ at West Virginia University \\ in partial fulfillment of the requirements for the degree of \\ Doctor of Philosophy \\ in \\ Engineering \\ Larry Banta, Ph.D., Chair \\ Ismail Celik, Ph.D. \\ Nigel Clark, Ph.D. \\ Eric Johnson, Ph.D. \\ Alfred Stiller, Ph.D.
}

Department of Mechanical and Aerospace Engineering

Morgantown, West Virginia 2003

Keywords: Aluminum Reduction Cell, Energy Balance, State Estimator, Finite Element Method, Dynamic Response, Parametric Analysis

Copyright 2003 Philip Biedler 


\section{ABSTRACT \\ Modeling of an Aluminum Reduction Cell for the Development of a State Estimator}

\section{Philip Biedler}

Electrolytic cells are used to produce aluminum from alumina ore. These cells use a carbon anode, a cryolitic bath, and a carbon containment vessel, which also serves as the cathode. The process is not completely understood because of the limited number of measurements and its complexity.

A finite element model was developed that simulates the electrical, thermal, and chemical phenomena occurring within the cell. The model was verified by comparing its output to data presented in the literature, and by comparing its output to data gathered from operating reduction cells at Century Aluminum in Ravenswood, WV. The model was used to study the reaction of the system to various changes in process variables, such as the cell voltage, the bath ratio, the alumina concentration, the metal pad depth and the current flow. Changes in these variables had a significant impact on the operating point of the cell. Because deviations from the target level for the process variables are often temporary, short-term changes in the operating state were quantified so that these effects could be accounted for when determining appropriate control actions.

Two simplified models were also developed. The first model was used to estimate the alumina concentration in the bath, and it included the chemical model and a scalar version of the electrical model. This estimator predicts occurrences of high and low alumina concentrations in operating reduction cells with a high level of accuracy. The second model was developed to estimate the bath temperature and the bath ratio. It includes the chemical model, a scalar version of the electrical model, and a thermal model that is made up of a few one-dimensional elements. This model does not appear to predict fluctuations in the temperature with a high degree of accuracy. However, using daily temperature measurements, the model is capable of accurately predicting the bath ratio.

In conclusion, the finite element model provides a useful tool for studying various process interactions, and the alumina concentration and ratio estimators provide the ability to reduce variability in these two important process variables. 


\section{$\underline{\text { Acknowledgements }}$}

I would like to express my appreciation to the U.S. Department of Energy, and Applied Industrial Solutions for their financial support of this project. I would also like to thank Century Aluminum in Ravenswood, WV for the financial and technical support they provided to this project. Finally, I would like to also acknowledge Dr. Larry Banta for his direction and assistance as my research advisor. 


\section{Table of Contents}

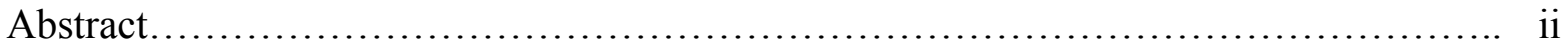

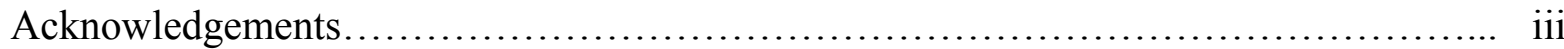

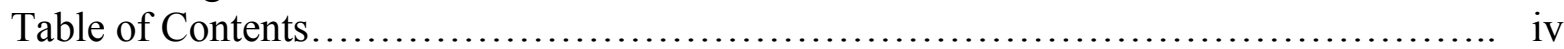

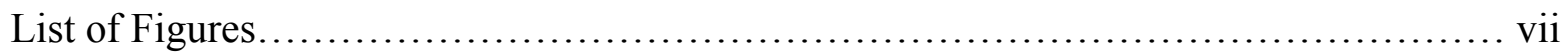

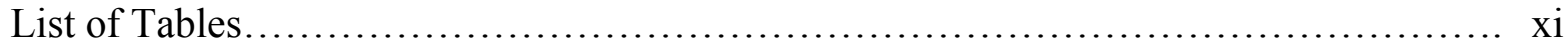

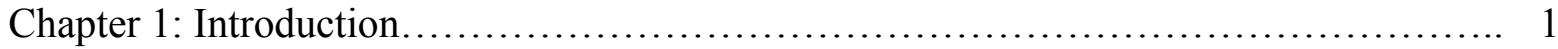

Section 1.1 Introduction to the Aluminum Industry.............................. 1

Section 1.2 Basics of the Aluminum Reduction Process............................ 1

Section 1.3 Industrial Production of Aluminum................................... 2

Section 1.4 Operating Objectives............................................. 5

Section 1.5 Existing Cell Control Strategies.................................... 8

Section 1.6 Difficulties in Reduction Cell Operation.............................. 9

Section 1.7 Pathways to Enhanced Operation.................................... 12

Section 1.8 Overview of the Proposed Research................................ 13

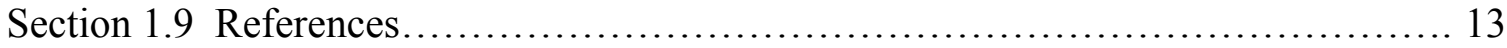

Chapter 2: Overview of Relevant Prior Research........................................ 15

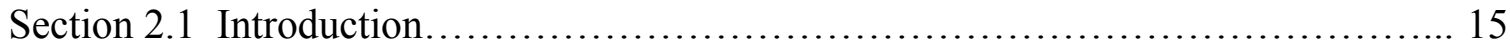

Section 2.2 Mathematical Models.................................................... 15

Section 2.3 Control Systems....................................................... 19

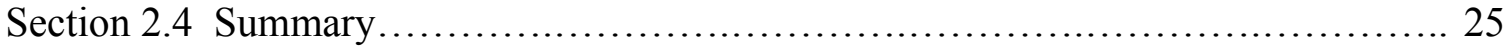

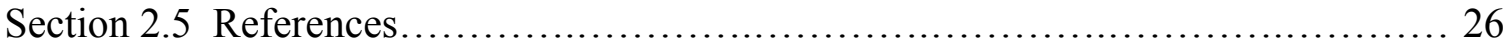

Chapter 3: Approach................................................................... 29

Chapter 4: Overview of the Finite Element Method...................................... 32

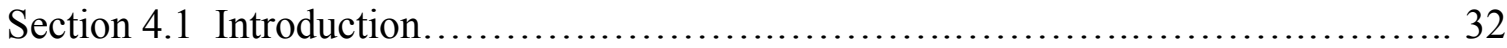

Section 4.2 Deriving the Finite Element Equations from the Differential Equations... 32

Section 4.3 Element Formulation.................................................. 35

Section 4.4 Natural Coordinates..................................................... 37

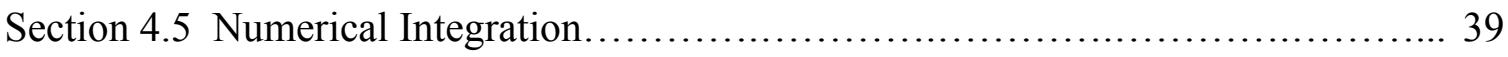

Section 4.6 Node Ordering.................................................... 40

Section 4.7 References............................................................ 41

Chapter 5: Voltage Model............................................................. 42

Section 5.1 Model Formulation.................................................... 42

Section 5.2 Electrical Conductivity of the Anode Carbon.......................... 43

Section 5.3 Anode-Bath Interface Overvoltages.................................. 44

Section 5.4 Electrical Conductivity of the Electrolyte................................... 50

Section 5.5 Electrical Conductivity of the Side Freeze.............................. 50

Section 5.6 Cathode Concentration Overvoltage..................................... 50

Section 5.7 Metal Pad-Carbon Cathode Interface Resistance.......................... 51

Section 5.8 Conductivity of the Cathode Assembly................................ 51

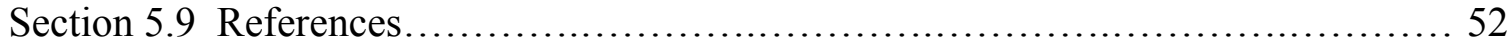

Chapter 6: Heat Transfer Model............................................................ 53

Section 6.1 Model Formulation..................................................... 53

Subsection 6.1.1 General Finite Element Formulation.............................. 53

Subsection 6.1.2 Weighting Function Formulation.............................. 56 
Subsection 6.1.3 Solution Approach........................................... 59

Section 6.2 Boundary Conditions and Internal Heat Generation...................... 61

Subsection 6.2.1 Approximate Cell Heat Balance................................. 61

Subsection 6.2.2 Convection and Radiation Boundary Conditions................. 62

Subsection 6.2.3 Anode Rod, Collector Bar, and Deck Plate Heat Losses.......... 66

Subsection 6.2.4 Internal Heat Generation and Consumption...................... 68

Section 6.3 Material Properties and Internal Heat Transfer Coefficients................. 72

Section 6.4 Sidewall Freeze............................................................ 76

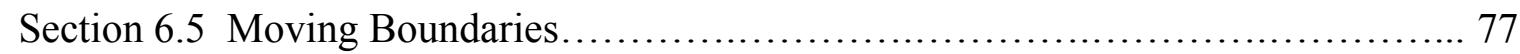

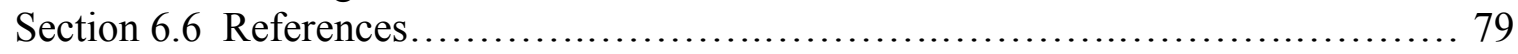

Chapter 7: Chemical Species Model................................................ 80

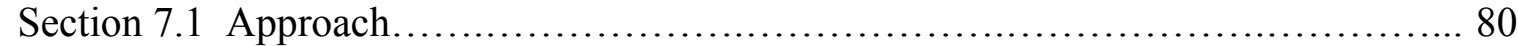

Section 7.2 Alumina Additions.................................................. 81

Section 7.3 Corrective Bath Additions............................................ 83

Section 7.4 Bath Evolution....................................................... 84

Section 7.5 Sodium Deposition................................................. 89

Section 7.6 Mass of the Bath, Metal Pad, and Anode Carbon.............................. 90

Section 7.7 Current Efficiency................................................... 91

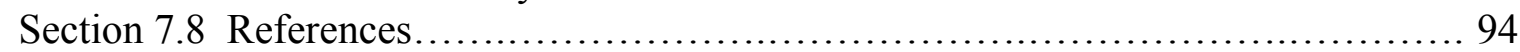

Chapter 8: Reduction Cell Model Verification......................................... 95

Section 8.1 Overview............................................................. 95

Section 8.2 Verification of the Voltage Model....................................... 95

Section 8.3 Verification of the Steady-State Thermal Model......................... 96

Section 8.4 Verification of the Transient Thermal Model............................... 98

Subsection 8.4.1 Verification of the Selected Time-Steps......................... 98

Subsection 8.4.2 Verification of the Thermal Time Scales....................... 102

Subsection 8.4.3 Comparison of Predicted and Measured Response for Voltage

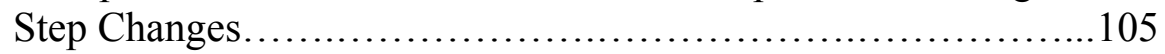

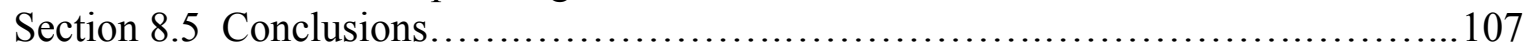

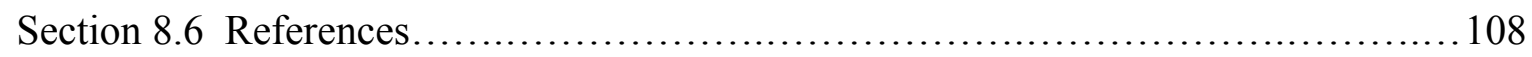

Chapter 9: Results from the Reduction Cell Model....................................... 109

Section 9.1 Results from the Voltage Model.......................................... 109

Subsection 9.1.1 Effects of Varying the Cell Current Density....................... 109

Subsection 9.1.2 Effects of Varying Bath Depth...................................111

Subsection 9.1.3 Effect of Ratio and Bath Temperature........................... 112

Subsection 9.1.4 Effect of Misset Anodes........................................... 113

Section 9.2 Results from the Combined Model........................................ 116

Subsection 9.2.1 Effect of Voltage Changes................................... 116

Subsection 9.2.2 Effect of Alumina Concentration Changes....................... 123

Subsection 9.2.3 Effect of Changes in the Bath Depth...............................124

Subsection 9.2.4 Effect of Changes in the Metal Pad Depth........................ 125

Subsection 9.2.5 Effect of Changes in the Top Crust Thickness.....................128

Subsection 9.2.6 Effects of Aluminum Fluoride and Soda Ash Additions........... 129

Subsection 9.2.7 Effects Caused by the Metal Tapping Cycle...................... 133

Subsection 9.2.8 Effect of Power Modulation..................................... 135

Subsection 9.2.9 Effect of Changes in the Alumina Feed Weight and Distribution 137 
Chapter 10: Alumina Concentration Estimator..................................... 141

Section 10.1 Approach.......................................................... 141

Section 10.2 Model Results...................................................... 146

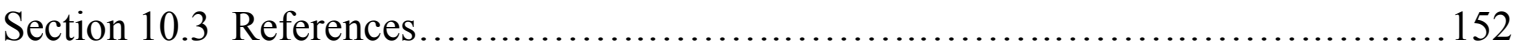

Chapter 11: Bath Temperature and Ratio Estimator.................................. 153

Section 11.1 Approach........................................................ 153

Section 11.2 Model Verification................................................... 156

Section 11.3 Estimator Results................................................... 159

Chapter 12: Conclusions and Future Work....................................... 162

Appendix A: Data from the Verification of the Alumina Concentration Estimator, and the

Temperature and Ratio Estimator................................. 165 


\section{$\underline{\text { List of Figures }}$}

Chapter 1: Introduction

Figure 1.1: Schematic of a vertical stud Soderberg reduction cell................... 3

Figure 1.2: Schematic of a prebake reduction cell............................... 3

Chapter 2: Overview of Relevant Prior Research

Chapter 3: Approach

Figure 3.1: Side view of a typical prebake reduction cell.......................... 30

Figure 3.2: End view of a prebake reduction cell with mesh....................... 30

Chapter 4: Overview of the Finite Element Method

Figure 4.1: Nine node quadrilateral element....................................... 36

Figure 4.2: Square element in the natural coordinate system....................... 38

Chapter 5: Voltage Model

Chapter 6: Heat Transfer Model

Figure 6.1: Nine node element with element parameters and positive velocity

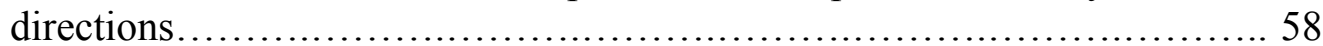

Figure 6.2: Schematic of the area between two pots............................ 64

Figure 6.3: Temperature distribution in the anode "fin" at nominal conditions......... 67

Figure 6.4: Schematic for air gap radiation coefficient determination................ 75

Figure 6.5: Top corner of the cell with mesh lines. (1. Sidewall freeze, 2. Top crust,

3. Anode 4. Bath, and 5. Metal pad) ............................... 78

Chapter 7: Chemical Species Model

Figure 7.1: Gaseous fluorine evolution in kilograms per metric ton of aluminum for various aluminum concentrations and bath ratios....................... 86

Figure 7.2: Rate of fluorine evolution in kilograms per metric ton of aluminum due to particulate emissions for various alumina concentrations at several ratio/temperature pairings..................................... 88

Figure 7.3: Rate of fluorine evolution in kilograms per metric ton of aluminum due to entrainment for various alumina concentrations at several ratio/temperature pairings............................................................ 89

Figure 7.4: Sodium consumption in kilograms per day for pots of differing ages........ 90 Chapter 8: Reduction Cell Model Verification

Figure 8.1: Voltage versus alumina concentration for various anode-cathode distances. 96

Figure 8.2: Contour plot of temperature predictions. Contours at 120, 260, 370, 540,

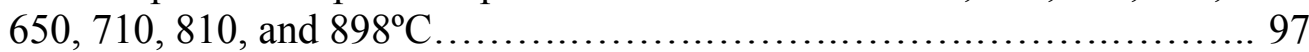

Figure 8.3: Comparison of measured and modeled sidewall ledge profile............... 98

Figure 8.4: Error in the bath temperature between simulations with a time-step of 1.0 Seconds and a time-step of 0.1 seconds............................... 99

Figure 8.5: Error in the bath temperature between simulations with a time-step of 300 seconds and a time-step of 30 seconds.............................. 100

Figure 8.6: Error in the sidewall thickness between simulations with a time-step of 300 seconds and a time-step of 30 seconds......................... 100

Figure 8.7: Error in the top crust temperature between simulations with a time-step of 300 seconds and a time-step of 30 seconds......................... 101

Figure 8.8: Error in the bottom temperature between simulations with a time-step of 300 seconds and a time-step of 30 seconds......................... 101 
Figure 8.9: Response of the bottom temperature to a step change in the voltage....... 103

Figure 8.10: Response of the sidewall temperature to a step change in the voltage..... 103

Figure 8.11: Response of the top crust to a step change in voltage..................... 104

Figure 8.12: Response of the bath temperature to several feed events................. 104

Figure 8.13: Comparison of measured and modeled bath temperature preceding and

following a step change in the cell voltage............................ 106

Figure 8.14: Comparison of measured and modeled bath temperature highlighting several feed events

Figure 8.15: Comparison of measured and estimated alumina concentration............ 107

Chapter 9: Results from the Reduction Cell Model

Figure 9.1: Voltage versus alumina concentration for applied current densities of 0.9, 1.0 , and $1.10 \mathrm{~A} / \mathrm{cm}^{2}$

Figure 9.2: Voltage versus alumina concentration for bath depths of 19.05, 15.88, 10.16 , and $5.08 \mathrm{~cm}$

Figure 9.3: Relative voltage with respect to a ratio of 1.12 versus alumina

Concentration for ratios of $1.00,1.06,1.18$, and 1.24

Figure 9.4: Comparison of current density at varying alumina concentrations for Anodes set at dfferent anode-cathode distances.

Figure 9.5: Expected current density when a given number of anodes are misset and The average current density is $1.00 \mathrm{~A} / \mathrm{cm}^{2}$.

Figure 9.6: Percentage of dissipated heat lost through the anode top, top crust, anode rod, and deck plate for different cell voltages.

Figure 9.7: Percentage of dissipated heat lost through the bath sidewall, metal pad sidewall, remaining sidewall, pot bottom, end walls, and collector bars for different cell voltages.

Figure 9.8: Ratio versus cell voltage starting from various ratios at a cell voltage of $4.50 \mathrm{~V}$

Figure 9.9: Bath temperature versus cell voltage starting from various ratios at a cell voltage of $4.50 \mathrm{~V}$

Figure 9.10: Sidewall freeze thickness versus cell voltage starting from various ratios

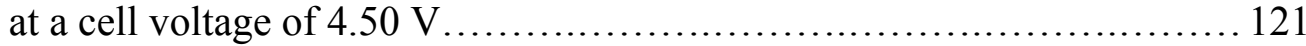

Figure 9.11: Ratio versus time for a step change in cell voltage from $4.50 \mathrm{~V}$ to $4.40 \mathrm{~V} .122$

Figure 9.12: Ratio versus alumina concentration.............................. 123

Figure 9.13: Time response for the ratio due to an alumina concentration change from $3.5 \%$ to $3.0 \%$.

Figure 9.14: Ratio versus bath depth.......................................... 125

Figure 9.15: Ratio versus metal pad depth.................................... 126

Figure 9.16: Sidewall thickness versus metal pad depth.......................... 126

Figure 9.17: Bath depth versus metal pad depth................................ 127

Figure 9.18: Time response for a change in the bath depth from $12.70 \mathrm{~cm}$ to $10.16 \mathrm{~cm} .127$

Figure 9.19: Ratio versus top crust thickness................................... 128

Figure 9.20: Time response of the bath ratio to a step change in the top crust thickness 129

Figure 9.21: Ratio versus fluoride additions for several final bath depths.............. 130

Figure 9.22: Ratio versus soda ash additions for several final bath depths............. 131

Figure 9.23: Initial bath depth versus fluoride additions for several final bath depths... 131

Figure 9.24: Initial bath depth versus soda ash additions for several final bath depths... 132 
Figure 9.25: Time response of the ratio to a $50 \mathrm{lb}(22.73 \mathrm{~kg})$ addition of aluminum fluoride

Figure 9.26: Time response of the ratio to a $50 \mathrm{lb}(22.73 \mathrm{~kg})$ addition of soda ash...... 133

Figure 9.27: Metal pad depth versus time for $24 \mathrm{hr}$ and $48 \mathrm{hr}$ tapping cycles........... 134

Figure 9.28: Bath ratio versus time for $24 \mathrm{hr}$ and $48 \mathrm{hr}$ tapping cycles................ 134

Figure 9.29: Bath temperature versus time for $24 \mathrm{hr}$ and $48 \mathrm{hr}$ tapping cycles.......... 135

Figure 9.30: Effect of 25\% power modulation for $1 \mathrm{hr}, 2 \mathrm{hr}, 4 \mathrm{hr}$, and $8 \mathrm{hr}$ on the bath temperature.................................................. 136

Figure 9.31: Effect of 25\% power modulation for $1 \mathrm{hr}, 2 \mathrm{hr}, 4 \mathrm{hr}$, and $8 \mathrm{hr}$ on the bath

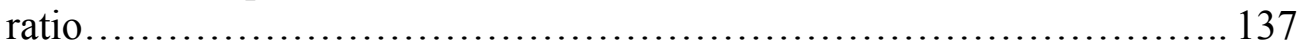

Figure 9.32: Effect of 25\% power modulation for $1 \mathrm{hr}, 2 \mathrm{hr}, 4 \mathrm{hr}$, and $8 \mathrm{hr}$ on the superheat...................................................... 137

Figure 9.33: Effect of 25\% power modulation for $1 \mathrm{hr}, 2 \mathrm{~h} 4,4 \mathrm{hr}$, and $8 \mathrm{hr}$ on the sidewall freeze thickness........................................... 138

Figure 9.34: Bath temperature response to feed events of $80 \%, 100 \%$, and $120 \%$ of the normal feed weight versus time.

Figure 9.35: Alumina concentration response to feed events of $80 \%, 100 \%$, and $120 \%$ of the normal feed weight versus time.

Figure 9.36: Bath temperature response to feed events containing $50 \%, 75 \%$, and $95 \%$
Alumina powder and $50 \%, 25 \%$, and $5 \%$ sludge versus time.............
Figure 9.37: Alumina concentration response to feed events containing $50 \%, 75 \%$, and

Figure 9.36: Bath temperature response to feed events containing $50 \%, 75 \%$, and $95 \%$
Alumina powder and $50 \%, 25 \%$, and $5 \%$ sludge versus time.......... 140
Figure 9.37: Alumina concentration response to feed events containing $50 \%, 75 \%$, and $95 \%$ alumina powder and 50\%, 25\%, and 5\% sludge versus time........ 142

Chapter 10: Alumina Concentration Estimator

Figure 10.1: Voltage versus alumina concentration for several anode-cathode

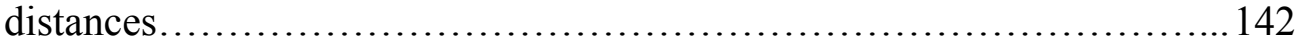

Figure 10.2: Histogram of the aluminum concentration samples.................... 147

Figure 10.3: Typical plot of the hysteresis voltage over a search-overfeed cycle....... 148

Figure 10.4: Relative estimated and measured voltage during a search-overfeed period for a cell that was correctly identified as having a low alumina concentration.

Figure 10.5: Estimated alumina concentration for the same search-overfeed period as shown in Figure 10.4.

Figure 10.6: Relative estimated and measured voltage during a search-overfeed period for a cell that was correctly identified as having a high alumina concentration.

Figure 10.7: Estimated alumina concentration for the same search-overfeed period as shown in Figure 10.6.

Chapter 11: Bath Temperature and Ratio Estimator

Figure 11.1: Schematic showing the elements, nodes, boundary conditions and connections used in the reduced order thermal model.................... 155

Figure 11.2: Schematic of a typical node and the neighboring elements and nodes..... 156

Figure 11.3: Comparison of the heat losses from different parts of the cell from the finite element model (FEM) and the reduced order model (ROM) ........ 157

Figure 11.4: Comparison of output ratios at different voltages for the finite element model (FEM) and the reduced order model (ROM)

Figure 11.5: Comparison of bath temperature predictions and measured values 
following a step change in the voltage ............................. 159

Figure 11.6: Estimated temperature verses actual temperature..................... 161

Figure 11.7: Estimated ratio versus actual ratio............................... 161

Chapter 12: Conclusions and Future Work 


\section{$\underline{\text { List of Tables }}$}

Chapter 1: Introduction

Chapter 2: Overview of Relevant Prior Research

Chapter 3: Approach

Chapter 4: Overview of the Finite Element Method

Table 4.1: Points and weights for Gauss-Legendere integration...................... 40

Chapter 5: Voltage Model

Chapter 6: Heat Transfer Model

Table 6.1: Heat losses through various cell components............................. 62

Table 6:2: Effective convection coefficients, estimated surface temperature, and

Ambient temperature for various cell surfaces........................ 62

Table 6.3: Thermochemical data for reaction components in $\mathrm{kJ} / \mathrm{mol}-\mathrm{K} \ldots \ldots \ldots \ldots \ldots \ldots . \ldots 1$

Chapter 7: Chemical Species Model

Chapter 8: Reduction Cell Model Verification

Table 8.1: Variable values used for verification run................................ 96

Table 8.2: Comparison of literature and model values for component voltages........... 96

Chapter 9: Results from the Reduction Cell Model

Chapter 10: Alumina Concentration Estimator

Table 10.1: Hysteresis voltage components.................................... 148

Table 10.2: Summary of the ability of the estimator to correctly identify occurrences

of high and low alumina concentrations............................ 152

Chapter 11: Bath Temperature and Ratio Estimator

Table 11.1: Descriptions for the part of the cell referred to by each column pairing in

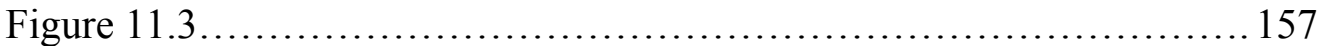

Chapter 12: Conclusions and Future Work 


\section{Chapter 1: Introduction}

\subsection{Introduction to the Aluminum Industry}

Aluminum is currently the most widely used non-ferrous metal. Since aluminum was discovered in 1825, the aluminum industry has grown rapidly. From 1900 to 2002, production grew from 6000 tons per year to 20.2 million tons per year [1,2]. Demand for aluminum is expected to continue to grow through the $21^{\text {st }}$ century. Much of the popularity of aluminum comes from its ductility, high electrical and thermal conductivity, high strength per unit weight, and impervious oxide layer. Aluminum is used in such applications as electrical wiring, aircraft structural members, and automobile bodies.

While the element itself is abundant, making up over $7 \%$ of the mass of the earth's crust, it is never found in nature in elemental form because of its high chemical reactivity [1]. Thus, means of extracting elemental aluminum from naturally occurring compounds have been a topic of much research.

\subsection{Basics of the Aluminum Reduction Process}

The current commercial method of producing aluminum from natural ores is a twostep process. First, the natural ores are converted to alumina, $\mathrm{Al}_{2} \mathrm{O}_{3}$, in what is called the Bayer Process. Then, the alumina is converted to aluminum through the Hall-Heroult process.

The Hall-Heroult process uses electrochemical means to reduce alumina to aluminum. Direct current flows from the anode through an electrolytic bath that contains the dissolved alumina. The aluminum is liberated from the oxygen in the alumina and deposited at the cathode. The oxygen combines with carbon from the anode to form 
carbon dioxide which is released as a gas. Thus, the anode is consumed during the process. A carbon lining is used as a containment vessel and to collect the current as it leaves the molten aluminum. The overall reaction for this process is endothermic and is given by Equation 1 .

$$
2 \mathrm{Al}_{2} \mathrm{O}_{3}+3 \mathrm{C} \rightarrow 3 \mathrm{CO}_{2}+4 \mathrm{Al}
$$

The electrolytic bath is primarily made up of molten cryolite, $\mathrm{Na}_{3} \mathrm{AlF}_{6}$. Other compounds are added to the cryolite to adjust the properties of the bath, in order to make the process more efficient. Some of these compounds include aluminum fluoride $\left(\mathrm{AlF}_{3}\right)$, calcium fluoride $\left(\mathrm{CaF}_{2}\right)$, and lithium fluoride $(\mathrm{LiF})$.

\subsection{Industrial Production of Aluminum}

On an industrial level, the Hall-Heroult process is carried out in devices called reduction cells. A group of cells is connected in series to form a potline. There are two basic types of reduction cells: the Soderberg cell and the prebake cell. A schematic of a Soderberg cell can be seen in Figure 1.1, and a schematic of a prebake cell can be seen in Figure 1.2. Both types of cells have a steel shell lined with a refractory material and carbon. The refractory material serves to reduce energy losses from the cell and the carbon serves as the cathode. The primary difference between the two types of cells is the type of anode used. 


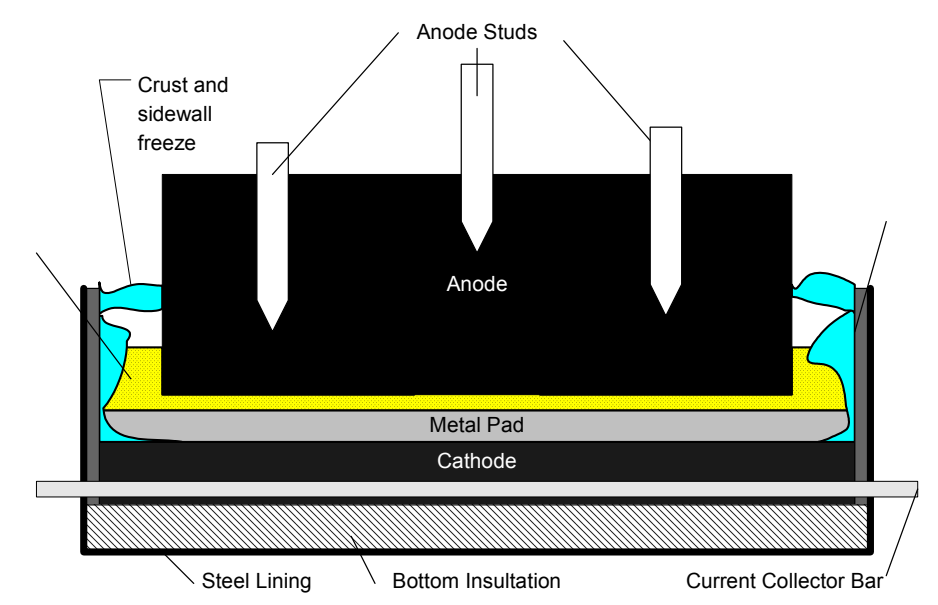

Figure 1.1: Schematic of a vertical stud Soderberg reduction cell

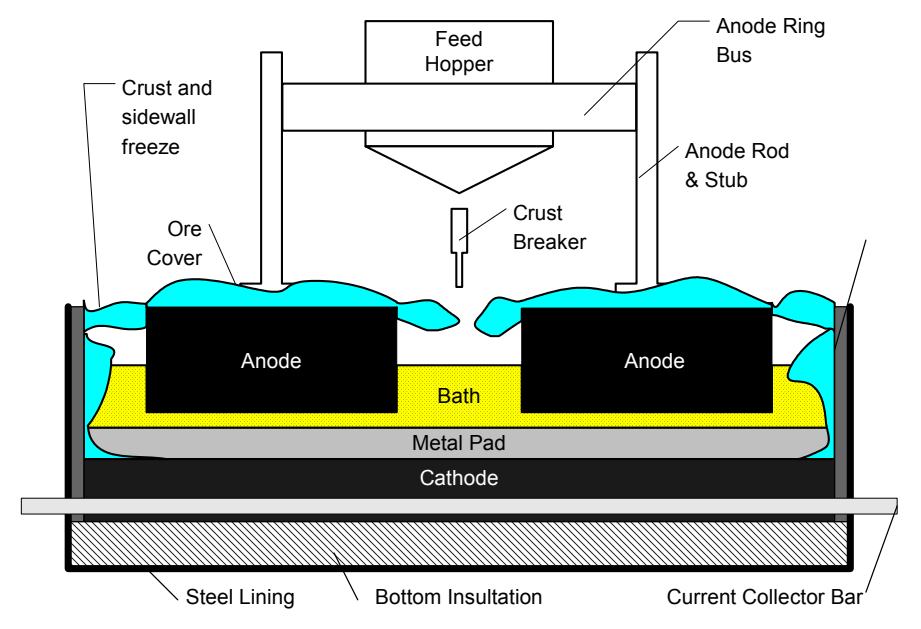

Figure 1.2: Schematic of a prebake reduction cell

Soderberg cells have one large anode. As the anode is consumed, fresh carbon coke and pitch are added, and the heat of the cell is used to bake this combination to form new anode material. While this method of baking the anode utilizes energy that is wasted in prebake cells, Soderberg cells have several shortcomings. One shortcoming is that it is difficult to hood the cells properly to remove potentially harmful gasses, such as HF and $\mathrm{CF}_{4}$, because of the setup of the anode. Another problem is that the resulting anode is not as electrically conductive as prebaked anodes because the Soderberg anodes are baked at a lower temperature. A third shortcoming is that the quality of the anode is not as high as 
for prebaked cells, leading to increased carbon consumption. Finally, the large size of the anode results in problems with the evolution of the carbon dioxide, leading to lower current efficiency and longer anode effects, or periods of high voltage. For these reasons, plants with Soderberg cells are no longer built, though there are older plants that still operate Soderberg cells.

The majority of cells in operation today are prebake cells. These cells utilize multiple anodes, placed in two rows along the length of the pot. The anodes are baked prior to insertion into the cell. These anodes are replaced in a systematic fashion as they are consumed.

Within each of these technologies, variations exist. One important variation is the amount of current passed through the cell. Older cell designs have an operating current as low as $75 \mathrm{kA}$ while the newest cell technology operates at as much as $500 \mathrm{kA}$. The size of the anodes, as well as the anode current density, determines the operating current. Older cells are smaller, but tend to be operated at a higher current density. The increased size of newer cells was made possible by computer simulations that allowed for cell designs that minimize magnetically induced oscillations of the molten metal. Larger cells are favored because they reduce the number of man-hours needed to produce a given quantity of aluminum.

The second major variation occurring within a particular cell technology is the manner in which the alumina is added to the bath. In the past, before the advent of the microcomputer, alumina was added manually in large batches and gradually dissolved into the bath. This method of adding alumina caused large swings in the dissolved alumina concentration, hereafter alumina concentration, in the bath, leading to a loss of 
cell efficiency and an increase in the number of anode effects. When computer control was added to the reduction process, improvements were made in the way in which alumina was added to the cell. The first advance was the addition of automatic crust breakers. With these devices, workers manually add large amounts of alumina. Then when the alumina concentration in the bath becomes low enough, the crust breaker is activated. The breaker breaks alumina rich crust into the bath, allowing it to dissolve more quickly, resulting in closer control of the alumina concentration. In recent years, another improvement has been made: the point feeder. The point feeder consists of a hopper that frequently adds a small amount of alumina. With this technology, the alumina concentration in the bath can be controlled to remain near some optimum level. This increases cell efficiency and reduces the frequency of anode effects.

\subsection{Operating Objectives}

Determining the optimal operating point of a reduction cell with a fixed geometry is a complex process, however, there are four main objectives. The main objectives are to operate at a high efficiency, minimize the number and duration of anode effects, maximize the life of the cell, and minimize the amount of carbon consumption. The primary variables which must be determined to meet the operating objectives include the following: anodic current density, total cell voltage, alumina concentration, bath temperature, bath composition, metal pad depth, and bath depth.

The efficiency of the process can be assessed in two ways. The first measure of process efficiency is current efficiency. This measure compares the ratio of the actual mass of aluminum produced to the theoretical amount of aluminum that should have been 
produced based on the current flow. Theoretically, $0.336 \mathrm{~g}$ of aluminum should be produced for every ampere-hour of electricity passed through the cell. The main source of current efficiency loss is due to the recombination of the carbon dioxide with the aluminum according to the following equation:

$$
\mathrm{Al}+\frac{3}{2} \mathrm{CO}_{2} \rightarrow \frac{1}{2} \mathrm{Al}_{2} \mathrm{O}_{3}+\frac{3}{2} \mathrm{CO}
$$

The rate of recombination is primarily controlled by the temperature, composition, and level of agitation of the electrolyte.

The second measure of process efficiency is the level of specific energy consumption. This is calculated by determining the number of kilowatt-hours of electricity needed to produce a kilogram of aluminum. The energy consumption is determined by both the design and the operation of the reduction cell. Cell design dictates the minimum possible energy consumption. This is a factor of the total current, the size of the anodes, the crosssection of the electrolyte, and the size of the carbon cathode blocks. Cell operation determines the difference between the minimum and the actual energy consumption. Alumina concentration in the electrolyte, the composition of the electrolyte, the temperature of the electrolyte, and the distance between the anode and the metal pad are the main operational factors that must be controlled to achieve minimum energy consumption.

Anode effects occur when the concentration of alumina in the bath drops below a critical level. They are characterized by the cell voltage jumping from $4.5 \mathrm{~V}$ to as much as $90 \mathrm{~V}$. The increase in voltage occurs at the anode-electrolyte interface and, as such, causes a significant increase in anode temperature and electrolyte temperature, disrupting the heat balance of the cell. Furthermore, anode effects result in the release of 
fluorocarbons, commonly known as greenhouse gases. For these reasons, it is desirable to minimize the number of anode effects by operating the cell at an alumina concentration greater than the critical level.

Cell failure occurs either when the bath penetrates through the cathode material or the sidewall carbon. In either case, the cell can no longer contain the electrolyte or the molten metal and must be shut down and rebuilt. There are three main factors that can compromise cell life. The first factor is starting up and shutting down the cell multiple times. When starting up a cell, significant stresses occur in the cathode lining because of the significant changes in temperature, from room temperature to more than $400^{\circ} \mathrm{C}$. These stresses can cause cracking that can lead to cathode failure. Cells are rarely completely shut down, in part because of this danger.

The second compromising factor is sludge accumulation under the metal pad. Sludge is a mixture of undissolved bath and alumina that sinks to the bottom of the cell. Sludge forms when the bath temperature is not sufficiently above the liquidus temperature or when the alumina is fed too rapidly. The sludge promotes the erosion of the cathode which can lead to cathode failure. Thus, it is important to feed the cell at an appropriate rate and to maintain the cell within an acceptable temperature range.

The third factor that can shorten the cell life is when the sidewall freeze melts, exposing the sidewall carbon to the extremely corrosive molten electrolyte. Reduction cells are designed so that under normal operating conditions a layer of electrolyte will freeze on the walls of the cell. This layer is called the sidewall freeze. If this protective layer melts, the electrolyte will begin to dissolve the sidewall carbon, leading to sidewall 
failure. Thus, it is imperative to operate the cell within the proper temperature range to maintain the sidewall freeze.

Excess carbon consumption occurs in two general ways: dusting and air burning of the anode. Dusting occurs at the electrolyte-anode interface. As the carbon anode is consumed, small particles can separate from the bulk of the anode. These particles are not consumed, but rather float on the electrolyte. Dusting is controlled by using high quality materials in the anodes and by properly baking the anodes. Air burning occurs on the top of the anode when the temperature of the anode exceeds a certain level. Air burning is most common in older anodes as they are smaller and have less thermal resistance. Air burning is prevented by covering the anodes with a mixture of frozen bath and alumina.

\subsection{Existing Cell Control Strategy}

The existing computerized cell controllers are designed to perform two main functions. The first function is to maintain the cell at a specified voltage. The second function is to maintain a sufficient alumina concentration in the bath to prevent anode effects. The variables provided to the controller include line current and cell voltage. These variables are used to calculate the cell resistance, which in turn is used to calculate the normalized cell voltage. Another value that is calculated is the noise voltage. The noise voltage is calculated in different ways depending on the cell controller. Two general approaches are used, a maximum minus minimum approach or a standard deviation approach.

The cell voltage is maintained by adjusting the anode cathode distance, the distance between the bottom of the anode and the top of the metal pad. This is accomplished by 
moving the anodes. In general, the cell controller aims to match the target voltage. However, if the cell noise exceeds a specified value, the anode cathode distance is increased to reduce metal pad oscillations.

The alumina concentration is maintained via a complex process. The controller cycles through periods of under-, over-, and normal-feeding of alumina. The length of time spent in each period and the extent of over and under-feeding varies with the controller. The under-feed mode forces the alumina concentration down to a certain level. The controller waits until the normalized voltage begins to increase at a certain rate. When this occurs, it means anode effect is approaching and that the alumina concentration is at a minimum operating level. As soon as this point is reached, alumina is fed into the bath at a high rate to increase the alumina concentration to the desired operating level. The length of the overfeeding period is adjusted depending on several factors, including how quickly the minimum alumina concentration was reached. After the overfeeding period, a normal feeding period is begun. During this period, the addition of alumina is made at a rate that theoretically equals the rate of consumption. The normal feeding rate is used until the next prescribed search period.

\subsection{Difficulties in Reduction Cell Operation}

Operating a reduction cell continuously near the optimal operating point is extremely difficult for several reasons. One reason is that reduction cells are difficult to instrument. Another reason is that there are many inputs to the cell that are not accurately measured. Finally, the control strategy used is not robust enough to optimize the system's performance. 
Aluminum reduction cells are difficult to instrument for several reasons. First, the high temperatures make many typical instrumentation devices unusable. The bath temperature exceeds $950^{\circ} \mathrm{C}$ and even the sidewall temperature can exceed $300^{\circ} \mathrm{C}$. Second, the strong magnetic fields can cause significant distortion in electrical signals. Third, the cell operation is noisy. The bubbling of the anode gas is chaotic and effects the overall cell voltage. Waves in the metal pad also cause fluctuations in the cell voltage that are difficult to predict exactly. Fourth, the area of greatest interest would be the region between the anode face and the metal pad, but the electrolyte in this region is extremely corrosive. As of yet, there are not any materials that can be affordably manufactured that will withstand the bath for an extended period of time.

Because of these difficulties, important quantities such as alumina concentration, bath temperature, anode cathode distance (the distance from the bottom of the anode to the top of the metal pad), metal pad depth, and bath depth are not measured on a continuous basis. The only two variables monitored on a continuous basis are the cell voltage, or the total voltage drop across the cell, and the line current, or the total current passing through the cell.

In addition to having few measurements with which to control the cell, many of the input quantities are not well measured. For example, the amount of alumina added to the electrolyte by each feed varies significantly. The main contributor to the variation is the frozen crust of alumina and electrolyte that covers the bath. Holes are broken in the crust so that the alumina can fall into the bath. However, some of the alumina is still trapped on top of the crust and some of the crust falls into the bath. Once the solid alumina enters the bath, it must dissolve before it is available for consumption by the 
process. The time lag between alumina addition and dissolution varies depending on the temperature of the electrolyte. As such, it is very difficult to know the quantity of alumina that is added to the bath and when that alumina becomes available to the process. Similar problems arise when accounting for other additions to the electrolyte.

While existing control algorithms do reasonably well at maintaining the prescribed alumina concentration and cell voltage, they do have several shortcomings. Some of the limitations result from simplifying assumptions that have been made to reduce the complexity of the problem. For example, in most existing controllers, changes in cell voltage are considered to be functions of only alumina concentration and the anode cathode distance. However, the cell voltage is also a function of bath temperature, sidewall freeze thickness, sludge formation, and electrolyte composition. Inappropriate control actions can result from this simplification. An increase in the amount of sludge in the bottom of the pot would result in an increase in the cathode voltage drop. The controller's response would likely be to reduce the anode cathode distance to bring the cell voltage back down to the set level. However, this approach would result in a reduced heat input to the cell, resulting in a potential for even more sludge accumulation. A second limitation of existing controllers is that they are not based on any explicit optimization. The controller endeavors to maintain the prescribed cell voltage, which is set by the operator, regardless of the impact on the heat balance and current efficiency. Even if an optimum state is achieved, the cell rarely operates in a steady state mode. Because of the set up of the controller, many cells spend as much or more time in the search and overfeed modes than in the normal feed mode. Thus, the cell is rarely, if ever, operating at an optimum level. 


\subsection{Pathways to Enhanced Operation}

Because of the immense amount of energy used in the aluminum reduction process, small operational improvements can produce significant savings. For example, a reduction in the cell voltage by $0.1 \mathrm{~V}$ on a single pot operating at $100,000 \mathrm{~A}$ would save about $90,000 \mathrm{~kW}-\mathrm{hrs}$ each year. At $\$ 0.05$ per kilowatt-hour that would equal a savings of $\$ 4,500$ per pot. In an established, highly competitive industry such as the aluminum industry, this is a significant amount of savings. A better understanding of the effects of operational parameters on the cell, as well as improved control algorithms, would make it possible to operate cells closer to their optimal level, thus saving significant amounts of energy and money.

One method of obtaining a better understanding of the effect of operational parameters on the cell, would be through mathematical modeling. A mathematical model can be used for a variety of purposes, depending on the form of the model. A model could be useful in determining the optimal set point for the cell. It could be used to determine the best metal pad depth, the optimal alumina concentration, or the operating bath temperature. A model could also be used to analyze significant changes in the cell operation. For example, the effect of changes in the size of the anode. Another possibility would be to study the potential for reducing the operating current during times of high energy demand in order to save on energy costs. Furthermore, a model would be useful in developing and testing new control algorithms without the threat of disturbing an operating pot. 
As discussed earlier, one limiting factor in the development of better control algorithms in the aluminum reduction process is the lack of continuous measurements. Similar problems are encountered in many other process industries. A well-known solution to this problem is the state estimator. The state estimator uses a type of mathematical model of the process, to estimate the values of different unmeasured variables that are of interest, the state variables. The estimated state variables can then be used to determine control actions that may be more appropriate than control actions determined exclusively from the measured outputs.

\subsection{Overview of the Proposed Research}

In order to develop a better understanding of the effect of operational parameters on the cell, a mathematical model of a reduction cell was developed. Because of the timedependent nature of the system, the model includes transient components. The model accounts for the electrical, thermal, and chemical phenomena occurring within the process. Verification of the model was accomplished using a combination of results cited in the literature and experimental results obtained using operating cells at Century Aluminum in Ravenswood, WV. The second part of this research was to adapt the original model so that it could be used as a state estimator. In order to accomplish this, the complexity of the original model was reduced so that it could be computed in real time by a desktop computer. 


\subsection{References}

1. Grjotheim, K. and B.J. Welch. Aluminum Smelter Technology. Aluminum-Verlag, Dusseldorf, 1988.

2. World Aluminum.org: Home of the International Aluminum Institute. "Primary Aluminum Production - Form 150.” International Aluminum Institute. 21 April $2003<\mathrm{http}: / /$ www.world-aluminum.org/iai/stats/150.html $>$. 


\section{Chapter 2: Overview of Relevant Prior Research}

\subsection{Introduction}

There is a large body of research in the aluminum reduction industry. Two specific areas of interest for this research are mathematical modeling and control systems. The first part of this chapter will overview various mathematical models that focus on the entire aluminum reduction process, as opposed to models that focus on only one specific aspect of the process. The second part of this chapter will focus on research in the area of control systems.

\subsection{Mathematical Models}

In modeling an aluminum reduction cell, there is a wide range of physiochemical phenomena that must be considered. Cross et al. [1] state that the major processes that must be modeled are the electro-kinetic behavior, the current density distribution, the magnetic field, the temperature distribution, the two-phase liquid bath, the oscillation of the electrolyte-metal pad interface, and the mechanical stresses. While much research has focused on individual processes from this list, the level of coupling between the different phenomena is significant and cannot be ignored. In addition to modeling this large number of processes, multiple time scales must be considered. For example, Taylor et al. [2] discusses time scales associated with thermal imbalances. Thermal imbalances caused by an addition of alumina take as long as 50 seconds to resolve, while both the rate of change of alumina concentration by consumption and the rate of change of the global electrolyte temperature have a time scale of minutes. Furthermore, thermal imbalances in the side linings and bottom insulation can have time scales on the order of 
hours, or even days. Because of the large number of processes involved and the wide range in time scales, models must be developed with specific goals in mind.

Mathematical models can be classified according to several criteria. The first method of classification is by the time-dependent nature of the model. The model will either be a steady-state model, in which there is no time dependence, or a transient model, in which model variables change with time. A second way of classifying models is as either a lumped parameter model or a distributed model. A lumped parameter model assumes that the variables are constant across space, whereas a distributed model allows the major variables to vary across space.

A steady-state distributed model allows a detailed look at the operating state of the cell. Models of this type are typically implemented using finite element techniques. The values of the desired variables are determined at specified points, called nodes, within the solution domain. A large number of nodes is typically used to ensure a high level of accuracy. Tabsh and Dupuis [3] state that a model with a high spatial resolution is useful in developing an optimal cell design. Optimal steady-state operation can be accomplished by gaining a thorough understanding of the temperature and current distribution in the cell. Extended cell life can be obtained by minimizing the stresses that develop in the carbon cathode and the pot shell due to thermal gradients. This detailed look at the steady-state operation of the cell is also useful when planning for changes in the physical structure or the operating point of an existing cell design. Many major smelters have developed steady-state models; however, details of these models have not been extensively presented in the literature. The main disadvantage of a steady-state 
distributed model is the inability to see the transient behavior of the cell. As noted earlier, the cell rarely operates at steady state.

Transient lumped parameter models are usually made up of a set of time-dependent differential equations that are solved over an interval of time. The set is usually limited to ten to twenty equations so that the set can be solved quickly, allowing for multiple time steps. These models are used to study the evolution of cell variables that change relatively rapidly over time, such as the alumina concentration and the cell voltage. The dynamic interactions between the variables can be examined, such as the effect of an alumina addition on the cell temperature or the effect of alumina concentration on the cell voltage. This ability makes these models particularly useful for the development and testing of control strategies as well as for conducting sensitivity analyses on various operating variables. The main limitation of transient lumped parameter models is the inability to look at the effects of local variations of conditions within the cell, which are often significant.

Tabsh et al. [4,5] developed a transient lumped parameter model, which was split into two parts. The first was a process model, and the second was a control model. The process model used 13 differential equations: the heat balance, the mass balance of 11 species, and the development of the anode cathode distance. The control model simulated the pot operation as characterized by the operating procedures and the cell control dynamics. This model was used with Monte Carlo simulations to study the sensitivity of the cell to various input variables. It was also used to study the sensitivity of the pot operation to the back electromotive force used to calculate the cell's pseudoresistance. The researchers found that the use of an appropriate back electromotive force 
is an effective way to reduce pseudo-resistance fluctuations caused by changes in the line current.

Tang et al. [6] discuss a dynamic model that has been under development since the 1970's. It simulates the chemical and physical processes of the reduction cell by solving heat and mass balance equations. The most recent version of the model simulates disruptive cell events, including metal tapping, anode changes, and anode effects. The Celtrol $^{\mathrm{TM}}$ control strategy is used to simulate the control actions. Cell voltage and alumina concentration were the model inputs, while the bath temperature, bath ratio, and superheat were the model outputs. Comparison of the model outputs to measured values over a 19 hour period yielded errors of $0.5 \%$ for temperature, $1.4 \%$ for bath ratio, and $7.9 \%$ for superheat. The relatively high error for superheat is likely due to the use of linear interpolation as an estimate of the actual value between physical measurements. The necessity of physical measurements for voltage and alumina concentration limit the usefulness of the model, because it cannot be used to estimate these quantities or to test new control sequences.

Wright [7] also developed a transient lumped parameter model. This model included sub-models for heat transfer, voltage, and mass balances and used the Celtrol ${ }^{\mathrm{TM}}$ control strategy to determine control actions. The model outputs were compared with physical measurements of voltage, alumina concentration, and temperature. The model produced reasonably accurate results over periods as long as 24 hours, however, further tuning of the heat transfer coefficients was needed. Though the model was not adapted for real time control, it was stated that it could be used to provide online estimates of additional 
variables, such as alumina concentration and temperature, that are not currently available via continuous measurement.

Transient distributed models combine the advantages of both the steady-state distributed models and transient lumped parameter models. With transient distributed models, both the time dependence and spatial dependence of the variables can be analyzed. Unfortunately it was not very feasible to develop models of this type in the past because of the computational requirements. However, with the advent of powerful microcomputers, transient, distributed parameter models can be computed in a reasonable amount of time.

Taylor et al. [2] developed a transient distributed model focusing on the thermal balance of a reduction cell. In their work, the fluid was modeled as three distinct phases: the electrolyte, the molten aluminum, and the sludge. The fluid regions of the cell were

divided into 45 interconnected and well-mixed tanks. A separate, finely meshed, steadystate system was used to determine the fluid flow between the tanks. A one-dimensional mesh was used to solve for the heat conduction from the fluid phases through the solid materials. Nineteen differential equations were used to solve the energy and mass balances. It was found that $98 \%$ of the total cell temperature drop occurred in the conductive materials making up the sidewall and the bottom insulation. The model also showed that significant energy imbalances could occur between different sections of the cell.

\section{$\underline{2.3 \text { Control Systems }}$}

The use of automatic control systems has contributed significantly to the increase in operational efficiency of aluminum smelters in the last several decades. There have been 
two general approaches to the design of a control system for an aluminum reduction cell. The first method has been to separate the control of short-term processes, such as alumina concentration and anode-cathode distance, from the control of long-term processes, such as temperature and bath ratio. The second method integrates the control of the short-term and long-term processes. In addition to these two different design strategies, there are multiple ways of formulating the control strategy. Some common approaches are rulebased, PID, state-space, and intelligent control systems.

McFadden et al. [8] state that the control approach most commonly used in reduction facilities is based on the use of multiple single-input single-output control loops. The control formulation is either rule-based, or based on basic PID controllers. In general, these control approaches have been developed from the manual control strategies of the past rather than through the rigorous mathematical modeling of the underlying processes.

PID control systems are one of the most common types of control systems in industrial use. Though they are relatively easy to implement, they are not very effective in multi-input multi-output applications, particularly nonlinear ones. McFadden et al. [8] state that controllers of this type are common. However, their development and operation has not been extensively discussed in the literature.

The Celtrol ${ }^{\mathrm{TM}}$ controller is a popular control system for the control of the alumina concentration, cell voltage, and cell noise, all short-term phenomena. This controller uses a group of rules to determine the alumina feed rate, when to move the anodes, and how to deal with disruptive cell events such as anode effect, anode changes, and metal tapping. Cell voltage and line current are the inputs to the controller and the control actions are alumina feeding and anode movement. In addition to performing control actions, the 
Celtrol $^{\mathrm{TM}}$ system also concentrates and filters the data and provides a user interface. Rule based systems are relatively easy to develop based on historical operating experience. However, control systems of this type are limited in the ability to optimize the operating point of the cell because they endeavor to operate the cell at a specified voltage, rather than attempting to minimize power consumption and maximize current efficiency.

Salt [9] discusses a model used for the control of the bath composition. Salt states that the control of the ratio of sodium fluoride to aluminum fluoride in the bath is determined by several factors. These include the rate of sodium absorbed into the carbon lining, the sodium content of the alumina, the bath temperature, the rate of aluminum fluoride evolution, and the amount of aluminum fluoride returned by the scrubbing system. A combination of historical trends, bath temperature measurements obtained when taking bath ratio measurements, and knowledge of the composition of the alumina are used to determine the necessary additions of sodium fluoride and aluminum fluoride.

Entner $[10,11]$ also developed a model that could be used to reduce fluctuations in the $\mathrm{AlF}_{3}$ concentrations. The time lag between bath additions and the reaction of the bath to these additions is cited as a significant contributor to this variability. Entner's model uses regression analysis and an average $\mathrm{AlF}_{3}$ over a time interval, which is adjusted to compensate for the time lag. This model was successful in reducing the variability of the $\mathrm{AlF}_{3}$ concentration. Entner $[12,13]$ also discussed an extension of the $\mathrm{AlF}_{3}$ control model, which aims at reducing fluctuations in the bath temperature.

While current control strategies work relatively well, there is room for improvement if the multivariable nature of the process is realized in the design of the controller [8]. State-space control and intelligent control are two main control strategies that are well 
adapted to use in multi-input multi-output systems. In state-space control, the physical process is modeled by a system of first order differential equations. The states are generally physical variables inherent to the process. For example, in an aluminum reduction cell, state variables might include alumina concentration, bath temperature, and bath ratio. One benefit of the state-space control approach is that it is sometimes possible to estimate the state variables that cannot be measured, using the measurable variables. This is accomplished by running a model of the system, an observer, in parallel with the actual system. The error between the output of the real system and that of the observer is used to adjust the estimates of the state variables. One common method for adjusting the estimates of the state variables is through the use of a Kalman filter. A Kalman filter produces estimates that are unbiased and have a minimum variance provided that the noise and system covariance matrices are known and the noise is white. A Kalman filter operating on a linear system under the previous assumptions guarantees stability, convergence, and optimality of the estimator [14]. Sorheim and Borg [14] state that the use of a linear model does not work well when used to model a reduction cell. Because of this, an extended Kalman filter, which can be used with a nonlinear system, must be employed. Unfortunately, the extended Kalman filter is much more computationally intensive than the standard Kalman filter and the the stability, convergence, and optimality of the estimator are not guaranteed. However, the nonlinear model does provide a more accurate model of the cell processes.

Sorheim and Borg [14] developed a nonlinear state space model with a sub-optimal extended Kalman filter. The model had 18 state variables. These included alumina and fluoride concentration, masses of the side linings, bath and metal pad temperatures, and 
temperatures at selected points in the insulation. Time integration was accomplished using a 5th order Runge-Merson algorithm. One difficulty encountered with this system was the variable number of measurements that were available. Cell resistance was available every 5 minutes while bath temperature was available every 8 hours and fluoride content was available every 24 hours. Modification of the estimator to account for this problem was relatively easy, but this made analysis of the observability of the system much more complex. Observability problems also resulted because there were too many thermal states to be identified with one thermal measurement. As such, the temperature of the side linings was not included in the extended Kalman filter equations, but was rather simulated as a function of the other state variables. Results from the use of the estimator for a period of 144 hours were discussed. It was found that the estimator produced temperature values accurate within the limits of measurement error.

Jie et al. [15] developed an adaptive extended Kalman filter. The adaptive filter is similar to the standard extended Kalman filter. The difference is that the filter coefficients are changed over time, allowing the model to adapt to changes in the behavior of the system. This model was more limited than that developed by Sorheim and Borg [14] in that the model of Jie et al. used alumina concentration as the only state variable and assumed a constant value for the other operating parameters such as bath temperature, anode-cathode distance, and bath composition. In addition to a discussion of the filter, Jie et al. also discuss pre-filtering of the cell resistance. They used a thirdorder lowpass Butterworth filter to remove the relatively high frequency noise associated with metal-pad oscillations, line current fluctuations, gas-bubble releases, and mechanical 
disturbances during feeding. This filtered signal provides a better input for the estimator, thus improving the stability of the estimator.

Intelligent control systems can be developed in a variety of ways. Three types of intelligent control systems are expert systems, fuzzy logic systems, and neural networks. Rolland et al. [16] developed an expert system for the control and supervision of aluminum reduction cells. The objectives of the system were to handle situations more equally for different pots and potlines, to assist operators in solving complex problems, and to increase process yields to that of the best section where differences in yields were due to differences in operation. The expert system was a computer code that was able to obtain knowledge from "experts" in the operation of reduction cells. This system was designed to be able to process this knowledge and use it to solve problems. An expert system overcomes the difficulty of formulating problems purely numerically because it can deal with both numeric and heuristic solution strategies. The system is not designed to replace standard control systems that control the alumina feeding and anode movements, but rather is designed to assist operators in judgement decisions such as the voltage set point and determination of exception events such as an anode that is not set correctly or a clogged feeder. Results from the implementation of the system were not discussed.

Meghlaoui et al. [17] developed a neural network to model an aluminum reduction cell. A neural network is a computing system made up of a number of simple, highly connected processing elements which process information to estimate the dynamic state response of a system to external inputs. The weighting of the inputs to the processing elements is adjusted through the use of a learning algorithm. In this paper, the neural 
network was used to predict future values of the voltage signal. It was found that the neural network was able to predict the cell resistance up to 15 minutes in the future. Thus, the application of the neural network was able to reduce the frequency of anode effects. However, the network must be continually retrained to recognize new cell dynamics. While neural networks are extremely powerful, they are limited in that they can only work with measured variables, unlike an observer which can provide information about unmeasured states. Furthermore, it is difficult to know the limitations of the design and training of the network and how the network will react to unique situations for which it has not been trained.

\subsection{Summary}

Significant amounts of research have been conducted in the areas of mathematical modeling and control system development. While some of this research has been discussed in the literature, there is also a significant amount that has been held as proprietary knowledge. From a review of the literature it appears that a transient, distributed model would be useful for studying local variations in the state of the cell as well as the dynamic behavior of the cell under different operating conditions. While models of this type have been developed by other researchers, the models have been primarily used to study short operational trends. However, the models have not been used to determine the response of reduction cells to significant changes to the operating parameters, such as cell voltage, aluminum concentration, bath temperature, and bath ratio. 
A useful adaptation of the model would be to reduce its complexity so that it could be used to estimate the state variables of interest, including alumina concentration, bath temperature and bath ratio on a real-time basis. This state estimator could then be incorporated into an enhanced nonlinear, multivariable control system. Other researchers have attempted to develop state estimators for the aluminum reduction process.

However, these attempts have not been successfully implemented because the models were generally either too simplistic to generate meaningful results or required physical measurements that are not feasible to make on an operational basis.

\section{$\underline{2.5 \text { References }}$}

1. Cross, M., K. Pericleous, L. Leboucher, T. N. Croft, V. Bojarevics, and A. Williams. "Multi-Physics Modeling of Aluminum Reduction Cells." Light Metals 2000: 285289.

2. Taylor, M. P., W. D. Zhang, V. Wills, and S. Schmid. "Dynamic Model for the Energy Balance of an Electrolysis Cell." Transactions of the Institution of Chemical Engineers 74 (1996): 913-933.

3. Tabsh, Imad and Marc Dupuis. "Medeling of Aluminum Reduction Cells Using Finite Element Analysis Techniques.” Light Metals 1995: 295-299.

4. Tabsh, Imad, Marc Dupuis, and Alexandre Gomes. "Process Simulation of Aluminum Reduction Cells.” Light Metals 1996: 451:457.

5. Tabsh, Imad and Marc Dupuis. "Simulation of the Dynamic Response of Aluminum Reduction Cells.” Light Metals 1997: 443:447. 
6. Tang, H.Q., N. Urata, C. M. Read, and S. L. Stejer. "Response of Hall-Heroult Cell to Step-Changes in Operating Conditions: Measurements and 'Dynamic' Simulations.” Light Metals 1998: 349-357.

7. Wright, A. "Dynamic Simulation and Control of Aluminum Reduction Smelting Cells.” Ph. D. Dissertation. U. Newcastle-upon-Tyne, U.K. 1993.

8. McFadden, Fiona J. Stevens, Geoffrey P. Bearne, Paul C. Austin, and Barry J. Welch. “Application of Advanced Process Control to Aluminum Reduction Cells - A Review.” Light Metals 2001: 1233-1242.

9. Salt, David J. "Bath Chemistry Control System." Light Metals 1990: 299-304.

10. Entner, Peter M. “Control of $\mathrm{AlF}_{3}$ Concentration.” Light Metals 1992: 369-374.

11. Entner, Peter M. "Further Development of the $\mathrm{AlF}_{3}$ Model." Light Metals 1993: $265-268$.

12. Entner, Peter M. "Control of Bath Temperature.” Light Metals 1995: 227-230.

13. Entner, Peter M. and G.A. Guomundsson. "Further Development of the Temperature Model." Light Metals 1996: 445-449.

14. Sorheim, Einar Arne and Peter Borg. "Dynamic Model and Estimator for Online Supervision of the Alumina Reduction Cell.” Light Metals 1989: 379-384.

15. Jie, Li, Yongzhong Huang, Huazhang Wang, and Yexiang Liu. “An Estimation Model of Alumina Concentration for Point-Feeding Aluminum Reduction Cells." Light Metals 1994: 441-447.

16. Rolland, W.K., A. Steinsnes, A. S. Larsen, and K. A. Paulsen. "HALDRIS - An Expert System for Process Control and Supervision of Aluminum Reduction Cells." Light Metals 1991: 437-443. 
17. Meghlaoui, A., R. T. Bui, J. Thibault, L. Tikasz, and R. Santerre. "Predictive Control of Aluminum Electrolytic Cells Using Neural Networks." Metallurgical and Materials Transactions B 29B (1998): 1007-1019. 


\section{Chapter 3: Approach}

This research focused on two main tasks: developing a transient, distributed model of an aluminum reduction cell, and adapting the model for use as a state estimator. The model includes the electrical, thermal, and chemical processes occurring within the cell. The electrical and thermal portions of the model were developed using finite element techniques. The chemical model was developed using scalar equations.

As in all modeling endeavors, compromises had to be made between the accuracy of the solution and the computational effort required to obtain a solution. In the electrical and thermal models, the spatial variation of the variables was limited to two dimensions rather than including all three dimensions. This simplification has little effect on the voltage distribution in the cell. As can be seen from the side view of the cell, shown in Figure 3.1, the current flow will be primarily vertical in nature in this plane. However, in the plane parallel to the end view of the cell, Figure 3.2, there will be significant gradients. There will be thermal gradients in this plane, however, almost all of the gradient will occur at the ends of the cell. Also the thermal gradients at the ends will be almost identical to the thermal gradients in the sides of the cell. Thus, the temperature distribution in the cell can be assumed to be two-dimensional by including a heat sink for the energy losses through the ends of the cell. In addition to limiting the spatial variation of the temperature and voltage to two dimensions, a relatively coarse mesh was used, as shown in Figure 3.2. The mesh has 292 elements and 1227 nodes. It provides acceptable accuracy in the voltage and temperature distributions while enabling a solution to be obtained quickly using a Pentium III processor. 


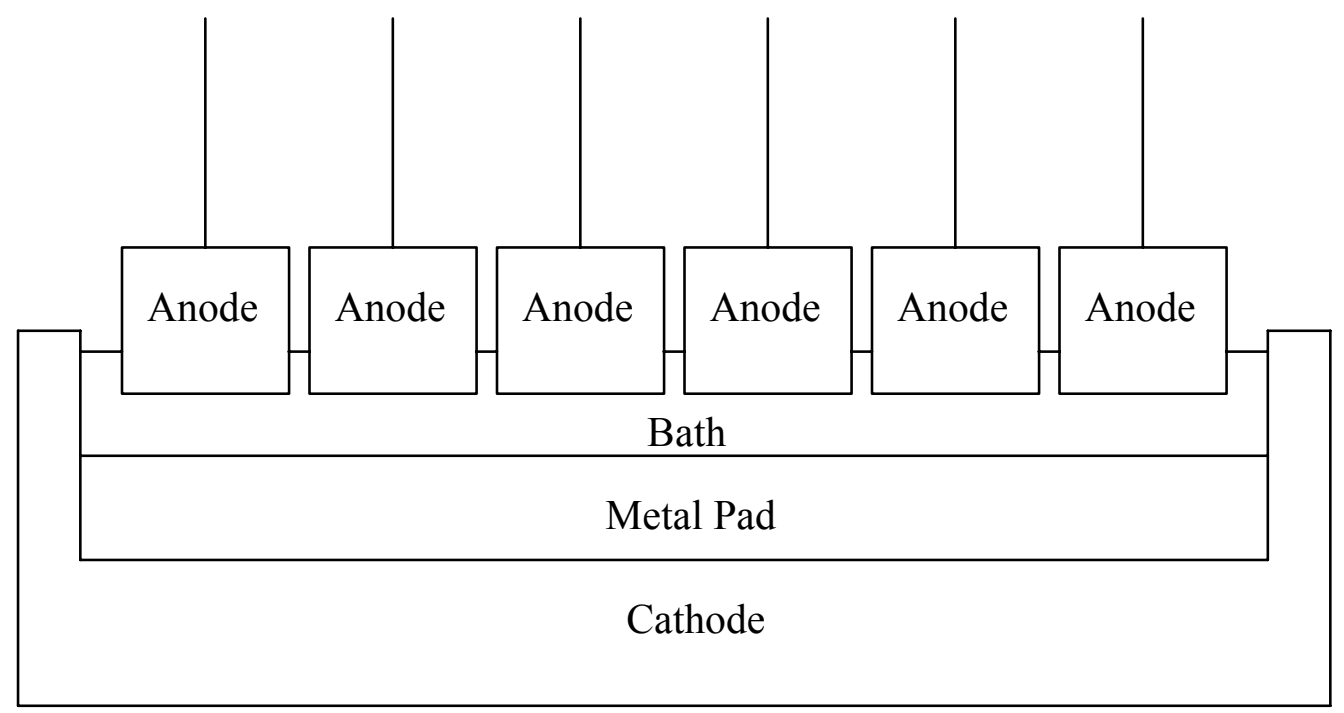

Figure 3.1: Side view of a typical prebake reduction cell

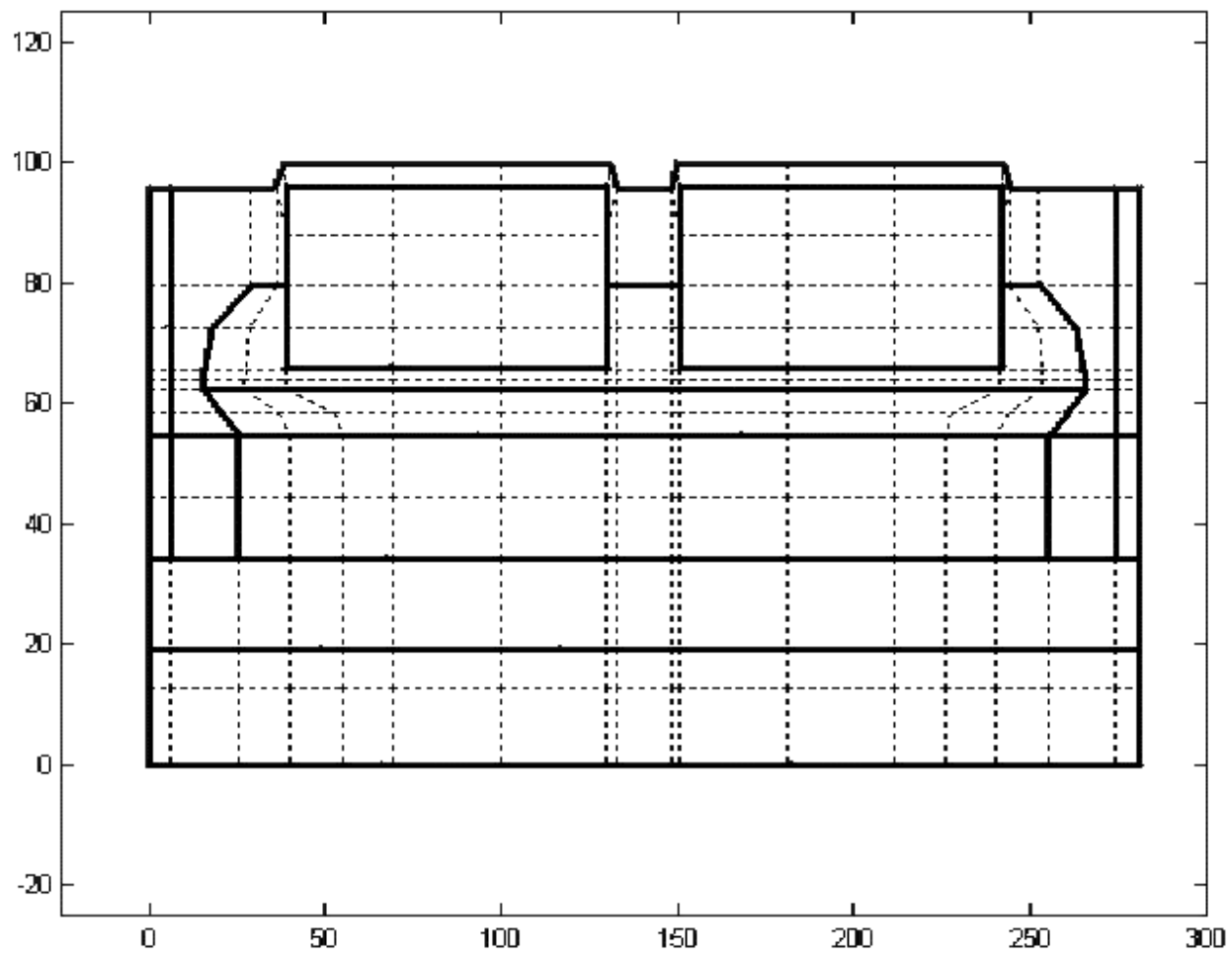

Figure 3.2: End view of a prebake reduction cell with mesh

The other significant simplification was assuming that the bath and metal pad regions were homogeneous. This allowed the chemical model to be developed using algebraic 
equations rather than using finite elements. In two dimensions, this is a fairly accurate assumption as the bubbles flowing from the bottom of the anode lead to a turbulent flow field that is conducive to mixing. Concentration gradients in the third dimension are more pronounced. However, accurately modeling the concentration gradients would require a detailed, three-dimensional fluids model that would require too much computational time. Because of this and the relative unimportance of the concentration gradients relative to changes in the bulk composition during normal operation, the bath and metal pad were assumed to be homogeneous.

After developing the distributed model, the model complexity was reduced to allow for very rapid computation of the cell state. Two separate models were developed. In the first model, the voltage model was reduced to a set of scalar equations and the chemical model was left unchanged. This model was used to estimate the alumina concentration. The second model utilized the algebraic voltage equations, the original chemical model, and a thermal model comprised of a group of 30 one-dimensional elements with 31 nodes. This model was used to estimate the bath temperature, and the bath ratio. 


\section{Chapter 4: Overview of the Finite Element Method}

\subsection{Introduction}

The finite element method is an approach to solving various differential equations. It is based on the idea of breaking the solution domain into a finite number of subdomains, called elements. Each element includes a certain number of nodes, points in the domain at which the solution of the field variable is desired. Within the element, an interpolation function is used to relate the solution at the nodes to the solution at any point within the element. Topics that will be discussed in this overview include the following: deriving the finite element equations from the differential equations, element formulation, natural coordinates, numerical integration, and node ordering.

\subsection{Deriving the Finite Element Equations from the Differential Equations}

One approach to deriving the finite element equations is through the method of weighted residuals (MWR), which is a technique for obtaining approximate solutions to differential equations. Consider the following differential equation:

$$
A(\phi)-f=0
$$

where $\phi$ is the field variable, $\mathrm{A}(\phi)$ is some differential operator, and $\mathrm{f}$ is a known function of the independent variables. The solution domain is $\Omega$ and is bounded by the surface $\Gamma$. First, the exact solution $\phi$ is replaced with the approximate solution $\widetilde{\phi}$ such that:

$$
\phi \approx \widetilde{\phi}=\sum_{i=1}^{m} N_{i} C_{i}
$$


where the $\mathrm{N}_{\mathrm{i}}$ are the interpolation functions, the $\mathrm{C}_{\mathrm{i}}$ are the unknowns, and $\mathrm{m}$ is the number of unknowns.

When $\widetilde{\phi}$ is substituted into (4.1), the equation will not be satisfied exactly. Rather the following will hold:

$$
A(\tilde{\phi})-f=R
$$

where $\mathrm{R}$ is the residual, or error, resulting from the approximation of $\phi$ by $\widetilde{\phi}$. It is desirable for the residual over the entire solution domain to be small. In order to accomplish this, a weighted average of the error is computed over the solution domain and set equal to zero according to the following equation:

$$
\int_{\Omega} R W_{i} d \Omega=\int_{\Omega}[A(\tilde{\phi})-f] W_{i} d \Omega=0 \quad i=1,2, \ldots, m
$$

where the $\mathrm{W}_{\mathrm{i}}$ are the weighting functions.

The choice of weighting function will influence the error distribution. Though a variety of principles exist for determining the weighting functions, the most common is called the Galerkin method. In this approach, the weighting functions are chosen to be equal to the interpolation functions. Thus, $\mathrm{W}_{\mathrm{i}}=\mathrm{N}_{\mathrm{i}}$ for $\mathrm{i}=1,2, \ldots, \mathrm{m}$. This yields the following set of equations:

$$
\int_{\Omega}[A(\widetilde{\phi})-f] N_{i} d \Omega=0 \quad i=1,2, \ldots, m
$$

Since Equation 4.1 applies to any individual point within the domain, it also applies to any group of points in the domain. As such, approximations of the form of Equation 4.2 can be applied to each element within the domain. This transforms Equation 4.5 into

$$
\int_{\Omega^{(e)}}\left[A\left(\widetilde{\phi}^{(e)}\right)-f^{e}\right] N_{i}^{(e)} d \Omega=0 \quad i=1,2, \ldots, r
$$


where the superscript (e) limits the range to a single element and $r$ is the number of unknowns assigned to each element. Applying Equation 4.6 to each element results in an $r$ by $r$ system of equations. Because the elements share nodes, some of the unknowns will be contained in multiple sets of these systems. The systems of equations must be assembled in such a way that all contributions related to a particular node are combined. This will form a square system with a size equal to the total number of unknowns.

In order for the assembly process to work properly, the interpolation functions must provide interelement continuity, at the element boundaries, of the unknowns, as well as the partial derivatives up to one order less than the highest order appearing in the expression that is to be integrated. This can limit the choice of interpolation function. While it is relatively easy to formulate interpolation functions that provide continuity of value, it is more difficult to obtain ones that provide continuity of slope and it is very difficult to obtain functions that provide continuity of curvature. Many differential equations contain terms with partial derivatives with an order greater than one. However, integration by parts can be applied to reduce the order of the derivatives in the integral expression. Recall from basic calculus that integration by parts in one dimension yields the following expression:

$$
\int_{a}^{b} u d v=[u v]_{a}^{b}-\int_{a}^{b} v d u
$$

where, in this case, $\mathrm{u}$ is the weighting function and $\mathrm{dv}$ includes the derivatives in the differential operator. Green's theorem is applied to integrate by parts in two dimensions. The following is the result:

$$
\int_{\Omega} u(\nabla \cdot v) d \Omega=\int_{\Gamma} u(v \cdot \hat{n}) d \Gamma-\int_{\Omega} v \cdot \nabla u d \Omega
$$


where, as previously, $\mathrm{u}$ is the weighting function and $\nabla \bullet v$ is the derivative in the differential operator. $\nabla$ is the gradient operator, which in two dimensions is given by:

$$
\nabla=\frac{\partial}{\partial x} \hat{i}+\frac{\partial}{\partial y} \hat{j}
$$

where $\hat{i}$, and $\hat{j}$ are unit vectors in the $\mathrm{x}$, and y directions, respectively. $\hat{n}$ is the unit normal vector to the boundary and is given by:

$$
\hat{n}=n_{x} \hat{i}+n_{y} \hat{j}
$$

Integration by parts will be used to reduce the order of all of the differential equations that will be used in this research so that elements requiring only continuity of the field variable may be used.

\subsection{Element Formulation}

An element can be identified primarily by the shape of the element, the number of nodes, and the type of interpolation function. The shape of the element is dictated by the shape of the domain and the number of dimensions that is covers. While elements can take on any shape that is desired, element shapes are generally limited in complexity so that the mathematics in computing the necessary integrals is simplified. The elements used in this research will contain only straight sides.

The number of nodes present in the element is also of significance. As more nodes are added to an element, the interpolation polynomial becomes more accurate. However, integration also becomes more computationally intensive. Furthermore, the number of nodes must be selected so that geometric isotropy can be maintained [1]. This means that the interpolation function must remain unchanged under a linear transformation. There are two axioms that ensure that a polynomial will possess geometric isotropy. The first is 
that polynomials of order $\mathrm{n}$ that are complete have geometric isotropy. Complete polynomials have the following form:

$$
P(x, y, z)=\sum_{l=1}^{n u m} \alpha_{l} x^{i} y^{j} \quad i+j \leq n
$$

where $\mathrm{P}(\mathrm{x}, \mathrm{y})$ is a polynomial in two dimensions, num is the number of terms of a polynomial containing all possible combinations of $\mathrm{i}$, and $\mathrm{j}$, and $\mathrm{n}$ is the order of the polynomial. The second axiom states that polynomials of order $\mathrm{n}$ that are incomplete, but contain the terms necessary to preserve symmetry, have geometric isotropy. This means that if in a two dimensional polynomial the $x^{2} y$ term is eliminated from the complete polynomial, the $\mathrm{xy}^{2}$ term must also be eliminated.

In this research, two-dimensional elements are used. They will be nine node quadrilaterals with an interpolation polynomial with the form given in Equation 4.12.

Figures 4.1 shows this element.

$$
\begin{aligned}
\phi(x, y) & =\alpha_{1}+\alpha_{2} x+\alpha_{3} y+\alpha_{4} x y+\alpha_{5} x^{2}+\alpha_{6} y^{2} \\
& +\alpha_{7} x^{2} y+\alpha_{8} x y^{2}+\alpha_{9} x^{2} y^{2}
\end{aligned}
$$

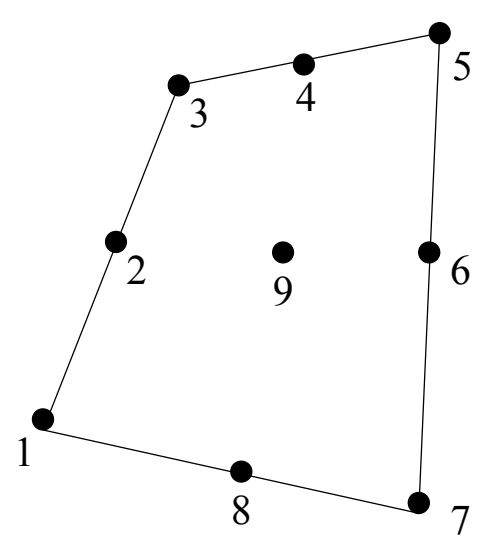

Figure 4.1: Nine node quadrilateral element 
Once the form of the interpolation function has been selected, the unknowns must be solved for each element. This will require the solution of a set of simultaneous equations. For a nine node quadrilateral element, the equations will take on the following form:

$$
\{\phi\}=\left\{\begin{array}{l}
\phi_{1} \\
\phi_{2} \\
\cdot \\
\cdot \\
\phi_{9}
\end{array}\right\}=\left[\begin{array}{ccccccccc}
1 & x_{1} & y_{1} & x_{1} y_{1} & x_{1}^{2} & y_{1}^{2} & x_{1}^{2} y_{1} & x_{1} y_{1}^{2} & x_{1}^{2} y_{1}^{2} \\
1 & x_{2} & y_{2} & x_{2} y_{2} & x_{2}^{2} & y_{2}^{2} & x_{2}^{2} y_{2} & x_{2} y_{2}^{2} & x_{2}^{2} y_{2}^{2} \\
\cdot & \cdot & \cdot & \cdot & \cdot & \cdot & \cdot & \cdot & \cdot \\
\cdot & \cdot & \cdot & \cdot & \cdot & \cdot & \cdot & \cdot & \cdot \\
1 & x_{9} & y_{9} & x_{9} y_{9} & x_{9}^{2} & y_{9}^{2} & x_{9}^{2} y_{9} & x_{9} y_{9}^{2} & x_{9}^{2} y_{9}^{2}
\end{array}\right]\left\{\begin{array}{c}
\alpha_{1} \\
\alpha_{2} \\
\cdot \\
\cdot \\
\alpha_{9}
\end{array}\right\}=[G]\{\alpha\}
$$

where: $\{\phi\}$ is a vector with the nodal values, $\phi_{1}, \phi_{2}, \ldots, \phi_{6}$. [G] is a matrix filled with the $\mathrm{x}$ and y positions of the nodes. $\{\alpha\}$ is a vector of the unknown coefficients. The solution is:

$$
\{\alpha\}=[G]^{-1}\{\phi\}
$$

The value of the interpolation polynomial at any point within the element can then be obtained via Equation 4.15.

$$
\phi=\left[\begin{array}{lllllllll}
1 & x & y & x y & x^{2} & y^{2} & x^{2} y & x y^{2} & x^{2} y^{2}
\end{array}\right]\{\alpha\}=[P]\{\alpha\}
$$

substituting for $\{\alpha\}$ yields:

$$
\phi=[P][G]^{-1}\{\phi\}=[P][R]\{\phi\}=[N]\{\phi\}
$$

\subsection{Natural Coordinates}

In general, the elements that are used to discretize the solution domain will not be regularly shaped. In order to simplify the integration over the area of the domain and to avoid scaling problems when one dimension is significantly larger than another, the original, irregular, element is mapped to a new coordinate system which results in a 
regular element. In two dimensions, the general quadrilateral is mapped to the square shown in Figure 4.2.

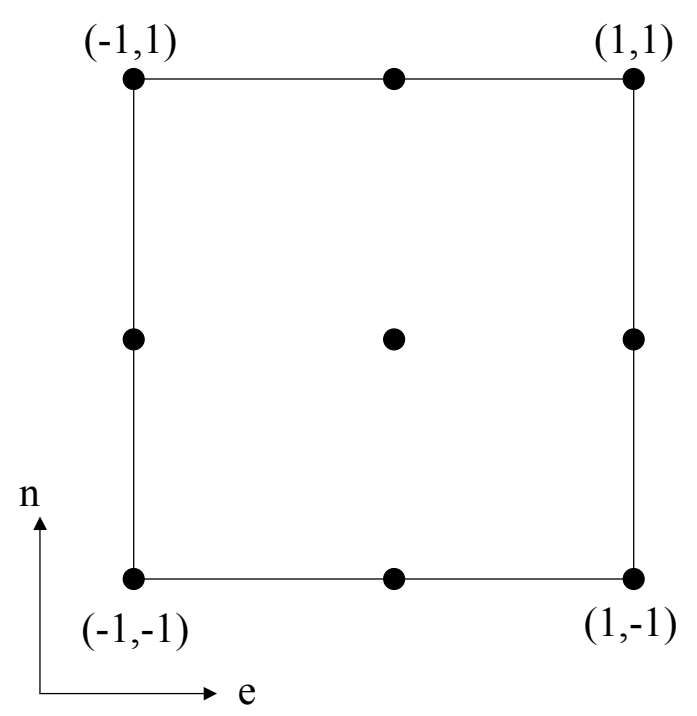

Figure 4.2: Square Element in the Natural Coordinate System

This mapping is accomplished by a nonlinear transformation of the following form:

$$
\begin{aligned}
& e=a_{1} x y+b_{1} x+c_{1} y+d_{1} \\
& n=a_{2} x y+b_{2} x+c_{2} y+d_{2} \\
& x=a_{3} e n+b_{3} e+c_{3} n+d_{3} \\
& y=a_{4} e n+b_{4} e+c_{4} n+d_{4}
\end{aligned}
$$

where: $\mathrm{e}$ and $\mathrm{n}$ are the natural coordinates, $\mathrm{x}$ and $\mathrm{y}$ are the global coordinates, and $\mathrm{a}_{\mathrm{i}}, \mathrm{b}_{\mathrm{i}}, \mathrm{c}_{\mathrm{i}}$, and $\mathrm{d}_{\mathrm{i}}$ are determined from the relative locations of the four corner nodes. The substitutions given in Equations 4.18-4.20 [2] can be made to convert the integral expressions in global coordinates to the natural coordinate system.

$$
\left[\begin{array}{l}
\frac{\partial}{\partial e} \\
\frac{\partial}{\partial n}
\end{array}\right]=\left[\begin{array}{ll}
\frac{\partial x}{\partial e} & \frac{\partial y}{\partial e} \\
\frac{\partial x}{\partial n} & \frac{\partial y}{\partial n}
\end{array}\right]\left[\begin{array}{l}
\frac{\partial}{\partial x} \\
\frac{\partial}{\partial y}
\end{array}\right]=[J]\left[\begin{array}{l}
\frac{\partial}{\partial x} \\
\frac{\partial}{\partial y}
\end{array}\right]
$$




$$
\begin{aligned}
& {\left[\begin{array}{l}
\frac{\partial}{\partial x} \\
\frac{\partial}{\partial y}
\end{array}\right]=\left[\begin{array}{ll}
\frac{\partial e}{\partial x} & \frac{\partial n}{\partial x} \\
\frac{\partial e}{\partial y} & \frac{\partial n}{\partial y}
\end{array}\right]\left[\begin{array}{c}
\frac{\partial}{\partial e} \\
\frac{\partial}{\partial n}
\end{array}\right]} \\
& \iint_{\text {area }} d x d y=\int_{-1}^{1} \int_{-1}^{1} \operatorname{det}[J] d e d n
\end{aligned}
$$

\subsection{Numerical Integration}

While exact integration of all of the integrals could be undertaken according to conventional means, this can prove to be quite complex because interpolation matrices must often be multiplied and then integrated, leading to a large number of terms that must be sorted and computed. Instead, numerical integration is used. Gaussian integration is a numerical integration technique that is particularly suited to the integration of polynomials. Using Gaussian integration, the function is evaluated at k points according to the following formula:

$$
\int_{-1}^{1} f(x) d x \approx \sum_{i=1}^{k} W_{i} f\left(x_{i}\right)
$$

where: $\mathrm{f}(\mathrm{x})$ is the function, $\mathrm{W}_{\mathrm{i}}$ is the weight, and $\mathrm{x}_{\mathrm{i}}$ is the point at which the function is evaluated. Because of the location of these points and the weighting assigned to each, the scheme exactly integrates a polynomial of degree up to $2 \mathrm{k}-1$. Table 4.1 provides the points and the weights for $\mathrm{k}$ between 1 and 8 for Gauss-Legendre integration[1]. 
Table 4.1: Points and weights for Gauss-Legendre integration

$\begin{array}{ccc}+/-x_{i} & k & W_{i} \\ 0.000000000000000 & 1 & 2.000000000000000 \\ 0.577350269189626 & 2 & 1.000000000000000 \\ & & \\ 0.000000000000000 & 3 & 0.888888888888889 \\ 0.774596669241483 & & 0.555555555555556 \\ & & \\ 0.339981043584856 & 4 & 0.652145154862546 \\ 0.861136311594053 & & 0.347854845137454 \\ & & \\ 0.000000000000000 & 5 & 0.568888888888889 \\ 0.538469310105683 & & 0.478629670499366 \\ 0.906179845938664 & & 0.236926885056189 \\ & & \\ 0.238619186083197 & 6 & 0.467913934572691 \\ 0.661209386466265 & & 0.360761573048139 \\ 0.932469514203152 & & 0.171324492379170 \\ & & \\ 0.000000000000000 & 7 & 0.417959183673469 \\ 0.405845151377397 & & 0.381830050505119 \\ 0.741531185599394 & & 0.279705391489277 \\ 0.949107912342759 & & 0.129484966168870 \\ 0.183434642495650 & 8 & 0.362683783378362 \\ 0.525532409916329 & & 0.313706645877887 \\ 0.796666477413627 & & 0.222381034453374 \\ 0.960289856497536 & & 0.101228536290376\end{array}$

\subsection{Node Ordering}

The number of unknowns can grow very large, leading to large matrices that must be solved. However, many of the matrix elements are zero because most of the nodes are not directly connected to the other nodes. Efficient numbering of the nodes leads to a matrix that has a minimum bandwidth. One of the most popular methods for ordering the nodes is the Cuthill-McKee Algorithm [3]. In this algorithm, adjacent nodes, nodes in an element that contains the original node, are first identified for each node. The number of adjacent nodes determines the degree of the element. Next a level structure is developed. 
A node with minimum degree is selected as the starting level. All nodes adjacent to this node are placed in the next level. The third and subsequent levels are formed from all nodes adjacent to the previous level that have not been included in a previous level. The nodes are then renumbered. The starting node is node 1. Subsequent nodes are numbered by moving up the level structure. Nodes within a level are numbered starting with the nodes adjacent to the lowest numbered node in the previous level. These adjacent nodes are numbered starting with the node with minimum degree. This algorithm can significantly reduce the bandwidth of the matrix resulting in faster computational times.

\subsection{References}

1. Huebner, Kenneth H., Earl A. Thornton, and Ted G. Byrom. The Finite Element Method for Engineers. John Wiley \& Sons, New York, NY, 1995.

2. Smith, I. M. and D. V. Griffiths. Programming the Finite Element Method. John Wiley \& Sons, New York, NY, 1982.

3. Oliker, Leonid, Xiaoye Li, Gerb Heber, and Rupak Biswas. "Ordering Unstructured Meshes for Sparse Matrix Computations on Leading Parallel Systems.” International Parallel and Distributed Processing Symposium - Solving Irregularly Structured Problems in Parallel Workshop, IEEE, 2000. 


\section{Chapter 5: Voltage Model}

\subsection{Model Formulation}

The voltage profile in the cell is determined using a two-dimensional Laplace equation with variable electrical conductivity, given in Equation 5.1.

$$
\frac{\partial}{\partial x}\left(k_{e} \frac{\partial V}{\partial x}\right)+\frac{\partial}{\partial y}\left(k_{e} \frac{\partial V}{\partial y}\right)=0
$$

where:

$\mathrm{k}_{\mathrm{e}}=$ the electrical conductivity of the element

$\mathrm{V}=$ the voltage

$\mathrm{x}$ and $\mathrm{y}=$ the position in global coordinates

The integral formulation in terms of the finite elements is given below:

$$
\iint_{A}\left(k _ { e } [ \frac { \partial N } { \partial x } ] ^ { T } \left[V^{e}\left[\frac{\partial N}{\partial x}\right]+k_{e}\left[\frac{\partial N}{\partial y}\right]^{T}\left[V^{e}\left[\frac{\partial N}{\partial y}\right]\right) d y d x=\int_{S} i N d s\right.\right.
$$

where:

$\mathrm{A}=$ the area of the element

$\mathrm{k}_{\mathrm{e}}=$ the electrical conductivity at the point of integration, determined by interpolation

$[\mathrm{N}]=$ the $9 \times 9$ interpolation matrix for an element

$\left[\mathrm{V}^{\mathrm{e}}\right]=$ the $9 \times 1$ vector of the nodal voltages for the element

$\mathrm{S}=$ the surface of the element

$i=$ the current density flowing across the surface of the element 
The solution domain for this model is from the top of the anode to the end of the cathode collector bars. A uniform current is applied to the top of the anode and a $0 \mathrm{~V}$ boundary condition is applied at the end of the cathode collector bars. The electrical conductivity matrix is solved using a modified form of Gaussian elimination that makes use of the limited matrix bandwidth. Several solution iterations are required as some of the electrical conductivity coefficients are dependent on the current density flowing through the element.

The cell voltage that is typically reported includes this solution domain as well as several other voltage drops. At Century Aluminum, this additional voltage averages $0.539 \mathrm{~V}$ At a nominal current of $93 \mathrm{kA}$, the effective resistance is $5.80 \times 10^{-6} \Omega$. The effects of this resistance are added to the voltage result obtained from the model.

The primary conductive regions in the cell are the carbon anode, the bath, the sidewall freeze, and the cathode assembly. The interface between these conductive regions generally has a contact resistance or an overvoltage. The insulating materials were assumed to be non-conductors and were not included in the computations. The metal pad has an electrical conductivity that is much higher than the other materials and will be assumed to be nearly a perfect conductor with an electrical conductivity of $1.0 \times 10^{6} \Omega^{-1} \mathrm{~cm}^{-1}$

\subsection{Electrical Conductivity of the Anode Carbon}

Grjotheim[1] states that the range for the electrical conductivity of the anode is between 0.009 and $0.011 \Omega$-cm. The average voltage drop across an anode at Century Aluminum is $0.263 \mathrm{~V}$. Using the nominal current of $4.65 \mathrm{kA}$ per anode and the average 
anode size, the resistivity of the anodes was calculated to be $0.009 \Omega-\mathrm{cm}$. Equivalently, the electrical conductivity is $110 \Omega^{-1}-\mathrm{cm}^{-1}$.

\subsection{Anode-Bath Interface Overvoltages}

There are several overvoltages that occur at the anode-bath interface. They are the reaction decomposition voltage, the anode surface overvoltage, the anode concentration overvoltage, and the bubble overvoltage. The combined effect of the overvoltages were modeled by a thin element between the anode and the bath with an effective electrical conductivity that produced the correct voltage. The current density needed to compute these overvoltages was calculated from the current flowing across the element face that was adjacent to the anode surface.

There are several possible reactions that could take place in a reduction cell. The following are the reactions with the corresponding reaction potentials given by Haupin[2]:

$$
\begin{array}{cc}
\mathrm{Al}_{2} \mathrm{O}_{3}+3 \mathrm{C} \leftrightarrow 3 \mathrm{CO}+2 \mathrm{Al} & E^{\circ}=1.02 \mathrm{~V} \\
2 \mathrm{Al}_{2} \mathrm{O}_{3}+3 \mathrm{C} \leftrightarrow 3 \mathrm{CO}_{2}+4 \mathrm{Al} & E^{\circ}=1.16 \mathrm{~V} \\
2 \mathrm{Na}_{3} \mathrm{AlF}_{6}+\mathrm{Al}_{2} \mathrm{O}_{3}+3 \mathrm{C} \leftrightarrow 3 \mathrm{COF}_{2}+6 \mathrm{NaF}+4 \mathrm{Al} & E^{\circ}=1.80 \mathrm{~V} \\
4 \mathrm{Na}_{3} \mathrm{AlF}_{6}+3 \mathrm{C} \leftrightarrow 3 \mathrm{CF}_{4}+12 \mathrm{NaF}+4 \mathrm{Al} & E^{\circ}=2.55 \mathrm{~V} \\
2 \mathrm{Na}_{3} \mathrm{AlF}_{6} \leftrightarrow 6 \mathrm{NaF}+2 \mathrm{Al} & E^{\circ}=4.41 \mathrm{~V}
\end{array}
$$

The second reaction is believed to be the primary reaction during normal electrolysis. The preference for the second reaction over the first is probably due to the cell current density surpassing the rate determining step for the first reaction. The fourth equation is believed to be the reaction that occurs at anode effect. 
Combining expressions from Haupin[2] and Solheim[3], the decomposition voltage for the reaction during normal electrolysis can be determined from Equation 5.4.

$$
E_{D e c}=E^{\circ}+\frac{R T}{F}\left[\frac{1}{6} \ln \left(\frac{a_{A l}^{2} a_{C O 2}^{1.5}}{a_{A l 2 O 3} a_{C}^{1.5}}\right)-\frac{1}{4} \ln \left(p_{C_{2}}\right)\right]
$$

Where:

$E_{\text {Dec }}=$ The decomposition voltage at any alumina concentration.

$\mathrm{E}^{\circ}=$ The standard reduction potential.

$\mathrm{R}=$ The universal gas constant.

$\mathrm{F}=$ Faraday's constant

$\mathrm{a}_{\mathrm{Al}}=$ activity of aluminum.

$\mathrm{a}_{\mathrm{CO} 2}=$ activity of carbon dioxide.

$\mathrm{a}_{\mathrm{Al} 2 \mathrm{O} 3}=$ activity of alumina .

$\mathrm{a}_{\mathrm{C}}=$ activity of carbon.

$\mathrm{p}_{\mathrm{CO} 2}=$ the partial pressure of $\mathrm{CO}_{2}$ in atmospheres, approximately $0.8 \mathrm{~atm}$ at cell conditions[3].

Haupin[2] gives an expression for determining the standard decomposition voltage as follows:

$$
E^{\circ}=\frac{\Delta G}{n F}
$$

where:

$\Delta \mathrm{G}=$ the Gibbs free energy change of the reaction at standard conditions.

$\mathrm{n}=$ the number of electrons transferred in the reaction ( 6 in this case). 
For the aluminum cell the standard conditions will occur at the bath temperature with the bath saturated with alumina, which yields an alumina activity coefficient of one.

The Gibbs free energy change for the reaction was derived from thermodynamic data for each of the reaction components. The result of this calculation was the Gibbs free energy change as a function of temperature. Converting into voltage the following expression is obtained.

$$
E^{\circ}=1.8915-5.591 \times 10^{-4} \times T
$$

Haupin[2] assumes that the activity of all coefficients except alumina to be approximately unity. The activity of alumina can be calculated by the following equation[3]:

$$
\ln a_{A l 2 O 3(T)}=\ln a_{A l 2 O 3(1300)}+\frac{H}{R}\left(\frac{1}{T}-\frac{1}{1300}\right)
$$

where:

$$
\begin{aligned}
& \ln a_{A l 2 / O 3(1300)}= \\
& 3 \ln \left(x_{A l 2 O 3}\right)-\frac{103.1+3.3 r-1.7(3-r)^{5}}{54} \cdot \ln \left(1+54\left(\% \mathrm{Al}_{2} \mathrm{O}_{3}\right)+11.16\right. \\
& \quad H=87000+7875(r-1)^{2} \cdot\left[1+\left(59-60\left(\% \mathrm{Al}_{2} \mathrm{O}_{3}\right)\right) \cdot e^{-60(\% A l 2 O 3)}\right]
\end{aligned}
$$

where:

$\mathrm{a}_{\mathrm{A} 12 \mathrm{O} 3(\mathrm{~T})}=$ the activity of the alumina at a given temperature

$\mathrm{x}_{\mathrm{A} 203}=$ the molar fraction of alumina in the bath.

$\mathrm{r}=$ the bath ratio on a molar basis.

$\mathrm{T}=$ the temperature in Kelvin. 
The anode surface overvoltage results because of either a slow chemical reaction or a slow charge transfer. The limiting factor is still unknown. The anode surface overvoltage can be calculated using Equation 5.10[4].

$$
\eta_{s a}=1.142 e-5 \ln \left(T_{A n B k}+273\right)(T) \ln \left(i / i_{r}\right)
$$

where:

$$
i_{r}=\exp \left[0.560 \ln \left(\left[\mathrm{Al}_{2} \mathrm{O}_{3}\right]+[\mathrm{LiF}] / 4\right)+0.276\left(R_{b}-1.5\right)-5.849\right]
$$

where:

$\mathrm{i}=$ the current density in $\mathrm{A} / \mathrm{cm}^{2}$

$\mathrm{i}_{\mathrm{r}}=$ the reaction limited current density

$\mathrm{T}_{\mathrm{AnBk}}=$ the anode baking temperature in ${ }^{\circ} \mathrm{C}$

$\left[\mathrm{Al}_{2} \mathrm{O}_{3}\right]$ and $[\mathrm{LiF}]=$ the weight percent of the named species

$\mathrm{R}_{\mathrm{b}}=$ the weight ratio of the bath

As electrolysis proceeds, oxygen is consumed at the anode-bath interface, resulting in a concentration gradient. This causes a concentration overvoltage which can be calculated using Equation 5.12[4].

$$
\eta_{c a}=[T / 23210] \ln \left[i_{c} /\left(i_{c}-i\right)\right]
$$

where:

$$
\begin{gathered}
i_{c}=[0.00464(T-273)-3.454]\left[C_{a}\left[\mathrm{Al}_{2} \mathrm{O}_{3}\right]+C_{b}\left[\mathrm{Al}_{2} \mathrm{O}_{3}\right]^{2}\right] A_{a n}^{-0.1} D_{s n} \\
C_{a}=1.443-1.985 R_{b}+1.131 R_{b}{ }^{2} \\
C_{b}=0.4122-0.2037 R_{b} \\
D_{s n}=i[0.00464(T-273)-3.4544]^{-1}\left[C_{a}[\text { AeOr }]+C_{b}[\text { AeOr }]^{2}\right]^{-1} A_{a n}^{0.01}
\end{gathered}
$$


where:

$\mathrm{i}_{\mathrm{c}}=$ the critical current density(the current density producing an anode effect)

$\mathrm{A}_{\mathrm{an}}=$ the area of the anode

$[\mathrm{AeOr}]=$ the alumina concentration in weight percent at which anode effect occurs

$\mathrm{D}_{\mathrm{sn}}=\mathrm{a}$ design factor which adapts the model to correct for variations in the alumina

concentration at which anode effect occurs for cells with the same current density.

Because the bottom of the anode is almost flat, a layer of carbon dioxide bubbles accumulates below the anode. The bubbles act as insulators, reducing the electrical conductivity of the electrolyte. The extra voltage resulting from the bubble layer can be calculated using the following equation[4].

$$
E_{b u b}=\frac{i}{\kappa}\left(\frac{d_{b} \Phi}{1-\Phi}\right)
$$

where:

$$
\begin{gathered}
d_{b}=(0.5517+i) /(1+2.167 i) \\
\Phi=0.5090+0.1823 i-0.1723 i^{2}+0.05504 i^{3}+ \\
\frac{\left(0.4322-0.3781 R_{b}\right)}{\left(1+1.637 R_{b}\right)}+\frac{\left[0.431-0.1437\left(\left[\mathrm{Al}_{2} \mathrm{O}_{3}\right]-[\mathrm{AeOr}]\right]\right.}{\left[1+7.353\left(\left[\mathrm{Al}_{2} \mathrm{O}_{3}\right]-[\mathrm{AeOr}]\right]\right.}
\end{gathered}
$$

where:

$\kappa=$ the electrical conductivity of the electrolyte(defined later)

$d_{b}=$ the thickness of the bubble layer

$\Phi=$ the fraction of the anode surface covered by the gas bubbles 
The anode concentration overvoltage and the bubble overvoltage are the components of the voltage that cause the high voltage that occurs at anode effect. Depletion of oxygen at the carbon-bath interface causes a concentration overvoltage. When the current density is high enough, there is no longer enough oxygen for the normal reaction to proceed, anode effect begins. This results in the concentration overvoltage increasing significantly and a secondary reaction, producing $\mathrm{CF}_{4}$ instead of $\mathrm{CO}_{2}$, proceeds. At the same time, the anodes become fully wetted by the gaseous products, leading to a significant increase in the bubble overvoltage. The model used by Haupin assumes that anode effect always occurs at the same alumina concentration for a given cell. At nominal conditions, this is true. However, nominal conditions do not always exist. Factors such as anode changes, anode setting height, and bath depth change the effective current density at the anode-bath interface and result in a change in the alumina concentration at which anode effect occurs. This can be accounted for by making a slight change to Haupin's model. The design factor will be calculated using nominal conditions as shown in Equation 5.20.

$$
\begin{aligned}
D_{\text {sn }} & =i_{\text {nom }}\left[0.00464\left(T_{\text {nom }}-273\right)-3.4544\right]^{-1} \\
& {\left[C_{\text {anom }}\left[A e O r_{\text {nom }}\right]+C_{\text {bnom }}\left[A e O r_{\text {nom }}\right]^{2}\right]^{-1} A_{\text {annom }}^{0.01} }
\end{aligned}
$$

The critical current density can then be calculated, as well as the concentration overvoltage. The only other change will be in the alumina concentration at which anode effect occurs, which is used to calculate the fraction of the anode surface covered with gas bubbles. This concentration is the alumina concentration that causes the critical current density to equal the actual current density. This concentration is determined by an iterative approach. 


\subsection{Electrical Conductivity of the Electrolyte}

The electrical conductivity of the electrolyte is of critical importance, as the voltage drop across the electrolyte represents a significant portion of the total voltage drop. Several relationships for the electrical conductivity of multi-component baths have been suggested. The most accurate one, to date, is given in Equation 5.21 [5]. The values are accurate to within $2.5 \%$.

$$
\begin{aligned}
\ln \kappa & =1.977-0.0200\left[\mathrm{Al}_{2} \mathrm{O}_{3}\right]-0.0131\left[\mathrm{AlF}_{3}\right]-0.0060\left[\mathrm{CaF}_{2}\right]-0.0106\left[\mathrm{MgF}_{2}\right] \\
& -0.0019[\mathrm{KF}]+0.0121[\mathrm{LiF}]-1204.3 / \mathrm{T}
\end{aligned}
$$

Where:

$\kappa=$ the electrical conductivity of the bath.

$\mathrm{T}=$ the bath temperature in Kelvin.

The quantities in brackets are concentrations in weight percent.

\subsection{Electrical Conductivity of the Side Freeze}

Frozen cryolite will generally be present on the sidewalls of the cell. Though it is not highly conductive, some current will still pass through the region. Literature cited by Haupin[6] suggests that the electrical conductivity at normal operating temperatures would be approximately $0.1 \Omega^{-1}-\mathrm{cm}^{-1}$.

\subsection{Cathode Concentration Overvoltage}

A relationship for the cathode concentration overvoltage has been developed by compiling data from several researchers[4]. The following relationship is valid for 
current densities above $0.1 \mathrm{~A} / \mathrm{cm}^{2}$, which is well below practical operating current densities, which generally range from 0.8 to $1.10 \mathrm{~A} / \mathrm{cm}^{2}$.

$$
\eta_{c c}=\frac{R T\left(1.375-0.125 R_{b}\right.}{1.5 F} \ln \left(\frac{i}{0.283}\right)
$$

where:

$\eta_{\mathrm{cc}}=$ the cathode concentration polarization

$\mathrm{R}=$ the universal gas constant

$\mathrm{T}=$ the temperature in Kelvin

$\mathrm{R}_{\mathrm{b}}=$ the weight ratio of the bath

$\mathrm{F}=$ Faraday's constant

$\mathrm{i}=$ the cathode current density

\subsection{Metal Pad-Carbon Cathode Interface Resistance}

The entire resistance of the lining structure, which includes the metal pad-carbon cathode interface resistance, the carbon cathode, and the cathode collector bars, is broken down by Lewis[7]. Based upon this data, the proportion of the cell lining resistance composed of the metal pad to carbon lining contact resistance is approximately $46 \%$ of the total lining resistance. The total cathode lining voltage is approximately $0.314 \mathrm{~V}$ at nominal operating conditions. Thus, the metal pad to carbon lining contact resistance causes a voltage drop of $0.144 \mathrm{~V}$. Based on an approximate carbon lining surface area, this yields a resistance of $0.22 \Omega$.

\subsection{Electrical Conductivity of the Cathode Assembly}

The resistivity of the carbon cathode blocks was obtained from material data supplied by the manufacturer. The electrical conductivity was $330 \Omega^{-1}-\mathrm{cm}^{-1}$. The cathode 
collector bars are made of steel, which has an electrical conductivity of $1.0 \times 10^{5} \Omega^{-1}-\mathrm{cm}^{-1}$. However, the carbon cathode-collector bar contact resistance must also be accounted for. According to Lewis[7], approximately $15 \%$ of the total lining voltage drop is made up by the collector bar and the contact resistance. Using nominal values, the electrical conductivity was calculated to be $212 \Omega^{-1}-\mathrm{cm}^{-1}$.

\subsection{References}

1. Grjotheim, K. et. al. Aluminum Electrolysis: Fundamentals of the Hall-Heroult Process. Aluminum-Verlag, Dusseldorf, 1982.

2. Haupin, W.E. "Electrode Reactions in Hall-Heroult Cells." Production of Aluminum and Alumina. A.R. Burkin, ed. John Wiley \& Sons, Chichester, 1987.

3. Solheim, Asbjorn and Asmund Sterten. "Activity of Alumina in the System NaF $\mathrm{AlF}_{3}-\mathrm{Al}_{2} \mathrm{O}_{3}$ at $\mathrm{NaF} / \mathrm{AlF}_{3}$ Molar Ratios Ranging from 1.4 to 3." Light Metals 1999. 445-452.

4. Haupin, W.E. "Interpreting the Components of Cell Voltage.” Light Metals 1998. $531-537$.

5. Hives, J., J. Thonstad, A. Sterten, and P. Fellner. "Electrical Conductivity of Molten Cryolite-Based Mixtures Obtained with a Tube-Type Cell Made of Pryolytic Boron Nitride.” Metalurgical and Materials Transactions B. April 1996. 255-260.

6. Haupin, W.E. “Chemical and Physical Properties of the Electrolyte.” Production of Aluminum and Alumina. A.R. Burkin, ed. John Wiley \& Sons, Chichester, 1987.

7. Lewis, R.A. Reduction Division Technical Manual I: Technical Fundamentals of the Aluminum Reduction Cell Process. Kaiser Aluminum and Chemical Corporation, Inc., 1973. 


\section{Chapter 6: Heat Transfer Model}

\subsection{Model Formulation}

\subsubsection{General Finite Element Formulation}

An aluminum reduction cell has both solid and fluid components. As such, both conduction and convection are important in modeling the thermal behavior of the system. In three dimensions, significant temperature gradients in the fluid regions can occur because of localized disturbances. However, in a two dimensional slice perpendicular to the long axis of the cell, the temperature gradients in the fluid regions are minimal because the bath and metal pad are well mixed. In a well-mixed fluid, most of the temperature gradient will occur over a small region at the edge of the fluid boundary. The bulk of the fluid can be assigned a high thermal conductivity which will account for the energy that is transported as a result of the fluid motion and will result in relatively small temperature gradients within the bulk of the fluid. A thin boundary layer around the edges of the fluid is assigned a thermal conductivity that will mimic the convective heat transfer coefficient between the fluid and the media it comes into contact with and will result in the proper temperature drop at the edges of the fluid. While this is the approach that was be used in this research, the full conduction-convection equation was programmed to allow for the potential of including a flow field if it is needed in the future. The conduction-convection equation is shown below:

$$
\rho c\left(\frac{\partial T}{\partial t}+u \frac{\partial T}{\partial x}+v \frac{\partial T}{\partial y}\right)=-\left(\frac{\partial q_{x}}{\partial x}+\frac{\partial q_{y}}{\partial y}\right)+Q
$$

where:

$\rho=$ the density 
$\mathrm{c}=$ the specific heat

$\mathrm{T}=$ the temperature

$\mathrm{u}=$ the $\mathrm{x}$-direction fluid velocity

$\mathrm{v}=$ the $\mathrm{y}$-direction fluid velocity

$\mathrm{q}_{\mathrm{x}}=$ the heat flow rate in the $\mathrm{x}$-direction

$\mathrm{q}_{\mathrm{y}}=$ the heat flow rate in the $\mathrm{y}$-direction

$\mathrm{Q}$ is the heat generation rate per unit area

For an isotropic material, the heat flow rates are given by the following:

$$
\begin{aligned}
& q_{x}=-k_{t} \frac{\partial T}{\partial x} \\
& q_{y}=-k_{t} \frac{\partial T}{\partial y}
\end{aligned}
$$

where:

$\mathrm{k}_{\mathrm{t}}=$ the thermal conductivity of the material

Applying the weighted residuals method to Equation 6.1 yields:

$\iint_{A}\left[\rho c \frac{\partial T}{\partial t}+\rho c u \frac{\partial T}{\partial x}+\rho c v \frac{\partial T}{\partial y}\right] W_{i} d y d x+\iint_{A}\left[\frac{\partial q_{x}}{\partial x}+\frac{\partial q_{y}}{\partial y}\right] W_{i} d y d x=\iint_{A} Q W_{i} d y d x$

where:

$\mathrm{W}_{\mathrm{i}}=$ the weighting function

$\mathrm{A}=$ the area of the element 
Applying Green's theorem to the heat flow rate integral produces Equation 6.4.

$$
\begin{gathered}
\iint_{A}\left[\rho c \frac{\partial T}{\partial t}+\rho c u \frac{\partial T}{\partial x}+\rho c v \frac{\partial T}{\partial y}\right] W_{i} d y d x-\iint_{A}\left[\frac{\partial W_{i}}{\partial x}+\frac{\partial W_{i}}{\partial y}\right]\left\{\begin{array}{l}
q_{x} \\
q_{y}
\end{array}\right\} d y d x= \\
\iint_{A} Q W_{i} d y d x-\int_{S}(q \cdot n) W_{i} d s
\end{gathered}
$$

where:

$q=$ the heat flow rate across the surface of the element

$\mathrm{n}=\mathrm{a}$ vector normal to the surface

$\mathrm{S}=$ the surface of the element

Converting to matrix notation and substituting expressions for the heat flow and the different types of boundary conditions in Equation 6.4 gives the following:

$$
\begin{gathered}
\iint_{A} \rho c[W]^{T}[N] d y d x\{T\}+\iint_{A} \rho c u[W]^{T}\left[\frac{\partial N}{\partial x}\right] d y d x\{T\}+\iint_{A} \rho c v[W]^{T}\left[\frac{\partial N}{\partial y}\right] d y d x\{T\}- \\
\iint_{A}\left[\frac{\partial W}{\partial x}\right]^{T} k_{t}\left[\frac{\partial N}{\partial x}\right] d y d x\{T\}+\iint_{A}\left[\frac{\partial W}{\partial y}\right]^{T} k_{t}\left[\frac{\partial N}{\partial y}\right] d y d x\{T\}+ \\
\int_{S} h[W]^{T}[N] d s\{T\}=\iint_{A} Q[W]^{T} d y d x+\int_{S} q_{s}[W]^{T} d s+\int_{S} h T_{e}[W]^{T} d s
\end{gathered}
$$

where:

$\mathrm{T}=[\mathrm{N}]\{\mathrm{T}\}$

$[\mathrm{W}]=$ the $9 \times 9$ weighting matrix for an element

$[N]=$ the $9 \times 9$ interpolation matrix for an element

$\{\mathrm{T}\}=\mathrm{a} 9 \mathrm{x} 1$ vector of the nodal temperatures for an element

$\mathrm{q}_{\mathrm{s}}$ is a specified heat flux on the surface

$h$ is a convective heat transfer coefficient

$\mathrm{T}_{\mathrm{e}}$ is the ambient temperature 
A term for radiation boundary conditions was not included in Equation 6.5 because radiation terms would result in a nonlinear equation. However, radiation is an important mode of heat loss. One method for linearizing radiation boundary conditions is to model them as a temperature dependent convective heat transfer boundary condition. This can be applied using the following formula:

$$
h_{e f f}\left(T_{S}\right)=\varepsilon \sigma\left(T_{s}^{2}+T_{a}^{2}\right)\left(T_{s}+T_{a}\right)
$$

where:

$h_{\text {eff }}\left(T_{s}\right)=$ the effective convective heat transfer coefficient at the surface temperature $\varepsilon=$ the emissivity of the surface

$\sigma=$ Boltzmann's constant $\left(5.6697 \times 10^{-8} \mathrm{~W} / \mathrm{m}^{2}-\mathrm{K}^{4}\right)$

$\mathrm{T}_{\mathrm{s}}=$ the surface temperature

$\mathrm{T}_{\mathrm{a}}=$ the ambient temperature

\subsubsection{Weighting Function Formulation}

The numerical solution of the convection-conduction equation can have extraneous numerical oscillations when the fluid velocity is high relative to the thermal conductivity and the element size. Finite element equations derived using Galerkin's method will cause these numerical oscillations. In order to eliminate the oscillations, the interpolation function and the weighting function cannot be equal. Instead, a special weighting function must be developed. Heinrich and Zienkiewicz[1] discuss the development of quadratic finite element schemes for both one and two-dimensions.

In one dimension, the weighting function is defined in terms of the interpolation function $\mathrm{N}$ and a modifying function $\mathrm{F}$. In this research, the interpolation function is 
quadratic. The weighting function will vary depending on the location within the element. For nodes at the end of the element, Equation 6.7 is used[1].

$$
W_{i}=W_{i}(x, \alpha)=N_{i}(x)-\operatorname{sign}(u) \alpha F(x)
$$

For the center node the weighting function is given by Equations 6.8 .

$$
W_{i}=W_{i}(x, \beta)=N_{i}(x)+4 \operatorname{sign}(u) \beta F(x)
$$

The modifying function, $\mathrm{F}$, is a cubic with the following form:

$$
F(x)=\frac{5}{2}\left(\frac{x}{h}\right)\left[2\left(\frac{x}{h}\right)^{2}-3\left(\frac{x}{h}\right)+1\right] \quad \text { for } 0 \leq x \leq h
$$

where $h$ is the length of the element. Heinrich and Zienkiewicz [1] show that oscillations can be avoided if $\beta$ and $\alpha$ are chosen according to the following relations:

$$
\begin{gathered}
\beta \geq \beta_{c} \equiv 1-\frac{4}{\gamma} \\
\alpha \geq \alpha_{c} \equiv 1-\frac{2}{\gamma} \\
\gamma=\left|\frac{u h}{k_{t}}\right|
\end{gathered}
$$

where:

$\beta_{\mathrm{c}}=$ the critical value of $\beta$

$\alpha_{c}=$ the critical value of $\alpha$

$\mathrm{u}=$ the fluid velocity

$\mathrm{h}=$ the element length

$\mathrm{k}_{\mathrm{t}}=$ the thermal conductivity.

The weighting function for a nine node quadrilateral element can be obtained by the multiplication of two one-dimensional weighting functions. In each dimension there will 
be three weighting functions. Six $\alpha$ and six $\beta$ parameters are necessary, three in each dimension for the three weighting functions. Figure 6.1 shows a schematic of an element with the $\alpha$ and $\beta$ parameters shown as well as the positive directions for the velocity vectors. The velocity used to compute $\alpha$ and $\beta$ can be obtained from the following expression:

$$
u_{i j}=\frac{1}{2}\left(\overrightarrow{\mathrm{V}}_{\mathrm{i}}+\overrightarrow{\mathrm{V}}_{\mathrm{j}}\right) \cdot \vec{l}_{i j}
$$

where $\mathrm{u}_{\mathrm{ij}}$ is the average velocity in the direction of side $\mathrm{i}, \mathrm{j}, \mathrm{V}_{\mathrm{i}}$ is the velocity vector at node $\mathrm{i}$, and $\mathrm{l}_{\mathrm{ij}}$ is the unit vector in the positive direction along side $\mathrm{i}, \mathrm{j}$.

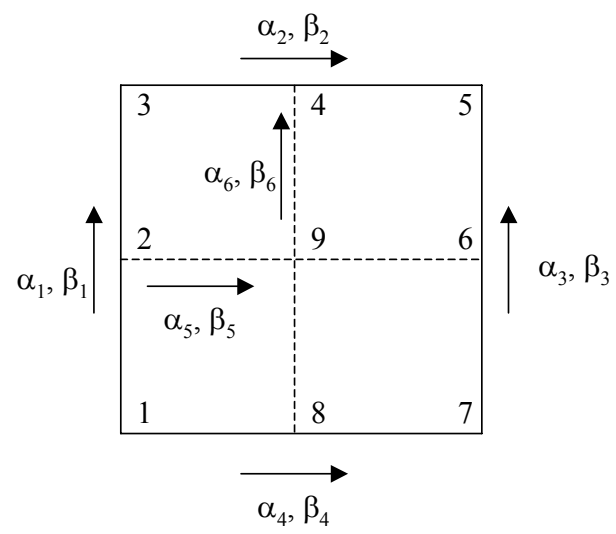

Figure 6.1: Nine node element with element earameters and positive velocity directions

The resulting weighting functions are given below:

$$
\begin{aligned}
& \mathrm{W}_{1}(\mathrm{x}, \mathrm{y})=\left(\mathrm{N}_{1}(\mathrm{x})-\alpha_{4} \mathrm{~F}(\mathrm{x})\right)\left(\mathrm{N}_{1}(\mathrm{y})-\alpha_{1} \mathrm{~F}(\mathrm{y})\right) \\
& \mathrm{W}_{2}(\mathrm{x}, \mathrm{y})=\left(\mathrm{N}_{2}(\mathrm{x})-\alpha_{5} \mathrm{~F}(\mathrm{x})\right)\left(\mathrm{N}_{1}(\mathrm{y})-\beta_{1} \mathrm{~F}(\mathrm{y})\right) \\
& \mathrm{W}_{3}(\mathrm{x}, \mathrm{y})=\left(\mathrm{N}_{3}(\mathrm{x})-\alpha_{2} \mathrm{~F}(\mathrm{x})\right)\left(\mathrm{N}_{1}(\mathrm{y})-\alpha_{1} \mathrm{~F}(\mathrm{y})\right) \\
& \mathrm{W}_{4}(\mathrm{x}, \mathrm{y})=\left(\mathrm{N}_{3}(\mathrm{x})-\beta_{2} \mathrm{~F}(\mathrm{x})\right)\left(\mathrm{N}_{2}(\mathrm{y})-\alpha_{6} \mathrm{~F}(\mathrm{y})\right) \\
& \mathrm{W}_{5}(\mathrm{x}, \mathrm{y})=\left(\mathrm{N}_{3}(\mathrm{x})-\alpha_{2} \mathrm{~F}(\mathrm{x})\right)\left(\mathrm{N}_{3}(\mathrm{y})-\alpha_{3} \mathrm{~F}(\mathrm{y})\right) \\
& \mathrm{W}_{6}(\mathrm{x}, \mathrm{y})=\left(\mathrm{N}_{2}(\mathrm{x})-\alpha_{5} \mathrm{~F}(\mathrm{x})\right)\left(\mathrm{N}_{3}(\mathrm{y})-\beta_{3} \mathrm{~F}(\mathrm{y})\right) \\
& \mathrm{W}_{7}(\mathrm{x}, \mathrm{y})=\left(\mathrm{N}_{1}(\mathrm{x})-\alpha_{4} \mathrm{~F}(\mathrm{x})\right)\left(\mathrm{N}_{3}(\mathrm{y})-\alpha_{3} \mathrm{~F}(\mathrm{y})\right) \\
& \mathrm{W}_{8}(\mathrm{x}, \mathrm{y})=\left(\mathrm{N}_{1}(\mathrm{x})-\beta_{4} \mathrm{~F}(\mathrm{x})\right)\left(\mathrm{N}_{2}(\mathrm{y})-\alpha_{6} \mathrm{~F}(\mathrm{y})\right) \\
& \mathrm{W}_{9}(\mathrm{x}, \mathrm{y})=\left(\mathrm{N}_{2}(\mathrm{x})-\beta_{5} \mathrm{~F}(\mathrm{x})\right)\left(\mathrm{N}_{2}(\mathrm{y})-\beta_{6} \mathrm{~F}(\mathrm{y})\right)
\end{aligned}
$$




\subsubsection{Solution Approach}

For steady state solutions, the solution will be obtained by using a modified form of Gaussian elimination that makes use of the limited matrix bandwidth. Multiple iterations will be needed because of coupling between the voltage model and the thermal model, as well as changes in geometry resulting from changes in the sidewall freeze thickness. Transient solutions will be obtained by using a time-marching algorithm based on finite difference methods, called the $\theta$ method. At any time $t_{\theta}$, the governing differential equation can be rewritten as:

$$
\left[C^{*}\right]\{\dot{T}\}_{\theta}+\left[K^{*}\right]\{T\}_{\theta}=\left\{R^{*}\left(t_{\theta}\right)\right\}
$$

where: $\left[\mathrm{C}^{*}\right],\left[\mathrm{K}^{*}\right]$, and $\mathrm{R}^{*}\left(\mathrm{t}_{\theta}\right)$ are obtained by combining the relevant terms from the differential equation. The following approximations are made to produce the resulting set of algebraic equations:

$$
\begin{gathered}
\{\dot{T}\}=\frac{\{T\}_{n+1}-\{T\}_{n}}{\Delta t} \\
\{T\}_{\theta}=(1-\theta)\{T\}_{n}+\theta\{T\}_{n+1} \\
\left\{R\left(t_{\theta}\right)\right\}=(1-\theta)\{R\}_{n}+\theta\{R\}_{n+1} \\
{\left[\theta[K]+\frac{1}{\Delta t}[C]\right]\{T\}_{n+1}=\left[-(1-\theta)[K]+\frac{1}{\Delta t}[C]\right]\{T\}_{n}+(1-\theta)\{R\}_{n}+\theta\{R\}_{n+1}}
\end{gathered}
$$

where:

$\mathrm{n}=$ the current time step

$\Delta t=$ the length of the time step 
The selection of $\theta$ produces different solution responses. For $\theta \geq 1 / 2$, the solution converges for all values of $\Delta \mathrm{t}$. For $\theta<1 / 2$, the solution is conditionally stable, converging for certain values of $\Delta \mathrm{t}$. The stability criteria is related to the eigenvalues of the system:

$$
\lambda_{i}=\frac{K_{i i}^{*}}{C_{i i}^{*}}
$$

where:

$\lambda_{i}=$ the eigenvalue of the ith node

Large eigenvalues, corresponding to a relatively high thermal conductivity and a relatively low heat capacity, require a smaller time step in order for the solution to be stable. The material properties vary significantly in an aluminum reduction cell. For example, the fluid regions will have properties resulting in very large eigenvalues, while the insulation materials will have properties resulting in very small eigenvalues. Thus, in order for the solution to converge with $\theta<1 / 2$, a very small time step would have to be chosen. However, a large number of time steps would be needed to observe any temperature change in the regions with small eigenvalues. In order to avoid this restriction on the time step, $\theta$ will be larger than $1 / 2$. Though the solution will converge, decaying oscillations will be present for $\theta$ between one-half and one. This is not desirable because of the coupling of the thermal and voltage models, as well as the nonlinear characteristics of the thermal model. Thus, a $\theta$ of 1 was used in this research.

The time step selected for a simulation is dependant on the information that is to be derived from the simulation. For this research, there are two general time scales that are 
of interest. The larger time scale deals with long term changes in the heat balance. For example, this time scale could be used to track the effect of changes in the ratio or the voltage set point. The smaller time step will be used when accurate values of the bath temperature are needed. This time scale will be used to resolve the effects of short term events such as alumina additions and anode effects. In order to determine appropriate time steps for the two cases, simulations were run using different time steps. The selected time step was the smallest time step that retained an accurate description of the system throughout the simulation. The larger time step was selected to be 300 seconds while the smaller time step was selected to be 1.0 second.

\section{$\underline{6.2 \text { Boundary Conditions and Internal Heat Generation }}$}

\subsubsection{Approximate Cell Heat Balance}

The solution domain for the thermal model will be the same as for the voltage model, extending from the top of the anode to the end of the cathode collector bars. The primary source of heat generation in an aluminum reduction cell is the electrical power dissipated by the cell. For cells at Century Aluminum, the nominal line current is $93 \mathrm{kA}$ and the average cell voltage is $4.02 \mathrm{~V}$ in the solution region, the electical power consumption is $374 \mathrm{~kW}$. A significant portion of this energy is consumed by the process reaction. At a temperature of $1248 \mathrm{~K}$, the reaction energy is $1234 \mathrm{~kJ} / \mathrm{mol}$ of aluminum produced. Under these conditions, 8.67 grams of aluminum are produced each second. Thus, the forward reaction consumes about $198 \mathrm{~kW}$. The back reaction, the result of current inefficiency, produces about $822 \mathrm{~kJ}$ of energy per mole of aluminum produced. At a current efficiency of $93 \%$, this is equivalent to $9 \mathrm{~kW}$. The net energy consumed by the reaction is about 
$189 \mathrm{~kW}$, leaving $185 \mathrm{~kW}$ of energy to be dissipated. Grjotheim and Welch[2] provide an approximate break-down of the heat losses from a reduction cell. This distribution is shown in Table 6.1 along with the equivalent wattage, wattage per unit length along the long axis of the cell, and wattage per unit area. This information will be used to test the accuracy of heat transfer coefficients and heat generation terms determined in the rest of the chapter.

Table 6.1: Heat losses through various cell components

\begin{tabular}{|l|c|c|c|c|}
\hline Component & $\%$ Total & $\mathrm{kW}$ & $\mathrm{W} / \mathrm{cm}$ & $\mathrm{W} / \mathrm{cm}^{2}$ \\
\hline Anode Top & $25.0 \%$ & 46.25 & 74.60 & 0.4108 \\
\hline Top Crust & $10.0 \%$ & 18.50 & 29.84 & 0.3012 \\
\hline Anode Stub & $8.0 \%$ & 14.80 & 23.87 & ---- \\
\hline Deck Plate & $7.0 \%$ & 12.95 & 20.89 & ---- \\
\hline Sidewall & $35.0 \%$ & 64.75 & 104.44 & 0.8703 \\
\hline Collector Bar & $8.0 \%$ & 14.80 & 23.87 & ---- \\
\hline Pot Bottom & $7.0 \%$ & 12.95 & 20.89 & 0.0744 \\
\hline
\end{tabular}

\subsubsection{Convection and Radiation Boundary Conditions}

The anode top, top crust, sidewall, and pot bottom lose heat through a combination of convection and radiation. Table 6.2 gives the effective convection coefficient for these components given the estimated surface temperature and ambient temperature based on the values shown in Table 6.1.

Table 6.2: Effective convection coefficients, estimated surface temperature, and ambient temperature for various cell surfaces

\begin{tabular}{|l|c|c|c|}
\hline Component & Surf. T(K) & Amb. T(K) & $\mathrm{h}_{\mathrm{c}}\left(\mathrm{W} / \mathrm{cm}^{2} \mathrm{~K}\right)$ \\
\hline Anode Top & 550 & 390 & $2.57 \mathrm{E}-03$ \\
\hline Top Crust & 525 & 390 & $2.23 \mathrm{E}-03$ \\
\hline Sidewall & 600 & 320 & $3.11 \mathrm{E}-03$ \\
\hline Pot Bottom & 380 & 320 & $1.24 \mathrm{E}-03$ \\
\hline
\end{tabular}

The anode top and the top crust should have similar heat transfer properties as both are exposed to the same air-flow pattern and both have loose alumina on the surface. Rye et al.[3] state that the convective heat transfer coefficient has been estimated at $1.00 \times 10^{-3}$ $\mathrm{W} / \mathrm{cm}^{2}-\mathrm{K}$. In their work, they arbitrarily chose an emissivity for the alumina of 0.4 as 
there are no measured values reported in the literature. Using this value and the temperatures given in Table 6.2, the effective heat transfer coefficient is $0.970 \times 10^{-3}$ $\mathrm{W} / \mathrm{cm}^{2}-\mathrm{K}$ for the anode top and $0.888 \times 10^{-3} \mathrm{~W} / \mathrm{cm}^{2}-\mathrm{K}$ for the top crust. Combining the effects of radiation and convection, the effective heat transfer coefficient is $1.970 \times 10^{-3}$ $\mathrm{W} / \mathrm{cm}^{2}-\mathrm{K}$ for the anode top and $1.888 \times 10^{-3} \mathrm{~W} / \mathrm{cm}^{2}-\mathrm{K}$ for the top crust.

The convection at the sidewall can be approximated as a natural flow along a vertical wall. Mills[4] provides a relationship for determining this value. Transition from the laminar to the turbulent regime occurs when the Grashof number, $\mathrm{Gr}=\beta \Delta \operatorname{Tgx}^{3} / \nu^{2}$, is approximately $1.0 \times 10^{9}$. For the conditions stated in Table 6.2, the flow will be turbulent. The relationships needed to calculate the convective coefficient are given below:

$$
\begin{gathered}
\Psi=\left[1+\left(\frac{0.492}{\operatorname{Pr}}\right)^{9 / 16}\right]^{-16 / 9} \\
\overline{N u}=0.68+0.670(R a \Psi)^{1 / 4}\left(1+1.6 \times 10^{-8} R a \Psi\right)^{1 / 12} \\
h_{c}=\frac{N u \cdot k}{x}
\end{gathered}
$$

where:

$\beta=$ the volumetric coefficient of thermal expansion (1/T for ideal gases)

$\mathrm{g}=$ acceleration due to gravity $\left(9.81 \mathrm{~m} / \mathrm{s}^{2}\right)$

$\mathrm{x}=$ the height of the wall

$v=$ the viscosity of the fluid

$\operatorname{Pr}=$ the Prandtl number

$\psi=$ the Prandtl number function

$\overline{N u}=$ the Nusselt number 
$\mathrm{Ra}=$ the Rayleigh number

$\mathrm{k}=$ the thermal conductivity

$\mathrm{h}_{\mathrm{c}}=$ the convective heat transfer coefficient

The Nusselt number is about $270 \mathrm{~W} / \mathrm{m}-\mathrm{K}$ yielding a heat transfer coefficient of $0.793 \times 10^{-3} \mathrm{~W} / \mathrm{cm}^{2}-\mathrm{K}$.

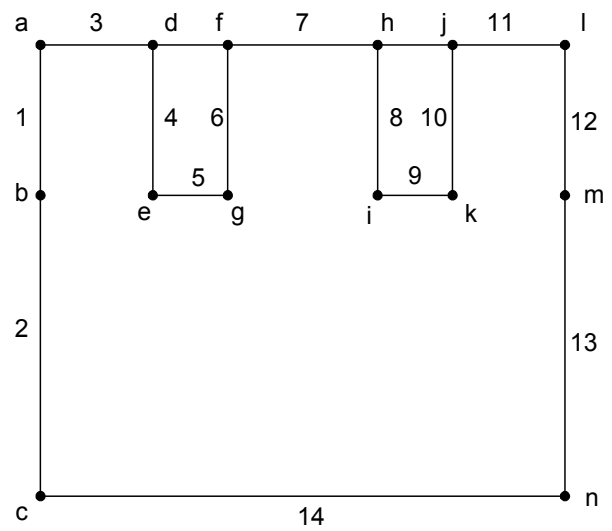

Figure 6.2: Schematic of the area between two pots

Figure 6.2 shows a side view of the region between two reduction cells looking down the length of the cells. Lines 1,2 and 12,13 are the sides of the pot. The sides of the pot are made of steel and will be assumed to have an emissivity of 0.60 [4]. Lines 4,5,6 and $8,9,10$ enclose the cathode bus bars. The bus bars are made of copper and will be assumed to have an emissivity of $0.7[4]$. Lines 3,7,11 are a grating for workers to walk on. The grating is made of steel. Because of the configuration of the grating, it is assumed that there is an insignificant amount of radiatitive energy that passes through the grating. The emissivity of the grating is assumed to be $0.6[4]$. Line 14 is the floor between the two pots. The emissivity of the floor is assumed to be 0.9 . The actual temperature of the pot sidewall is used as the temperature for one of the pot sides. The other pot side is assumed to have a temperature of $315^{\circ} \mathrm{C}$. All other surfaces are assumed 
to have a temperature of $75^{\circ} \mathrm{C}$. The radiosity of each surface is determined using the following set of linear equations:

$$
J_{i}=\varepsilon_{i} E_{b i}+\left(1-\varepsilon_{i}\right) \sum_{k=1}^{14} J_{k} F_{i k}
$$

where:

$\mathrm{J}_{\mathrm{i}}=$ the radiosity of side $\mathrm{i}$

$\varepsilon_{\mathrm{i}}=$ the emisivity of surface $\mathrm{i}$

$\mathrm{E}_{\mathrm{bi}}=$ the blockbody emissive power of side $\mathrm{i}\left(\sigma \mathrm{T}_{\mathrm{i}}^{4}\right)$

$F_{i j}=$ the fraction of energy leaving side $i$ that is intercepted by side $j$

The radiant heat transfer and effective convection coefficient can then be determined from Equation 8.25.

$$
q_{i}=\frac{\varepsilon_{i}}{1-\varepsilon_{i}}\left(E_{b i}-J_{i}\right)=h_{e f f}\left(T_{i}-T_{a}\right)
$$

where:

$\mathrm{q}_{\mathrm{i}}=$ the radiant heat transfer per unit area

$h_{\text {eff }}=$ the effective convection heat transfer coefficient

$\mathrm{T}_{\mathrm{a}}=$ the ambient temperature

The pot bottom can be assumed to be a heated horizontal plate facing down. Mills[4] provides the following relationship for determining the Nusselt number:

$$
\overline{N u}=6.5\left[1+\frac{L}{W}\right]\left[\left(1+13.5 R a_{L}^{-0.16}\right)^{0.39}-\left(13.5 R a_{L}^{-0.16}\right)^{0.39}\right] R a_{L}^{0.13}
$$

where: 
$\mathrm{L}=$ the length of the short side of the plate

$\mathrm{W}=$ the length of the long side of the plate

The Rayleigh number is $9.16 \times 10^{10}$, the Nusselt number is 104.5 , and the convection heat transfer coefficient is $0.105 \times 10^{-3} \mathrm{~W} / \mathrm{cm}^{2}-\mathrm{K}$. Using an emissivity of 0.91 , the effective coefficient for the radiation is $0.891 \times 10^{-3} \mathrm{~W} / \mathrm{cm}^{2}-\mathrm{K}$. Combining the convection and radiation coefficients, yields a total coefficient of $0.996 \times 10^{-3} \mathrm{~W} / \mathrm{cm}^{2}-\mathrm{K}$.

\subsubsection{Anode Rod, Collector Bar, and Deck Plate Heat Losses}

The loss of heat from the anode rods, cathode collector bars, and the deck plate were modeled as heat sinks applied to the appropriate region of the cell. The anode rod assembly is a complex combination of pieces that are welded together. The anode rod is connected to the carbon anode by a cast iron filling and is clamped to the anode bus. Part of the anode rod is inside the cell hood where ambient temperatures are around $390 \mathrm{~K}$ and part of it is outside the hood where ambient temperatures are about $310 \mathrm{~K}$. Because of the complex geometry and the variation in ambient temperatures, it is difficult to accurately model the heat losses leaving the system through the anode rods. Grjotheim and Welch[2] estimate that the heat loss through the anode rods is about $8 \%$ of the total cell heat losses or $14.80 \mathrm{~kW}$ for cells at Century Aluminum. Under nominal conditions, this heat loss should be reasonably accurate. The primary factor that driving changes in the heat loss would be a temperature change at the top of the anode. This could be caused by a change in the bath temperature, a change in the anode height, or a change in the amount of insulation that is present on top of the anode. In order to estimate the impact of a 
change in the temperature at the top of the anode, the anode rod is assumed to be a fin with a specified temperature distribution. One end of the fin is assigned the temperature of the anode top and the other end is assigned a temperature of $390 \mathrm{~K}$. The temperature distribution in the fin is assumed to be linear. The ambient temperature is assumed to be 390K. The fin was divided into four sections, each with unit surface area. Heat losses were by a combination of radiation and convection, each contributing approximately half of the heat loss. A unit convection heat transfer coefficient and a unit emissivity is assumed for the fin. A convection factor and a radiation factor were adjusted to produce the correct heat loss at nominal conditions. A schematic of the fin with the appropriate temperatures at nominal conditions is shown in Figure 6.4. At nominal conditions, the temperature at the top of the anode was $1071.3 \mathrm{~K}$, the convection factor was $8.75 \times 10^{-3}$, and the radiation factor was 1.38. The heat losses resulting from the anode rods were modeled as uniformly distributed heat sinks applied on the elements in the two upper corners of each anode.

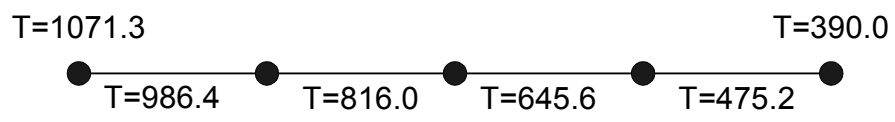

Figure 6.3: Temperature distribution in the anode "fin" at nominal conditions

The geometry involved in the cathode collector bar heat losses is also complex. As a result, this heat sink will be modeled in the same way as the heat losses from the anode rods. The differences are that the ambient temperature for the cathode collector bars is $320 \mathrm{~K}$, the cooler end of the fin will be assumed to be $320 \mathrm{~K}$, and the magnitude of radiation heat losses will be assumed to be one-half the heat losses due to convection. The hotter end of the fin will be set at the sidewall temperature, where the collector bars exit the cell. At nominal conditions, the temperature at the sidewall was $744.5 \mathrm{~K}$, the 
convection factor was $18.7 \times 10^{-3}$, and the radiation factor was 3.36 . The heat losses resulting from the collector bars were modeled as uniformly distributed heat sinks applied on the elements at the sidewall where the collector bars exit the cell.

The deck plate rests on top of the cell wall and acts as a large fin. The heat losses from the deck plate will be modeled in the same way as the heat losses from the cathode collector bars, with the same ambient temperature, cool end temperature, and distribution between convection and radiation. The hot end of the fin will be at the average temperature on the outside edge of the elements in the upper corners of the cell. At nominal conditions, this temperature was $472.3 \mathrm{~K}$, the convection factor was $42.42 \times 10^{-3}$, and the radiation factor was 12.89 . The heat losses resulting from the deck plate bars were modeled as uniformly distributed heat sinks applied on the elements at the upper corners of the cell.

\subsubsection{Internal Heat Generation and Consumption}

The electrical energy dissipated, the energy consumed by the net forward reaction, the energy consumed in heating and dissolving the alumina feed material, and the energy leaving the cell through the end walls were modeled as heat sinks or sources on one or more elements. A large amount of electrical power is dissipated by the cell. The magnitude can be computed using the following equation:

$$
Q_{\Omega}=\iint_{A} k_{e}\left[\frac{\partial^{2} V}{\partial x^{2}}+\frac{\partial^{2} V}{\partial y^{2}}\right][W]^{T} d y d x
$$

where:

$\mathrm{Q}_{\Omega}=$ the ohmic heat generation

$\mathrm{k}_{\mathrm{e}}=$ the electrical conductivity of the element 
$\mathrm{V}=$ the voltage

A multiplier is needed to modify this heat generation. The voltage solution is obtained by applying the actual current density to the anode surface. However, there are gaps between the anodes. Thus, there are two-dimensional slices that do not have an applied current density. Thus, a multiplier is used so that the correct amount of power is introduced to the cell. For cells at Century Aluminum, the multiplier is 0.835 . The ohmic heat generation is applied to all elements for which there is a voltage solution.

The energy required for the net forward reaction will be removed from the reaction zone, which is the bath directly under the anodes. Two reactions must be considered, the forward reaction, Equation 6.28, in which aluminum is produced from alumina, and the backward reaction, Equation 6.29, in which alumina is produced from aluminum.

$$
\begin{aligned}
& \mathrm{Al}_{2} \mathrm{O}_{3}(s, \alpha, T)+1.5 \mathrm{C}(s, T) \rightarrow 2 \mathrm{Al}(l, T)+1.5 \mathrm{CO}_{2}(g, T) \\
& 2 \mathrm{Al}(l, T)+3 \mathrm{CO}_{2}(g, T) \rightarrow \mathrm{Al}_{2} \mathrm{O}_{3}(s, \alpha, T)+3 \mathrm{CO}(g, T)
\end{aligned}
$$

The reactants in the forward reaction are dissolved alumina that is in the alpha phase at the bath temperature, and carbon that is a solid at the bath temperature. The products are liquid aluminum at the bath temperature and carbon dioxide gas at the bath temperature. The forward reaction is driven by the current flowing through the cell, while the backward reaction is facilitated by carbon dioxide that remains dissolved in the bath. The reactants in the backward reaction are liquid aluminum at the bath temperature and carbon dioxide gas at the bath temperature. The products are dissolved alpha alumina at the bath temperature and carbon monoxide gas at the bath temperature. The enthalpy 
change for the forward and backward reactions can be calculated using Equations 6.30 and 6.31 respectively.

$$
\begin{aligned}
\Delta H(T)= & 2 \Delta H_{f}(\mathrm{Al})+1.5 \Delta H_{f}\left(\mathrm{CO}_{2}\right)-\Delta H_{f}\left(\mathrm{Al}_{2} \mathrm{O}_{3}\right)+ \\
& 2\left[\mathrm{H}_{T}-\mathrm{H}_{298}\right](\mathrm{Al})+1.5\left[\mathrm{H}_{\mathrm{T}}-\mathrm{H}_{298}\right]\left(\mathrm{CO}_{2}\right)- \\
& {\left[\mathrm{H}_{T}-\mathrm{H}_{298}\right]\left(\mathrm{Al} \mathrm{O}_{2}\right)-1.5\left[\mathrm{H}_{T}-H_{298}\right](\mathrm{C}) } \\
\Delta H(T)= & \Delta H_{f}\left(\mathrm{Al}_{2} \mathrm{O}_{3}\right)+3 \Delta H_{f}(\mathrm{CO})-2 \Delta H_{f}(\mathrm{Al})+ \\
& 3 \Delta H_{f}\left(\mathrm{CO}_{2}\right)+\left[H_{T}-H_{298}\right]\left(\mathrm{Al}_{2} \mathrm{O}_{3}\right)+ \\
& 3\left[H_{T}-H_{298}\right](\mathrm{CO})-2\left[\mathrm{H}_{T}-\mathrm{H}_{298}\right](\mathrm{Al})- \\
& 1.5\left[\mathrm{H}_{T}-H_{298}\right]\left(\mathrm{CO}_{2}\right)
\end{aligned}
$$

where:

$\Delta \mathrm{H}(\mathrm{T})=$ the enthalpy of reaction

$\Delta \mathrm{H}_{\mathrm{f}}()=$ the heat of formation

$\left[\mathrm{H}_{\mathrm{T}}-\mathrm{H}_{298}\right]=$ the enthalpy difference between the substance at standard conditions and actual conditions

$\mathrm{T}=$ the absolute temperature $(\mathrm{K})$

$\left[\mathrm{H}_{\mathrm{T}}-\mathrm{H}_{298}\right]$ can be calculated from Equation 6.30. Values for the constants can be found in Table 6.3 for each component, except carbon[5]. Carbon has a heat of formation of 0 because it is a pure substance. It has a heat capacity of $0.01068 \mathrm{~kJ} / \mathrm{mol}-\mathrm{K}$.

$$
\left[H_{T}-H_{298}\right]=A \cdot t+B \cdot t^{2} / 2+C \cdot t^{3} / 3+D \cdot t^{4} / 4-E / t+F-\Delta H_{f}
$$

where:

$\mathrm{t}=\mathrm{T} / 1000$ 
Table 6.3: Thermochemical data for reaction components in $\mathrm{kJ} / \mathrm{mol}-\mathrm{K}$

\begin{tabular}{|c|c|c|c|c|}
\hline Particapant: & Alpha Alumina & Aluminum & Carbon Dioxide & Carbon Monoxide \\
\hline $\mathrm{H}_{\mathrm{f}}$ & $-1.67569 \mathrm{E}+03$ & $1.05620 \mathrm{E}+01$ & $-3.93522 \mathrm{E}+02$ & $-1.10527 \mathrm{E}+02$ \\
\hline$A$ & $1.02429 \mathrm{E}+02$ & $3.17510 \mathrm{E}+01$ & $2.49974 \mathrm{E}+01$ & $2.55676 \mathrm{E}+01$ \\
\hline$B$ & $3.87498 \mathrm{E}+01$ & $3.93583 \mathrm{E}-08$ & $5.51870 \mathrm{E}+01$ & $6.09613 \mathrm{E}+00$ \\
\hline$C$ & $-1.59109 \mathrm{E}+01$ & $-1.78652 \mathrm{E}-08$ & $-3.36914 \mathrm{E}+01$ & $4.05466 \mathrm{E}+00$ \\
\hline$D$ & $2.62818 \mathrm{E}+00$ & $2.69417 \mathrm{E}-09$ & $7.94839 \mathrm{E}+00$ & $-2.67130 \mathrm{E}+00$ \\
\hline E & $-3.00755 \mathrm{E}+00$ & $5.48004 \mathrm{E}-09$ & $-1.36638 \mathrm{E}-01$ & $1.31021 \mathrm{E}-01$ \\
\hline$F$ & $-1.71793 \mathrm{E}+03$ & $-9.45684 \mathrm{E}-01$ & $-4.03608 \mathrm{E}+02$ & $-1.18009 \mathrm{E}+02$ \\
\hline
\end{tabular}

The net energy used by the reaction can be calculated using Equation 6.33.

$$
Q_{\text {react }}=\Delta H(\text { forward })+(1-\% C E) \Delta H(\text { back })
$$

where:

$\mathrm{Q}_{\text {react }}=$ the net energy used by the reaction in $\mathrm{kJ} / \mathrm{mol}$ of alumina.

$\% \mathrm{CE}=$ the current efficiency of the cell

The alumina is fed into the bath as a batch addition and must be heated from the ambient temperature, about $390 \mathrm{~K}$, to the bath temperature. Additional energy is used in the dissolution process and in converting any of the alumina that is in the gamma phase to the alpha phase. The energy required to heat the alumina can be calculated by computing $\left[\mathrm{H}_{\mathrm{T}}-\mathrm{H}_{298}\right]$ at the bath temperature and the ambient temperature and subtracting the values. Grjotheim et al.[6] state that the heat of solution for alumina in electrolyte at a concentration of $2 \mathrm{wt} \%$ is $190 \mathrm{~kJ} / \mathrm{mol}$. The energy needed to convert the gamma alumina to alpha alumina can be determined from the following:

$$
Q_{c o n v}=\left(\Delta H_{f}(\alpha)-\Delta H_{f}(\gamma)\right)(\% \gamma)
$$

where: 
$\mathrm{Q}_{\mathrm{conv}}=$ the energy needed to convert gamma alumina to alpha alumina $(\mathrm{kJ} / \mathrm{mol})$

$\Delta \mathrm{H}_{\mathrm{f}}(\alpha)=$ the heat of formation for alpha alumina $(-1675.69 \mathrm{~kJ} / \mathrm{mol})[5]$.

$\Delta \mathrm{H}_{\mathrm{f}}(\gamma)=$ the heat of formation for gamma alumina $(-1656.86 \mathrm{~kJ} / \mathrm{mol})[5]$.

$\% \gamma=$ the percentage of gamma phase in the alumina

The ends of the cell are a significant source of energy loss, but are not physically modeled in this two-dimensional model. However, the thermal processes occurring at the ends of the cell and the sides of the cell are almost identical. Because of this, the heat flux flowing from the entire sidewall will be calculated on a per unit length basis and assumed to be $20 \%$ less than the heat leaving the ends on a per unit length basis. The net energy will be calculated and modeled as a heat sink applied over the entire bath and metal pad regions.

\subsection{Material Properties and Internal Heat Transfer Coefficients}

The density, thermal conductivity and heat capacity of the cell materials are needed in order to solve for the temperature distribution in the cell. Based on measurements by Rye et al.[3], the thermal conductivity of the top crust is about $5.0 \times 10^{-3} \mathrm{~W} / \mathrm{cm}-\mathrm{K}$. The density of the crust is $2.4 \mathrm{~g} / \mathrm{cm}^{3}$ [7]. Values for the heat capacity of the crust are not available in the literature. However, an estimate of the heat capacity can be obtained from the heat capacity of frozen electrolyte, which is $1.85 \mathrm{~J} / \mathrm{g}-\mathrm{K}$ [8]. The heat capacity and density of the loose cover that is on top of the anode will be assumed to be the same as for the crust. The thermal conductivity of the loose cover is $2.0 \times 10^{-3} \mathrm{~W} / \mathrm{cm}-\mathrm{K}$. The thermal conductivity of the carbon anode is $6.3 \times 10^{-2} \mathrm{~W} / \mathrm{cm}-\mathrm{K}[9]$, the heat capacity is 
$0.889 \mathrm{~J} / \mathrm{g}-\mathrm{K}[5]$, and the density is $1.45 \mathrm{~g} / \mathrm{cm}^{3}$ [10]. Based on the manufacturer's data sheet, the sidewall lining, made of silicon carbide, has a thermal conductivity of 0.173 $\mathrm{W} / \mathrm{cm}-\mathrm{K}$, a heat capacity of $0.921 \mathrm{~J} / \mathrm{g}-\mathrm{K}$, and a density of $2.60 \mathrm{~g} / \mathrm{cm}^{3}$. Taylor $[8]$ states that the frozen electrolyte has a thermal conductivity of $1.07 \times 10^{-2} \mathrm{~W} / \mathrm{cm}-\mathrm{K}$, a heat capacity of $1.85 \mathrm{~J} / \mathrm{g}-\mathrm{K}$, and a density of $2.85 \mathrm{~g} / \mathrm{cm}^{3}$. The thermal conductivity of molten electrolyte is quite low. However, because of the vigorous circulation provided by the escaping gas bubbles, the electrolyte is nearly isothermal. In order to model this without solving for the underlying flow field, the thermal conductivity was set at $10 \mathrm{~W} / \mathrm{cm}-\mathrm{K}$. The heat capacity and density of the electrolyte are $1.657 \mathrm{~J} / \mathrm{g}-\mathrm{K}$ and $2.14 \mathrm{~g} / \mathrm{cm}^{3}$, respectively [9]. The molten aluminum has a higher thermal conductivity than the electrolyte, but it is not mixed as vigorously. Thus, the effective thermal conductivity will be assumed to be $5 \mathrm{~W} / \mathrm{cm}-\mathrm{K}$. The heat capacity and density of the aluminum are $1.088 \mathrm{~J} / \mathrm{g}-\mathrm{K}$ and $2.29 \mathrm{~g} / \mathrm{cm}^{3}$, respectively [9]. Based on data from the manufacturer, the carbon cathode blocks have a thermal conductivity of $0.15 \mathrm{~W} / \mathrm{cm}-\mathrm{K}$ and a density of 1.60 $\mathrm{g} / \mathrm{cm}^{3}$. The heat capacity is approximately $0.889 \mathrm{~J} / \mathrm{g}-\mathrm{K}$ [5]. The cathode collector bars are made of steel. The steel was assumed to have a thermal conductivity of $0.31 \mathrm{~W} / \mathrm{cm}$ $\mathrm{K}$, a heat capacity of $0.460 \mathrm{~J} / \mathrm{g}-\mathrm{K}$, and a density of $7.84 \mathrm{~g} / \mathrm{cm}^{3}[4]$. According to Taylor et al. [8], the bottom insulation has a thermal conductivity of $3.2 \times 10^{-3} \mathrm{~W} / \mathrm{cm}-\mathrm{K}$, a heat capacity of $1.40 \mathrm{~J} / \mathrm{g}-\mathrm{K}$, and a density of $1.80 \mathrm{~g} / \mathrm{cm}^{3}$.

In addition to the physical materials making up the cell, there are several internal heat transfer coefficients that will be modeled by an effective conductivity. These will include the convection heat transfer coefficient between the electrolyte and the ledge, the metal pad and the ledge, the electrolyte and the metal pad, the metal pad and the carbon 
cathode, the electrolyte and the anode, and the radiation coefficient between the electrolyte and the crust. Chen et al.[11] tabulate estimates of the bath-ledge and metal pad-ledge convection coefficients from various researchers. There is significant variation in the estimates, but a bath-ledge heat transfer coefficient of $0.12 \mathrm{~W} / \mathrm{cm}^{2}-\mathrm{K}$ and a metal pad-ledge heat transfer coefficient of $0.04 \mathrm{~W} / \mathrm{cm}^{2}-\mathrm{K}$ appear to be reasonable approximations. Taylor[5] suggests a $0.10 \mathrm{~W} / \mathrm{cm}^{2}-\mathrm{K}$ heat transfer coefficient between the electrolyte and the metal pad and a $0.04 \mathrm{~W} / \mathrm{cm}^{2}-\mathrm{K}$ coefficient between the metal pad and the carbon cathode. The heat transfer coefficient between the anode and the electrolyte will be assumed to be $0.12 \mathrm{~W} / \mathrm{cm}^{2}-\mathrm{K}$ as there are not any values cited in the literature.

The bath and the crust are generally separated by a small air gap. As air flow is minimal, radiation is the primary means of energy transfer. There are three air gap regions, one on each side of the cell and another in the center channel between the two anodes. All three will be modeled in the same way. The crust thickness will be assumed to be constant at $12.0 \mathrm{~cm}$ and the air gap fixed at $2.5 \mathrm{~cm}$. Each air gap will be modeled as an infinitely long rectangular shaft. The width of the gap will be $15 \mathrm{~cm}$ for the gaps at the side of the cell and $21 \mathrm{~cm}$ for the gap in the center of the cell. Figure 6.4 shows a schematic of the setup. Side 1 will be the bath, side 2 will be frozen electrolyte for the side gaps and the carbon anode for the center gap, side 3 will be the crust, and side 4 will be the carbon anode. The emissivity of the bath is $0.90[3]$, the emissivity of the crust is 0.20 [3], the emissivity of the frozen electrolyte will be assumed to be the same as for the crust, and the emissivity of the carbon is 0.90 [4]. The temperature will be assumed to be known from the previous time step. 


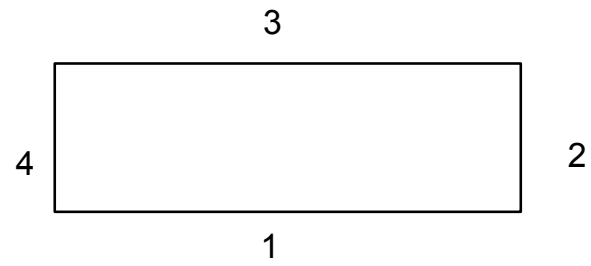

Figure 6.4: Schematic for air gap radiation coefficient determination

The following set of linear equations must be solved to determine the radiosity of each surface:

$$
\begin{aligned}
& J_{1}=\varepsilon_{1} E_{b 1}+\left(1-\varepsilon_{1}\right)\left(J_{2} F_{12}+J_{3} F_{13}+J_{4} F_{14}\right) \\
& J_{2}=\varepsilon_{2} E_{b 2}+\left(1-\varepsilon_{2}\right)\left(J_{1} F_{21}+J_{3} F_{23}+J_{4} F_{24}\right) \\
& J_{3}=\varepsilon_{3} E_{b 3}+\left(1-\varepsilon_{3}\right)\left(J_{1} F_{31}+J_{2} F_{32}+J_{4} F_{34}\right) \\
& J_{4}=\varepsilon_{4} E_{b 4}+\left(1-\varepsilon_{4}\right)\left(J_{1} F_{41}+J_{2} F_{42}+J_{3} F_{43}\right)
\end{aligned}
$$

where:

$\mathrm{J}_{\mathrm{i}}=$ the radiosity of side $\mathrm{i}$

$\mathrm{E}_{\mathrm{bi}}=$ the blackbody emissive power of side $\mathrm{i}\left(\sigma \mathrm{T}_{\mathrm{i}}^{4}\right)$

$F_{i j}=$ the fraction of energy leaving side $i$ that is intercepted by side $j$

The following are the needed shape factors[4]:

$$
\begin{aligned}
& F_{12}=F_{14}=F_{32}=F_{34}=\frac{1}{2}\left[1+\left(\frac{2.5}{L}\right)-\left[1+\left(\frac{2.5}{L}\right)^{2}\right]^{1 / 2}\right] \\
& F_{21}=F_{23}=F_{41}=F_{43}=\frac{L}{2.5} F_{12} \\
& F_{13}=F_{31}=\left[1+\left(\frac{2.5}{L}\right)^{2}\right]^{1 / 2}-\left(\frac{2.5}{L}\right) \\
& F_{24}=F_{42}=\left[1+\left(\frac{L}{2.5}\right)^{2}\right]^{1 / 2}-\left(\frac{L}{2.5}\right)
\end{aligned}
$$

where:

$\mathrm{L}=$ the length of faces 1 and $3,15 \mathrm{~cm}$ for the sides and $21 \mathrm{~cm}$ for the center 
Once the radiosity equations have been solved, the effective thermal conductivity for the element can be determined from Equation 6.35.

$$
\frac{\dot{Q}_{3}}{A}=\frac{\varepsilon_{3}}{1-\varepsilon_{3}}\left(E_{b 3}-J_{3}\right)=-\frac{k}{x}\left(T_{3}-T_{1}\right)
$$

where:

$\mathrm{k}=$ the thermal conductivity of the element

$\mathrm{x}=$ element thickness

\subsection{Sidewall Freeze}

The sidewall freeze plays an important role in maintaining the bath temperature at the correct operating level. This is because the ledge will melt or freeze so that the temperature at the ledge-bath interface is maintained at the liquidus temperature. The liquidus temperature can be determined from Equation 6.38[12].

$$
\begin{aligned}
t_{l}= & 1011+0.50\left[\mathrm{AlF}_{3}\right]-0.13\left[\mathrm{AlF}_{3}\right]^{2.2}-\frac{3.45\left[\mathrm{CaF}_{2}\right]}{1+0.0173\left[\mathrm{CaF}_{2}\right]}+ \\
& 0.124\left[\mathrm{CaF}_{2}\right]\left[\mathrm{AlF}_{3}\right]-0.00542\left(\left[\mathrm{CaF}_{2}\right]\left[\mathrm{AlF}_{3}\right]\right)^{1.5}- \\
& \frac{7.93\left[\mathrm{Al}_{2} \mathrm{O}_{3}\right]}{1+0.0936\left[\mathrm{Al}_{2} \mathrm{O}_{3}\right]-0.0017\left[\mathrm{Al}_{2} \mathrm{O}_{3}\right]^{2}-0.0023\left[\mathrm{AlF}_{3}\right]\left[\mathrm{Al}_{2} \mathrm{O}_{3}\right]}- \\
& \frac{8.90[\mathrm{LiF}]}{1+0.0047[\mathrm{LiF}]+0.0010\left[\mathrm{AlF}_{3}\right]^{2}}-3.95\left[\mathrm{MgF}_{2}\right]-3.95[\mathrm{KF}]
\end{aligned}
$$

where: $\mathrm{t}_{1}=$ the liquidus temperature in ${ }^{\circ} \mathrm{C}$ and the bracketed expressions are in weight percent.

Melting of the ledge, as the result of higher bath temperatures, decreases the thermal resistance in the sidewall region, resulting in an increased heat flow. Freezing of the ledge, as the result of colder bath temperatures, increases the thermal resistance in the 
sidewall region, resulting in a decreased heat flow. In this way the sidewall freeze acts as a self correcting mechanism for maintaining the cell at the desired temperature. The latent heat of fusion of the bath, $520 \mathrm{~kJ} / \mathrm{kg}$ further acts to damp the effects of energy imbalances in the cell.

\section{$\underline{6.5 \text { Moving Boundaries }}$}

One factor that complicates the solution process is that the geometry of the cell changes. These changes include the following: the anode-cathode distance, the bath depth, the metal pad depth, the anode height, and the thickness of the sidewall freeze. When a change in the geometry occurs, the nodal locations are recalculated using the same sidewall freeze profile. The bath depth and metal pad depth are then adjusted until their masses equal their masses before the change. This results in approximate conservation of mass. The existing nodal temperatures are then used to calculate the temperature at subsequent time steps. From a theoretical perspective, this approach does not explicitly conserve all of the mass and energy in the system during the transition period. However, from a practical standpoint, this approach maintains the important system characteristics. The only region of the cell in which mass will not be conserved is in the sidewall freeze region when changes in the bath depth or metal pad depth occur. This results because as the bath and metal pad depths change, the sidewall freeze elements are stretched or compressed in the vertical axis (see Figure 6.5). In the physical system, there is generally an air gap between the top crust and the bath surface. The thickness of the air gap would change as the bath and metal pad depth change. However, it is difficult to model the other factors that affect the size of the air gap. For this reason, 
in the present model, the thickness of the air gap is assumed to remain fixed. This forces the size of the sidewall freeze region to change with changing bath depths and metal pad depths, resulting in a lack of mass conservation. Because the sidewall mass is not used in any other calculations, the lack of mass conservation should not pose a problem.

However, the lack of mass conservation does lead to a lack of energy conservation because the variability in mass will result in variability in the thermal mass of the system. Changes in the thermal mass of the system will affect the time constants associated with thermal changes in the cell. The mass variability is anticipated to be small relative to the total mass of the system and, thus, should not have an appreciable impact on the system time constants.

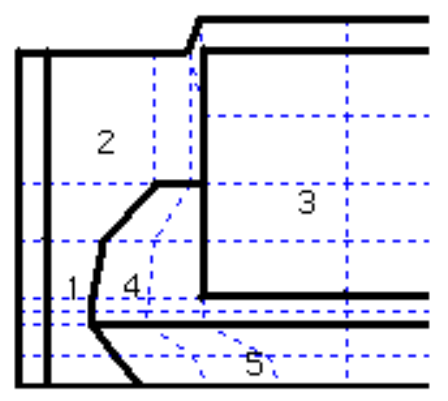

Figure 6.5: Top corner of the cell with mesh lines. (1. Sidewall freeze, 2. Top crust, 3. Anode, 4. Bath, and 5. Metal pad)

\section{$\underline{6.6 \text { References }}$}

1. Heinrich, J.C. and Zienkiewicz, O.C. "Quadratic Finite Element Schemes for TwoDimensional Convective Transport Problems.” International Journal for Numerical Methods in Engineering. Vol. 11, 1831-1844 (1977).

2. Grjotheim, K. and B.J. Welch. Aluminum Smelter Technology - A pure and Applied Approach. Aluminum-Verlag(Dusseldorf): 1988, pp 183. 
3. Rye, Ketil A., Jomar Thonstad, and Xiaoling Liu. "Heat Transfer, Thermal Conductivity, and Emissivity of Hall-Heroult Top Crust.” Light Metals 1995. 441449.

4. Mills, A.F. Heat Transfer. Irwin, Boston(1992).

5. NIST Standard Reference Database. Number 69, July 2001. Ed. E.S. Domalski and E.D. Hearing.

6. Grjotheim, K. et al. Aluminum Electrolysis: Fundamentals of the Hall-Heroult Process. Aluminum-Verlag, Dusseldorf, 1982:pp 382.

7. Rye, Ketil. "Alumina Crusting in Cryolitic Melts Part II: Bulk Properties of Crust." Light Metals 1992. 503-509.

8. Taylor, M.P., W.D. Zhang, V. Wills, and S. Schmid. "A Dynamic Model for the Energy Balance of an Electrolysis Cell.” Transactions of the Institution of Chemical Engineers 74 (1996): 913:933.

9. Lewis, R.A. Reduction Division Technical Manual I: Technical Fundamentals of the Aluminum Reduction Process. Kaiser Aluminum and Chemical Corporation Inc., 1973.

10. Jarrett, N. “Anode Manufacture.” Production of Aluminum and Alumina. A.R. Burkin, ed. John Wiley \& Sons, Chichester, 1987.

11. Chen, J.J. et al. "A Study of Cell Ledge Heat Transfer Using an Analogue Ice-Water Model.” Light Metals 1994. 285:293.

12. Solheim, Asbjorn, et al. "Liquidus Temperatures for Primary Crystallization of Cryolite in Molten Salt Systems of Interest for Aluminum Electrolysis.” Metallurgical and Materials Transactions B. Vol. 27B, 739-744 (1996). 


\section{Chapter 7: Chemical Species Model}

\subsection{Approach}

In order to model the behavior of an aluminum reduction cell, the mass of the bath, the mass of the metal pad, the mass of the anode material, and the chemical composition of the bath must be tracked. Chemical species of interest include alumina $\left(\mathrm{Al}_{2} \mathrm{O}_{3}\right)$, sodium fluoride $(\mathrm{NaF})$, aluminum fluoride $\left(\mathrm{AlF}_{3}\right)$, and calcium fluoride $\left(\mathrm{CaF}_{2}\right)$. The bath ratio, or the ratio of the mass of sodium fluoride to the mass of aluminum fluoride, is also of importance.

Alumina enters the cell as a powder, dissolves into the bath and is consumed by the reaction process. Sodium fluoride and aluminum fluoride form as a result of trace amounts of sodium and fluorine in the alumina feed material and the additions of soda ash $\left(\mathrm{Na}_{2} \mathrm{CO}_{3}\right)$ and aluminum fluoride. They are consumed as a result both of the volatilization of the bath and of sodium being deposited in the cell lining. Calcium fluoride enters the bath as a trace component of the alumina feed and leaves the bath through volatilization and deposition in the cathode materials. The mechanisms by which calcium fluoride enters and leaves the bath have not been extensively studied, because typical variations in the calcium fluoride concentration have a minimal effect on the overall heat balance of the cell. Because of this, the mass of calcium fluoride in the bath will be assumed to be fixed. The carbon anode material is added periodically when anodes are replaced and is consumed by the reaction process and as a result of burning if it is exposed to air when at a high temperature.

In order to accurately describe the spatial variation of the concentration of the chemical species of interest, a detailed, three-dimensional fluids model would be needed. 
Such a detailed fluids model would require too much computational time and would not enhance the accuracy of the chemical model significantly. Thus, the bath is assumed to be homogeneous.

\subsection{Alumina Additions}

Alumina is the primary addition made to any aluminum reduction cell. At Century Aluminum in Ravenswood, WV, additions of about $5.5 \mathrm{~kg}$ are made at intervals of approximately 5-6 minutes. Alumina additions are not made in a neat and precise manner. Before the alumina is fed, a hole is broken in the crust that covers the electrolyte. The crust is made up of a mixture of frozen bath and alumina from previous additions that did not dissolve. Depending on the density of the crust, chunks of crust may float on top of the electrolyte, sink to the bath - metal pad interface, or sink to the bottom of the pot. Regardless of the final location, the chunks of crust will eventually melt and dissolve into the electrolyte, though the time required will vary depending on their location, as well as the bath temperature and superheat. Once a hole has been broken into the crust, alumina powder is dumped into the hole from a height of about $0.75 \mathrm{~m}$. Most of the alumina falls through the hole in the crust, but a significant amount lands on the crust surrounding the hole. Some of the alumina which falls through the hole in the crust will sink into the bath and dissolve quickly, some of the alumina will remain floating on top of the bath and will gradually dissolve, and some of the alumina will form agglomerates of alumina and frozen bath that will sink to the bottom of the cell and dissolve very slowly. 
The percentage of alumina entering the bath through each of the described mechanisms varies from feed to feed based on cell conditions and random factors. Because of the intricacies of the process and the magnitude of the random influences, a simplified model was developed in which two dissolution mechanisms were assumed. Both mechanisms were assumed to be governed by a first-order differential equation, given by Equation 7.1, with the difference being the dissolution constant.

$$
\frac{d C}{d t}=-k C
$$

where:

$\mathrm{C}=$ the concentration of undissolved alumina (powder or sludge) in the bath. $\mathrm{t}=$ time in seconds. $\mathrm{k}=$ the dissolution constant in seconds ${ }^{-1}$.

The first mechanism models the alumina that dissolves quickly. This would include all of the powder that came in contact with the bath and did not form agglomerates. On average, about $75 \%$ of the total alumina addition enters the bath in this manner. Based on work by Haverkamp et al.[1] and Kobbeltvedt et al.[2] and based on plant measurements, the dissolution constant for this portion of the alumina addition was estimated to be $0.099 \mathrm{~s}^{-1}$. The second mechanism models the portion of the alumina addition that dissolves more slowly. This would include the chunks of crust that are broken in as well as any powder that forms agglomerates. Approximately $25 \%$ of the total alumina addition enters the bath in this manner and a dissolution constant of $5.0 \times 10^{-3} \mathrm{~s}^{-1}$ is used. The first mechanism will be referred to as dissolution of alumina powder, while the second mechanism will be referred to as dissolution of sludge. 
Though the feed material is primarily alumina, it also contains small amounts of sodium and fluorine. The sodium is a natural impurity in the feed material and exists as sodium oxide $\left(\mathrm{Na}_{2} \mathrm{O}\right)$. It combines with aluminum fluoride to form sodium fluoride and alumina according to Equation 7.2. The sodium concentration will typically range from $0.5 \%$ to $3.0 \%$. The fluorine in the feed material exists as aluminum fluoride. Significant amounts of aluminum fluoride do not naturally occur in the feed material. However, in order to meet emission standards, aluminum smelters typically employ dry scrubbers which use the ore to remove fluorides from the effluent pot gases. Thus, the fluorine content can range from negligible when pure ore is being used to as much as 2.5 or $3.0 \%$ when ore from the scrubbers is being used.

$$
3 \mathrm{Na}_{2} \mathrm{O}+2 \mathrm{AlF}_{3} \rightarrow 6 \mathrm{NaF}+\mathrm{Al}_{2} \mathrm{O}_{3}
$$

The concentration of sodium and fluorine in the feed material is measured about once a month, but it can change significantly over periods of less than 24 hours. As such, this is a significant source of error in trying to predict changes in the chemical composition of the bath.

\subsection{Corrective Bath Additions}

Over time the actual bath ratio will drift from the target ratio. When this occurs, corrective additions are made to return the bath to the proper ratio. In Ravenswood, ratio measurements are made once a week and the corrective additions are added to the cell over the ensuing week. Two types of additions are made, aluminum fluoride, to decrease the ratio, and soda ash $\left(\mathrm{Na}_{2} \mathrm{CO}_{3}\right)$, to increase the ratio. The soda ash combines with 
aluminum fluoride to form sodium fluoride, alumina, and carbon dioxide according to Equation 7.3.

$$
3 \mathrm{Na}_{2} \mathrm{CO}_{3}+2 \mathrm{AlF}_{3} \rightarrow 6 \mathrm{NaF}+\mathrm{Al}_{2} \mathrm{O}_{3}+3 \mathrm{CO}_{2}
$$

The aluminum fluoride is added in $50.0 \mathrm{lb}(22.7 \mathrm{~kg})$ increments to the hoppers containing the alumina feed material. The addition is not mixed with the feed material, so the time required for the addition to enter the bath will vary. The soda ash is added directly to the bath in $50.0 \mathrm{lb}(22.7 \mathrm{~kg})$ bags. This is done by breaking a hole in the crust and dropping the bag directly into the hole. The exact timing of the addition is not recorded and the rate at which the material will enter solution will vary depending on how well the crust was broken in, as well as on the temperature and superheat of the bath.

\subsection{Bath Evolution}

There are three main ways fluorine and sodium leave the cell through the effluent gasses. They include gaseous fluoride evolution, particulate evolution by the volatilization of the electrolyte, and particulate evolution by the entrainment of droplets of liquid electrolyte[3]. Hydrogen fluoride (HF) makes up the majority of the gaseous fluoride. The hydrogen fluoride and alumina are formed by combining aluminum fluoride with water according to equation 7.4.

$$
2 \mathrm{AlF}_{3}+3 \mathrm{H}_{2} \mathrm{O} \leftrightarrow 6 \mathrm{HF}+\mathrm{Al}_{2} \mathrm{O}_{3}
$$

The water enters the cell primarily through moisture in the alumina feed material and as hydrogen in the carbon anodes. Haupin[3] gives the following equation for calculating the rate of gaseous fluoride evolution, which is used in the present research. 


$$
\begin{aligned}
F_{G}= & \frac{2310000-955000 R}{P_{b} \% C E} \exp \left(7.533-\frac{8444}{T}\right) . \\
& \left(\frac{\% \mathrm{H}_{2} \mathrm{O} \text { in } \mathrm{Al}_{2} \mathrm{O}_{3}}{37.44}+\frac{\% \mathrm{H} \text { in anodes }}{21.5}\right)^{0.5} \cdot \\
& \exp \left(0.44199-3.1733 \mathrm{R}+0.78127 R^{2}\right) . \\
& \left(\frac{\% \mathrm{Al}_{2} \mathrm{O}_{3}}{\% \mathrm{Al}_{2} \mathrm{O}_{3}^{\text {sat }}}\right)^{-0.462}
\end{aligned}
$$

where:

$\mathrm{F}_{\mathrm{G}}=$ the mass of gaseous fluoride in kilograms per metric ton of aluminum.

$\mathrm{R}=$ the weight ratio of the bath.

$\mathrm{P}_{\mathrm{b}}=$ the barometric pressure in $\mathrm{kPa}$.

$\% \mathrm{CE}=$ the current efficiency.

$\mathrm{T}=$ the bath temperature in Kelvin.

$\% \mathrm{Al}_{2} \mathrm{O}_{3}=$ the concentration of alumina in the bath in weight percent.

$\% \mathrm{Al}_{2} \mathrm{O}_{3}{ }^{\text {sat }}=$ the saturation concentration of alumina in the bath in weight percent.

The saturation concentration of alumina in the bath can be calculated using Equation 7.6[4].

$$
\begin{aligned}
& \% \mathrm{Al}_{2} \mathrm{O}_{3}^{\text {sat }}=A\left(\frac{T-273}{1000}\right)^{B} \\
& A=11.9-0.062 x_{S A l F_{3}}-0.003 x_{S A l F_{3}^{2}}-0.20 \mathrm{CaF}_{2} \\
& B=4.8-0.048 \mathrm{xsAlF}_{3}
\end{aligned}
$$

where:

$\mathrm{T}=$ the temperature in Kelvin.

$\mathrm{xsAlF}_{3}=$ the concentration in weight percent of excess aluminum fluoride in the bath. $\mathrm{CaF}_{2}=$ the concentration of calcium fluoride in the bath. 
Figure 7.1 shows the amount of fluoride leaving the cell for varying alumina concentrations and bath ratios. The temperature was assumed to be $20^{\circ} \mathrm{C}$ above the liquidus temperature for a given alumina concentration and bath ratio. Haupin[3] suggests that the percentage of water in the alumina is approximately $2.8 \%$ and the percentage of hydrogen in the anodes is about $0.093 \%$. These values were used in the simulations, since data specific to operating conditions at Century Aluminum is not available.

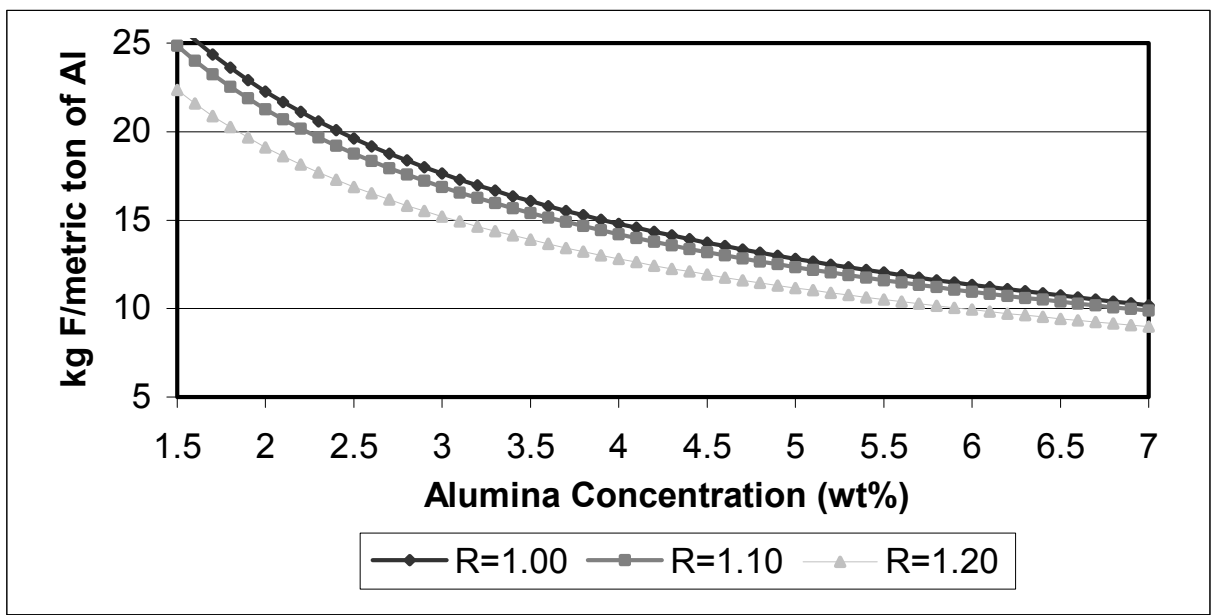

Figure 7.1: Gaseous fluorine evolution in kilograms per metric ton of aluminum for various aluminum concentrations and bath ratios

The composition of the vapor produced by a cryolite bath is $\mathrm{NaAlF}_{4}$. The vapor exists as both the monomer and as the dimer, $\mathrm{Na}_{2} \mathrm{Al}_{2} \mathrm{~F}_{8}$. The vapor forms from the combination of sodium fluoride and aluminum fluoride according to Equation 7.7.

$$
\mathrm{NaF}+\mathrm{AlF}_{3} \rightarrow \mathrm{NaAlF}_{4}
$$

Assuming the pot gases are saturated with vapor, Equation 7.8 can be used to calculate the rate of fluoride evolution due to particulate emissions resulting from volatilization[3].

$$
F_{V P}=\frac{204000}{\% C E} \frac{P_{m}+2 P_{d}}{P_{b}}
$$


where:

$\mathrm{F}_{\mathrm{VP}}=$ the rate of fluoride evolution in kilograms per metric ton of aluminum.

$\mathrm{P}_{\mathrm{m}}=$ the partial pressure of the monomer in $\mathrm{kPa}$.

$\mathrm{P}_{\mathrm{d}}=$ the partial pressure of the dimer in $\mathrm{kPa}$.

The partial pressures of the monomer and dimer can be calculated using the following equations[7]:

$$
\begin{aligned}
& \log \left(P_{V}\right)=\left(B-\frac{A}{T}\right) \\
& A=7101.6+3069.7 R-635.77 R^{2}+\frac{764.5 \% \mathrm{Al}_{2} \mathrm{O}_{3}}{1+1.0817 \% \mathrm{Al}_{2} \mathrm{O}_{3}}+13.2 \mathrm{CaF}_{2} \\
& B=7.0174+0.6844 R-0.08464 R^{3}+\frac{1.1385 \% \mathrm{Al}_{2} \mathrm{O}_{3}}{1+3.2029 \% \mathrm{Al}_{2} \mathrm{O}_{3}}+0.0068 \mathrm{CaF}_{2}
\end{aligned}
$$

where:

$\mathrm{P}_{\mathrm{V}}=$ the vapor pressure over the electrolyte.

$$
P_{m}=\frac{-1+\left(1+4 K P_{V}\right)^{0.5}}{2 K}
$$

where:

$\mathrm{K}=$ the equilibrium constant for dimerization.

$$
\begin{gathered}
K=\exp \left(\frac{-21414}{T}+15.6\right) \\
P_{d}=P_{V}-P_{m}
\end{gathered}
$$

Figure 7.2 shows the rate of fluoride evolution due to particulate emissions for various alumina concentrations for several ratio/temperature pairings. 


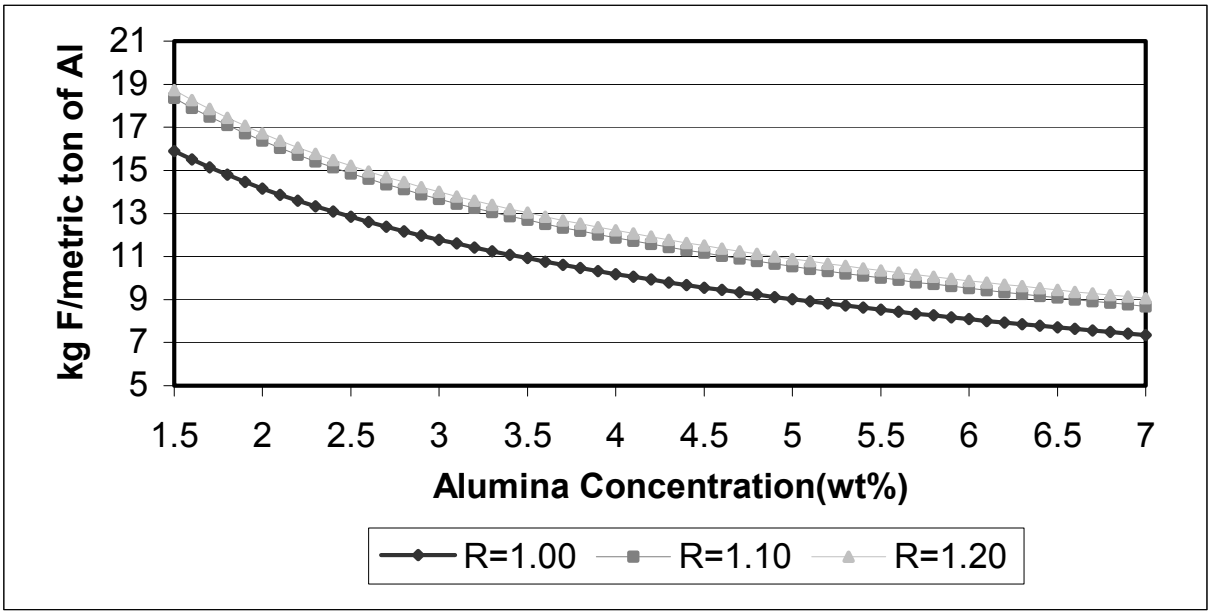

Figure 7.2: Rate of fluorine evolution in kilograms per metric ton of aluminum due to particulate emissions for various alumina concentrations at several ratio/temperature pairings

After accounting for the gaseous fluoride evolution and the particulate emissions, there is significant error between measured fluoride losses and estimates produced by the model. There are several theories as to the reason for this error. One theory is that the difference is the result of electrolyte being entrained by the effluent gases. Based on this theory, Haupin[3] developed an empirical model for calculating the amount of entrained electrolyte.

$$
F_{E}=\frac{1}{\% C E}\left(\begin{array}{c}
-17030+29800 R-13000 R^{2}+67 \% \mathrm{Al}_{2} \mathrm{O}_{3} \\
-173 t-0.3896 t^{2}+141.6 R \cdot t
\end{array}\right)
$$

where:

$\mathrm{F}_{\mathrm{E}}=$ the rate of fluoride evolution in kilograms per metric ton of aluminum.

$\mathrm{t}=\mathrm{T}(\mathrm{K})-1243$

Unfortunately, this formula can generate negative values under certain conditions, because it merely accounts for differences between measured values and the estimates produced by the gaseous fluoride and particulate emissions models. Thus, this equation does not generate accurate values for the amount of fluoride that is actually lost due to 
entrainment. However, the combination of the three models should provide a reasonable estimate of the material leaving the electrolyte via the effluent gases. Figure 7.3 shows the estimates of entrained electrolyte generated by Equation 7.13.

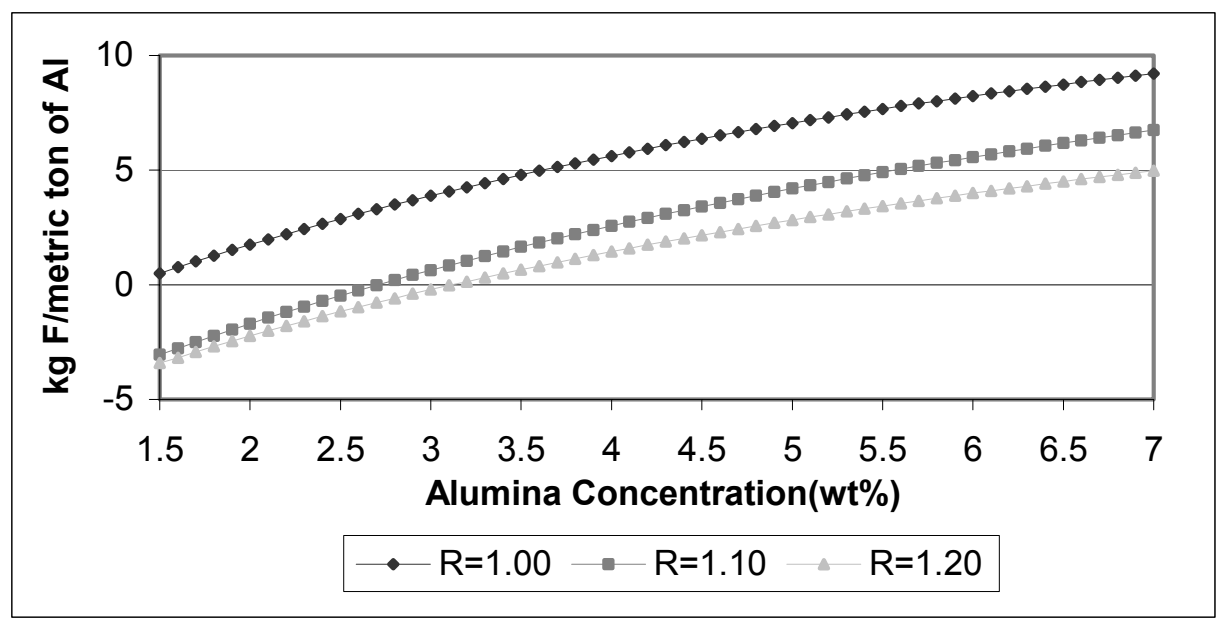

Figure 7.3: Rate of fluorine evolution in kilograms per metric ton of aluminum due to entrainment for various alumina concentrations at several ratio/temperature pairings

\section{$\underline{7.5 \text { Sodium Deposition }}$}

As the cell ages, a significant amount of sodium is deposited in the lining material. The rate of sodium deposition is highest when a cell is newer and gradually slows as the cell ages. The rate of sodium deposition will vary between cell designs and will vary depending on the materials used to make the cell. Assuming that an insignificant amount of sodium is deposited in the lining material in old pots (1000 days or more), the rate of sodium deposition can be estimated by subtracting the amount of soda ash required for older pots to the amount of soda ash required for younger pots. Figure 7.4 shows the rate of sodium consumption based on data from Century Aluminum in Ravenswood, WV. 


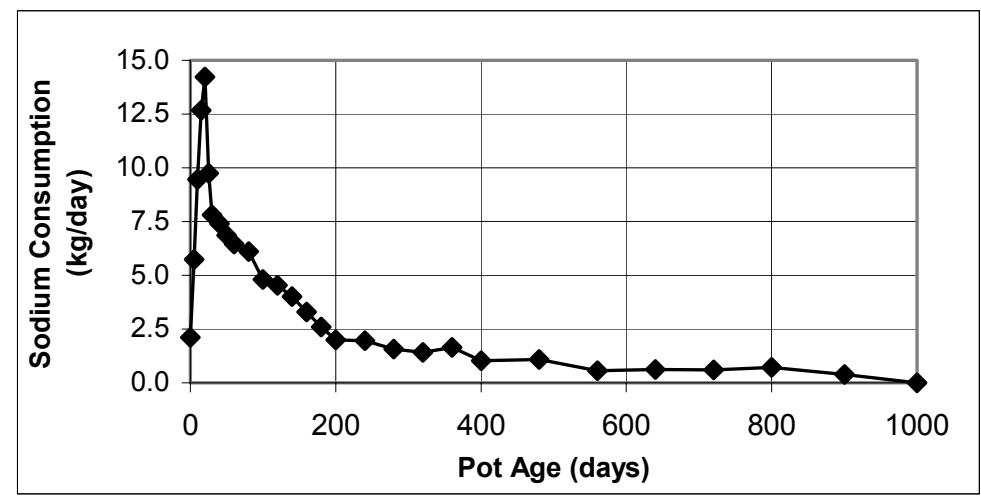

Figure 7.4: Sodium consumption in kilograms per day for pots of differing ages

\subsection{Mass of the Bath, Metal Pad, and Anode Carbon}

The initial mass of the bath and the metal pad is calculated from measurements of the bath depth and metal pad depth and the estimated anode-cathode distance. The initial mass of the anode carbon is calculated from the average anode cross-section. Changes in the bath mass are computed by calculating the flow of material into the bath from alumina feeds, bath additions, and melting of the sidewall ledge and out of the bath from bath volatilization, aluminum production, and freezing of the sidewall ledge. The mass of the metal pad will increase at the rate of aluminum production and will be decreased when tapping, or metal removal, occurs every other day. The mass of the anode carbon will decrease as carbon dioxide is released due to the forward chemical reaction, and will increase when new anodes replace spent anodes. The theoretical rate of metal production is given by Faraday's Law, Equation 7.14.

$$
M_{A l}^{*}=\frac{I \Delta t A}{F n}
$$

where:

$\mathrm{M}_{\mathrm{Al}}{ }^{*}=$ the theoretical mass of aluminum produced in kilograms.

$\mathrm{I}=$ the current in kiloamperes. 
$\Delta \mathrm{t}=$ the length of time in seconds.

$\mathrm{A}=$ the atomic weight of the element being deposited (26.98 $\mathrm{g}$ for aluminum).

F = Faraday's constant (96480 ampere-seconds).

$\mathrm{n}=$ the number of charges involved in the reaction ( 3 in for this reaction).

Because the process is not completely efficient, the actual mass of aluminum produced will fall short of the theoretical amount. The actual mass of aluminum can be determined as follows:

$$
M_{A l}=\frac{\% C E}{100} M_{A l}^{*}
$$

where:

$\mathrm{M}_{\mathrm{Al}}=$ the actual mass of aluminum produced in kilograms.

$\% \mathrm{CE}=$ the current efficiency expressed as a percentage.

\subsection{Current Efficiency}

Haupin[5] gives the following relationship for current efficiency.

$$
\% C E=100\left(1-\frac{r_{m}}{r_{A l}^{*}}\right)
$$

where:

$\mathrm{r}_{\mathrm{m}}=$ the rate of metal transfer through the bulk of the electrolyte in grams per second.

$\mathrm{r}_{\mathrm{Al}}{ }^{*}=$ the theoretical rate of aluminum production in grams per second. 
The rate of metal transfer through the bulk of the electrolyte can be calculated using Equation 7.17.

$$
r_{m}=A_{A l} k_{A l} C_{A l}^{*}(1-f)
$$

where:

$\mathrm{A}_{\mathrm{Al}}=$ the contact area between the metal pad and electrolyte.

$\mathrm{k}_{\mathrm{Al}}=$ the mass transfer coefficient.

$\mathrm{C}_{\mathrm{Al}}{ }^{*}=$ the saturation concentration of aluminum in the electrolyte.

$\mathrm{f}=\mathrm{a}$ factor relating the concentration of dissolved metal in the bulk electrolyte to its saturation value

The factor, $\mathrm{f}$, can be assumed to be constant. One estimate of $\mathrm{f}$ is 0.113 [5]. The mass transfer coefficient can be calculated as follows[6]:

$$
k_{A l}=2.147 \times 10^{-11}\left(\frac{i \cdot T}{A C D}\right)^{1.42}\left(1+313.3 v^{2.5}\right)\left(\frac{\mu}{\rho}\right)^{0.33} D^{0.67}
$$

where:

$\mathrm{i}=$ the anodic current density in $\mathrm{A} / \mathrm{m}^{2}$.

$\mathrm{T}=$ the temperature in Kelvin.

$\mathrm{ACD}=$ the anode-cathode distance in meters.

$\mathrm{v}=$ the maximum velocity in the metal pad.

$\mu=$ the viscosity of the bath.

$\rho=$ the density of the bath.

$\mathrm{D}_{\mathrm{Al}}=$ the diffusivity of aluminum in the bath . 
The maximum velocity in the metal pad is generally unknown and will be assumed to be constant. The viscosity of the bath, the density of the bath, and the diffusivity of aluminum in the bath can be assumed to be constant over a typical range of operation. The saturation concentration of aluminum in the bath can be calculated using Equation $7.19[6]$

$$
\begin{array}{r}
C_{A l}^{*}=-0.2877+0.0268 R+0.0003(T-273)- \\
0.0019 \% \mathrm{CaF}_{2}-0.0043 *\left(\% \mathrm{Al}_{2} \mathrm{O}_{3}-12.5\right)
\end{array}
$$

where:

$\mathrm{R}=$ the bath ratio.

$\mathrm{T}=$ the temperature in Kelvin.

$\% \mathrm{CaF}_{2}=$ the percentage of calcium fluoride in the bath.

$\% \mathrm{Al}_{2} \mathrm{O}_{3}=$ the percentage of alumina in the bath.

Combining all of these expressions results in the following equation for calculating the current efficiency:

$$
\% C E=100\left(1-\text { const }\left(\frac{i \cdot T}{A C D}\right)^{1.42} C_{A l}^{*}\right)
$$

where:

const $=\mathrm{a}$ constant that fits the curve to known results for a given cell technology. For the cells at Century Aluminum in Ravenswood, WV, the constant is $3.4 \times 10^{-7}$. 


\subsection{References}

1. Haverkamp, R.G., B.J. Welch, and J.B. Metson. "Models of Alumina Dissolution in Cryolite." Proceedings of the Eighth International Symposium on Molten Salts. Electrochemical Society, 1992, 646-659.

2. Kobbeltvedt, Ove, Sverre Rolseth, and Jomar Thonstad. "The Dissolution Behaviour of Alumina in Cryolite Bath on a Laboratory Scale and in Point Fed Industrial Cells." Proceedings of the 8th Aluminum Symposium, 1995, 127-135.

3. Haupin, W.E. "Environmental Considerations." Production of Aluminum and Alumina. A.R. Burkin, ed. John Wiley \& Sons, Chichester, 1987.

4. Solheim, A., E. Skybakmoen, L. Stoen, A. Sterten, and T. Store. "Liquidus Temperature and Alumina Solubility in the System $\mathrm{Na}_{3} \mathrm{AlF}_{6}-\mathrm{AlF}_{3}-\mathrm{LiF}-\mathrm{CaF}_{2}-\mathrm{MgF}_{2} . "$ Light Metals 1995. 451-460.

5. Haupin, W.E. "Current Efficiency." Production of Aluminum and Alumina. A.R. Burkin, ed. John Wiley \& Sons, Chichester, 1987.

6. Wright, A. "Dynamic Simulation and Control of Aluminum Reduction Smelting Cells.” Diss. U. Newcastle-upon-Tyne, 1993.

7. Haupin, W.E. "Chemical and physical properties of the electrolyte." Production of Aluminum and Alumina. A.R. Burkin, ed. John Wiley \& Sons, Chichester, 1987. 


\section{Chapter 8: Reduction Cell Model Verification}

\subsection{Overview}

The reduction cell model is composed of the finite element voltage model, the finite element thermal model, and the algebraic chemical species model. In order to verify the accuracy of each of these components, tests were run to compare the model outputs to results presented in the literature and to measurements taken from operating cells at Century Aluminum in Ravenswood, WV.

\subsection{Verification of the Voltage Model}

In order to verify the accuracy of the voltage model, the output of the model was compared to values presented in the literature. The first point of verification was to determine whether the distribution of the voltage was correct. Table 8.1 shows the values that were used to obtain the results. When possible, the values in the table correspond to the values used to obtain the literature values. Table 8.2 compares the voltage components obtained using the model to the voltage components suggested by Haupin[1]. The model produces a similar voltage profile as that given by Haupin. The differences that do occur are likely a result of different cell geometries and differences in the properties of the anode and cathode materials. After verifying the distribution of the voltage at a specified operating point, the model was run at various points within the operating range to compare the voltage trends with those shown in the literature. The alumina concentration was varied from $7.5 \%$ to just above $2.0 \%$ by weight for three anode-cathode distances, $4.0 \mathrm{~cm}, 4.2 \mathrm{~cm}$, and $4.4 \mathrm{~cm}$. Figure 8.1 shows the results. The model produces results similar to those shown by Haupin[1]. 
Table 8.1: Variable values used for verification run

\begin{tabular}{|l|c|}
\hline \multicolumn{1}{|c|}{ Variable } & Value \\
\hline Alumina(wt\%) & 3.0 \\
\hline Bath Ratio(weight) & 1.15 \\
\hline Bath Temperature(K) & 1244 \\
\hline Calcium Fluoride(wt\%) & 6.5 \\
\hline Anode-Cathode Dist(cm) & 4.2 \\
\hline Current Density(A/cm2) & 0.80 \\
\hline Anode Bake Temp(C) & 1473 \\
\hline Anode Effect Alumina(wt\%) & 2.0 \\
\hline
\end{tabular}

Table 8.2: Comparison of literature and model values for component voltages

\begin{tabular}{|l|c|c|}
\hline \multicolumn{1}{|c|}{ Component } & Model Volt. & Lit. Volt. \\
\hline Anode & 0.234 & 0.235 \\
\hline Bubbles & 0.278 & 0.259 \\
\hline Anode Concentration & 0.045 & 0.024 \\
\hline Anode Surface & 0.529 & 0.510 \\
\hline Decomposition & 1.196 & 1.208 \\
\hline Electrolyte & 1.580 & 1.640 \\
\hline Cathode Concentration & 0.037 & 0.037 \\
\hline Cathode Assembly & 0.322 & 0.300 \\
\hline
\end{tabular}

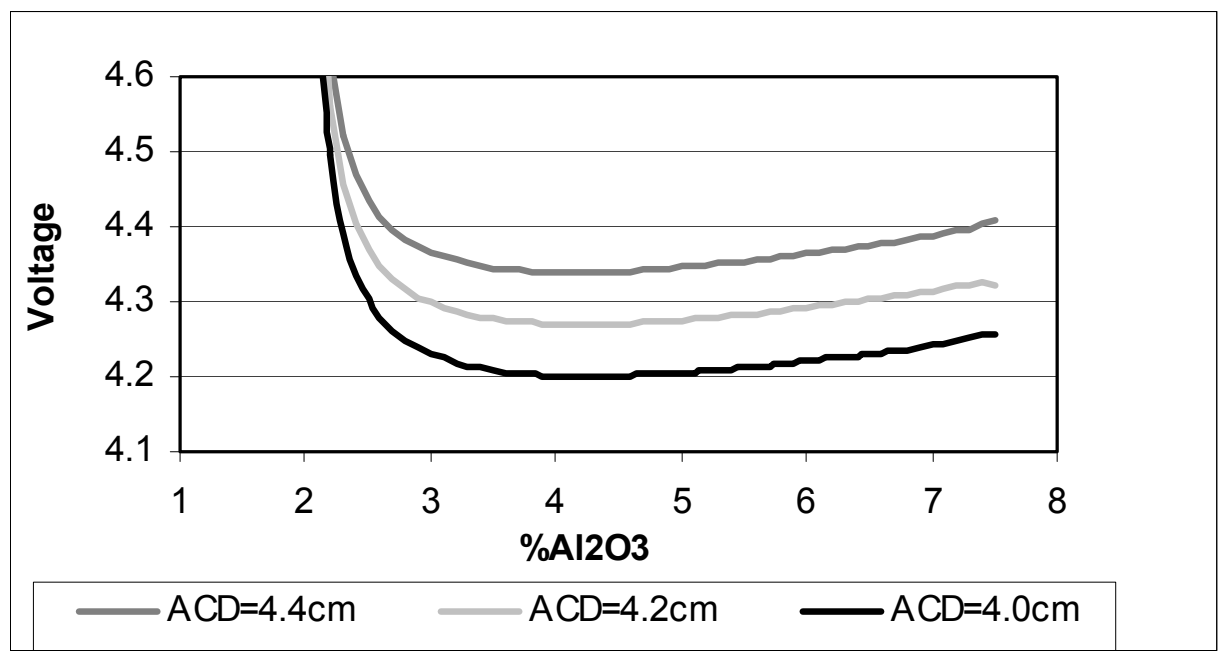

Figure 8.1: Voltage versus alumina concentration for various anode-cathode distances

\subsection{Verification of the Steady-State Thermal Model}

Experimental measurement of the temperature distribution in an operating reduction cell is not feasible. In order to verify the thermperature profile generated by the model, a 
comparison was made between contour plots generated by this model and models discussed in the literature. Figure 8.2 shows a contour plot of the predicted temperatures in a reduction cell modeled after those currently operating at Century Aluminum in Ravenswood, WV. The results were generated with a cell voltage of $4.53 \mathrm{~V}$, a bath ratio of 0.94 , a metal pad depth of $10.16 \mathrm{~cm}$, and a bath depth of $19.05 \mathrm{~cm}$. The contour lines are quite similar to those predicted in models by Valles and Lenis[2] and Taylor et al.[3]. Further verification of the model can be found in the limited amount of physical data that was able to be taken from operating cells. The measured bath temperature was $925^{\circ} \mathrm{C}$ and the estimated bath temperature was $927^{\circ} \mathrm{C}$. The measured sidewall temperature was $311^{\circ} \mathrm{C}$ and the predicted temperature was $320^{\circ} \mathrm{C}$. The heat flux from the sidewall was measured to be $0.70 \mathrm{~W} / \mathrm{cm}^{2}$ and the predicted heat flux was $0.69 \mathrm{~W} / \mathrm{cm}^{2}$. Figure 8.3 shows a plot comparing measured values of the sidewall ledge thickness to the thickness predicted by the model. The measured values were obtained by averaging the results from six measurements. The model provides a good prediction of the sidewall ledge profile.

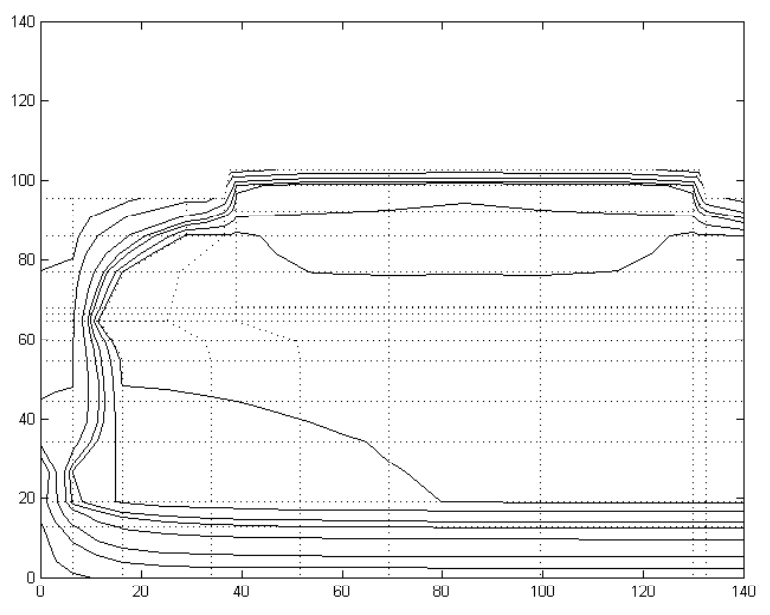

Figure 8.2: Contour plot of temperature predictions. Contours at 120, 260, 370, 540, 650, 710, 810, and $898^{\circ} \mathrm{C}$. 


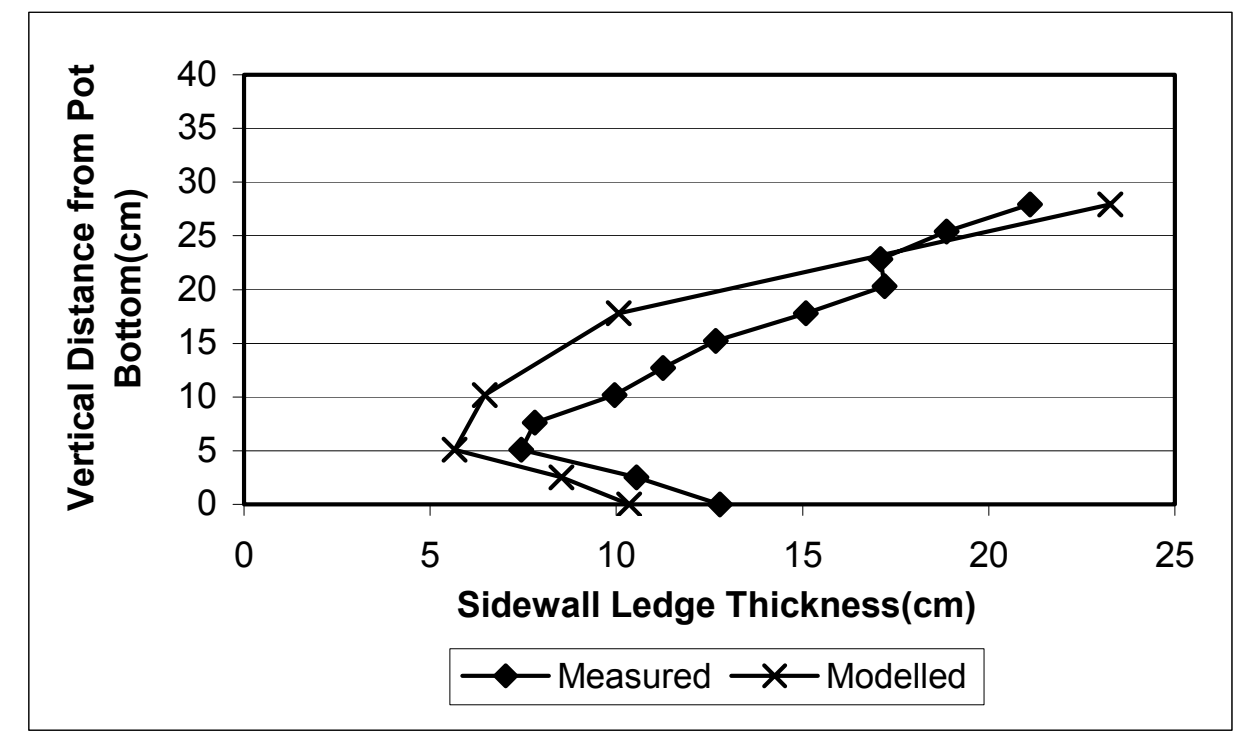

Figure 8.3: Comparison of measured and modeled sidewall ledge profile

\subsection{Verification of the Transient Thermal Model}

\subsubsection{Verification of the Selected Time-Steps}

In order for a transient model to be sufficiently accurate, a time-step must be selected that is small enough to accurately capture the system dynamics. As discussed in Chapter 6, two time-steps were used in this work, depending on the nature of the simulation to be run. For simulations which included feed events, a time-step of 1.0 seconds was used, and for simulations in which the feed was assumed to be added uniformly, a time-step of 300 seconds was used. In order to verify that these time-steps were appropriate, two simulations were run, one to verify each time-step.

To verify the 1.0 second time-step, several feed events were simulated using both the 1.0 second time-step and the 0.1 second time-step. For this simulation, the variable of most interest was the bath temperature. Figure 8.4 shows the difference between the estimated bath temperature in the two simulations. The maximum difference is about $0.15^{\circ} \mathrm{C}$ which is negligible for the purposes of this model. Thus, a 1.0 second time-step 
is sufficiently short to accurately describe the effects of short term fluctuations in the bath temperature caused by events such as alumina feeds.

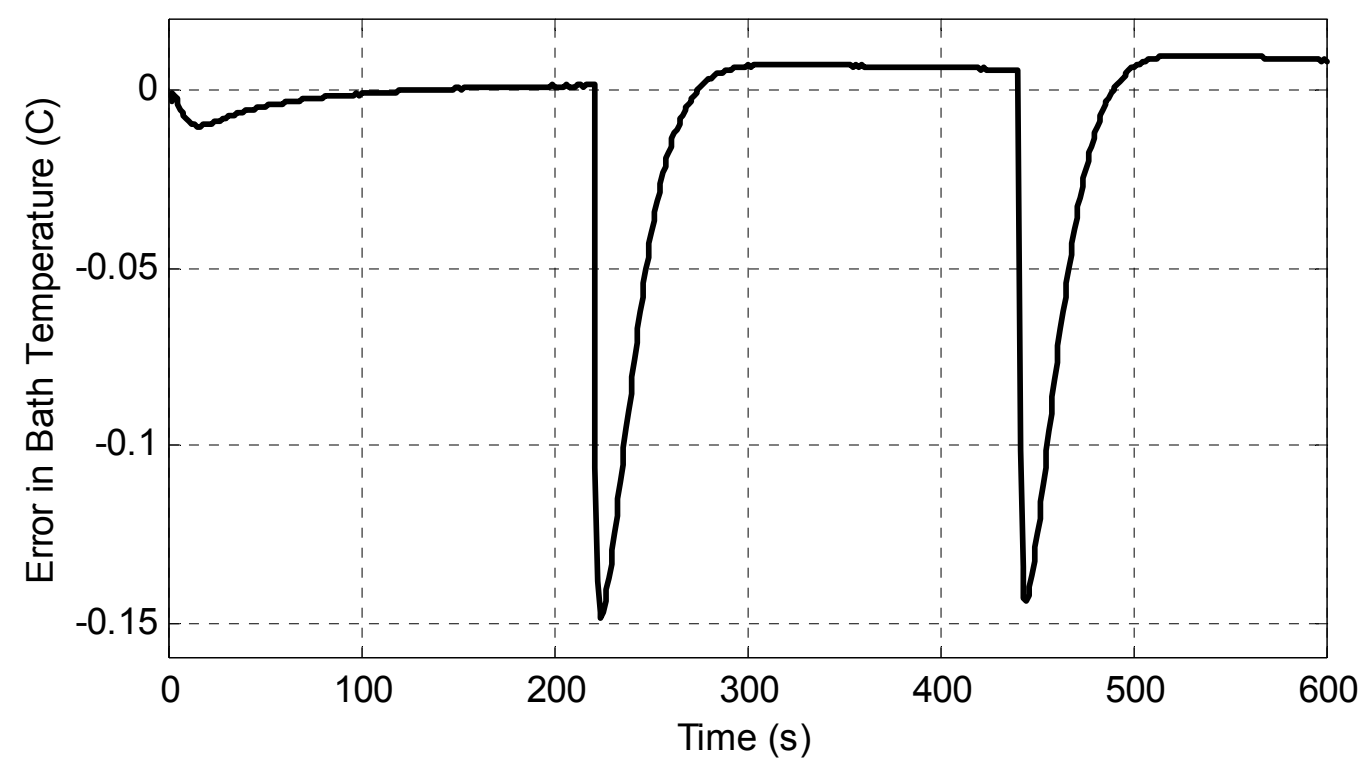

Figure 8.4: Difference in the estimated bath temperature between simulations with a time-step of 1.0 seconds and a time-step of 0.1 seconds

To verify the 300 second time-step, a step change in the voltage from $4.50 \mathrm{~V}$ to $4.60 \mathrm{~V}$ was used with a 300 second time-step and a 30 second time-step. Figure 8.5 shows the difference between the estimated bath temperature in the two simulations. Figures 8.6 through 8.8 show the differences in the sidewall thickness, top crust temperature, and bottom temperature respectively. The bath temperature shows the largest difference, as would be expected because of its high thermal conductivity. However, the error is only a few percent of the total temperature change. The other portions of the cell show smaller temperature differences because these regions have a lower thermal conductivity. Thus, the limiting factor, in terms of the selected time-step, is the high thermal conductivity assigned to the bath and metal pad regions. Based on these results, the 300 second timestep is sufficiently short to maintain sufficient accuracy for long-term trends, such as changes in the voltage level. 


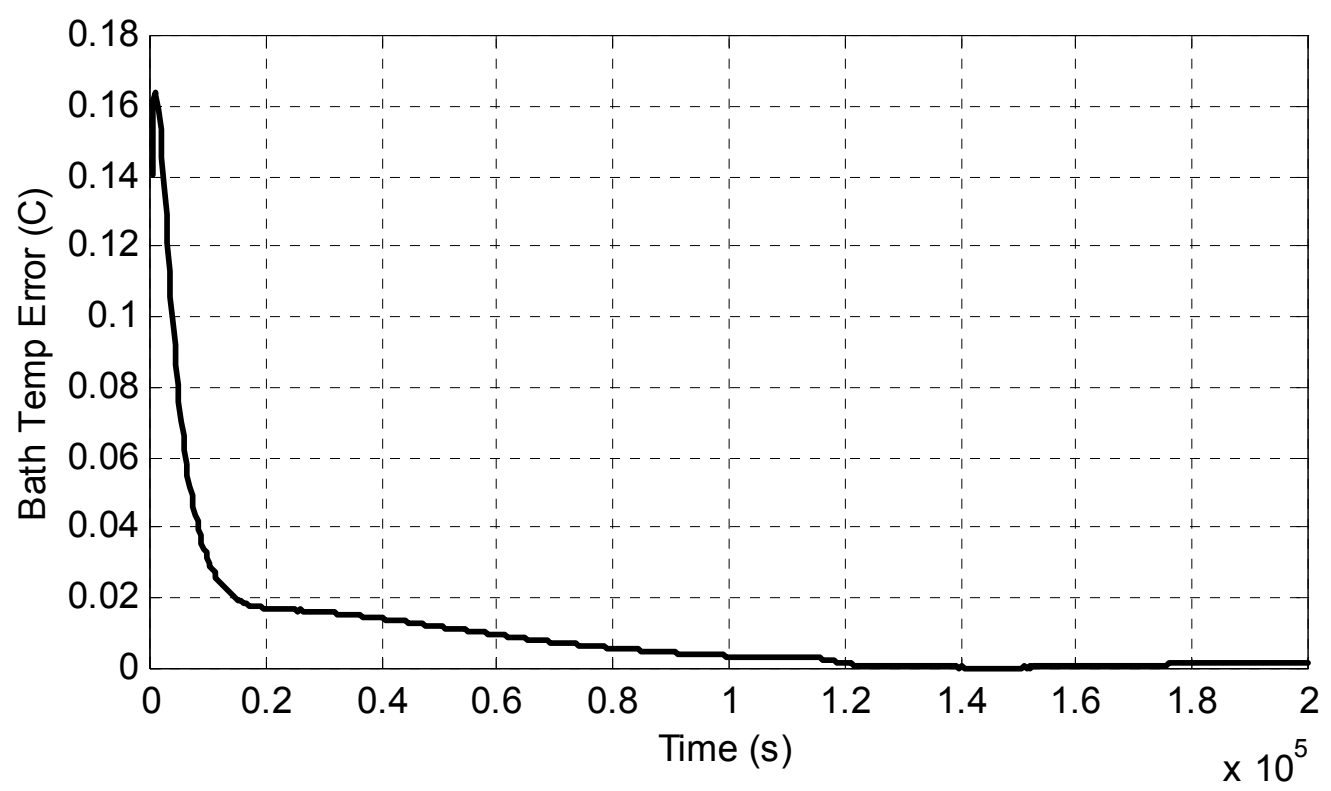

Figure 8.5: Error in the bath temperature between simulations with a time-step of 300 seconds and a

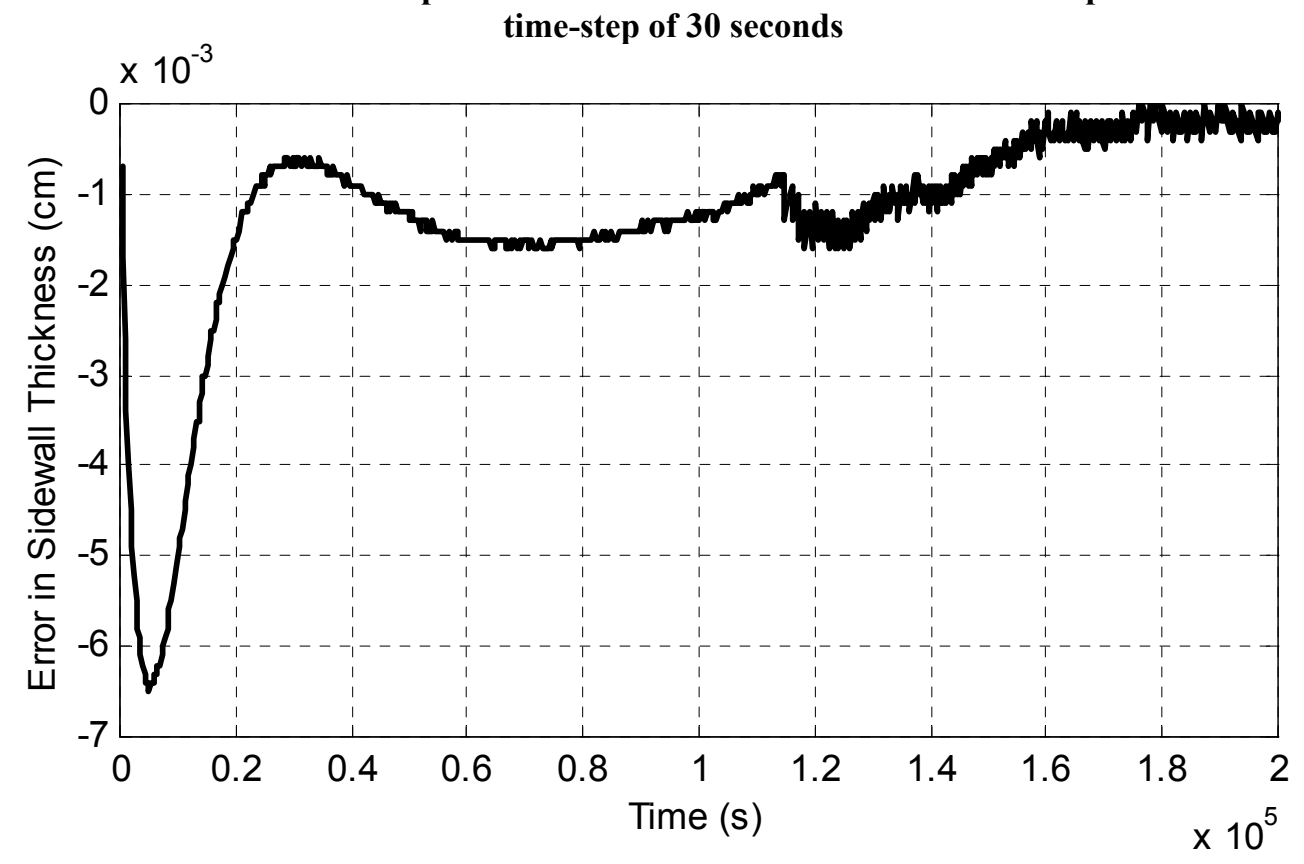

Figure 8.6: Difference in the estimated sidewall thickness between simulations with a time-step of 300 seconds and a time-step of 30 seconds 


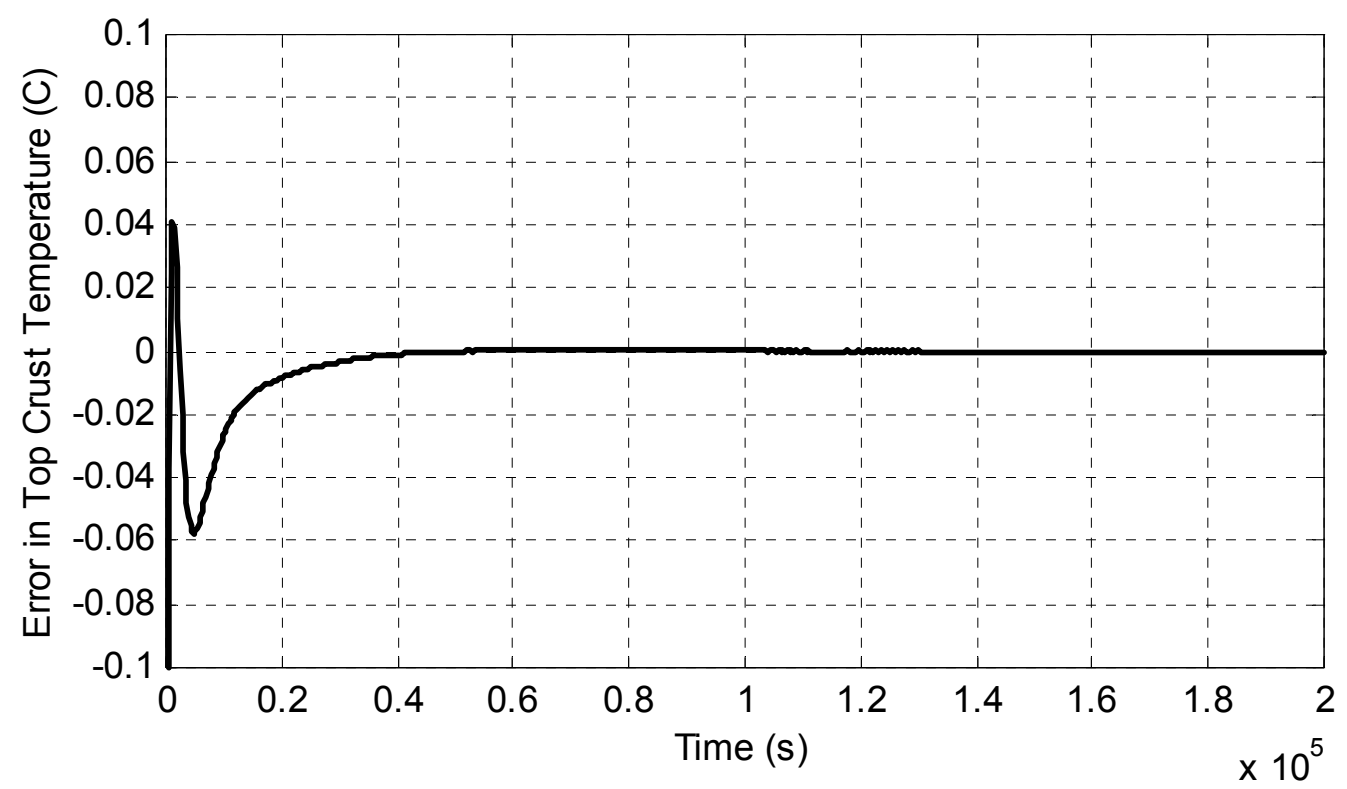

Figure 8.7: Difference in the estimated top crust temperature between simulations with a time-step of

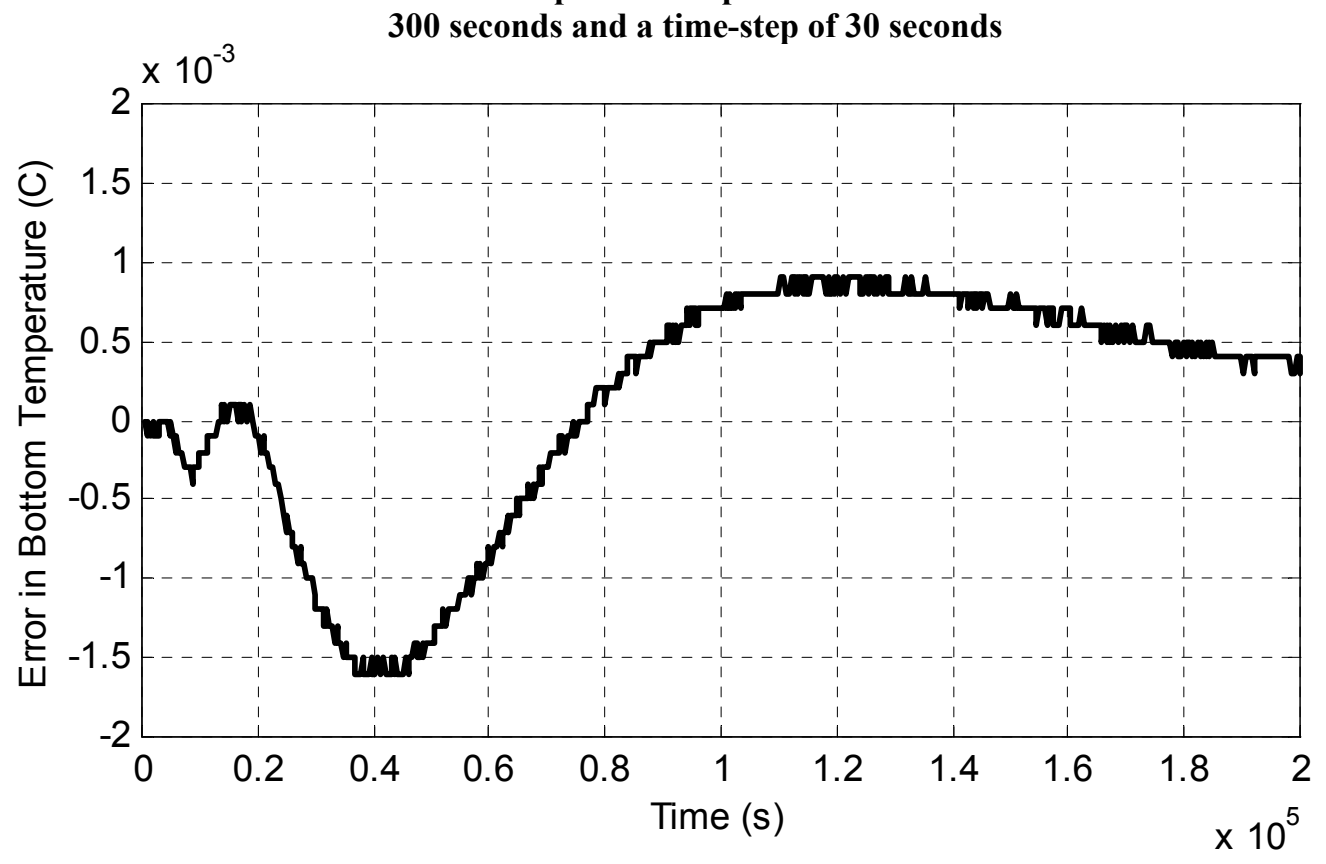

Figure 8.8: Difference in the estimated bottom temperature between simulations with a time-step of 300 seconds and a time-step of 30 seconds 


\subsubsection{Verification of the Thermal Time Scales}

An important characteristic of a thermal system is the time scale required for process disturbances to reach steady-state. The overall time scale of a system is governed by the portion of the system which has the smallest ratio of thermal conductivity to heat capacity. In an aluminum reduction cell, the overall time scale is governed by the insulation in the bottom of the cell. The pot bottom generally requires several days to achieve $90 \%$ of the temperature change resulting from a step change in operating conditions. The bath, top crust and sidewall react more quickly, but the slow response of the bottom insulation slows their response as well. Figure 8.9 shows the response of the bottom temperature to a step change in the voltage from $4.50 \mathrm{~V}$ to $4.60 \mathrm{~V}$. In this simulation, the pot bottom achieves $90 \%$ of the total change in 47 hours. Figures 8.10 and 8.11 show the response of the sidewall temperature and the top crust, respectively. The sidewall has a response time of 24 hours, and the top crust has a response time of 35 hours. Figure 8.12 shows the response of the bath temperature to several feed events. The temperature does not reach a steady state value, but the response time is on the order of several minutes. 


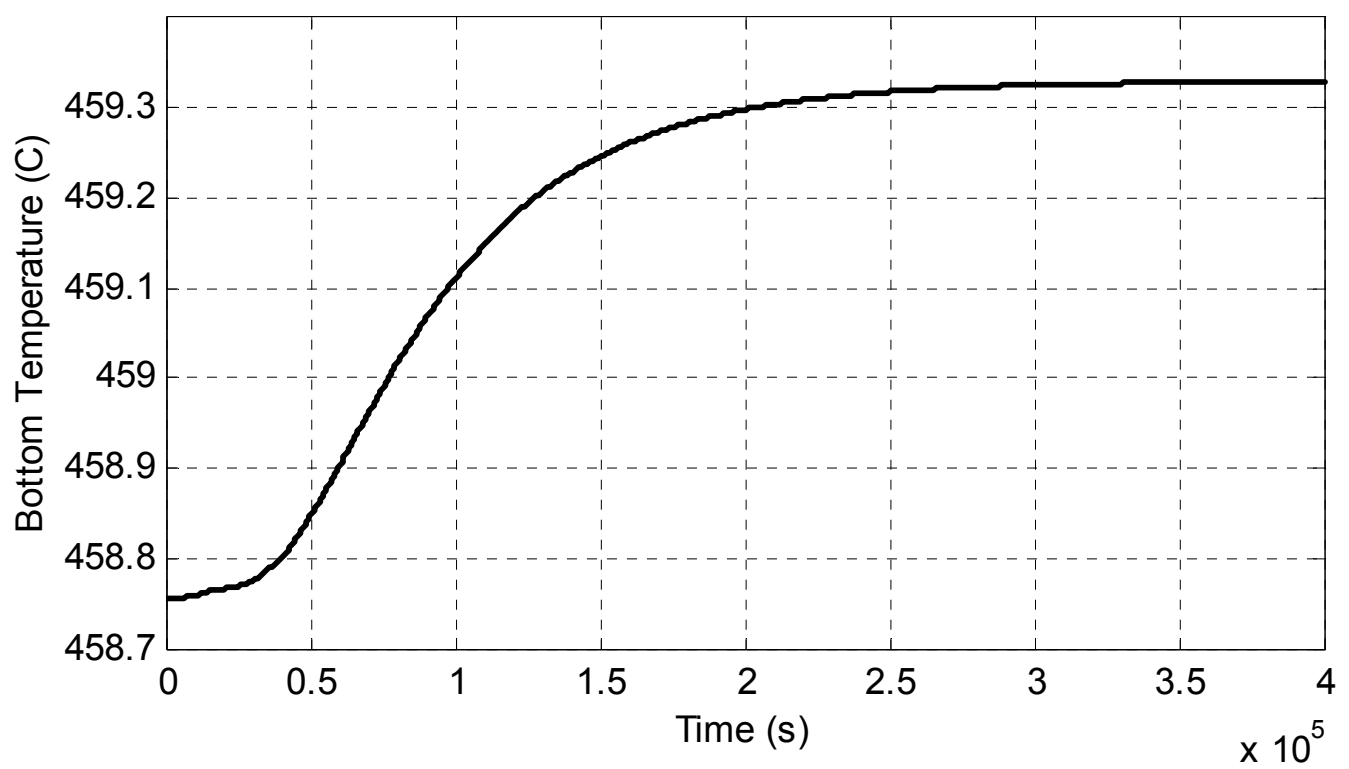

Figure 8.9: Response of the bottom temperature to a step change in the voltage

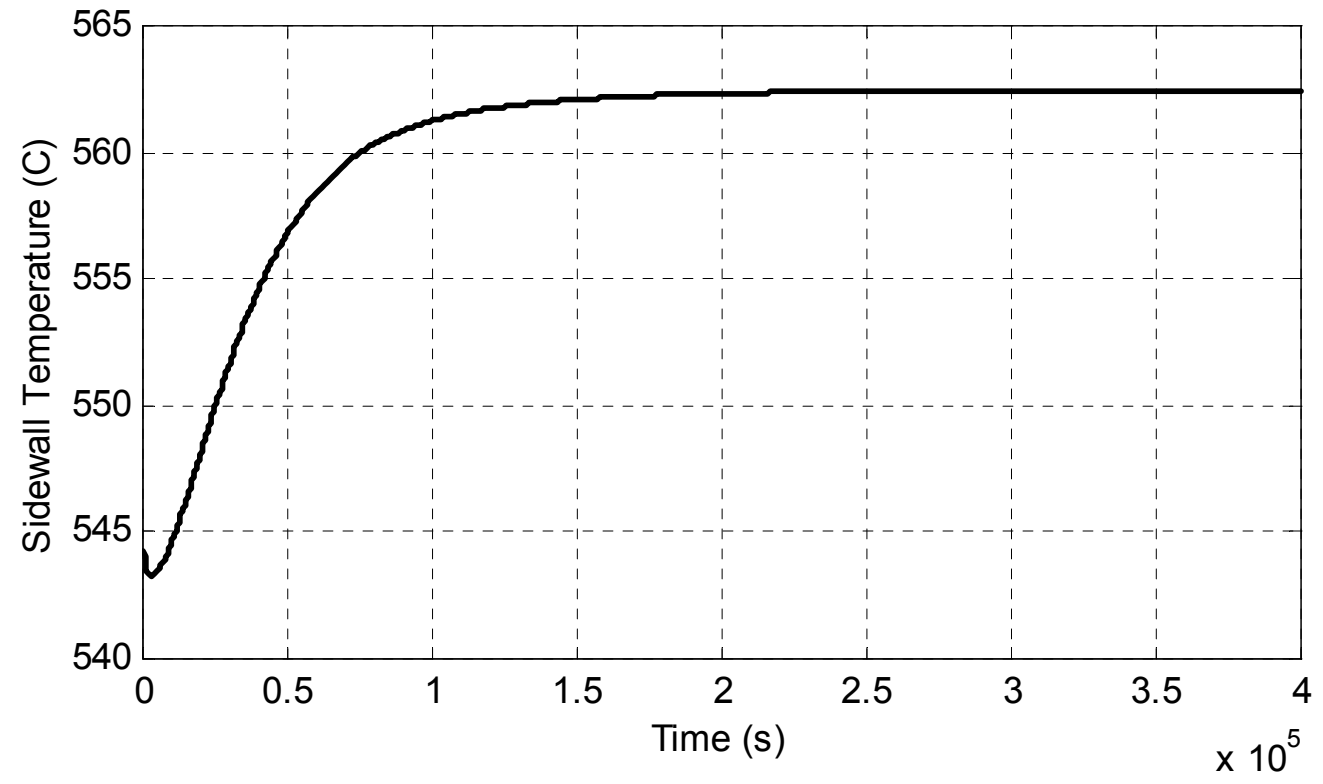

Figure 8.10: Response of the sidewall temperature to a step change in the voltage 


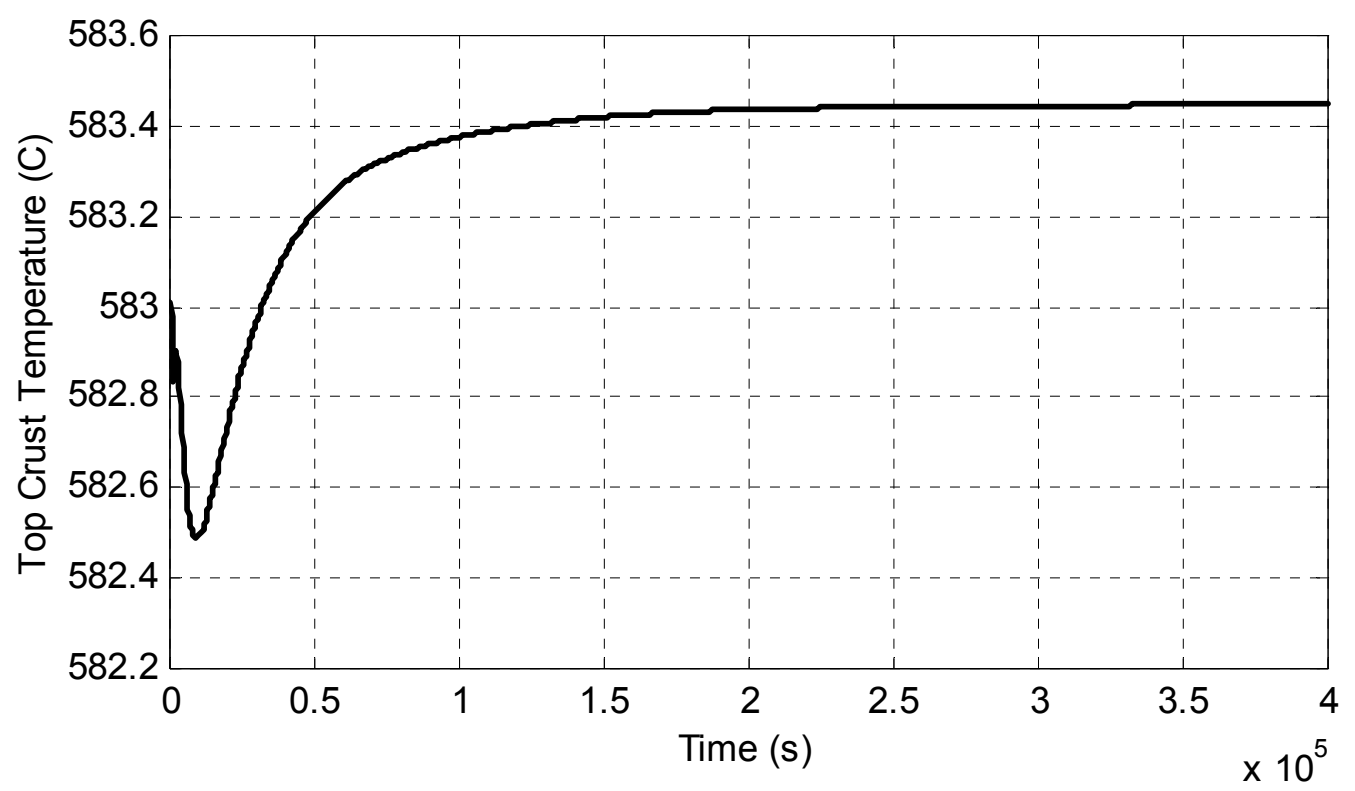

Figure 8.11: Response of the top crust to a step change in voltage

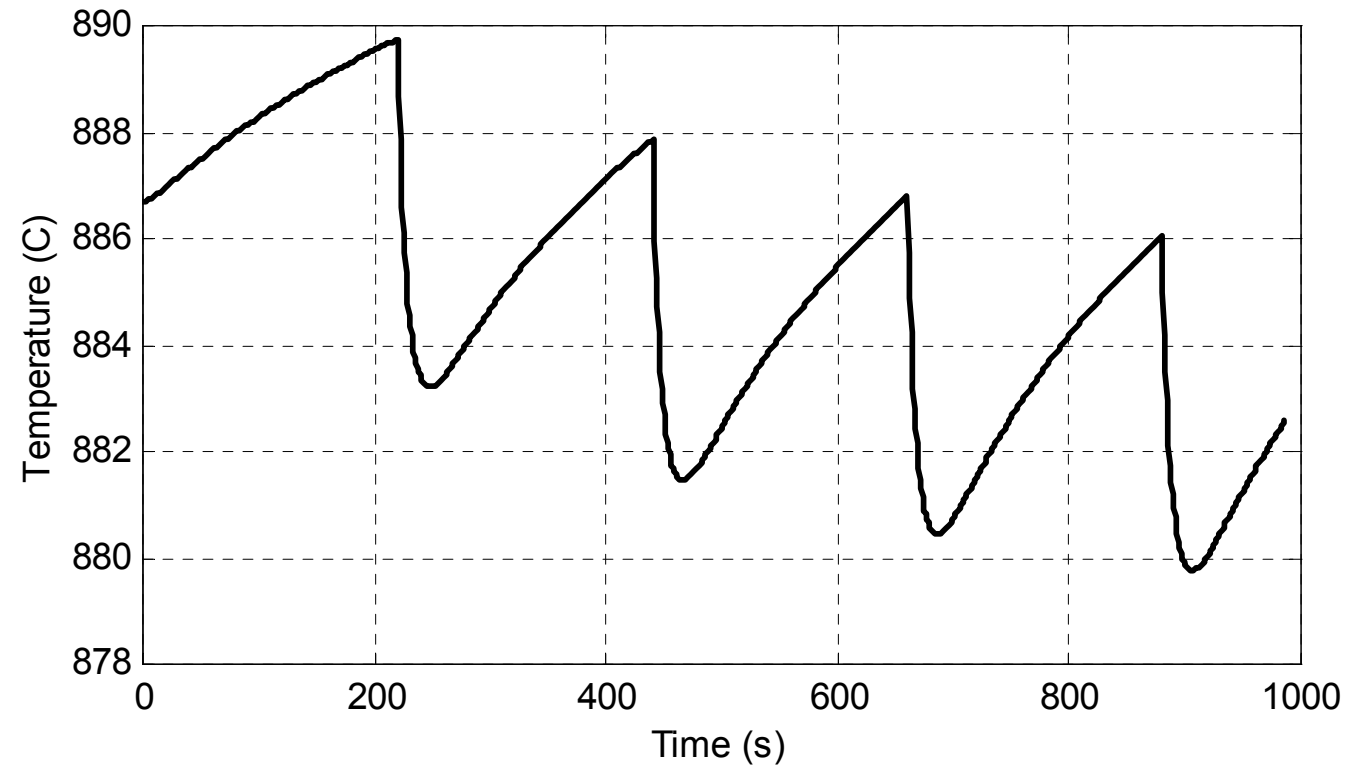

Figure 8.12: Response of the bath temperature to several feed events 


\subsubsection{Comparison of Predicted and Measured Response for Voltage Step Changes}

A final step in the verification process was to compare the transient model results to measurements taken from an operating reduction cell. The bath temperature was measured every 0.2 seconds and the alumina concentration an bath ratio were measured at intervals of 10 to 20 minutes. Before the measurements were taken, the cell had been operating at about $4.50 \mathrm{~V}$ for a several hours. Once the measurements were begun, the cell was allowed to complete a normal feed period, a no feed period, and an overfeed period. After this feed cycle was complete, the voltage was raised to $4.75 \mathrm{~V}$, and data was recorded for two more feed cycles. The entire measurement period covered about 4 $1 / 2$ hours.

Figure 8.13 compares the measured and modeled temperatures during the test period. The model closely tracks measured temperature. The primary point of discontinuity is at about $7000 \mathrm{~s}$, when the anodes were raised to increase the voltage. The corresponding, unexpected temperature drop is probably the result of cold crust material falling into the bath. This additional heat sink would explain the continued overestimation of the temperature during the remainder of the test period.

Figure 8.14 zooms in on a portion of Figure 8.13 to highlight several feed events. The model accurately tracks the magnitude and shape of the temperature fluctuations in this region. The magnitude of the fluctuations is controlled by the weight of the feed material and the ratio of the feed material that enters the bath as powder or as sludge. The shape of the curve is controlled by the dissolution rates for the powder and sludge. 


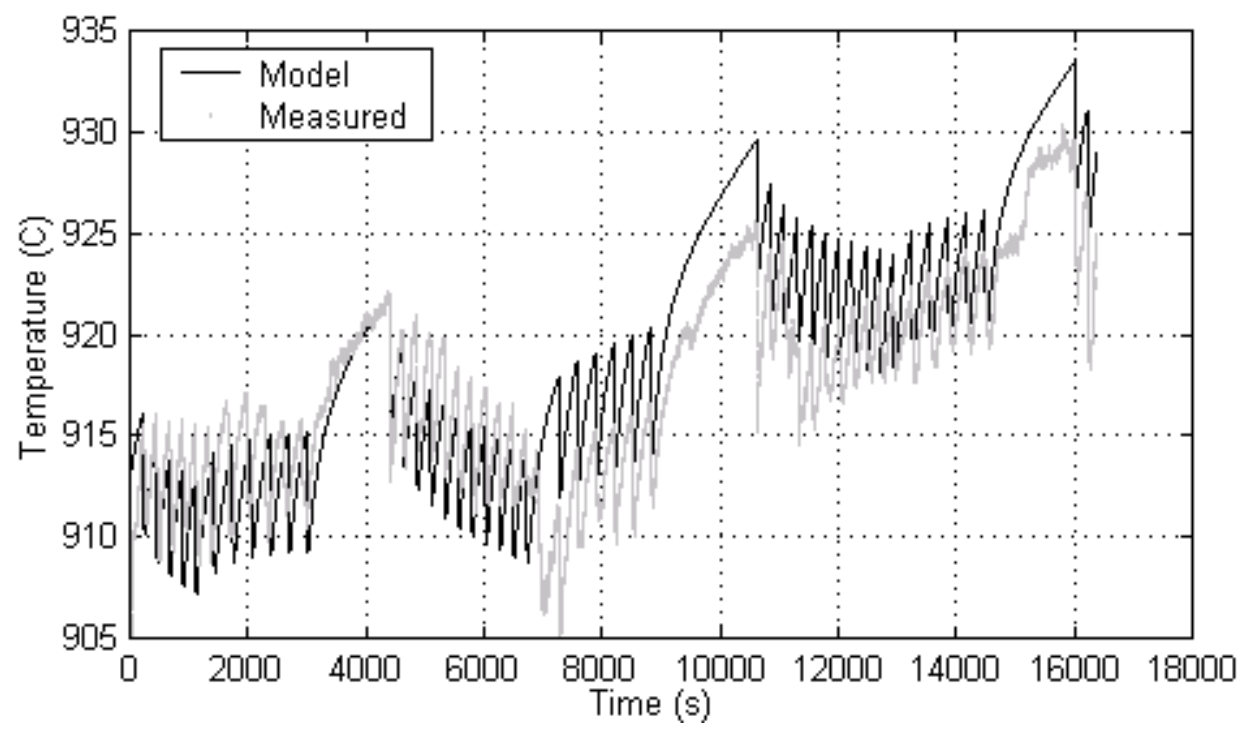

Figure 8.13: Comparison of measured and modeled bath temperature preceding and following a step change in the cell voltage

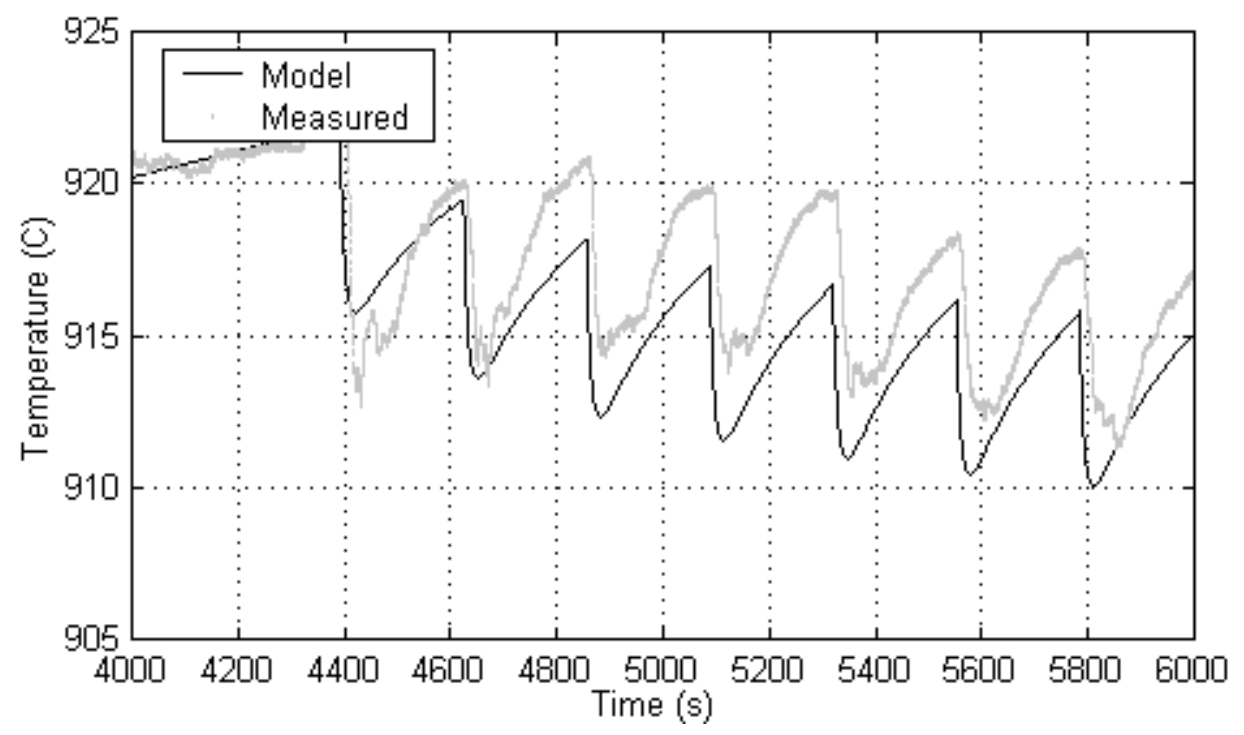

Figure 8.14: Comparison of measured and modeled bath temperature highlighting several feed events

Figure 8.15 shows the measured and modeled alumina concentration during the simulation period. The simulation tracks the general trend, but the scatter in the measured values makes it difficult to determine how well the model is tracking the trends due to a single normal feed, no feed, underfeed cycle. The only strong conclusion that can be gathered from the measured data is that over the course of the simulation the 
alumina concentration decreased by about $1.0 \%$. This decrease in the alumina concentration indicates that the average mass of alumina fed at each feed event for this simulation was $10 \%$ less than the average feed weight.

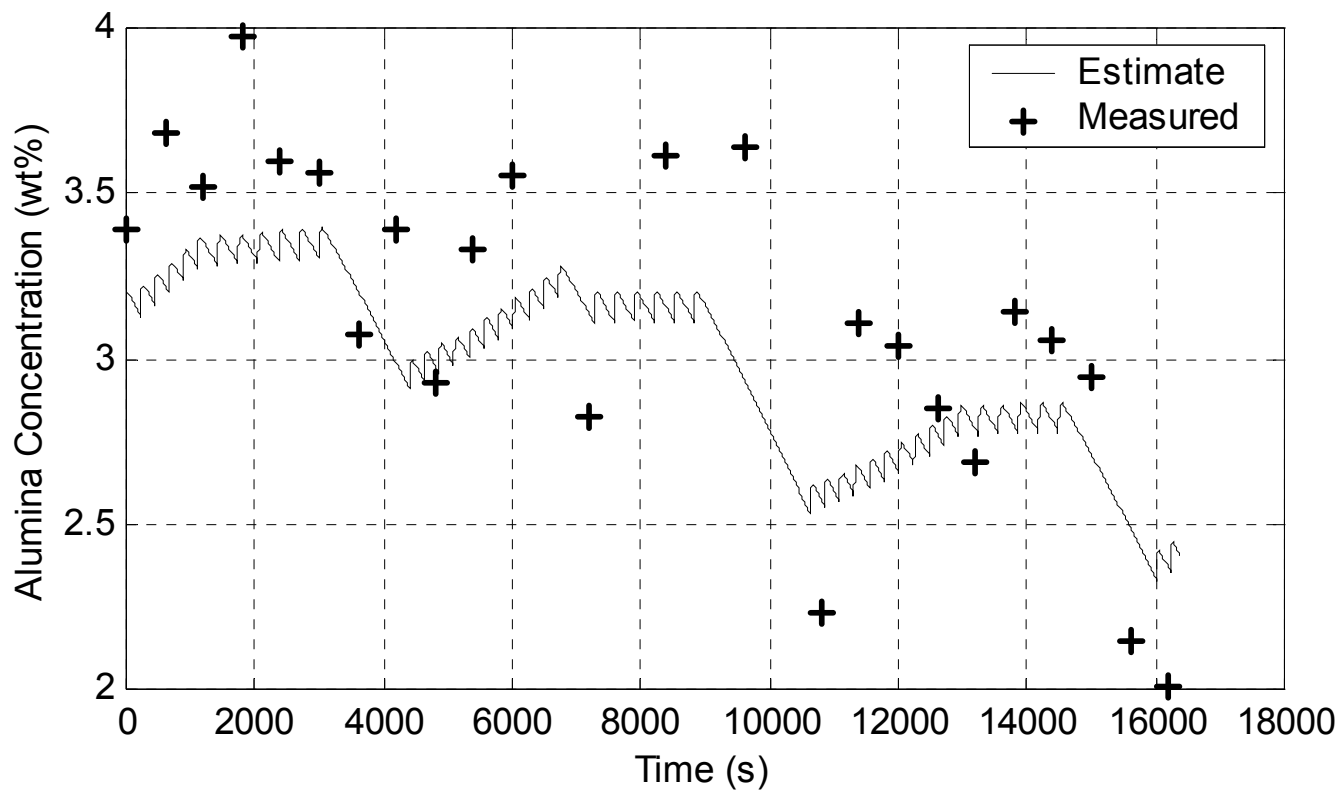

Figure 8.15: Comparison of measured and estimated alumina concentration

\subsection{Conclusions:}

A variety of methods were used to verify the accuracy of the finite element model that has been developed. The voltage model was primarily verified by comparison to results shown in the literature. The steady-state and transient aspects of the thermal model were verified by comparisons to results from the literature as well as from physical measurements made in operating reduction cells. Based on the data available, the model provides a good representation of the physical system. 


\subsection{References:}

1. Haupin, W.E. “Interpreting the Components of Cell Voltage.” Light Metals 1998. $531-537$.

2. Valles, A. and V. Lenis. "Prediction of Ledge Profile in Hall-Heroult Cells." Light Metals 1995. 309-313.

3. Taylor, M.P., W.D. Zhang, V. Wills, and S. Schmid. "A Dynamic Model for the Energy Balance of an Electrolysis Cell." Transactions of the Institution of Chemical Engineers 74 (1996): 913:933. 


\section{Chapter 9: Results from the Reduction Cell Model}

\subsection{Results from the Voltage Model}

The voltage model was used to simulate various process events which are difficult to produce in practice. However, the results are of interest for developing a better understanding of how different variables affect cell operation, and for developing operational approaches. Four simulations were run to study the effects of current density, bath depth, ratio and temperature, and misset anodes.

\subsubsection{Effects of Varying the Cell Current Density}

The first study involved varying the current density at the top of the anode and observing the resulting voltage at various alumina concentrations when a constant anodecathode distance is maintained. The results are shown in Figure 9.1. Increasing the applied current density increases the cell voltage as well as the alumina concentration at which anode effect occurs.

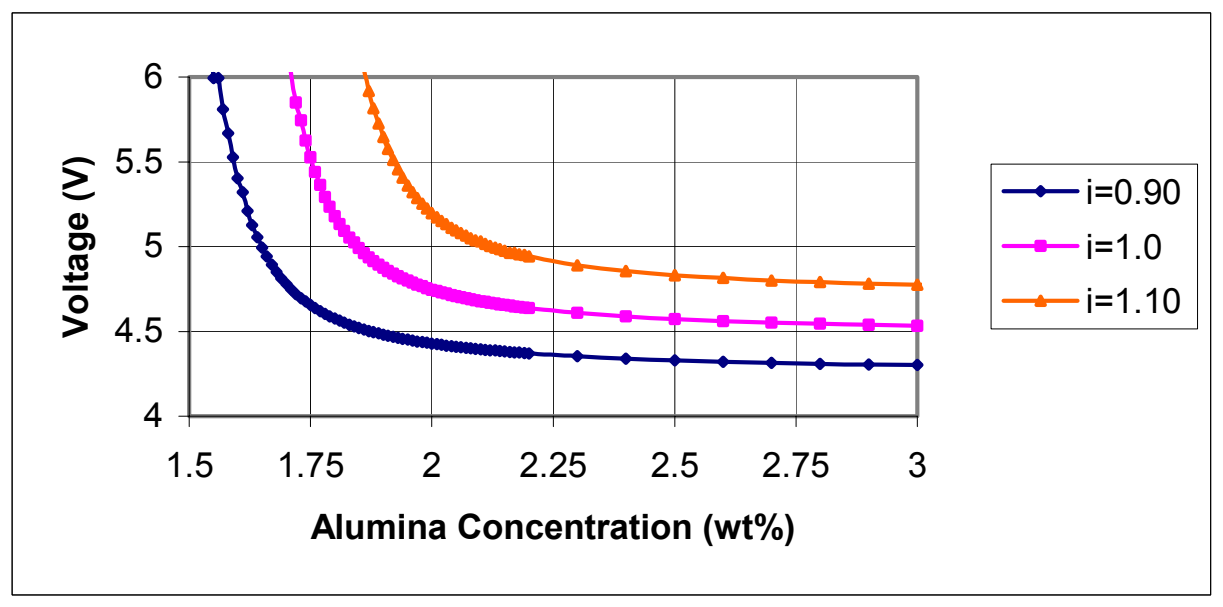

Figure 9.1: Voltage versus alumina concentration for applied current densities of 0.9, 1.0, and $1.10 \mathrm{~A} / \mathrm{cm}^{2}$ 
There are two primary reasons for changes in the applied current density, namely changes in the line current and changes in the net anode area. The line current fluctuates constantly as the result of operational upsets in the line, particularly anode effects. These line current fluctuations may be on the order of $20 \%$, but are generally short in nature. The line current is also changed depending on the season to reduce the impact of ambient temperature changes. However, this is generally a change of less than $1 \%$. The line current may also be changed to increase or decrease the quantity of metal produced. Smelters often increase the line current in order to increase production and increase profitability. However, there is a limit to increases in current density, because increased current density also increases the cell voltage. For example, if the cell in Figure 9.1, was operated at a current density of $1.0 \mathrm{~A} / \mathrm{cm}^{2}$ and a current efficiency of $93 \%$, the electrical energy consumption would be $14.52 \mathrm{~kW} / \mathrm{kg}$ of aluminum. If the cell was operated at 1.1 $\mathrm{A} / \mathrm{cm}^{2}$ and the same current efficiency, the increased cell voltage would result in an electrical energy consumption of $15.28 \mathrm{~kW} / \mathrm{kg}$ of aluminum. Depending on the cost structure of the smelter, the additional metal production may not offset the increased energy costs.

There are two main reasons that the net anode cross-sectional area changes: changes in the anode dimensions, and the removal of anodes for replacement. Changes in the anode dimensions are generally made to facilitate increased line current, though they may also be made to decrease the current density. For cells at the Century plant in Ravenswood, two anodes out of a total of twenty anodes are replaced at one time. When the anodes are removed, the effective current density increases by $10 \%$. This increased current density will remain in effect even after the new anodes are inserted because the new anodes 
gradually take on the full current load over a period of about 24 hours. Over this time period, particularly the first 8-12 hours, the cell is more susceptible to anode effects because anode effect is more likely to occur at a higher alumina concentration.

\subsubsection{Effects of Varying Bath Depth}

Bath depth is another factor that influences the cell voltage and the alumina concentration at which anode effect occurs. Figure 9.2 shows the cell voltage versus alumina concentration for several bath depths. Bath depth can change because the mass of the bath changes as a result of bath additions, because the volume available for the bath changes as a result of moving the anodes, or because both the mass of the bath and the available volume change because of melting or freezing of the side ledge. Because the bath depth is larger than the anode-cathode distance, part of the anode sides is in contact with the bath. This additional contact area provides a secondary current path, reducing the maximum current density at the anode bottom. As the bath depth increases from relatively low levels, such as from 2.00 in $(5.08 \mathrm{~cm})$ to 4.00 in $(10.16) \mathrm{cm}$, the effect on the voltage and alumina concentration at anode effect is pronounced. However, at higher levels, such as 6.25 in $(15.88 \mathrm{~cm})$, increasing the bath depth has a minimal impact because the resistance of the bath negates the increased contact area. Thus, extremely low bath levels may increase the likelihood of an anode effect. However, typical fluctuations in the bath level should have a negligible impact on the alumina concentration at which anode effect will occur. 


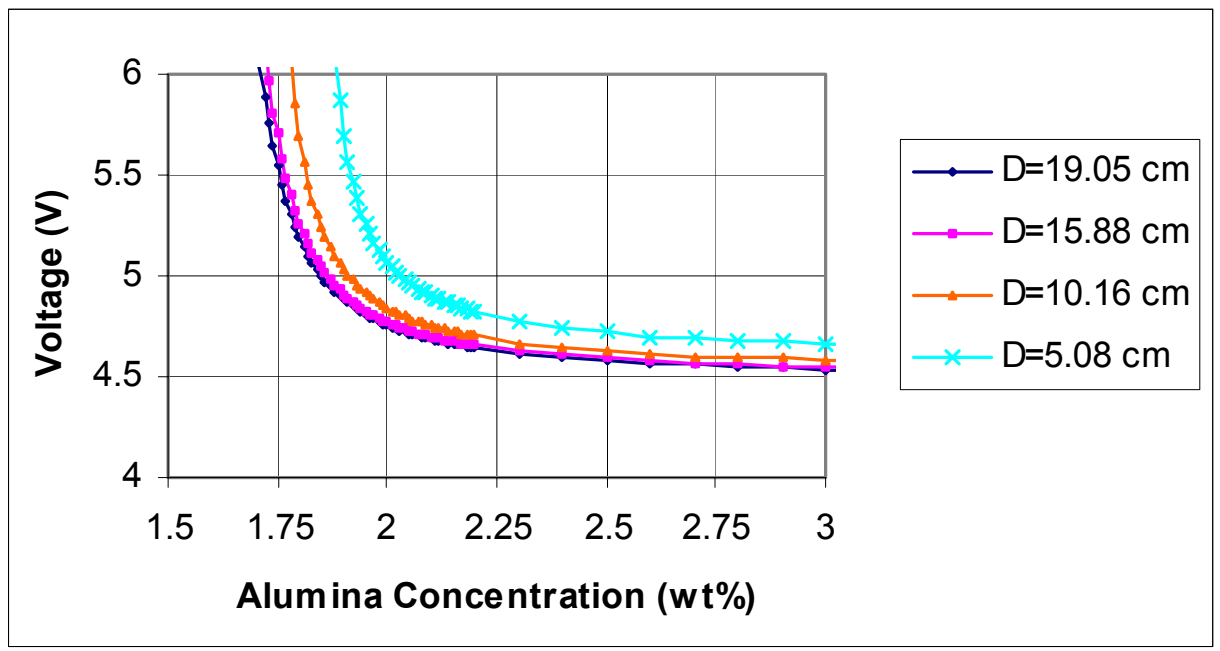

Figure 9.2: Voltage versus alumina concentration for bath depths of $19.05,15.88,10.16$, and $5.08 \mathrm{~cm}$

\subsubsection{Effect of Ratio and Bath Temperature}

The bath temperature and the bath ratio are closely linked because the liquidus temperature of the bath is primarily a function of the ratio, and the bath temperature generally averages between 5 to 10 degrees above the liquidus temperature. Figure 9.3 shows the change in voltage that results when the ratio and the temperature are changed from a nominal value of 1.12 for the ratio and a bath temperature of $972^{\circ} \mathrm{C}$. At alumina concentrations above $2.25 \%$, the effect of ratio changes on the voltage is constant. This is because the overvoltage components are negligible at higher alumina concentrations. The voltage difference is the result of changes in the bath resistivity. At low alumina concentrations, the shape of the voltage curve changes as the ratio changes. 


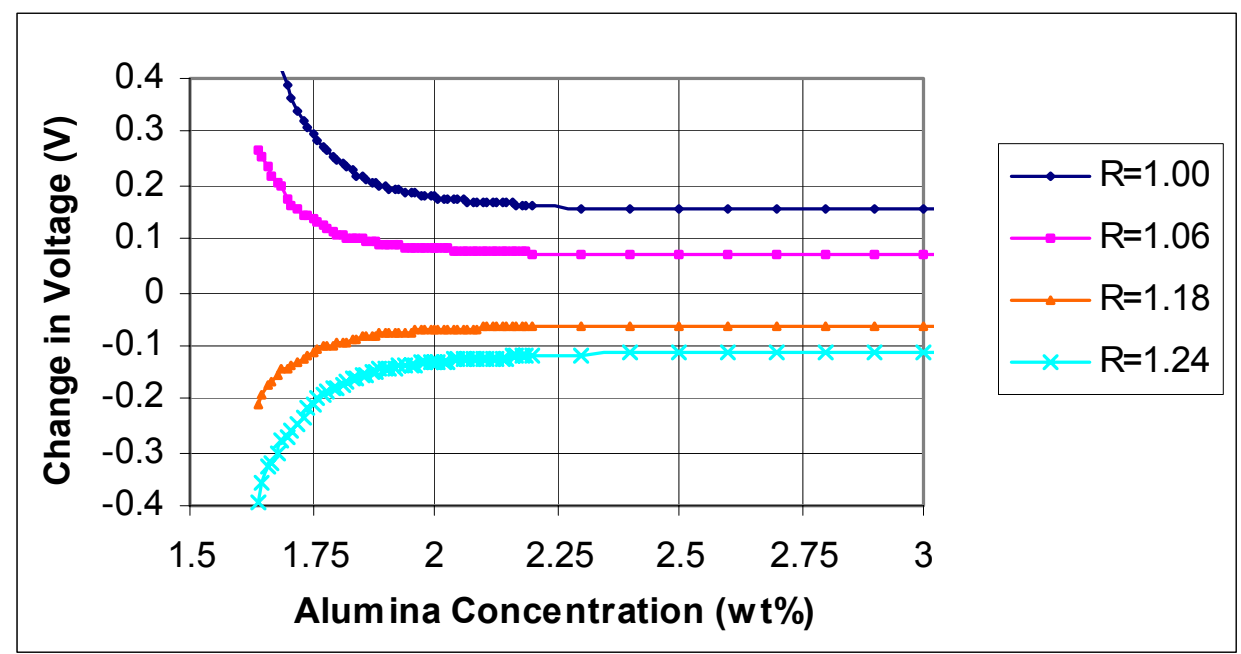

Figure 9.3: Relative voltage with respect to a ratio of 1.12 versus alumina concentration for ratios of 1.00, 1.06, 1.18, and 1.24

\subsubsection{Effect of Misset Anodes}

The anodes in a cell are connected by a large copper bus, so there is a relatively small voltage difference between the tops of different anodes. However, differences in the anode size and the vertical position of the anode can cause variability in the current flowing through the individual anodes. Figure 9.4 shows the results of a simulation in which half of the anodes are set at an anode-cathode distance of $3.4 \mathrm{~cm}$, and the other half of the anodes are set so that the anode-cathode distance is $0.6 \mathrm{~cm}$ lower. At alumina concentrations above $3.0 \%$, the anodes that are set low draw about $10 \%$ more current then the anodes set at the nominal value. At lower alumina concentrations, the disparity in current densities changes rapidly, until the current densities are equal at anode effect. 


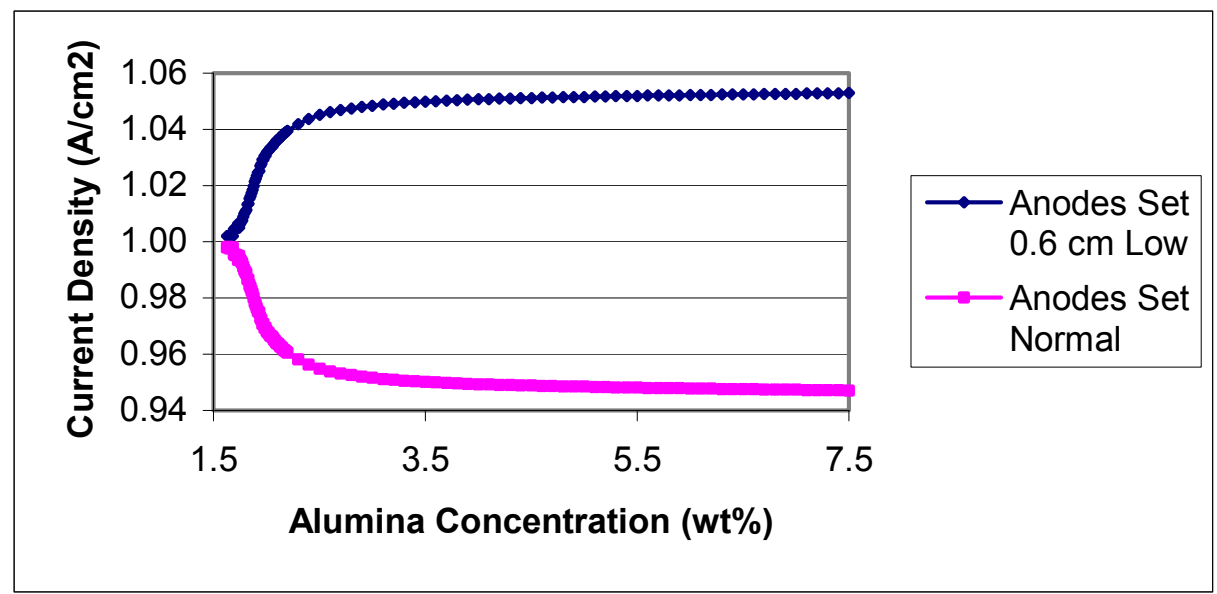

Figure 9.4: Comparison of current density at varying alumina concentrations for anodes set at different anode-cathode distances

Figure 9.4 helps to explain the rapid fluctuation in the current flowing through individual anodes that is observed just before anode effect. Because the electrolyte in a reduction cell is not homogeneous, there are alumina concentration gradients within the cell which fluctuate with time. Under normal conditions, current density fluctuations caused by the changing gradients are small. However, as anode effect approaches, small changes in the concentration can lead to significant changes in the current density flowing through anodes with different sizes or anode cathode distances.

Anodes that are set either too high or too low can cause serious problems in a reduction cell. Some of the problems are related to the variability in the current density which results. Ideally, all of the anodes would be set at the same anode-cathode distance, resulting in an even current distribution and even consumption of the anodes. When anodes are set too high, these anodes will not carry as much of the current load, resulting in the other anodes being consumed more quickly. When anodes are set too low, they will carry too much current and will be consumed more quickly. Also, because of the higher current load, these anodes will become hotter, leading to the top of the anode burning. If an anode is set too low, the metal pad may come into direct contact with the 
anode. This results in shorting which lowers the current efficiency of the process. Even if shorting does not occur, the variability in the current load carried by each anode can result in oscillations in the metal pad because of the unbalanced magnetics. Because of these problems, it is important to be able to correct anodes that have been set incorrectly. Currently, workers periodically check the current distribution in the cell and adjust anodes that are drawing too much current or too little current. However, there are no guidelines for making these adjustments and overcompensation often results. Figure 9.5 provides a series of curves for determining the extent to which anodes are misset. For example if one pair of anodes is set $1.27 \mathrm{~cm}$ high and one pair is set $1.27 \mathrm{~cm}$ low, the high anodes would have a current density of $0.85 \mathrm{~A} / \mathrm{cm}^{2}$, the low anodes would have a current density of $1.22 \mathrm{~A} / \mathrm{cm}^{2}$, and the anodes that are set correctly would have a current density of $1.00 \mathrm{~A} / \mathrm{cm}^{2}$.

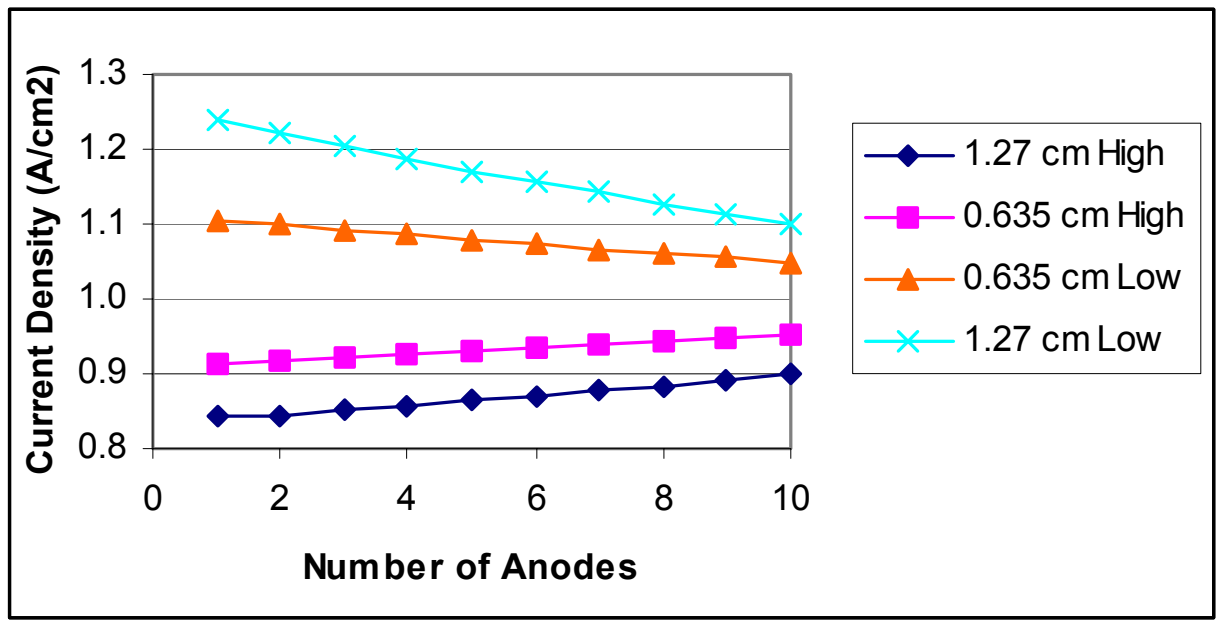

Figure 9.5: Expected current density when a given number of anodes are misset and the average current density is $1.00 \mathrm{~A} / \mathrm{cm}^{2}$ 


\subsection{Results from the Combined Model}

The combined model includes the voltage, thermal, and chemical model. It was used to simulate the effects of various process disturbances on the operation of a reduction cell. Two types of simulations were run. The first type of simulation involved applying step changes to the operating state of the cell and tracking the state of the cell until a steady-state condition was reached. Step changes included changes in the voltage, alumina concentration, bath depth, metal pad depth, and top crust thickness, as well as additions of aluminum fluoride and soda ash. The second type of simulation involved more dynamic processes, such as studying the effect of changing the tapping cycle, of using power modulation, and of variation in the feed weight and alumina distribution. In the simulations, a "controller" was used to simulate the actions of a typical cell controller. This included maintaining the voltage at the designated level by adjusting the anodecathode distance. In all of the simulations, except the ones studying the effects of variation in the feed weight and alumina distribution, the alumina concentration was maintained by continuously feeding alumina at the rate necessary to replenish alumina consumed by the process reaction. Metal was also removed at a rate equal to the rate of production. All other process variables were allowed to fluctuate based on the mass balance equations.

\subsubsection{Effect of Voltage Changes}

The cell voltage changes considerably over time as the result of the control strategy and based on the operator's opinion of how the cell is operating. Changes in the cell voltage can have a significant impact on thermal balance of the cell, and this effect needs 
to be quantified. In order to do this, the cell voltage was first increased from $4.50 \mathrm{~V}$ to $5.00 \mathrm{~V}$ in steps of $0.10 \mathrm{~V}$ and then decreased from $4.50 \mathrm{~V}$ to $4.10 \mathrm{~V}$ in steps of $0.10 \mathrm{~V}$. The specified voltage was maintained until the cell reached steady-state. This was repeated starting at bath ratios ranging from 0.80 to 1.30 on a weight basis. The desired voltage was maintained throughout the simulation by adjusting the anode-cathode distance.

Figures 9.6 and Figure 9.7 show the effect of the voltage changes on the percentage of the dissipated energy leaving various cell components. The starting ratio had a minimal effect on the distribution of the heat losses, and had no effect on the trend versus voltage. Thus, for clarity, only the losses for a starting ratio of 1.10 are shown. There is a significant change in the heat balance resulting from such a large voltage change. The percentage of heat lost through the sidewalls and endwalls increases considerably as the voltage increases. This is because the frozen ledge that protects the sidewalls melts as the bath temperature increases, increasing the thermal conductivity in that region of the cell. For the remaining cell components, the percentage of heat lost decreases, because the bath temperature does not increase in proportion to the increased heat that must be dissipated and the thermal conductivity remains approximately constant. Thus, the top and bottom of the cell, which have a relatively fixed thermal conductivity, lose about the same amount of heat on an absolute basis, but lose less on a relative basis. 


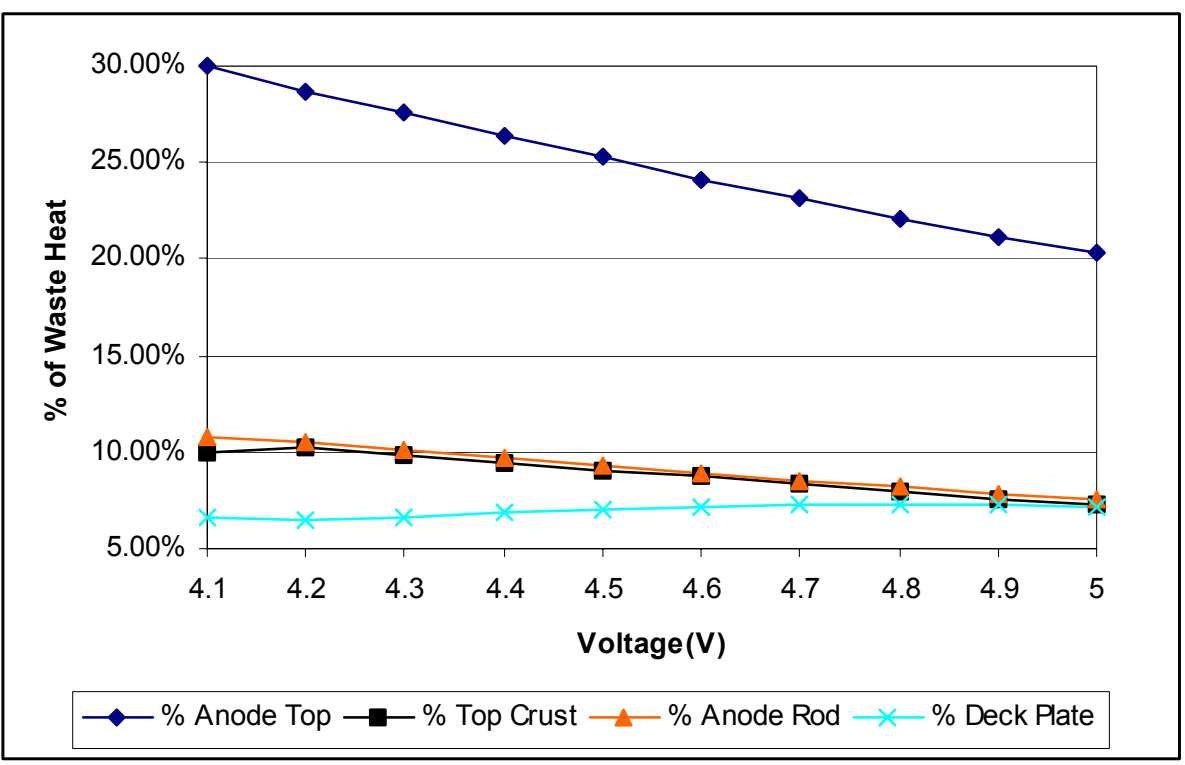

Figure 9.6: Percentage of dissipated heat lost through the anode top, top crust, anode rod, and deck plate for different cell voltages

Figure 9.8 shows the effect of the voltage changes on the ratio. The ratio changes are caused by the melting and freezing of the sidewall ledge. Large ratio changes occur over this voltage range. For example, when starting at a ratio of 1.10 at $4.50 \mathrm{~V}$, the ratio drops to 0.934 at $4.10 \mathrm{~V}$ and rises to 1.149 at $5.00 \mathrm{~V}$. While such a large voltage fluctuation should not occur in general, smaller fluctuations of $0.30 \mathrm{~V}$ are common. A rise in voltage from $4.40 \mathrm{~V}$ to $4.70 \mathrm{~V}$ would raise the ratio from 1.073 to 1.125 . 


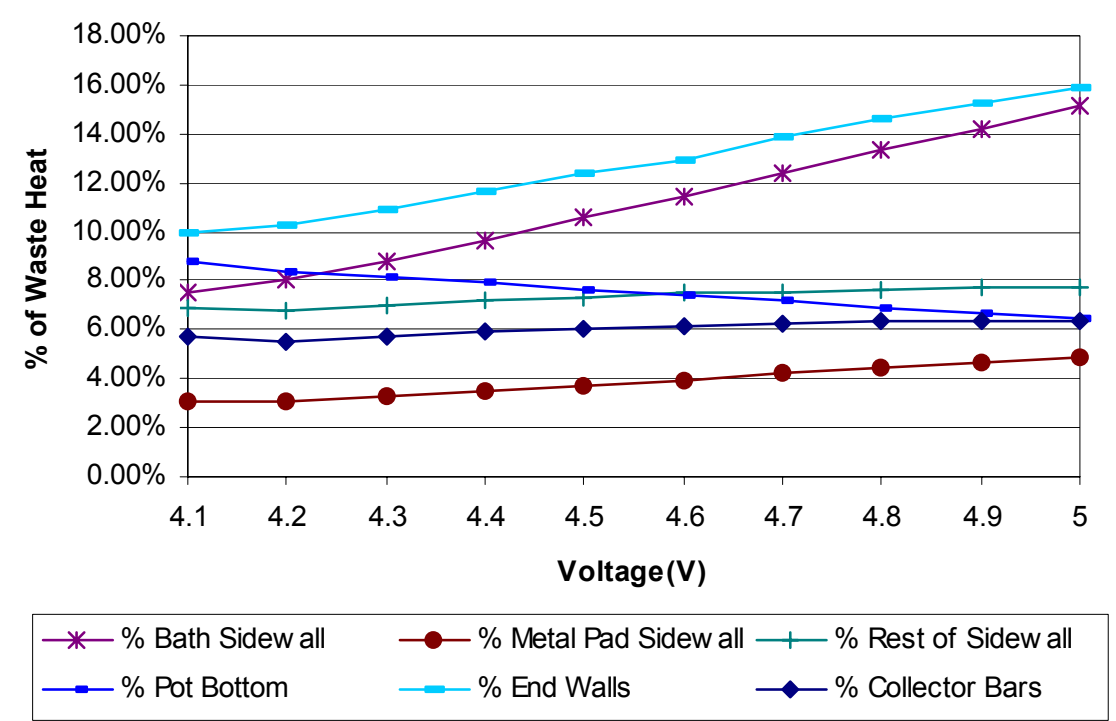

Figure 9.7: Percentage of dissipated heat lost through the bath sidewall, metal pad sidewall, remaining sidewall, pot bottom, end walls, and collector bars for different cell voltages

The voltage changes cause other fluctuations as well. The bath depth decreases by about $4 \mathrm{~cm}$ as the voltage is increased, as a result of the increasing anode-cathode distance. The metal pad depth decreases by about $1 \mathrm{~cm}$ because the melting sidewall ledge increases the cross-sectional area available for the metal.

In general, a cell will have a target ratio and cell voltage. Figure 9.8 can be used to adjust ratio measurements from cells operating at a voltage that is higher or lower than the target voltage. A cell with a target voltage of $4.40 \mathrm{~V}$ and a target ratio of 1.07 would appear to need a significant adjustment if the measured ratio was 1.17. However, if the cell is temporarily at $4.70 \mathrm{~V}$, the actual ratio is closer to 1.12 , which is not far from the target. 


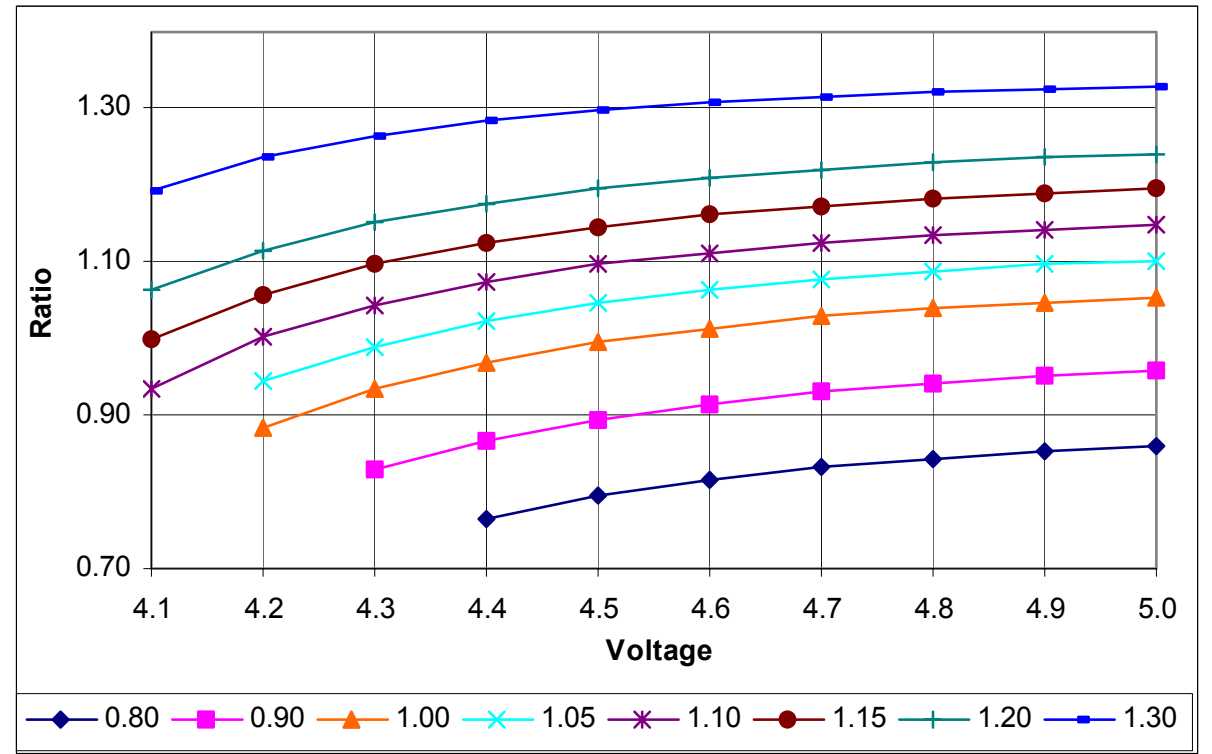

Figure 9.8: Ratio versus cell voltage starting from various ratios at a cell voltage of $4.50 \mathrm{~V}$

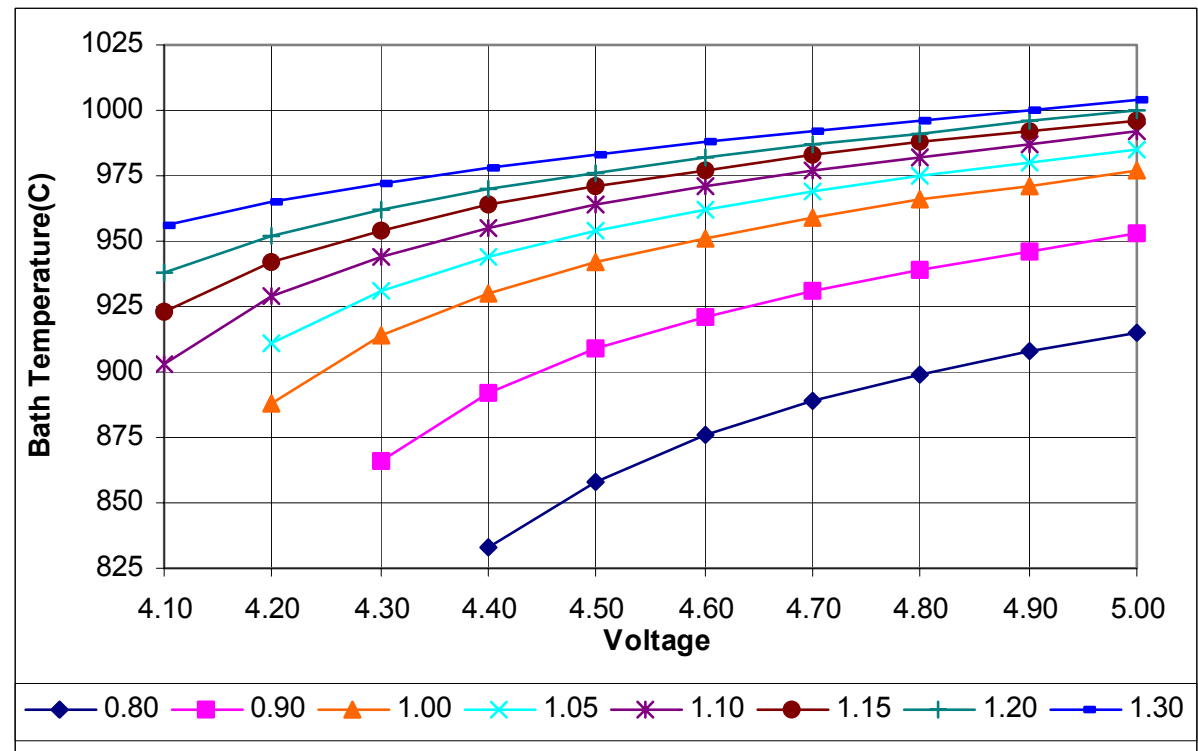

Figure 9.9: Bath temperature versus cell voltage starting from various ratios at a cell voltage of $4.50 \mathrm{~V}$ 


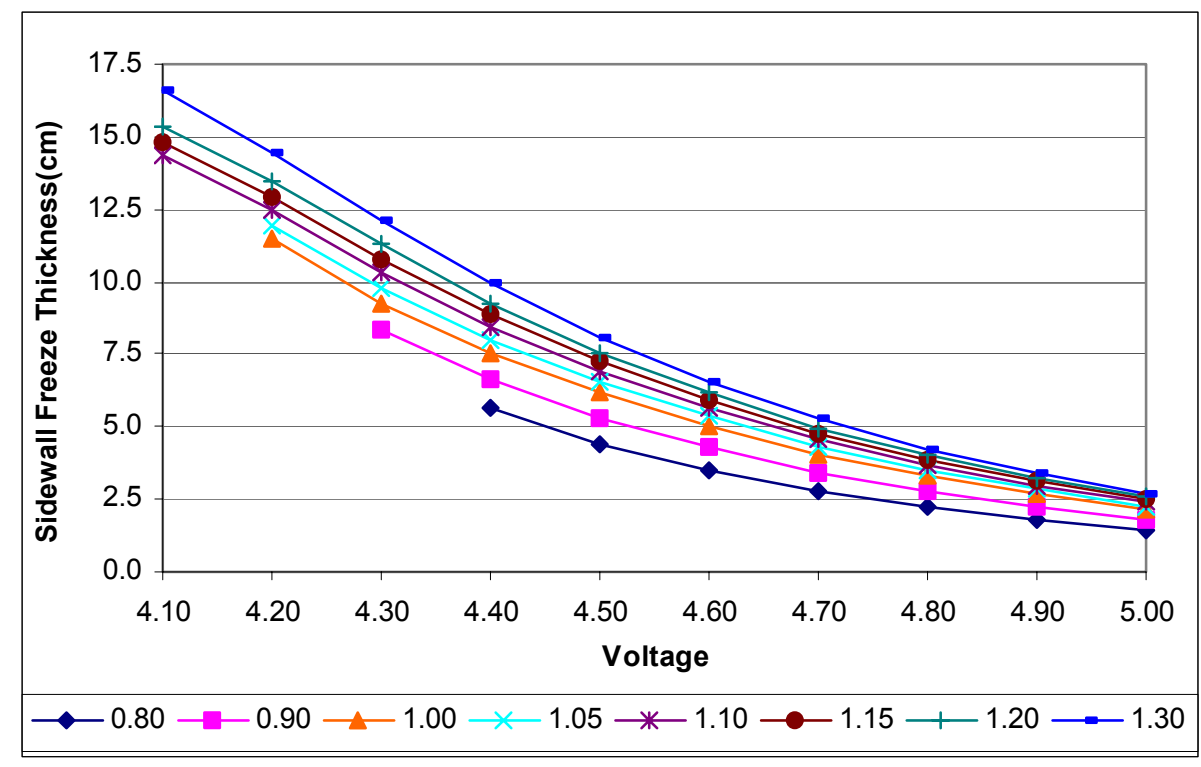

Figure 9.10: Sidewall freeze thickness versus cell voltage starting from various ratios at a cell voltage of $4.50 \mathrm{~V}$

Another use for this simulation is to analyze the effectiveness of the common approach of "warming" a cell up by increasing the voltage. Figure 9.9 shows that the bath temperature and the ratio follow similar trends as the cell voltage is increased. While the superheat increases as the voltage increases, leading to a higher bath temperature, the increasing ratio also causes the temperature to rise due to the increasing liquidus temperature. At a quick glance it appears that adding voltage effectively "warms" the cell. The temperature increases, and the ratio increases. However, the cost must be considered. Figure 9.10 shows the thickness of the sidewall freeze at the bathmetal pad interface versus voltage for several ratios. The sidewall freeze thins significantly as the voltage is increased. Starting at a ratio of 1.073 and a voltage of 4.40 $\mathrm{V}$, the sidewall freeze is $8.47 \mathrm{~cm}$. Increasing the voltage to $4.70 \mathrm{~V}$ reduces this to 4.58 $\mathrm{cm}$. Such a significant decrease in the sidewall thickness increases the likelihood that some or all of the sidewall lining will become exposed, resulting in an increased risk of a sidewall failure. Worse still is the fact that a "cold" pot with a low ratio starts with a 
thinner sidewall freeze. Furthermore, the pot would return to the low ratio condition once the voltage increase was removed unless a corrective bath addition was made in the meantime. Thus, for a pot with a low temperature and bath ratio, the use of a voltage increase to raise the temperature is less desirable than a corrective bath addition because of the increased electrical costs, as well as the increased potential for early sidewall failure associated with raising the voltage. Finally, if voltage changes are used to effect changes in the thermal balance of the cell, sufficient time must be given for the process to occur. Figure 9.11 shows the bath ratio versus time when the cell voltage was reduced from $4.50 \mathrm{~V}$ to $4.40 \mathrm{~V}$. Almost 26 hours were required for the cell to achieve $90 \%$ of the ratio change expected from the voltage adjustment.

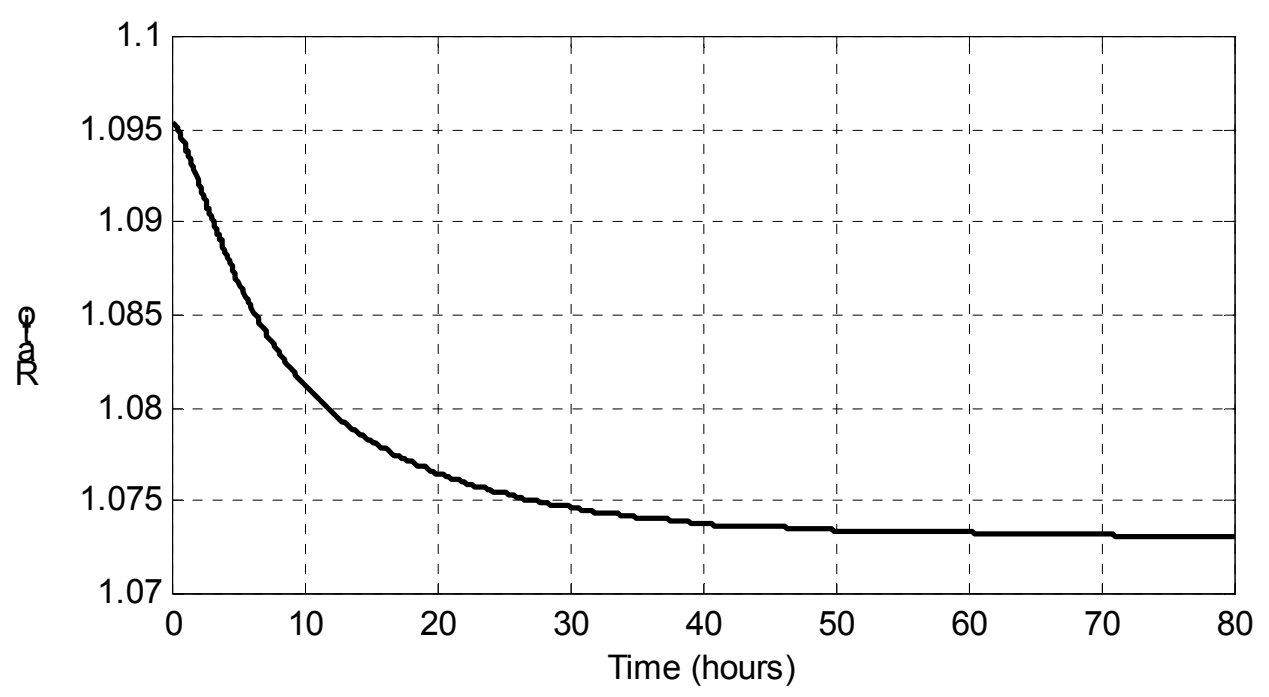

Figure 9.11: Ratio versus time for a step change in cell voltage from $4.50 \mathrm{~V}$ to $4.40 \mathrm{~V}$ 


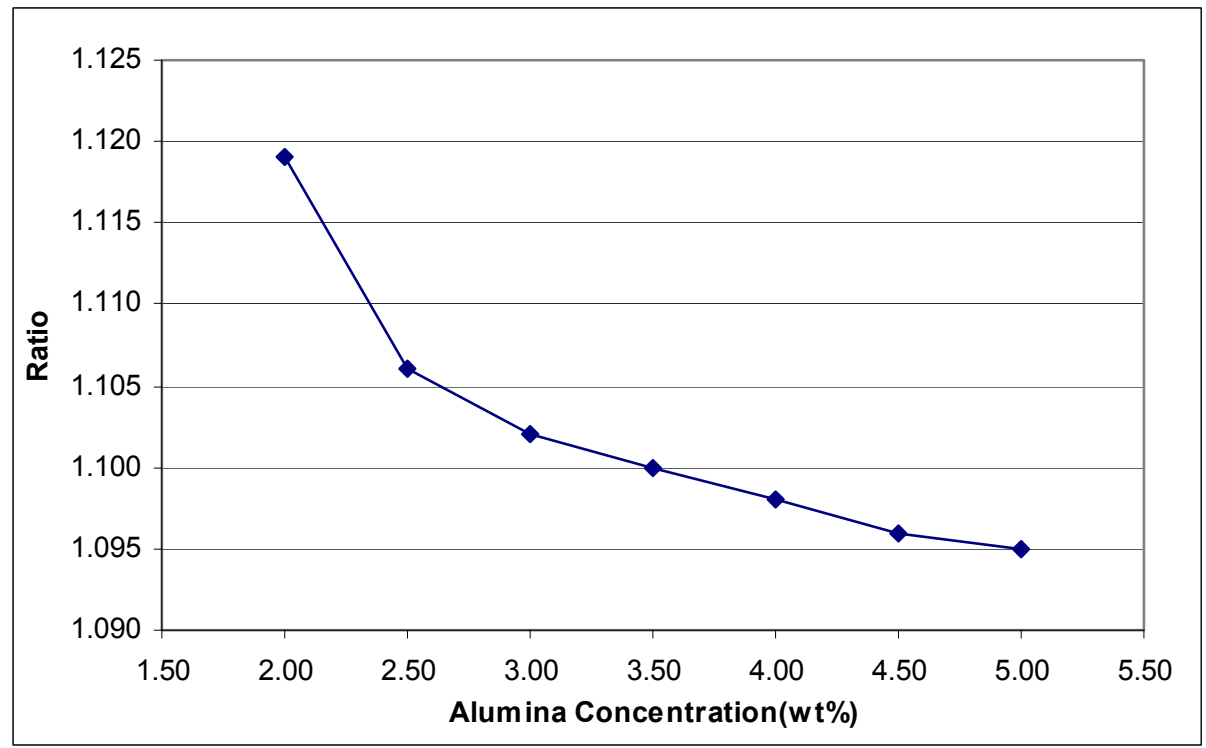

Figure 9.12: Ratio versus alumina concentration

\subsubsection{Effect of Alumina Concentration Changes}

Changes in the alumina concentration affect the ratio because the alumina concentration is a factor in the liquidus equation. However, the effects of alumina concentration changes are much smaller than those caused by voltage changes. Figure 9.12 shows the ratio versus alumina concentration in weight percent. This curve can be applied to operating cells by using the average alumina concentration over a period of about one day. Over a typical sustainable operating range of $2.5 \%$ to $4.5 \%$, the ratio changes by 0.01 . At very low alumina concentrations, the ratio change is even larger, however, it is unlikely that the cell could be operated at such a low alumina concentration long enough to reach a steady state condition without an anode effect. Figure 9.13 shows the time response for the ratio when the alumina concentration changes from $3.5 \%$ to $3.0 \%$. The time required for the ratio to achieve $90 \%$ of its steady state change is 31 hours. The initial drop in the ratio occurs because the change in the alumina concentration immediately lowers the liquidus temperature of the bath causing some of 
the bath to freeze. However, the distribution of heat generation and heat dissipation also changed, ultimately causing ledge to melt and the ratio to rise.

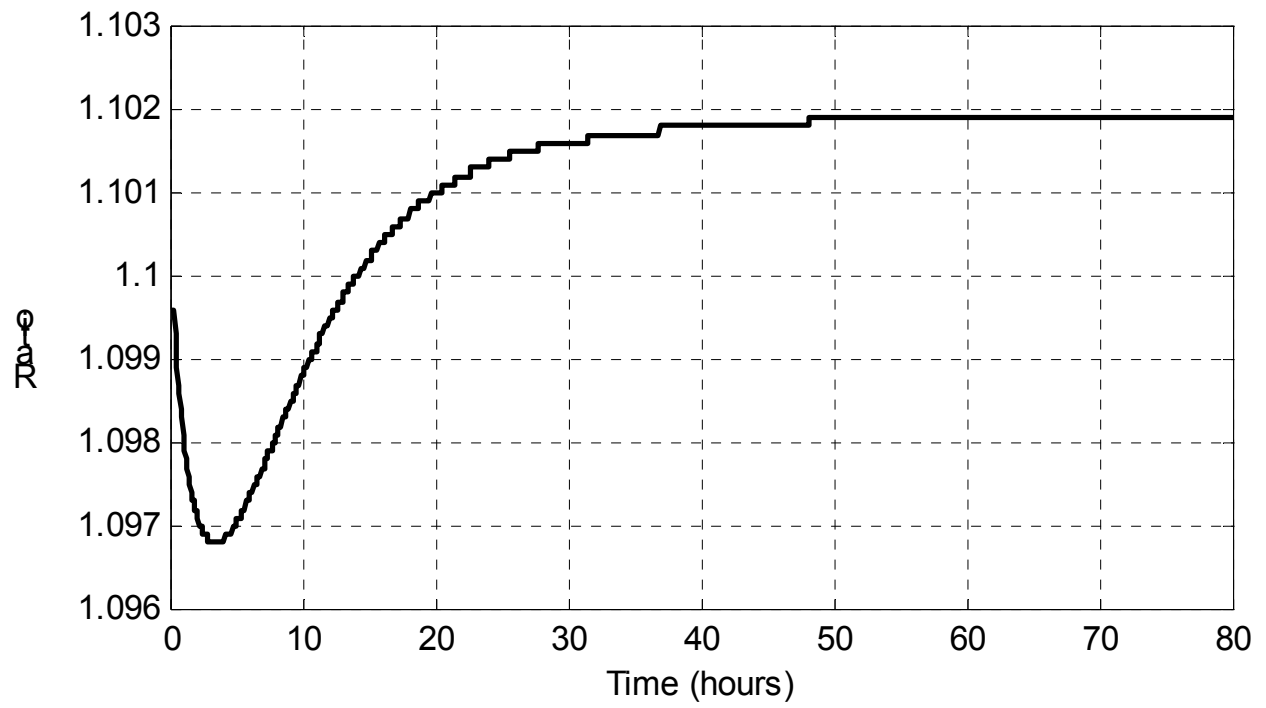

Figure 9.13: Time response for the ratio due to an alumina concentration change from $3.5 \%$ to $3.0 \%$

\subsubsection{Effect of Changes in the Bath Depth}

Figure 9.14 shows the effect of changes in the bath depth on the ratio. The change in ratio is relatively small, about 0.006 , considering the magnitude of the bath depth change. This is surprising, because the heat losses through the sidewall region adjacent to the bath are significant, and increasing the bath depth increases the area for heat to be transferred out of the cell. 


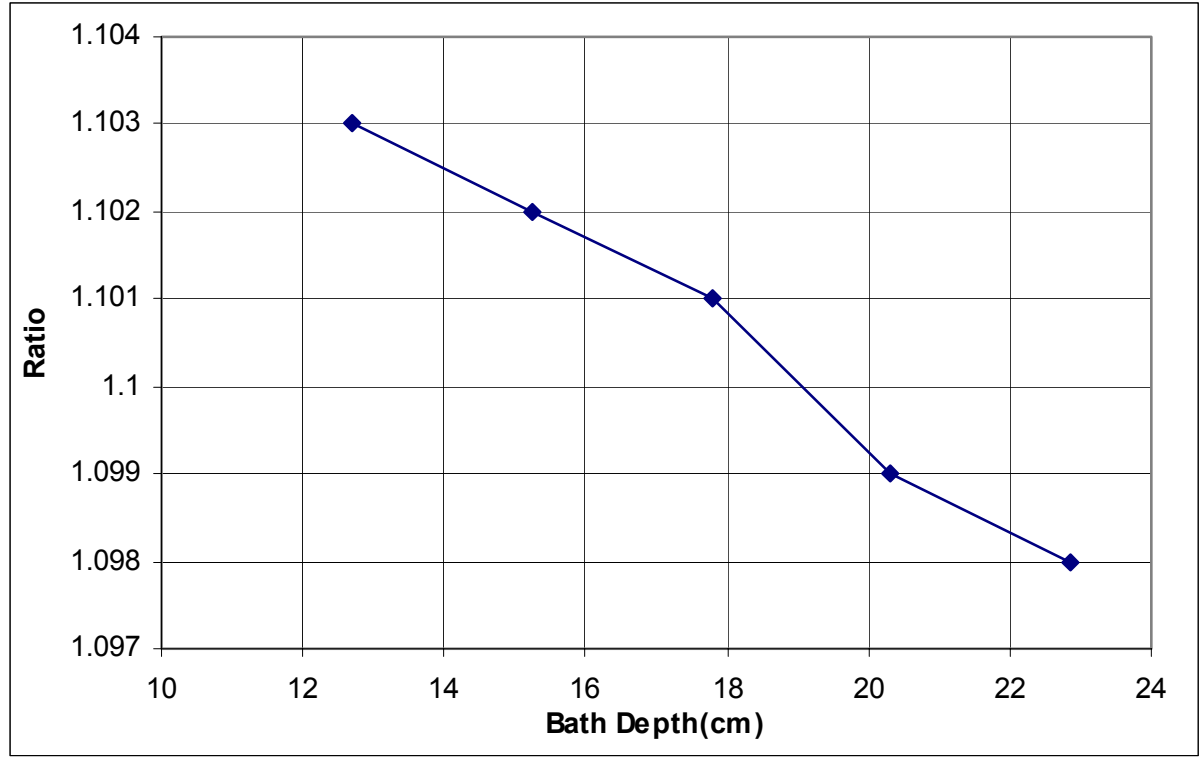

Figure 9.14: Ratio versus bath depth

\subsubsection{Effect of Changes in the Metal Pad Depth}

Unlike changes in the bath depth, changes in the metal pad depth did result in significant changes to the heat balance of the cell. Figure 9.15 shows the effect of metal pad depth changes on the ratio. Fluctuations in the metal pad depth can be as much as five centimeters, which would result in a ratio fluctuation of 0.03 . Figure 9.16 shows the relationship between the metal pad depth and the sidewall thickness. The sidewall thickness increases significantly as the metal pad depth is increased. This is because the surface area adjacent to the metal pad region increases, while the amount of heat available for dissipation remains the same. Figure 9.17 plots bath depth versus metal pad depth. The magnitude of the bath depth change is surprising, but is not unreasonable considering that a significant amount of bath is consumed in increasing the ledge thickness in the metal pad region. Approximately 29 hours are required to reach $90 \%$ of the steady state level, as shown in Figure 9.18. The significant changes in the thermal state of the cell due to changes in the metal pad depth underscore the importance of 
accurately measuring the quantity of metal in the cell and of accurately removing the correct amount of metal when tapping.

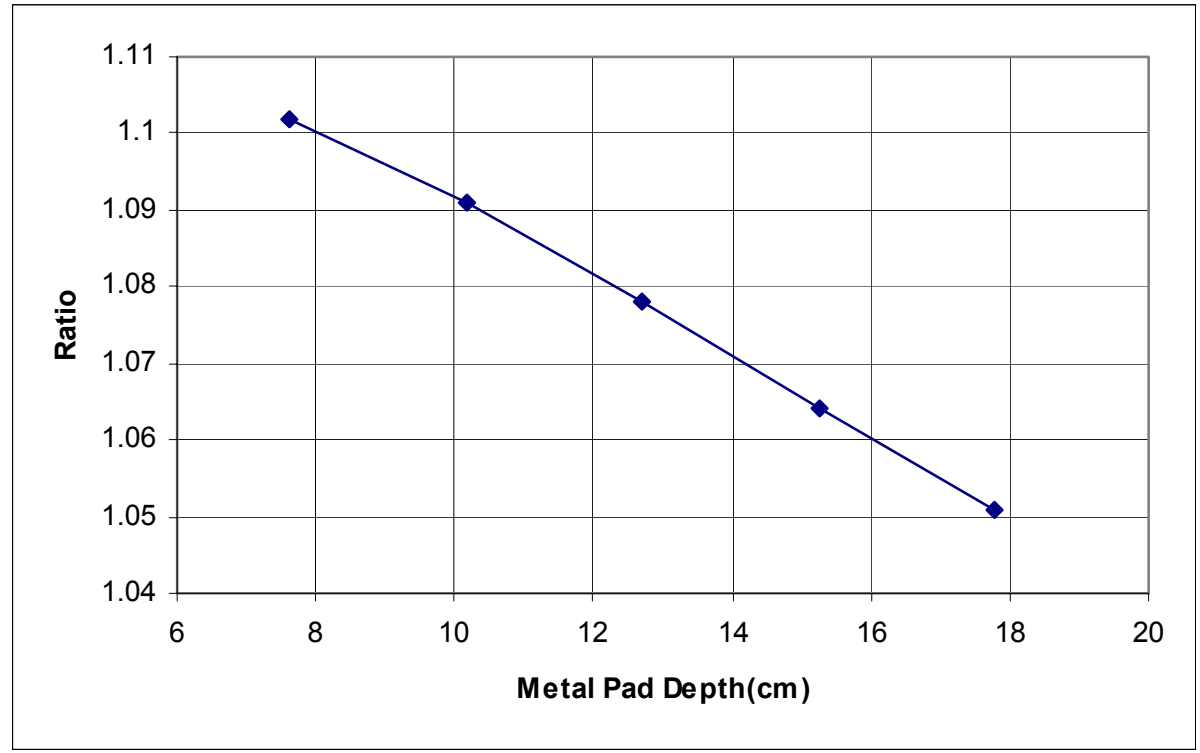

Figure 9.15: Ratio versus metal pad depth

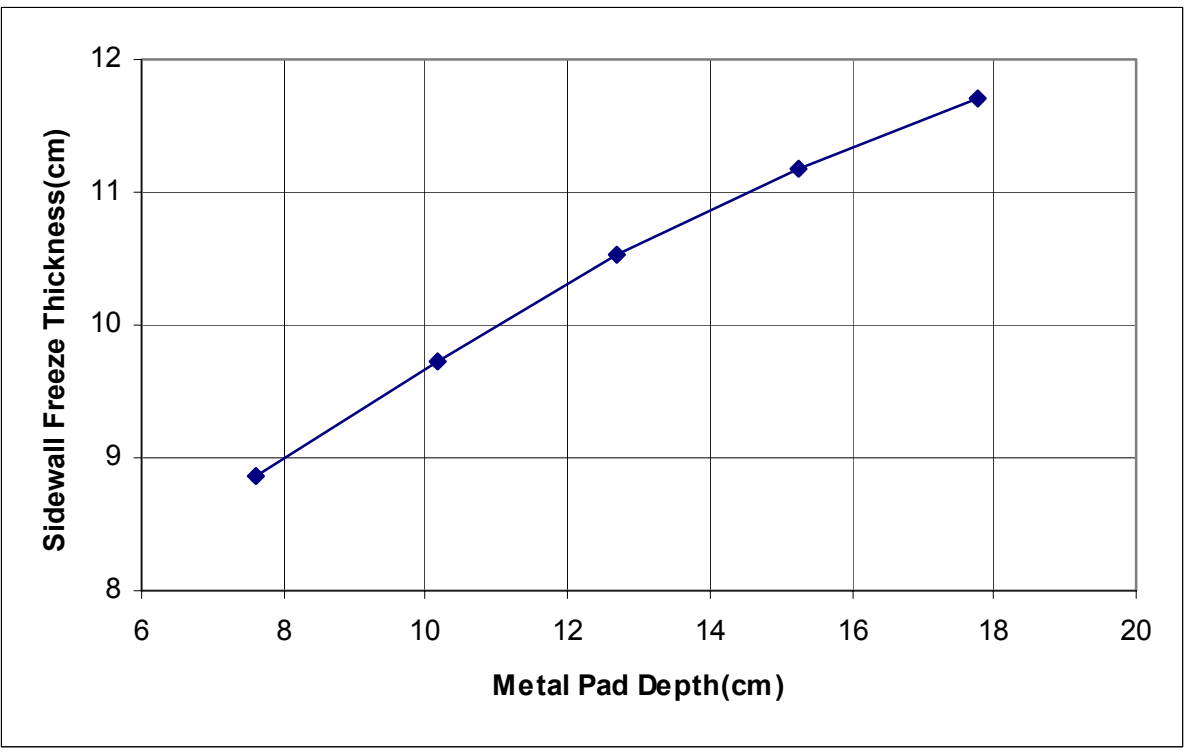

Figure 9.16: Sidewall thickness versus metal pad depth 


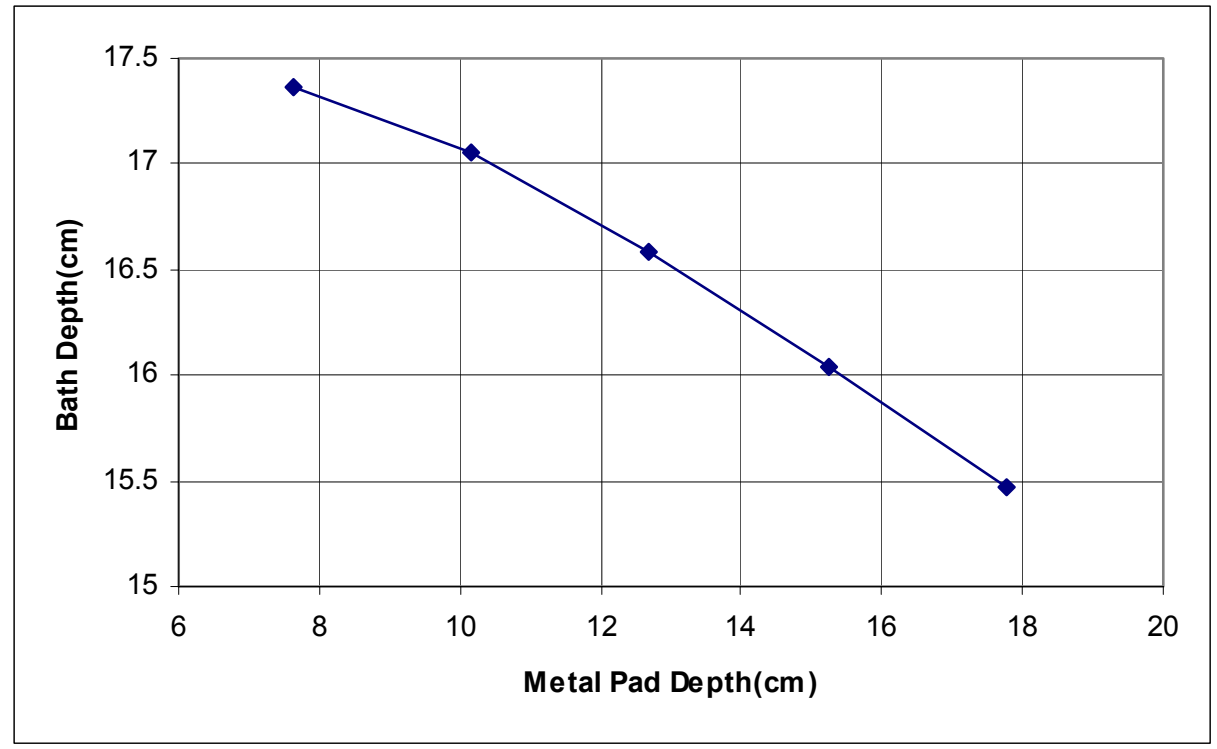

Figure 9.17: Bath depth versus metal pad depth

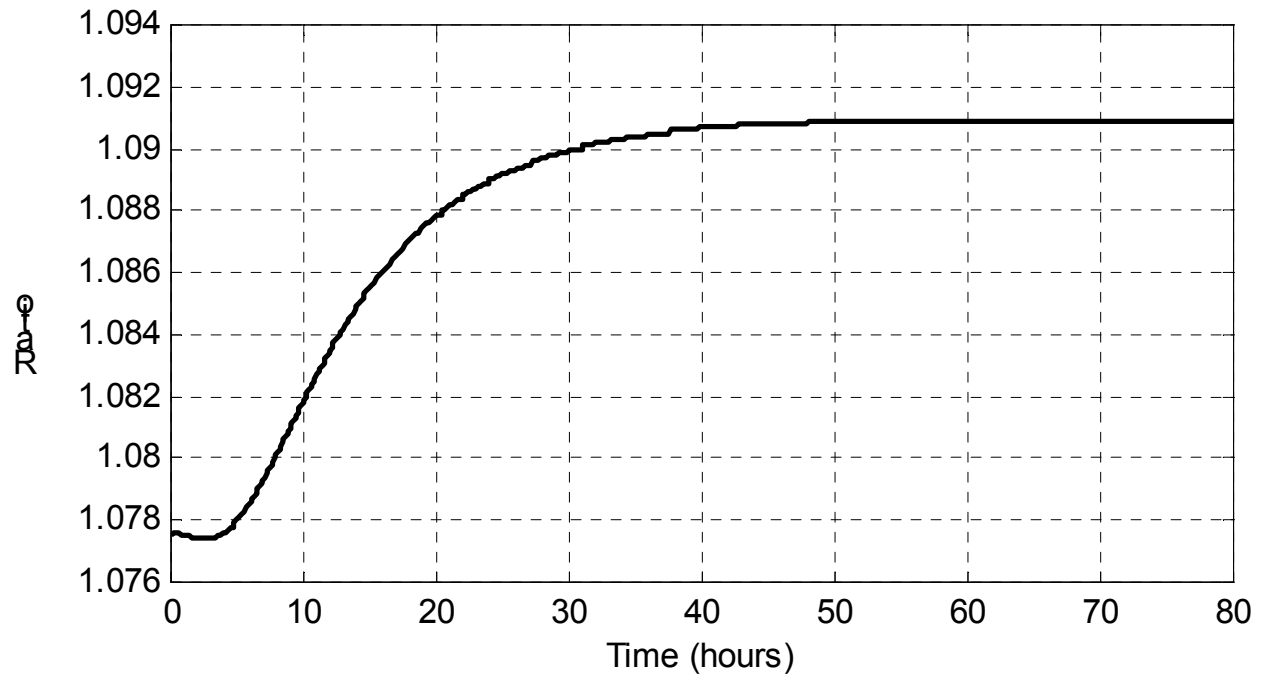

Figure 9.18: Time response for a change in the metal pad depth from $12.70 \mathrm{~cm}$ to $10.16 \mathrm{~cm}$ 


\subsubsection{Effect of Changes in the Top Crust Thickness}

Figure 9.19 shows the effect of changes in the top crust thickness on the bath ratio. As the top crust thickness increases, the rate of change in the ratio decreases. However, as the top crust thickness decreases, changes in the ratio accelerate. This highlights the importance of maintaining adequate crust cover. If cell events, such as excessive anode moves or a prolonged anode effect, caused the crust to melt or disintegrate and the damage was not corrected, serious thermal cooling could result. Figure 9.20 shows the time response of the ratio to a change in the top crust thickness. About 30 hours are required for the ratio to reach $90 \%$ of its steady state level.

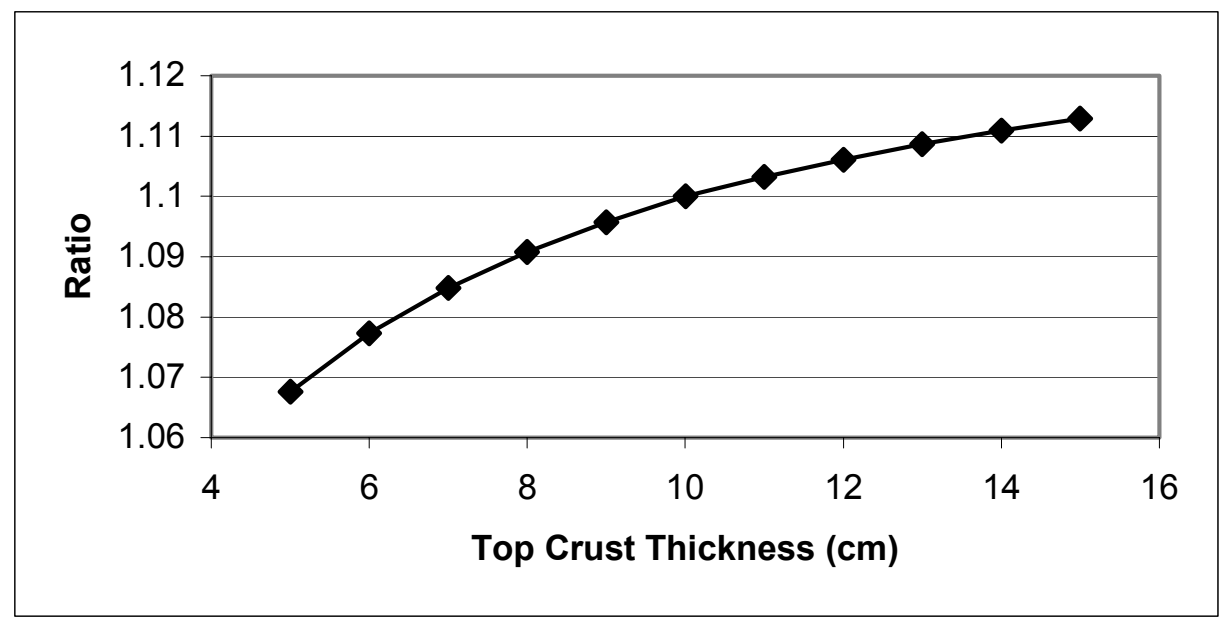

Figure 9.19: Ratio versus top crust thickness 


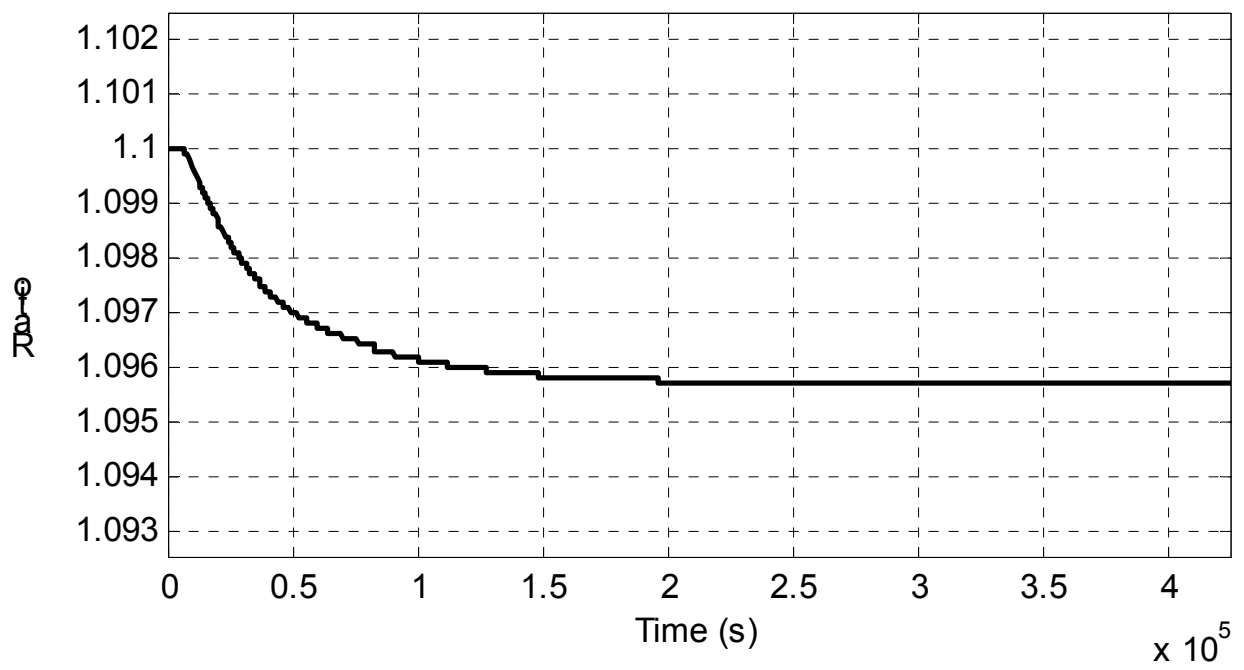

Figure 9.20: Time response of the bath ratio to a step change in the top crust thickness

\subsubsection{Effects of Aluminum Fluoride and Soda Ash Additions}

As mentioned earlier, aluminum fluoride and soda ash additions are made to restore the bath ratio to a desired level. Figure 15 and Figure 16 show the ratio change resulting from aluminum fluoride and soda ash additions for several final bath depths. If the target ratio is 1.10 , a fluoride addition of $100 \mathrm{~kg}$ would be needed for a cell with a ratio of 1.20 if the final bath depth is $15.24 \mathrm{~cm}$. The additions could be physical additions of aluminum fluoride or soda ash, or effective additions due to fluorine and sodium in the incoming ore. The slope of the curves for both fluorine and soda ash additions are almost identical, with a $50 \mathrm{~kg}$ addition causing about a 0.044 change in the ratio when the final bath depth is $19.05 \mathrm{~cm}$. The slope of the curve is unchanged by the starting ratio, but increasing the bath depth decreases the ratio change effected by a given addition. Figure 17 and Figure 18 show the change in bath depth that will result for various fluoride and soda ash additions. Soda ash additions do not cause a change in the bath depth, as an increased sidewall thickness, due to the higher ratio, balances the effect of 
the addition. Thus, for soda ash additions, the initial and final bath depths are about the same. However, fluoride additions significantly increase the bath depth because melting sidewall freeze is added to the mass of the fluoride addition. Furthermore, the anodecathode distance decreases because of the lowered electrical conductivity of the electrolyte, further increasing the bath depth. Thus, when fluoride additions are needed, Figure 15 and Figure 17 must be used together to determine the proper addition. For example, if the target ratio is 1.10 and the initial ratio is 1.20 , and the bath depth is about $16 \mathrm{~cm}$, a fluoride addition of $115 \mathrm{~kg}$ is needed, and the final bath depth will be about 19 $\mathrm{cm}$.

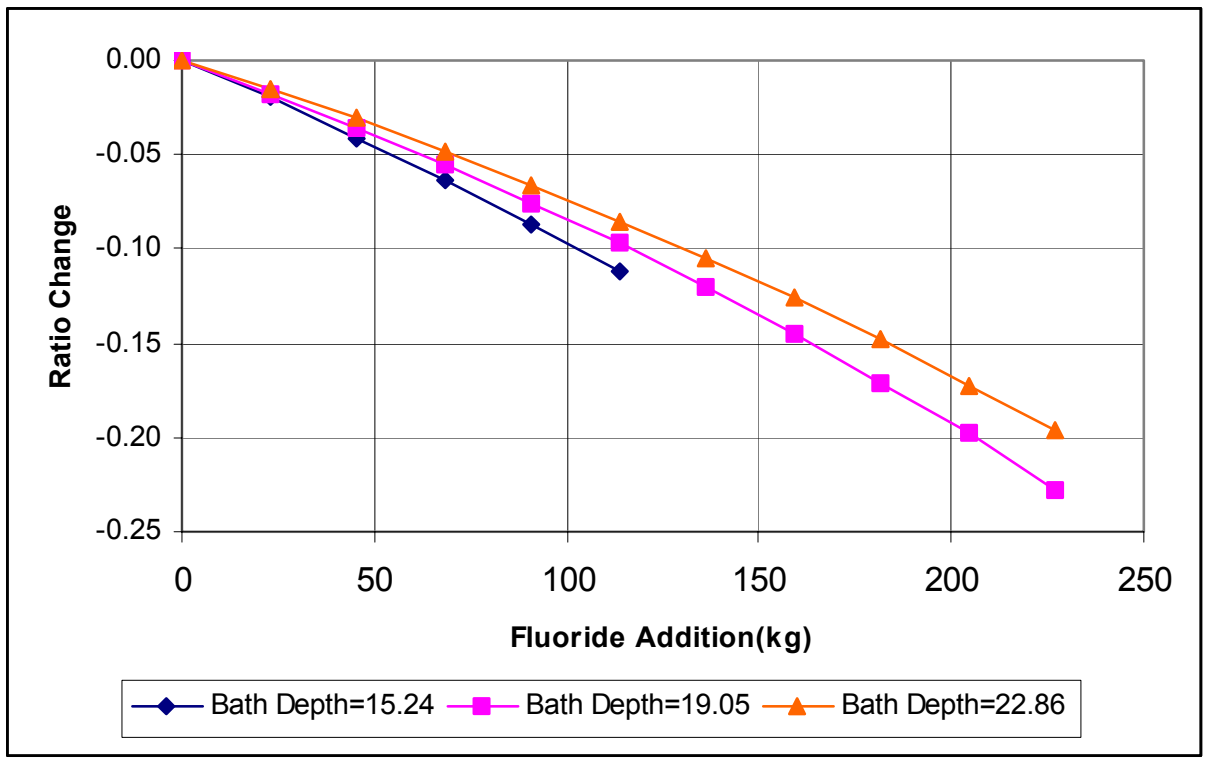

Figure 9.21: Ratio versus fluoride additions for several final bath depths 


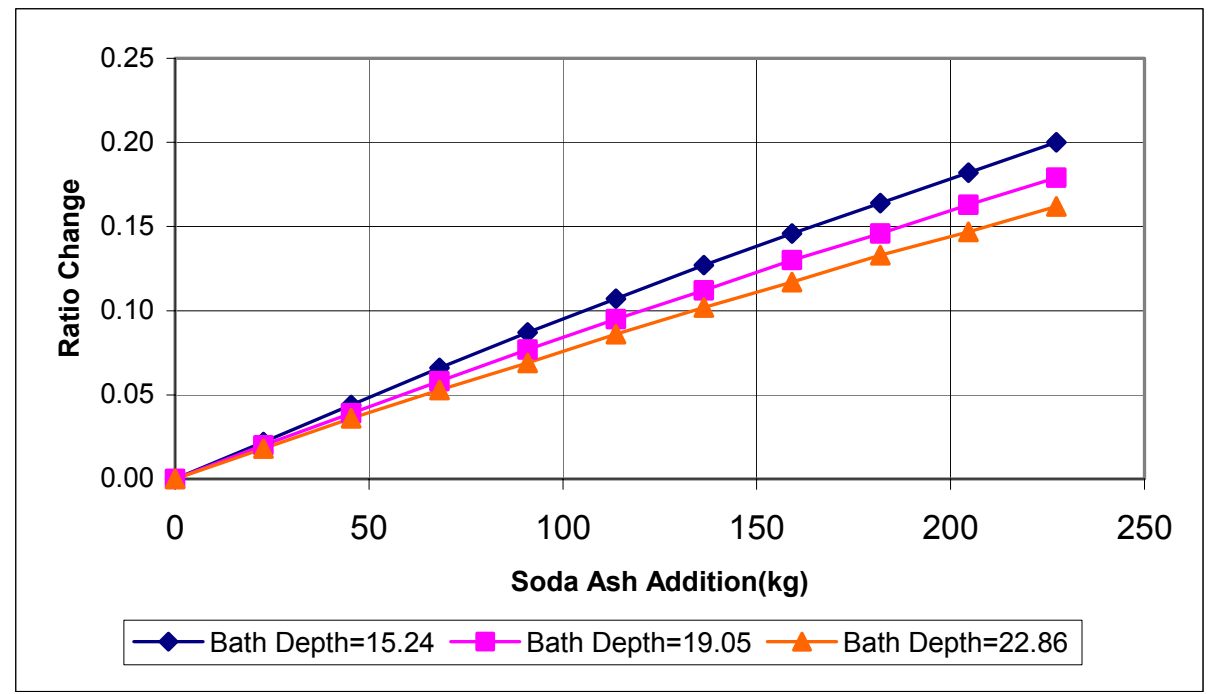

Figure 9.22: Ratio versus soda ash additions for several final bath depths

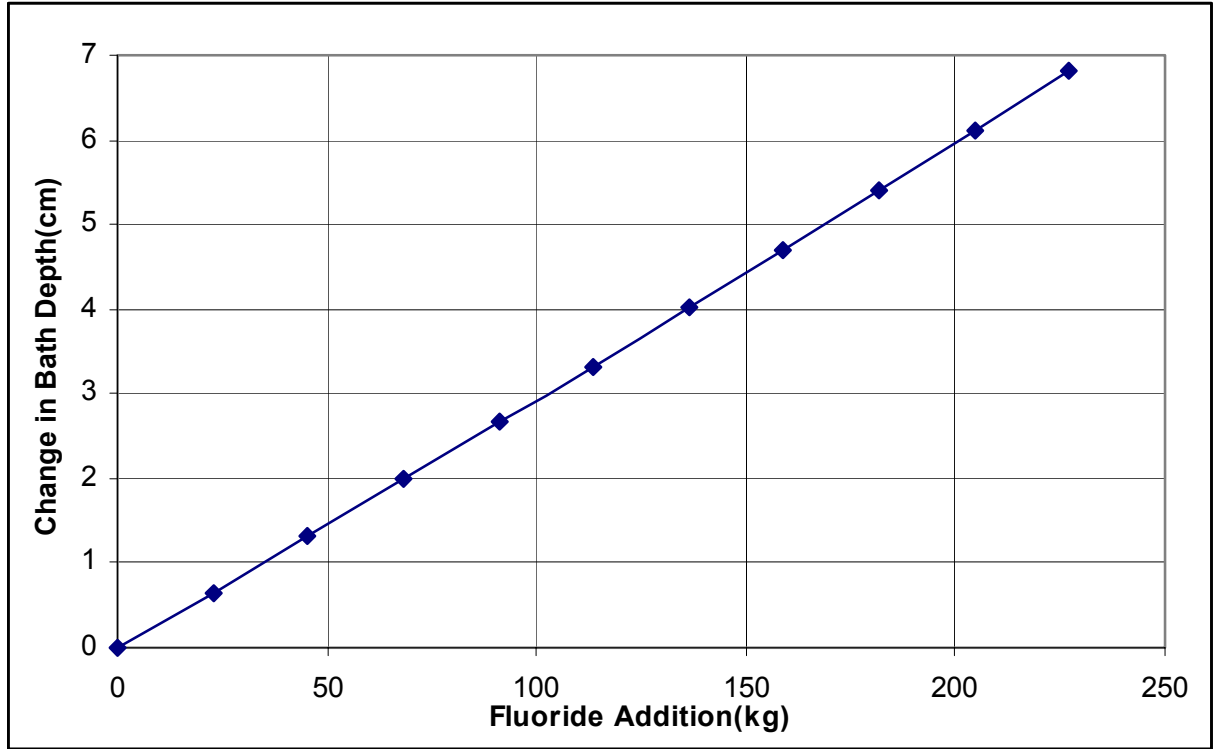

Figure 9.23: Initial bath depth versus fluoride additions for several final bath depths 


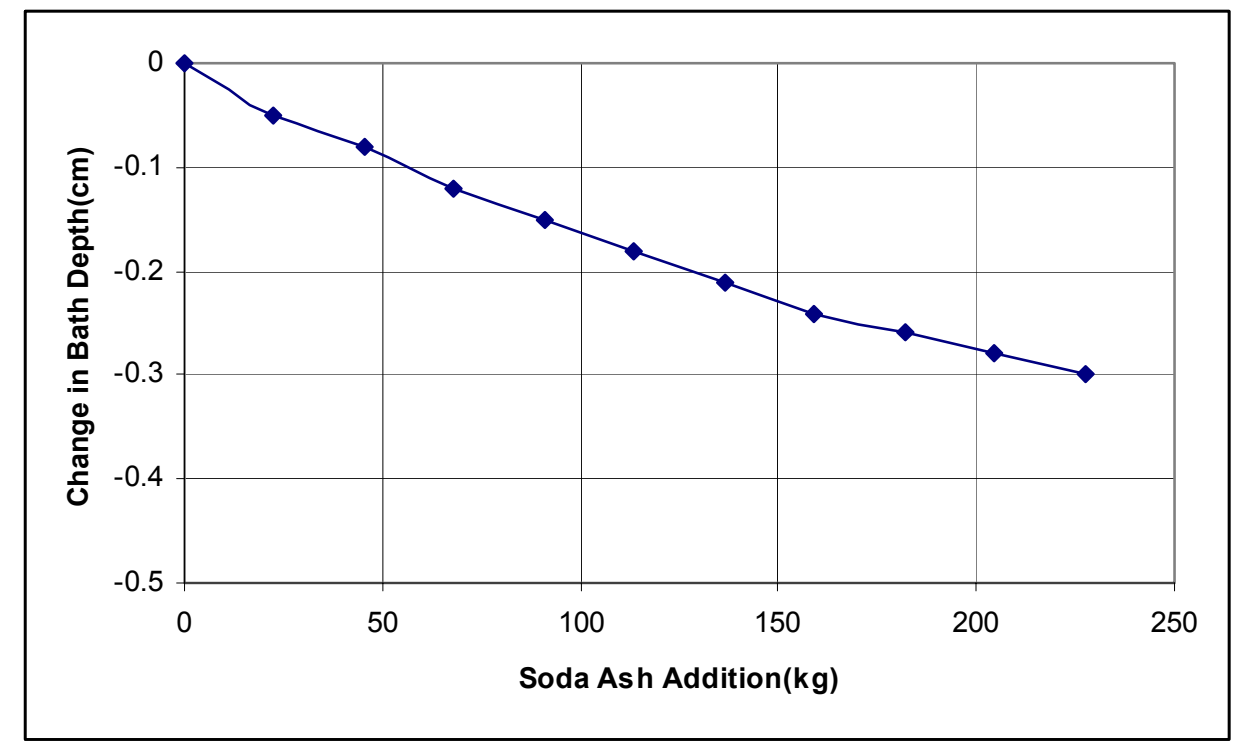

Figure 9.24: Initial bath depth versus soda ash additions for several final bath depths

The results of this simulation can also be used to determine the effect of changes in the concentration of fluorine or sodium in the incoming alumina ore. A change of $0.25 \%$ by weight of fluorine in the ore for a one-week period would be equivalent to a $34 \mathrm{~kg}$ addition of aluminum fluoride. This would result in a -0.03 change in the ratio. A change of $0.25 \%$ by weight of sodium in the ore for a one-week period would be equivalent to a $54 \mathrm{~kg}$ addition of soda ash. This would change the ratio by 0.047 .

The time response of the system to a $50.0 \mathrm{lb}(22.7 \mathrm{~kg})$ addition of aluminum fluoride and soda ash is shown in Figure 9.25 and Figure 9.26 respectively. In the simulation, the addition is made directly to the bath, resulting in the initial peak or minimum. However, the new ratio results in a changed heat balance, leading to the ledge melting (in the case of a fluoride addition) or freezing (in the case of a soda ash addition). This secondary effect requires about one day to resolve and leads to a slight damping of the effect of the bath addition. 


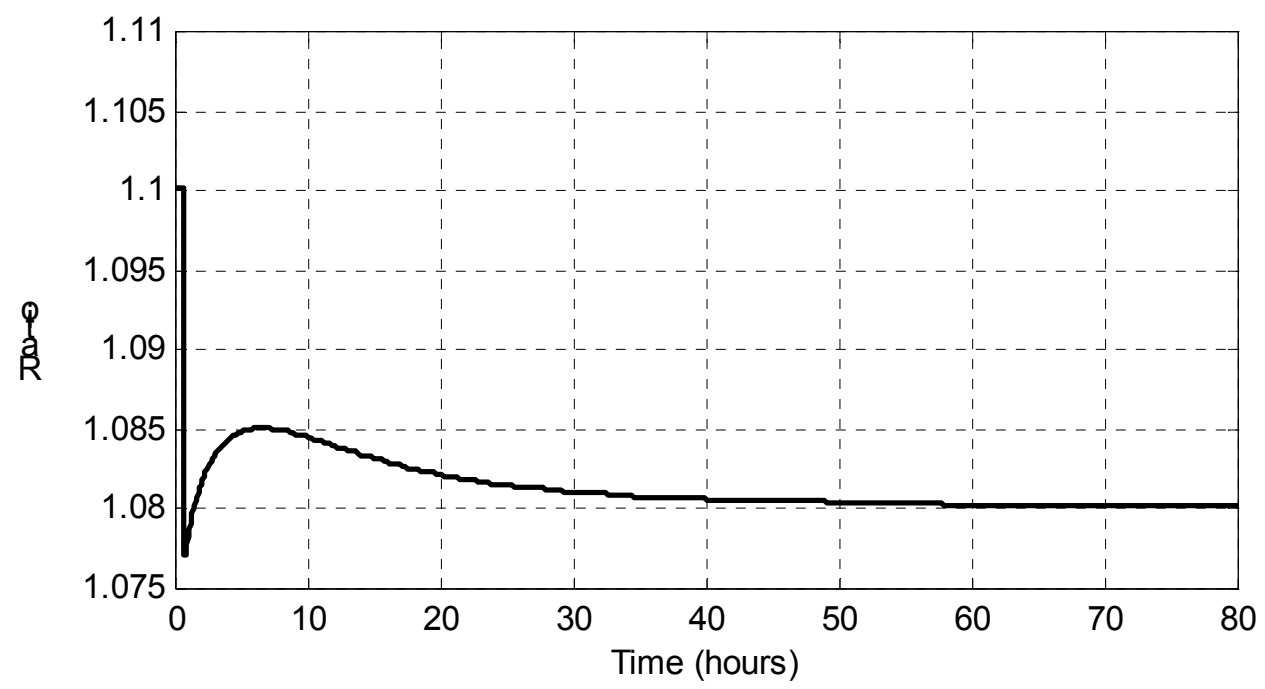

Figure 9.25: Time response of the ratio to a $50.0 \mathrm{lb}(22.73 \mathrm{~kg})$ addition of aluminum fluoride

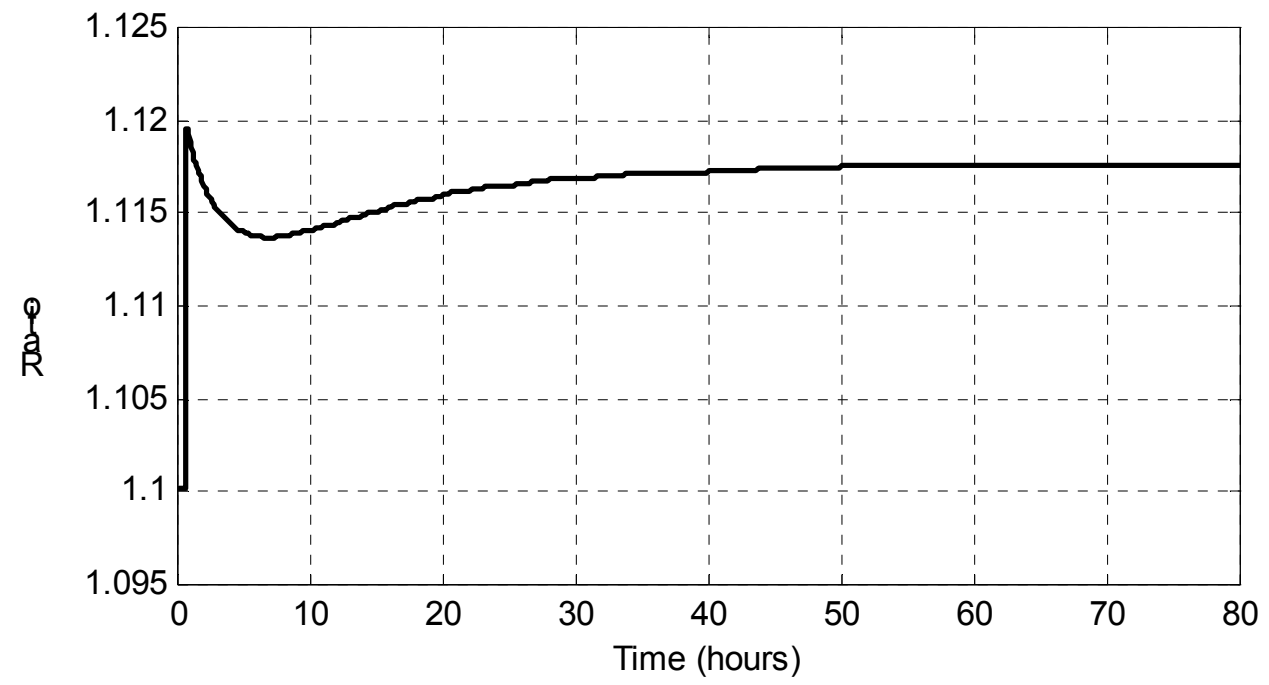

Figure 9.26: Time response of the ratio to a $50.0 \mathrm{lb}(22.7 \mathrm{~kg})$ addition of soda ash

\subsubsection{Effects Caused by the Metal Tapping Cycle}

The aluminum that is produced in a reduction cell is accumulates over time and is removed in bulk by a process called tapping. The length of time between each tapping event varies by smelter, but typical intervals are 24 and 48 hours. Figure 9.27 shows metal pad depth versus time for a $24 \mathrm{hr}$ tapping cycle and a $48 \mathrm{hr}$ tapping cycle. Figure 
9.28 shows the effect of the metal tapping cycle on the ratio. The $24 \mathrm{hr}$ cycle produces ratio oscillations of 0.003 , while the $48 \mathrm{hr}$ cycle produces ratio oscillations of 0.011 .

Figure 9.29 shows the effect of the metal tapping cycle on the temperature. The $24 \mathrm{hr}$ cycle produces temperature oscillations of $0.9^{\circ} \mathrm{C}$ and the $48 \mathrm{hr}$ cycle produces temperature oscillations of $2.8^{\circ} \mathrm{C}$. This shows that shortening the period between taps, reduces operational fluctuations.

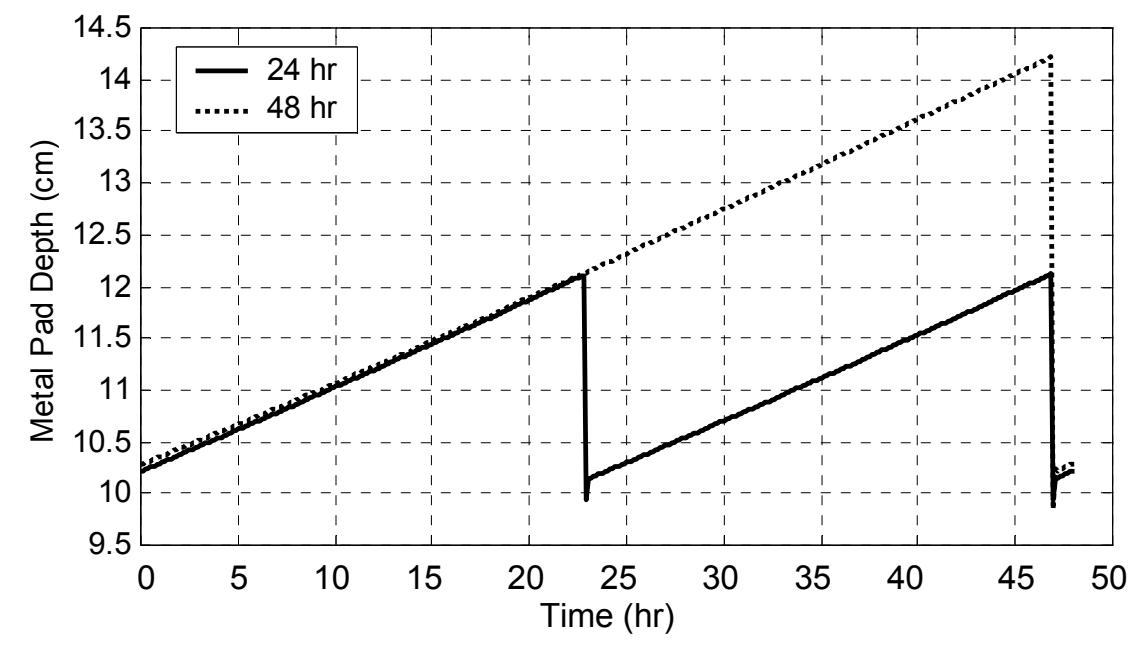

Figure 9.27: Metal pad depth versus time for $24 \mathrm{hr}$ and $48 \mathrm{hr}$ tapping cycles

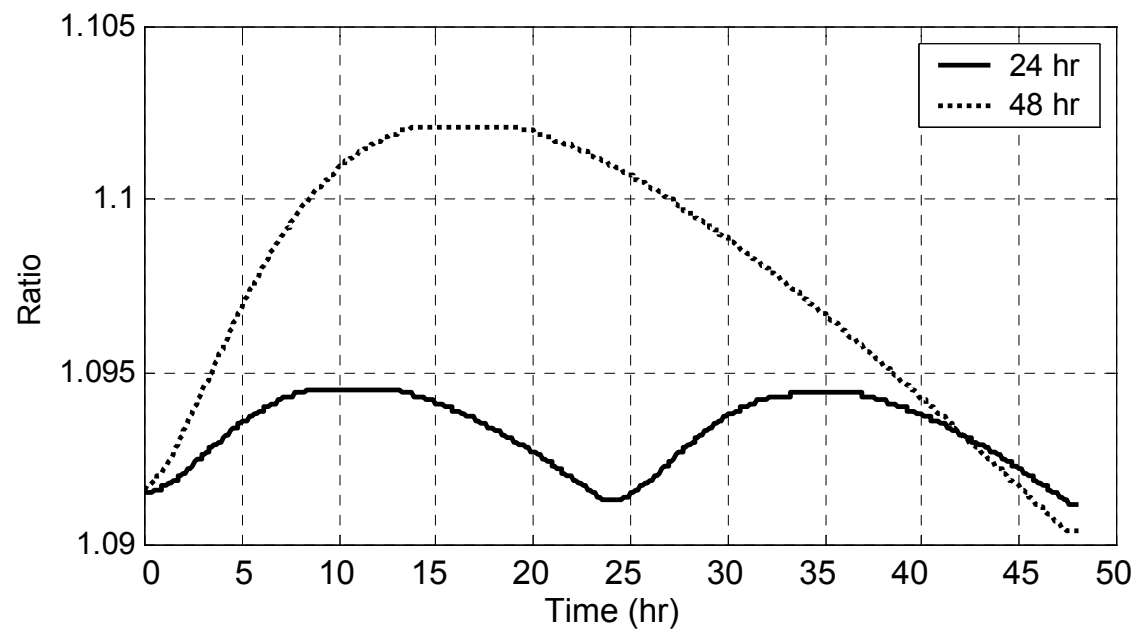

Figure 9.28: Bath ratio versus time for $24 \mathrm{hr}$ and $48 \mathrm{hr}$ tapping cycles 


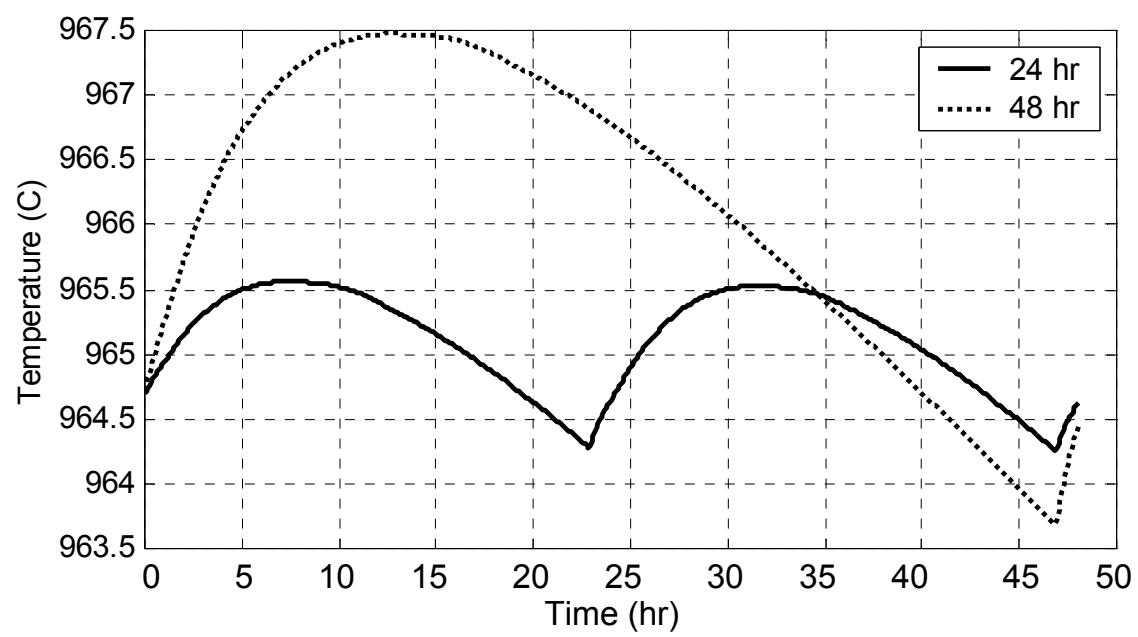

Figure 9.29: Bath temperature versus time for $24 \mathrm{hr}$ and $48 \mathrm{hr}$ tapping cycles

\subsubsection{Effect of Power Modulation}

Today, many smelters are required to include power modulation agreements in their electric supply contracts. Typically, these agreements require the smelter to reduce its power consumption by some percentage during times of peak electrical demand. In order to look at the effects of power modulation and to provide insight into some strategies that could be employed to minimize the effects of power modulation, a simulation was run in which the power input to the cell was reduced by $25 \%$ for $1 \mathrm{hr}, 2 \mathrm{hr}, 4 \mathrm{hr}$, or $8 \mathrm{hr}$ during a $24 \mathrm{hr}$ period. The modulation was achieved by decreasing the current by $25 \%$ while maintaining the same cell voltage. Several consecutive days were tracked as times of peak electrical demand occur for several days. Figure 9.30 shows the resulting bath temperature, and Figures 9.31 and 9.32 show the resulting superheat and sidewall thickness, respectively. These plots show that power modulation is a very disruptive event. The negative superheat values that result are a significant cause for concern. The low superheat values would make it very difficult to dissolve sufficient quantities of 
alumina to continue operation. This could result in a significant increase in the number of anode effects, particularly when the current was increased back to the nominal value. Operation through a $1 \mathrm{hr}$ or possibly $2 \mathrm{hr}$ period of modulation, might be possible. However, operation through a $4 \mathrm{hr}$ or $8 \mathrm{hr}$ period of modulation would probably be impossible because of the very negative levels of superheat. Another problem with a $4 \mathrm{hr}$ or $8 \mathrm{hr}$ period of modulation would be that manual events such as anode changes and metal tapping would be very difficult because of the significant amount of ledge freezing that would result. It is interesting to note that the cell appears to reach a new "steady state" condition based on the new power level after several days of power modulation. This helps to reduce the magnitude of the fluctuations that are observed. If long periods of power modulation are necessary, it would be best, if possible, to add energy to the cell either through increased voltage or increased current before and after the power modulation. This would be particularly helpful in reducing the magnitude of the negative superheat excursions.

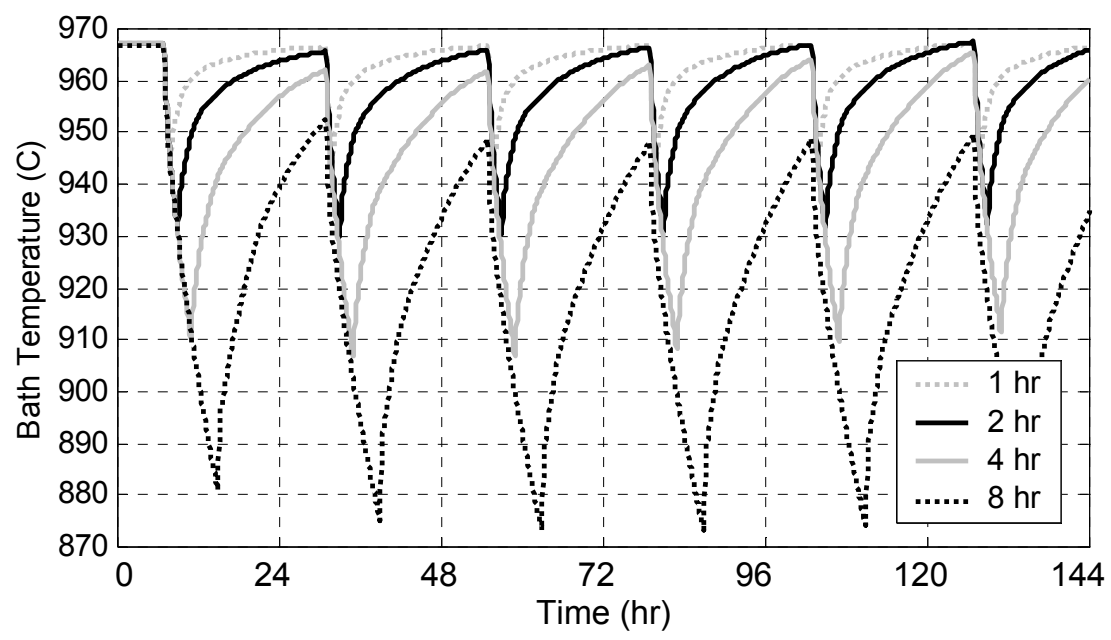

Figure 9.30: Effect of $25 \%$ power modulation for $1 \mathrm{hr}, 2 \mathrm{hr}, 4 \mathrm{hr}$ and $8 \mathrm{hr}$ on the bath temperature 


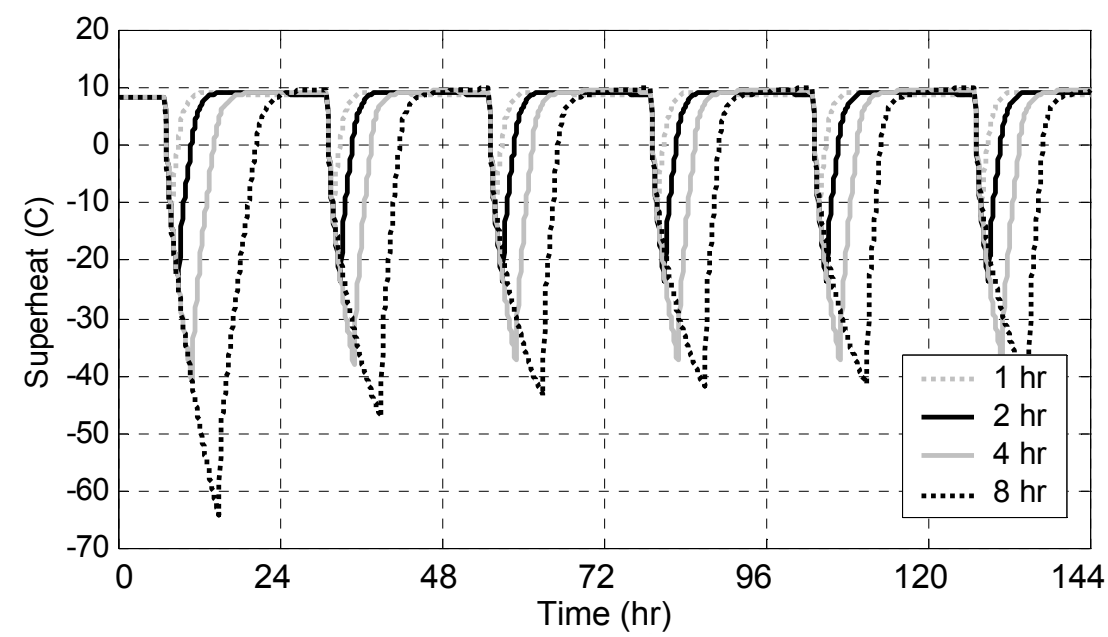

Figure 9.31: Effect of 25\% power modulation for $1 \mathrm{hr}, 2 \mathrm{hr}, 4 \mathrm{hr}$, and $8 \mathrm{hr}$ on the superheat

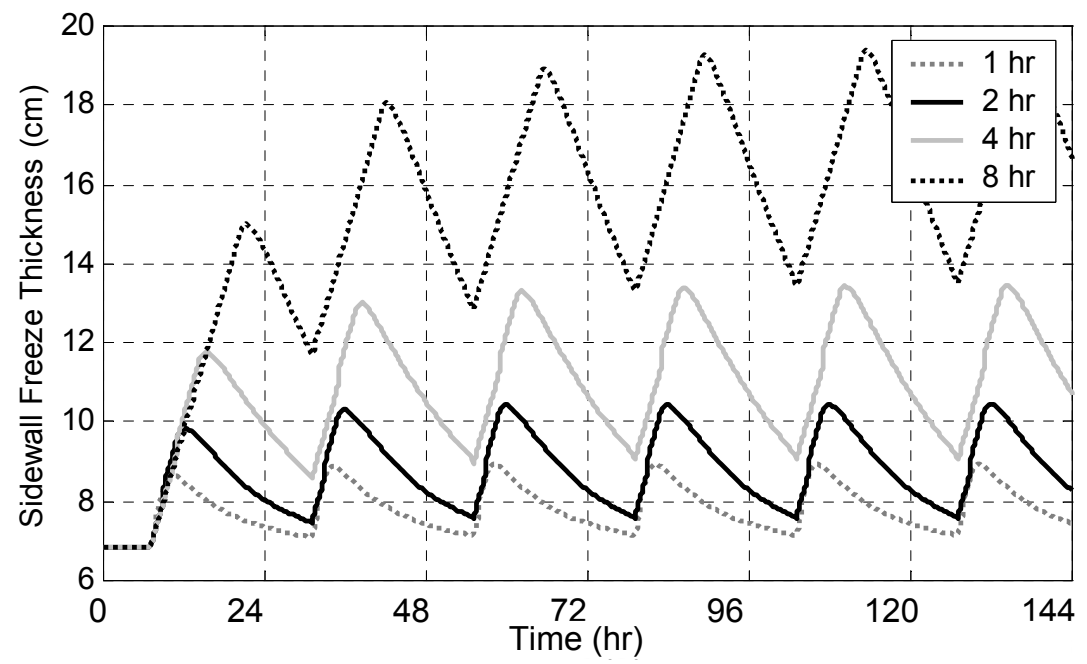

Figure 9.32: Effect of 25\% power modulation for $1 \mathrm{hr}, 2 \mathrm{hr}, 4 \mathrm{hr}$, and $8 \mathrm{hr}$ on the sidewall freeze thickness

\subsubsection{Effect of Changes in the Alumina Feed Weight and Distribution}

Alumina additions are the most important factor that causes temperature fluctuations over short periods of time. Several simulations were run to determine the effect of changing the feed weight and the ratio of powder to sludge. Figure 9.33 shows the response of the bath temperature to three different feed weights, and Figure 9.34 shows the alumina concentration response. As the feed weight is increased, the initial temperature drop increases as well. The temperature difference slowly returns to zero. 
The alumina concentration change increases with increasing feed weight, however, the alumina concentration difference between the feed weights does not return to zero.

Figure 9.35 shows the response of the bath temperature to three different feed weight distributions, and Figure 9.36 shows the alumina concentration response. The initial temperature difference quickly returns to zero, as energy is required to dissolve the sludge. The alumina concentration difference gradually decreases as the sludge dissolves.

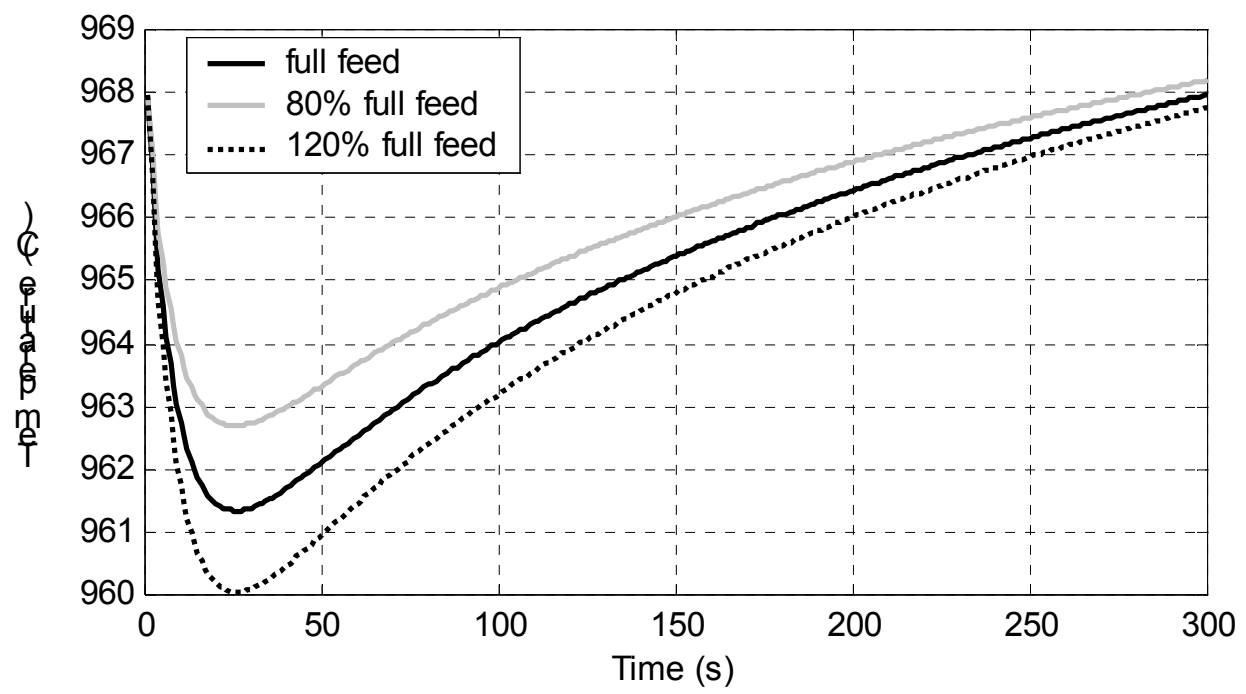

Figure 9.33: Bath temperature response to feed events of $80 \%, 100 \%$, and $120 \%$ of the normal feed weight versus time 


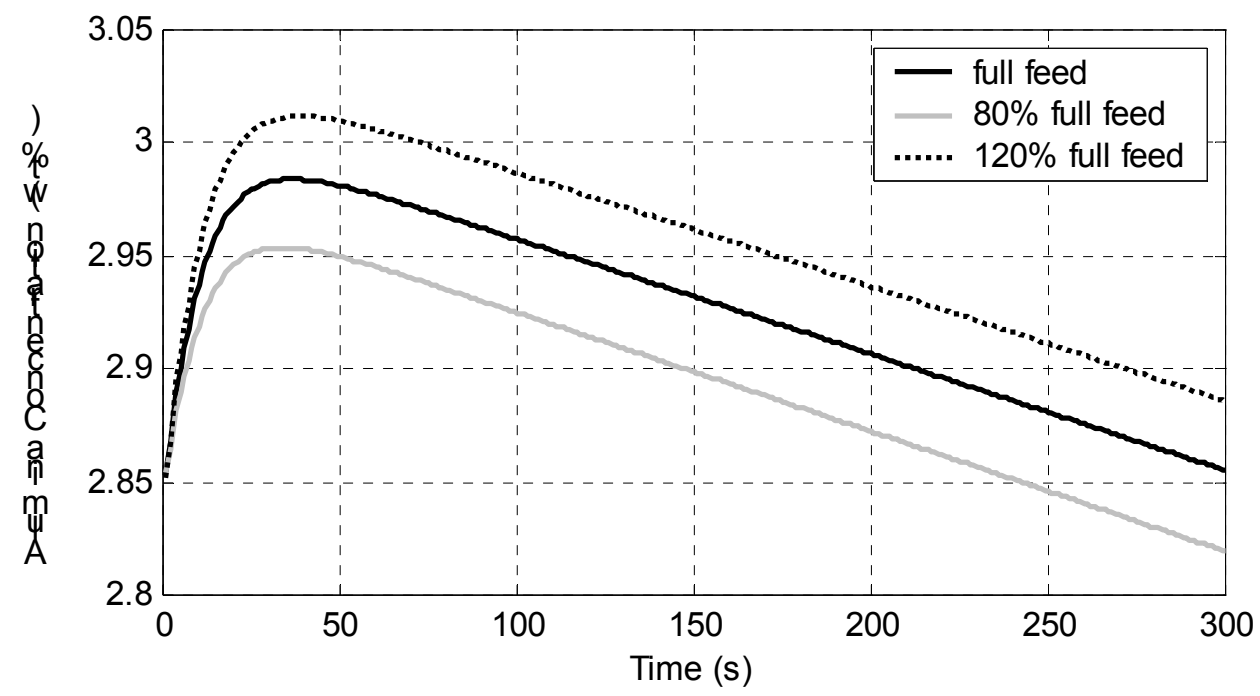

Figure 9.34: Alumina concentration response to feed events of $80 \%, 100 \%$, and $120 \%$ of the normal feed weight versus time

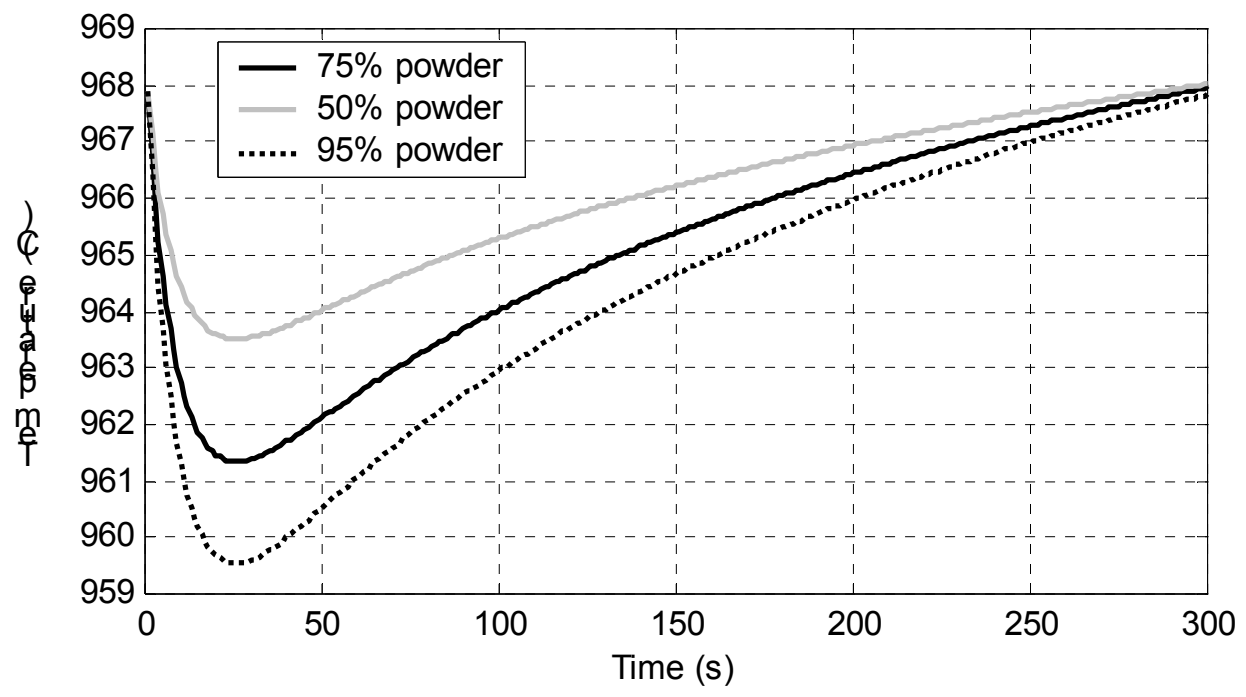

Figure 9.35: Bath temperature response to feed events containing $50 \%, 75 \%$, and $95 \%$ alumina powder and $50 \%, 25 \%$, and $5 \%$ sludge versus time 


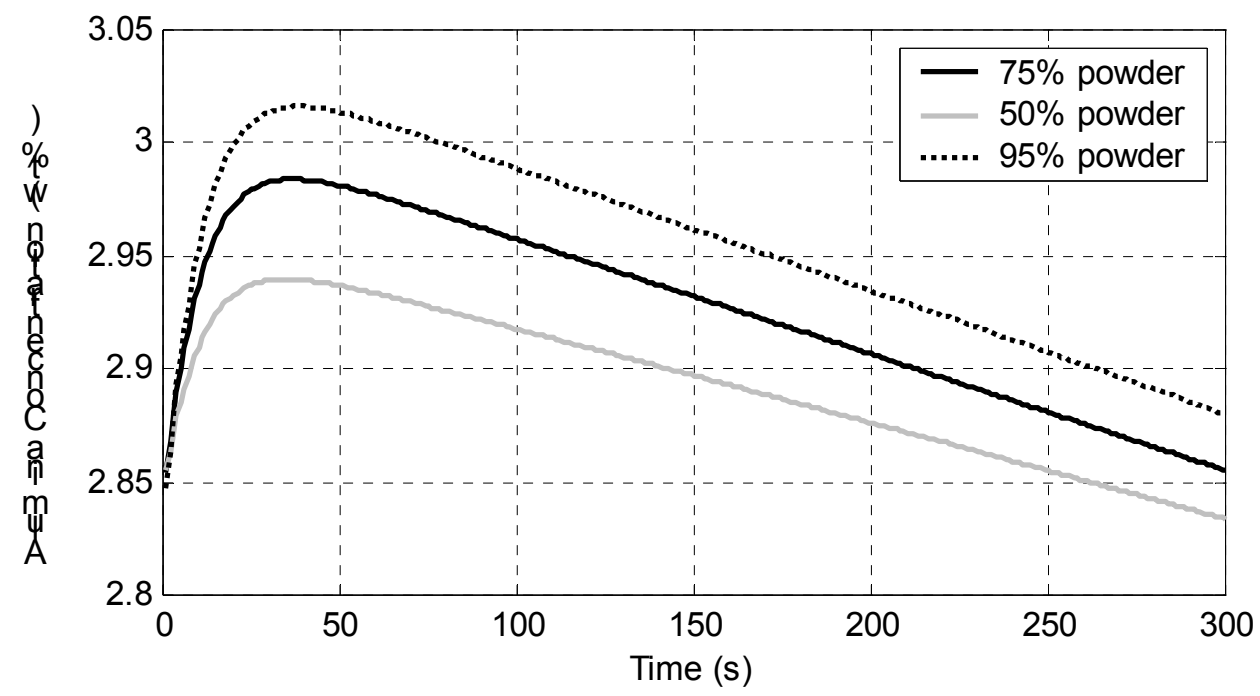

Figure 9.36: Alumina concentration response to feed events containing $50 \%, 75 \%$, and $95 \%$ alumina powder and $50 \%, 25 \%$, and $5 \%$ sludge versus time 


\section{Chapter 10: Alumina Concentration Estimator}

\subsection{Approach}

The alumina concentration in the bath changes significantly over time as alumina is consumed in the process reaction and as alumina feed material is added. Controlling the alumina concentration in the bath is important because low alumina concentrations can lead to anode effects and high alumina concentrations can lead to an excessive buildup of sludge at the bottom of the pot. However, the alumina concentration cannot be directly measured on a continuous basis, but must instead be inferred from the voltage signal.

Changes in the alumina concentration, the anode-cathode distance, and oscillations in the metal pad are the primary sources of fluctuation in the voltage signal. Figure 10.1 shows the relationship between alumina concentration, anode-cathode distance, and cell voltage. At low alumina concentrations, the voltage is very sensitive to changes in the alumina concentration. At higher alumina concentrations, the voltage curve is relatively insensitive to changes in the alumina concentration. Over a period of 5 minutes, without any feeding, the alumina concentration would decrease by about $0.16 \%$ in cells in Ravenswood, WV. At an alumina concentration of $3.0 \%$, a decrease in the concentration of $0.16 \%$ would increase the voltage $0.0065 \mathrm{~V}$. At a concentration of $2.5 \%$, the same decrease in concentration would increase the voltage $0.0152 \mathrm{~V}$.

The effect of changes in anode-cathode distance is almost constant for all alumina concentrations. A typical change in the anode-cathode distance would be 0.12 to $0.24 \mathrm{~cm}$ to achieve a change in voltage of 0.05 to $0.10 \mathrm{~V}$. Voltage fluctuations resulting from oscillations in the metal pad are typically called noise. During normal operation, the voltage fluctuation due to noise is generally 0.01 to $0.04 \mathrm{~V}$ over a 30 -second period. 
However, if the cell becomes unstable, the noise value will jump to over $0.10 \mathrm{~V}$. The cell controller attempts to filter out the effects of the noise, but when the noise value is high, the metal pad oscillations can cause fluctuations in the reported cell voltage of several hundredths of a volt.

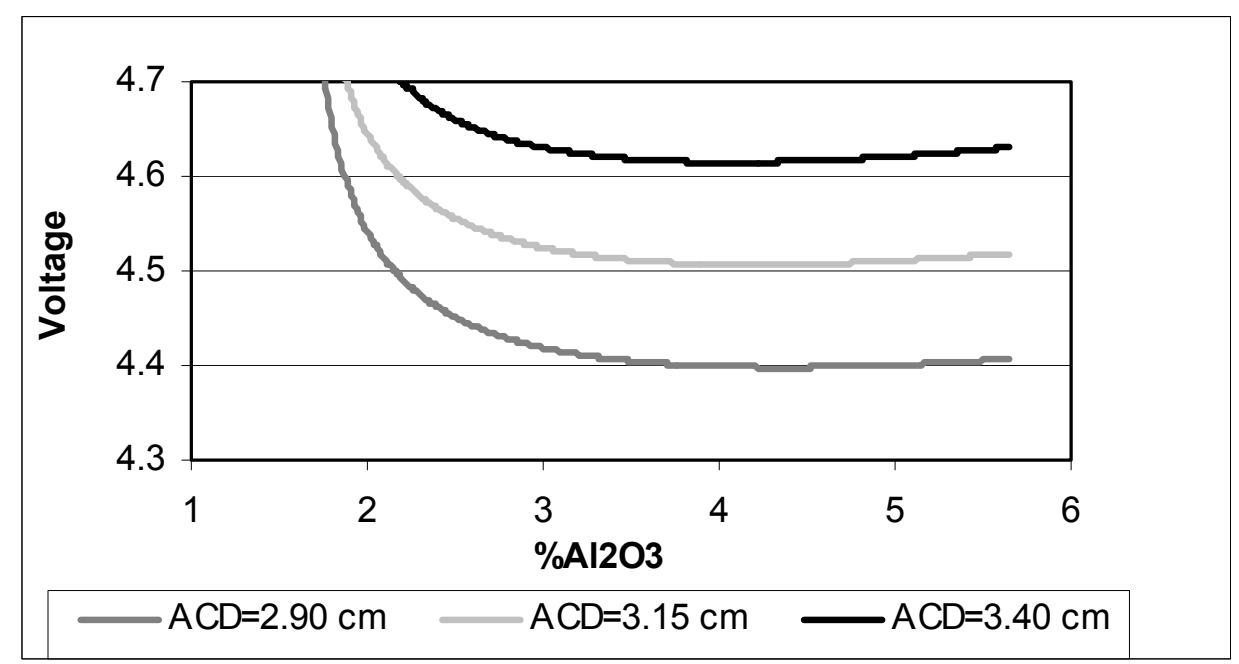

Figure 10.1: Voltage versus alumina concentration for several anode-cathode distances

The present control system uses the following sequence to control the alumina concentration:

1. Search: No alumina is fed to the cell and anode moves are restricted. After nine minutes, the slope of the voltage curve is measured. Positive slopes are taken to mean that the alumina concentration is low, meaning that the cell has been underfed. Negative slopes are taken to mean that the alumina concentration is high, meaning that the cell has been overfed. The controller then waits until the voltage has risen $0.045 \mathrm{~V}$ from the minimum voltage reached during the search period.

2. Overfeed Period: The feed time is set at some fraction of the standard feed time, based on the feed status (overfed or underfed) determined in the search period. Anode moves remain restricted. This feed rate remains in effect until the voltage has 
risen or fallen by a certain amount, based on the feed status, or until a certain length of time has passed, a minimum of 20 minutes and a maximum of 45 minutes.

3. Normal Feed Period: The cell is fed at its standard feed rate, and anode moves are allowed. This period lasts for 30 minutes, at which time the search period begins.

During the normal feed period, voltage changes due to changes in the alumina concentration are generally small. This makes it virtually impossible to determine the alumina concentration from the voltage curve during this time period. Because of this, the search and overfeed periods will be used to estimate the alumina concentration.

The voltage curve during the estimation period is calculated using the algebraic relationships described in Chapter 5. The current density needed to calculate the overvoltage components was determined to be $0.92 \mathrm{~A} / \mathrm{cm}^{2}$ using the finite element model. Another voltage component must be included in the estimator model which was not discussed in Chapter 5. This is a hysteresis effect which results from fluctuations in the feed rate [1]. The equations in Chapter 5 were developed under static, laboratory conditions, not industrial conditions and, as such, do not include such transient effects.

The exact mechanism for this hysteresis is not known, but the favored explanation is that as alumina is fed into the bath, a portion of the alumina remains in a solid state and sinks to the bath-metal pad interface [1]. The resulting film acts to increase the cell resistance. When the cell transitions from search to overfeeding, the film resistance will gradually increase leading to a higher voltage than would be expected from chemical changes alone. It is unclear what will happen when the transition from rapid feeding to normal feeding occurs. The film resistance may decrease slowly or it may remain 
essentially unchanged. When the transition from normal feeding to search occurs, the remaining film resistance will gradually decrease, resulting in a cell voltage that is lower than expected.

Kvande, Moxnes, and Rolseth [1] varied the alumina concentration from near the saturation limit to the concentration resulting in anode effect by using a long overfeeding period followed by a long underfeeding period. They measured the maximum voltage difference between the underfeeding and overfeeding curves at fixed alumina concentrations. They obtained values ranging from $20 \mathrm{mV}$ to $160 \mathrm{mV}$ as the magnitude of the hysteresis effect. These results are not immediately applicable to the reduction cells currently being studied, as the cells currently of interest operate at a much lower line current with shorter periods of underfeeding and overfeeding.

Since the exact mechanism governing the hysteresis effect is unknown, two generic second-order systems were used to simulate its effect. The first system tracks the alumina that is settling to form the film and the second system tracks the thickness of the film. The hysteresis voltage is then calculated by multiplying the thickness of the film by a resistance parameter. Equations 10.1 through 10.3 can be used to calculate the hysteresis voltage.

$$
\begin{gathered}
s(k+1)=\left(2-r_{s 1} \Delta t\right) s(k)-\left(1-r_{s 1} \Delta t+r_{s 2} \Delta t^{2}\right) s(k-1)+c_{1} \Delta t^{2} f(k) \\
t(k+1)=\left(2-r_{t 1} \Delta t\right) t(k)-\left(1-r_{t 1} \Delta t+r_{t 2} \Delta t^{2}\right) t(k-1)+s(k)-s(k-1) \\
V_{h}(k)=c_{2} t(k)
\end{gathered}
$$

where:

$\mathrm{s}=$ the amount of alumina that is expected to settle to the film

$\mathrm{k}=$ the current time step 
$\Delta t=$ the length of each time-step

$\mathrm{r}_{\mathrm{s} 1}, \mathrm{r}_{\mathrm{s} 2}=$ one of the two system constants for the alumina settling system

$\mathrm{c}_{1}=\mathrm{a}$ constant related to the amount of alumina that is expected to settle from each feed

$\mathrm{f}=$ an operator indicating whether a feed event has occurred

$\mathrm{t}=$ the thickness of the film

$r_{t 1}, r_{t 2}=$ one of the two system constants for the film thickness system

$c_{2}=$ the effective resistivity of the film

$\mathrm{V}_{\mathrm{h}}=$ the hysteresis voltage

The estimator calculates the hysteresis voltage at every data point. The change in the alumina concentration is calculated at each data point using the model described in

Chapter 7. When the end of an overfeed period is reached, the following steps are taken to estimate the alumina concentration at the end of the overfeed period:

1. Calculate the average measured voltage for the search-overfeed period and compute an approximate anode-cathode distance based on this voltage using a nominal alumina concentration of $3.00 \mathrm{wt} \%$.

2. Cycle through values for the terminal alumina concentration, the concentration at the end of the overfeed period, from $2.50 \mathrm{wt} \%$ to $4.00 \mathrm{wt} \%$ in steps increasing from 0.05 $\mathrm{wt} \%$ to $0.10 \mathrm{wt} \%$ as the terminal aluminum concentration increases.

3. At each terminal alumina concentration, calculate the alumina concentration at each data point in the search-overfeed period. This is done by summing the change in the alumina concentration at each point from the current point to the end of the overfeed period and subtracting this change from the terminal alumina concentration. 
4. At each terminal alumina concentration, calculate the cell voltage at each data point using the calculated alumina concentration and the approximate anode-cathode distance.

5. At each terminal alumina concentration, calculate the relative calculated voltage at each point by subtracting the average calculated voltage from each of the calculated voltage values. Calculate the relative measured voltage in the same way. Since the anode-cathode distance should be constant over this interval, calculating the relative voltages eliminates voltage discrepancies resulting from errors in the approximate anode-cathode distance and produces a curve that should be exclusively a function of the alumina concentration.

6. Calculate the average tracking error by summing the absolute value of the error between the relative calculated voltage and the relative measured voltage and dividing by the number of points.

7. The terminal alumina concentration that produces the minimum tracking error is the estimated alumina concentration.

\subsection{Model Results}

In order to calibrate and test the estimator, a data set was generated by measuring the alumina concentration at the end of the overfeed period in nine cells over a period of three days. Ninety-eight samples were obtained. The raw data is given in Appendix A. The average alumina concentration was $3.73 \mathrm{wt} \%$, and the standard deviation was 1.66 $\mathrm{wt} \%$. The target alumina concentration at the end of the overfeed period is $3.00 \mathrm{wt} \%$. Figure 10.2 shows a histogram of the data. The data is skewed toward high alumina 
concentrations because a significant number of samples have a concentration that is 4.00 $\mathrm{wt} \%$ or larger. Because the voltage curve is very insensitive to alumina concentration changes when the alumina concentration is greater than $3.50 \mathrm{wt} \%$, accurate estimates of the alumina concentration above this value should not be expected. This is not a problem in practice because knowledge that the alumina concentration is above $3.50 \%$ is sufficient for taking corrective action. Because of this, the measured alumina concentration was capped at $3.50 \mathrm{wt} \%$. With the cap in place, the average alumina concentration dropped to $3.20 \mathrm{wt} \%$, and the standard deviation dropped to $0.36 \mathrm{wt} \%$.

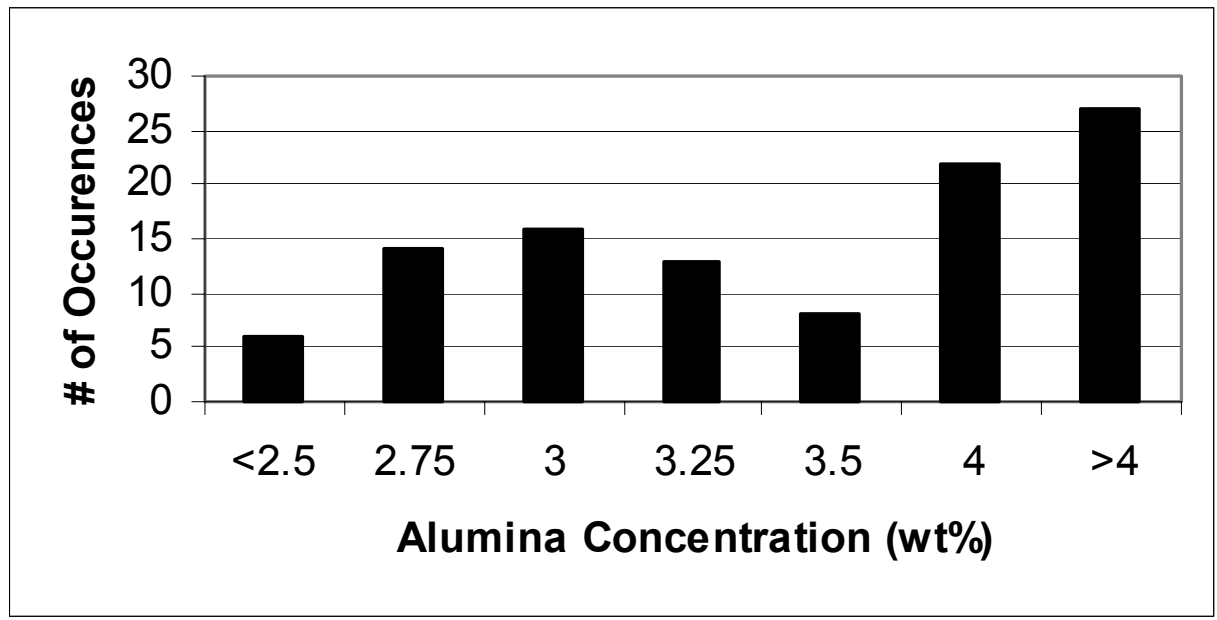

Figure 10.2: Histogram of the alumina concentration samples 


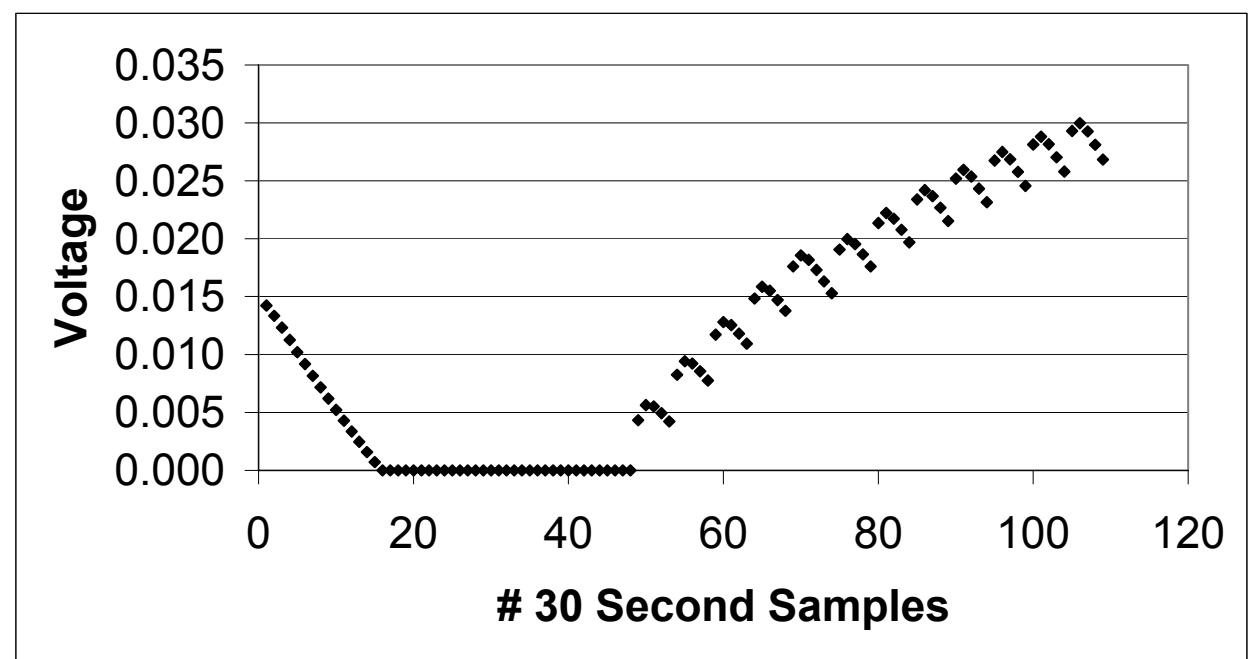

Figure 10.3: Typical plot of the hysteresis voltage over a search-overfeed cycle

Before estimates could be generated, values had to be determined for the hysteresis voltage components. Table 10.1 shows the resulting values. These values were chosen as they produced the minimum average tracking error over the entire data set. The average tracking error was $0.012 \mathrm{~V}$. Figure 10.3 shows a typical plot of the hysteresis voltage over a search-overfeed period.

Table 10.1: Hysteresis voltage components

\begin{tabular}{|c|c|}
\hline $\mathrm{c}_{1}$ & $1.67 \times 10^{-6}$ \\
\hline $\mathrm{r}_{\mathrm{s} 1}$ & $1.67 \times 10^{-4}$ \\
\hline $\mathrm{r}_{\mathrm{s} 2}$ & $1.11 \times 10^{-5}$ \\
\hline $\mathrm{r}_{\mathrm{t} 1}$ & $2.33 \times 10^{-2}$ \\
\hline $\mathrm{r}_{\mathrm{t} 2}$ & $1.00 \times 10^{-5}$ \\
\hline $\mathrm{c}_{2}$ & $3.20 \mathrm{E}+00$ \\
\hline
\end{tabular}

The average estimated alumina concentration was $3.16 \mathrm{wt} \%$, and the standard deviation was $0.34 \mathrm{wt} \%$. The raw results are given in Appendix A. The standard deviation of the error between the estimated and actual alumina concentrations was 0.30 $\mathrm{wt} \%$. If the maximum tracking error is capped at $0.012 \mathrm{~V}$ to eliminate voltage curves for which poor fits were obtained, the standard deviation of the alumina concentration error drops to $0.25 \%$. Figure 10.4 shows the relative measured voltage and relative estimated 
voltage for a cell that was correctly identified as having a low alumina concentration.

The estimated alumina concentration was $2.80 \mathrm{wt} \%$, and the actual concentration was $2.51 \%$. Figure 10.5 shows the estimated alumina concentration over the same period.

Figures 10.6 and 10.7 show the same data for a cell that was correctly identified as having an alumina concentration of greater than $3.50 \mathrm{wt} \%$. Figures 10.4 and 10.6 show that the estimator closely tracks the cell voltage during the search-overfeed period. The only point where significant error is evident is in Figure 10.6 shortly after sample 40. This disparity is likely the result of metal pad oscillations which distort the measured voltage during this short time period.

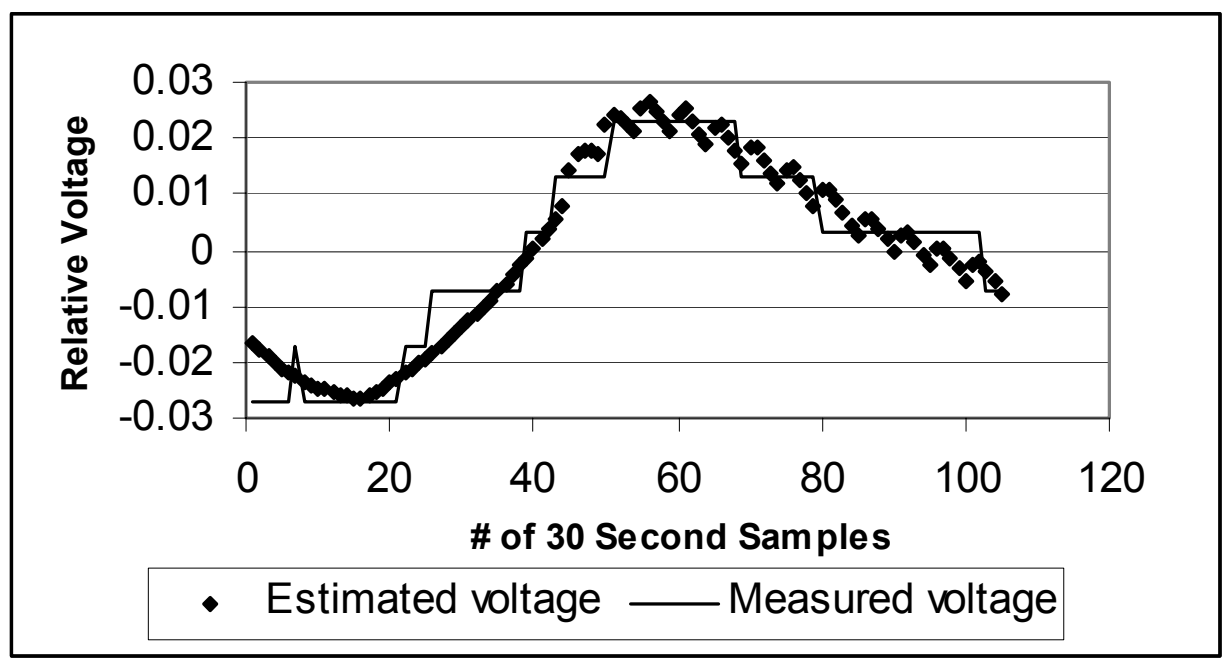

Figure 10.4: Relative estimated and measured voltage during a search-overfeed period for a cell that was correctly identified as having a low alumina concentration 


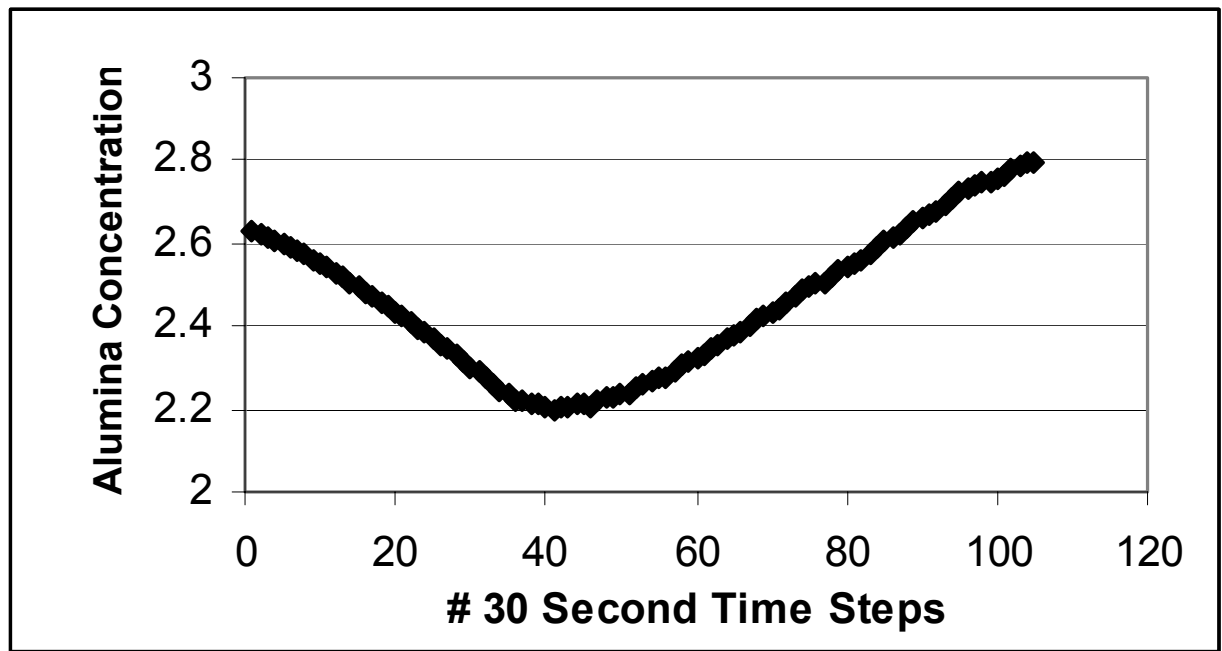

Figure 10.5: Estimated alumina concentration for the same search-overfeed period as shown in Figure 10.4

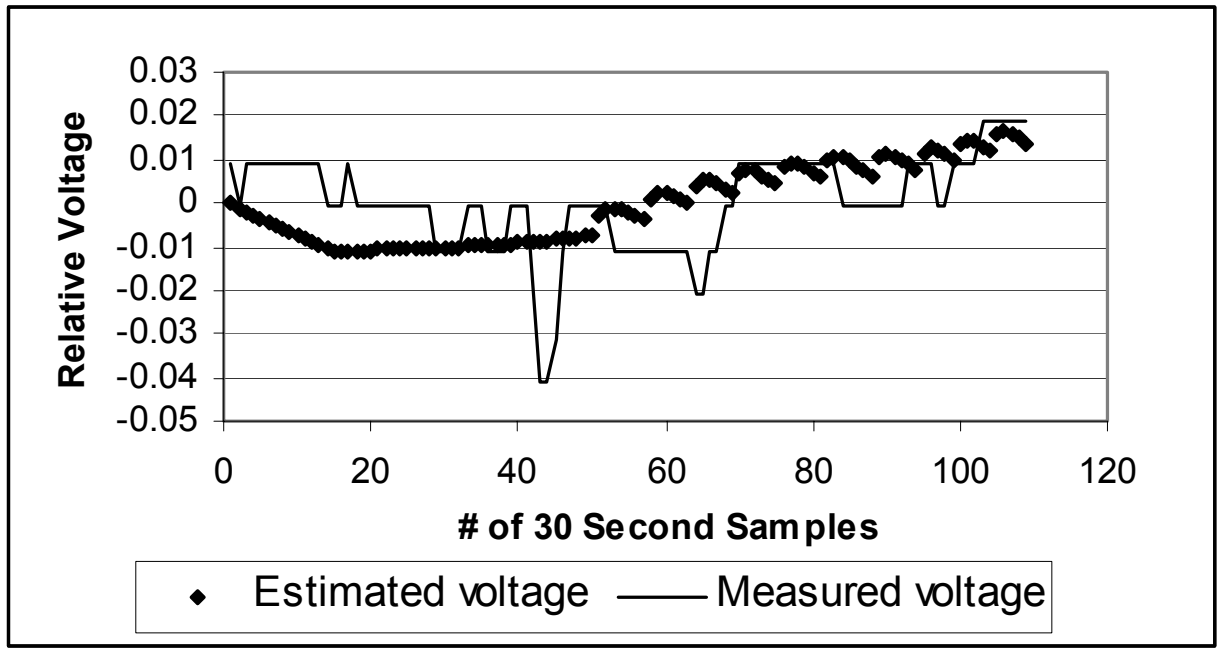

Figure 10.6: Relative estimated and measured voltage during a search-overfeed period for a cell that was correctly identified as having a high alumina concentration 


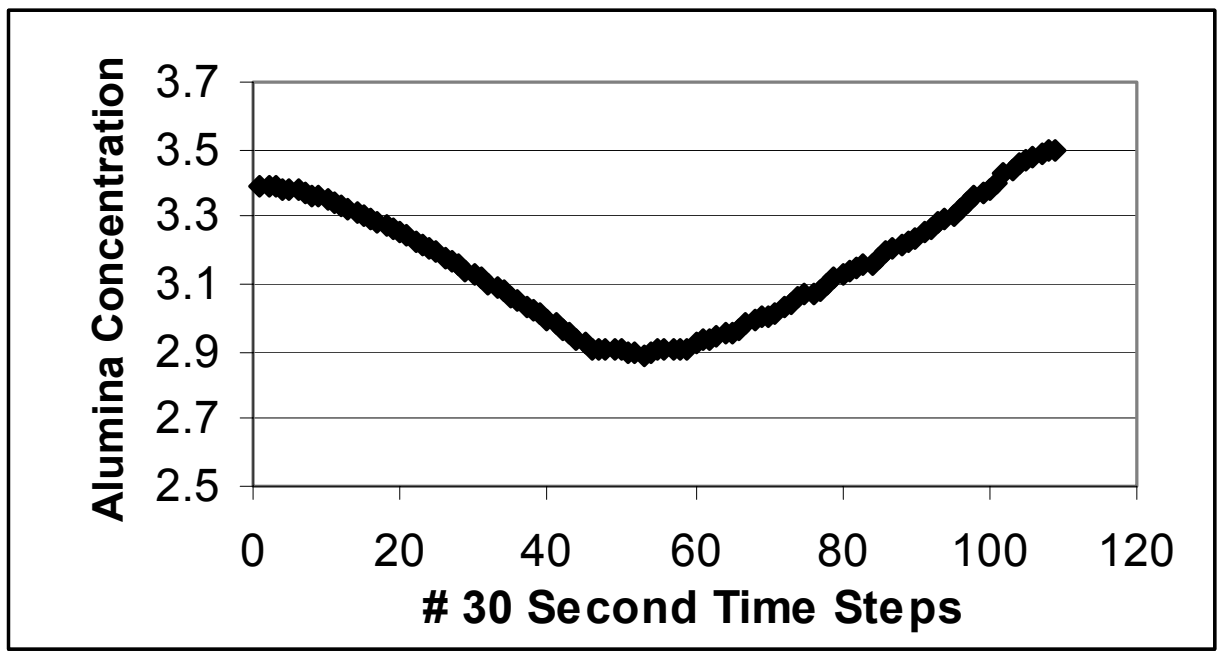

Figure 10.7: Estimated alumina concentration for the same search-overfeed period as shown in Figure 10.6

From an operational standpoint, the most important capability of the estimator is to correctly identify pots that have either a high or a low alumina concentration. If the concentration is high, the feed rate should be decreased and if the concentration is low, the feed rate should be increased. Table 10.2 summarizes the results. In this table, concentrations greater than or equal to $3.20 \mathrm{wt} \%$ are considered high, and those which are less than or equal to $2.80 \mathrm{wt} \%$ are considered low. Measured concentrations between $2.80 \mathrm{wt} \%$ and $3.20 \mathrm{wt} \%$ are not considered in this analysis as significant problems should not result if these data points are incorrectly identified as too high or too low, and the feed rate is subsequently increased or decreased. Correct high and low estimates occur when the estimated and measured values agree on the concentration level. Incorrect high estimates occur when the measured value is greater than $3.20 \mathrm{wt} \%$, but the estimated concentration is less than or equal to $2.80 \mathrm{wt} \%$. Incorrect low estimates occur when the actual concentration is lower than $2.80 \mathrm{wt} \%$, and the estimated concentration is greater than $3.20 \mathrm{wt} \%$. The estimator is capable of correctly identifying about $40 \%$ of the high and low alumina concentration occurrences. When a high or low concentration is 
predicted, the estimate is correct approximately $80 \%$ of the time. Thus, the alumina concentration estimator shows potential to aid in identifying cells that are operating at an alumina concentration that is high or low. While the estimator is not refined enough to completely replace the existing feed control strategy, incorporating it into the existing feed control strategy should increase the number of cells operating close to target alumina concentration.

Table 10.2: Summary of the ability of the estimator to correctly identify occurrences of high and low alumina concentrations

\begin{tabular}{|l|c|c|c|c|c|c|}
\cline { 2 - 7 } \multicolumn{1}{c|}{} & \multicolumn{2}{c|}{ \# of Occurrences } & \% of Total Samples & \multicolumn{2}{c|}{ \% of High or Low } \\
\cline { 2 - 7 } \multicolumn{1}{c|}{} & High & Low & High & Low & High & Low \\
\hline Measured Data & 56 & 19 & $57.14 \%$ & $19.39 \%$ & $100.0 \%$ & $100.0 \%$ \\
\hline Correct Estimate & 22 & 8 & $22.45 \%$ & $8.16 \%$ & $39.3 \%$ & $42.1 \%$ \\
\hline Incorrect Estimate & 5 & 2 & $5.10 \%$ & $2.04 \%$ & $8.9 \%$ & $10.5 \%$ \\
\hline$\%$ Correct & $81.5 \%$ & $80.0 \%$ & \multicolumn{4}{|c}{} \\
\hline
\end{tabular}

\section{$\underline{10.3 \text { References }}$}

1. Kvande, Halvor, Bjorn Moxnes, and Sverre Rolseth. "Pseudo Resistance Curves Measured in Industrial Aluminum Electrolysis Cells.” Light Metals 1997. 403-409. 


\section{Chapter 11: Bath Temperature and Ratio Estimator}

\subsection{Approach}

The bath temperature and the ratio are important control parameters. Maintaining a stable bath temperature and a stable ratio near optimal levels will result in manual operations being relatively easy, the current efficiency being high, and the cell voltage being low. Currently, bath temperature is measured three times a week, and the bath ratio is measured only once a week. The bath temperature measurements are recorded, but they are not actively used to determine whether corrective additions of aluminum fluoride or soda ash should be made. Thus, the entire bath temperature/ratio control strategy is based on a single measurement taken once a week. This results in significant variability in the ratio from week to week and from pot to pot. The standard deviation of the ratio is currently about 0.07 . One reason for this is that the measurement has a significant amount of error. The measurement has a standard deviation of about 0.03 .

Another reason for the variability in the ratio are significant short term fluctuations in the ratio occur as the result of changes in the voltage, metal pad level, and the top crust condition. If these changes are not taken into account, the measured ratio will not correctly describe the cell's condition. Finally, the levels of sodium and fluoride in the feed material vary significantly over time and can cause significant ratio fluctuations over a week's time.

Increasing the frequency of ratio samples and using this information to make corrective bath additions would be the most direct way to decrease the variability in the ratio, but this is not feasible. A second approach would be to estimate the ratio from the temperature measurements that are already taken and make corrective bath additions 
based on the estimated ratio. The drawback of this approach is that the bath temperature is more susceptible than the ratio to short-term cell disturbances. Being able to predict the effects of short term cell disturbances on the ratio and temperature would be helpful in reducing the ratio fluctuations that are currently present.

In order to estimate the temperature and ratio, a new model was developed that could be computed more quickly than the finite element model. The cell voltage was computed using the algebraic relationships in Chapter 5. The chemical species model presented in Chapter 7 was also used. A different approach had to be used in computing the temperature distribution in the cell. In this model, the cell was modeled by a group of 30 one-dimensional elements with 31 nodes and 12 boundary conditions. A schematic showing the elements, nodes, boundary conditions, and their connections is given in Figure 11.1. Each major region in the cell is represented by at least one element. Regions of the cell which have significant heat losses in more than one dimension are broken into two elements with heat losses in the secondary direction leaving between the two elements. Equation 11.1 gives a simple relationship governing the heat flow at node.

$$
\frac{\left(C_{a}+C_{b}\right)}{2 \Delta t}\left(T_{1}-T_{1}^{0}\right)+K_{a}\left(T_{1}-T_{0}\right)-K_{b}\left(T_{2}-T_{1}\right)=Q
$$

where:

$\mathrm{C}_{\mathrm{i}}=$ the heat capacity of the specified element in Joules (see Figure 11.2).

$\Delta \mathrm{t}=$ the time step.

$\mathrm{T}_{\mathrm{i}}=$ the temperature at the specified node at the current time step in $\mathrm{K}$.

$\mathrm{T}_{\mathrm{i}}^{0}=$ the temperature at the specified node at the previous time step in $\mathrm{K}$.

$\mathrm{K}_{\mathrm{i}}=$ the thermal conductivity of the specified element.

$\mathrm{Q}=$ internal heat generation or losses due to boundary conditions. 


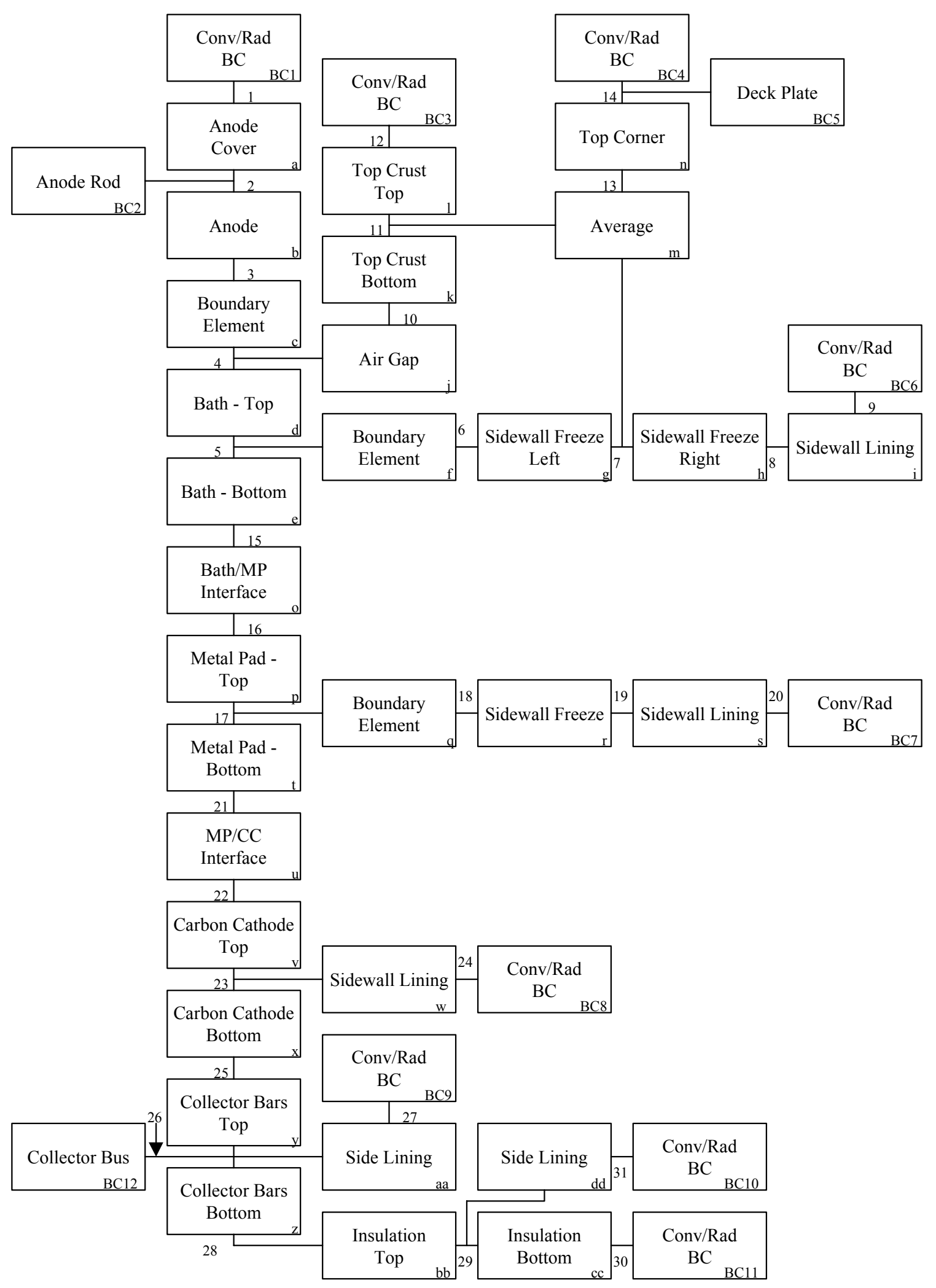

Figure 11.1: Schematic showing the elements, nodes, boundary conditions and connections used in the reduced order thermal model 


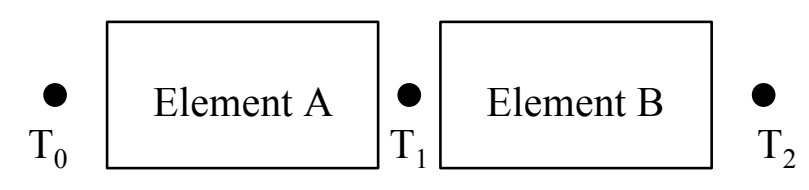

Figure 11.2: Schematic of a typical node and the neighboring elements and nodes

Equation 11.1 can be computed for each node to form a system of 31 equations and 31 unknowns which can be solved using Gaussian elimination. Note that the equation is fully implicit in time. Thus, the same numerical stability characteristics apply to this system of equations as applied in the thermal finite element model. The same material properties and boundary conditions were used in this reduced order model as were used in the thermal finite element model discussed in Chapter 6.

\subsection{Model Verification}

The reduced order model is not expected to be as accurate as the finite element model, but it should produce similar results. The first step was to verify the distribution of the heat losses from the cell at nominal operating conditions. Figure 11.3 shows a bar graph comparing the heat losses from different portions of the cell for the reduced order model and the finite element model. Table 11.1 provides the cell section referred to by each column pair in Figure 11.3. These results show that the distribution of the heat losses in the two models is almost identical. 


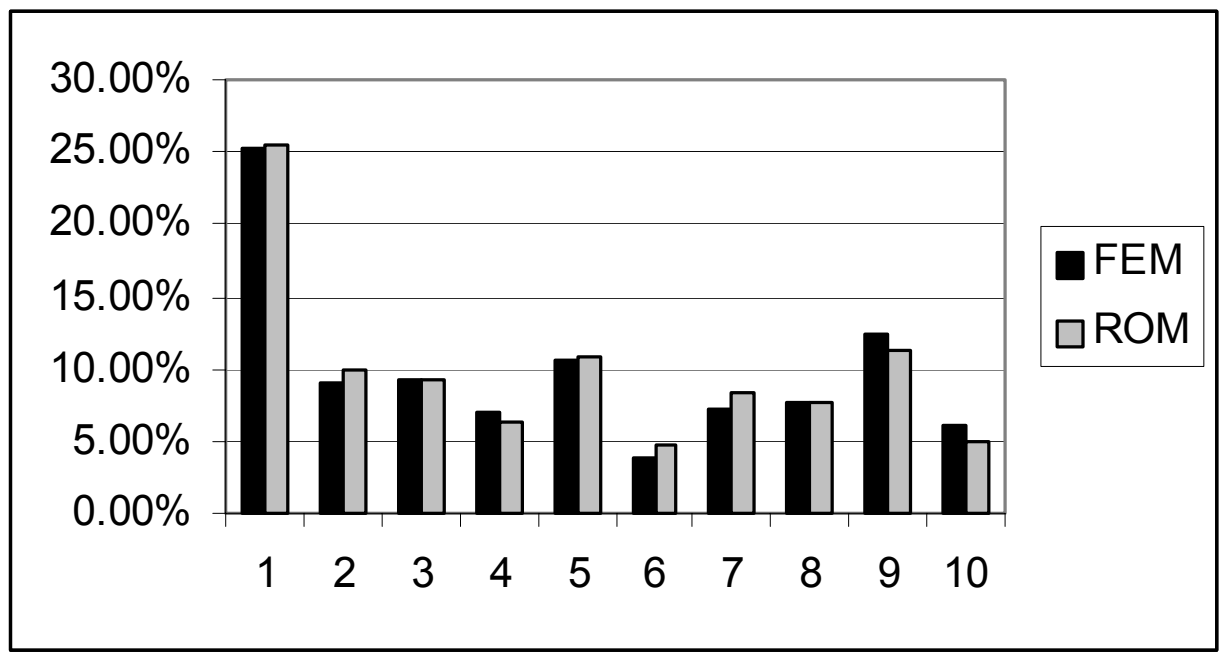

Figure 11.3: Comparison of the heat losses from different parts of the cell from the finite element model (FEM) and the reduced order model (ROM)

Table 11.1: Descriptions for the part of the cell referred to by each column pairing in Figure 11.3

\begin{tabular}{|l|c|}
\hline Cell Section & $\#$ \\
\hline$\%$ Anode Top & 1 \\
\hline$\%$ Top Crust & 2 \\
\hline$\%$ Anode Rod & 3 \\
\hline$\%$ Deck Plate & 4 \\
\hline$\%$ Bath Sidewall & 5 \\
\hline$\%$ Metal Pad Sidewall & 6 \\
\hline$\%$ Rest of Sidewall & 7 \\
\hline$\%$ Pot Bottom & 8 \\
\hline$\%$ End Walls & 9 \\
\hline$\%$ Collector Bars & 10 \\
\hline
\end{tabular}

Several simulations were also run to determine whether the reduced order model

produced reasonable results. In the first simulation, the voltage was varied from $5.00 \mathrm{~V}$ to $4.10 \mathrm{~V}$ in steps of $0.10 \mathrm{~V}$. At each step the cell was allowed to reach a steady-state level. The ratio at each voltage step was compared to results from the same simulation run using the finite element model. The results are shown in Figure 11.4. The reduced order model produces almost identical results in the general operating range of the cell (4.40 to $4.80 \mathrm{~V})$. However, at extreme values differences in the results are apparent. This is a direct result of the larger spatial elements that are used in the reduced order model. 


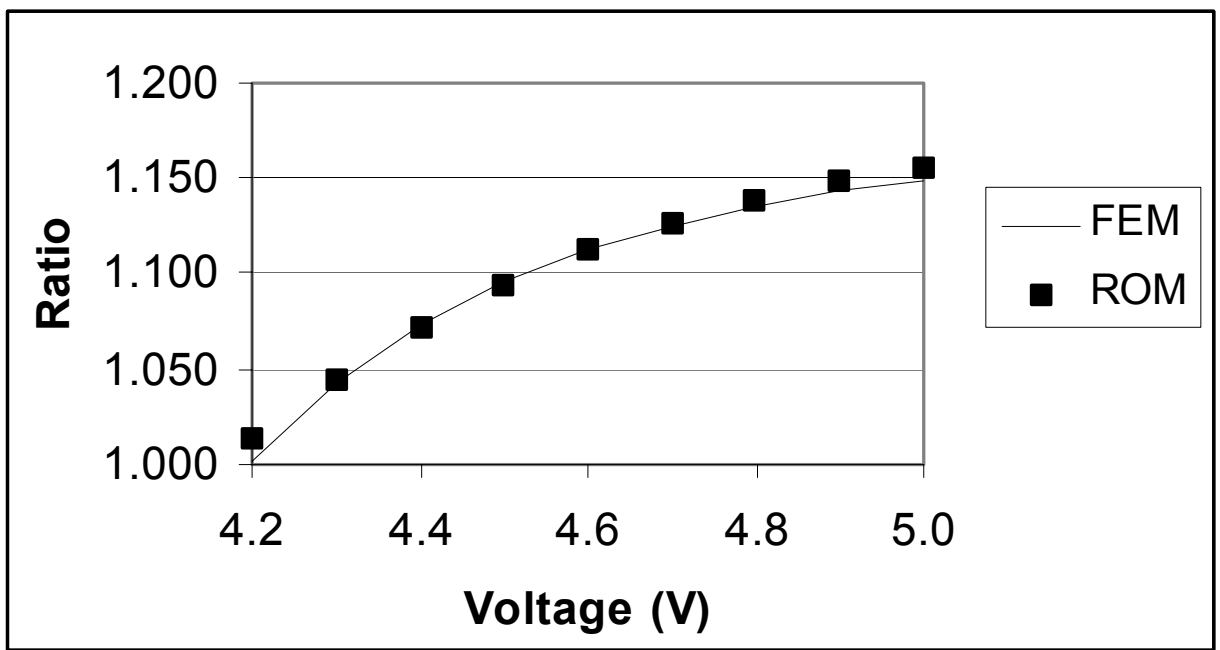

Figure 11.4: Comparison of output ratios at different voltages for the finite element model (FEM) and the reduced order model (ROM)

In a second simulation, the output of the model is compared to physical bath temperature measurements that were taken following a step change in the voltage. The results are shown in Figure 11.5. The model appears to track the measured temperature with reasonable accuracy. The primary difference is in the magnitude of the bath temperature fluctuations associated with each feed event. The reason for this is that the alumina is fed into only a portion of the total bath, which results in large local shifts in the temperature. In the reduced order model, the bath is modeled as two elements. Each feed event is assumed to take energy from the entire bath, resulting in a greater thermal mass to damp the effects of the thermal shock. Thus, the difference in the magnitude of the temperature fluctuations after each feed is not of significant concern. 


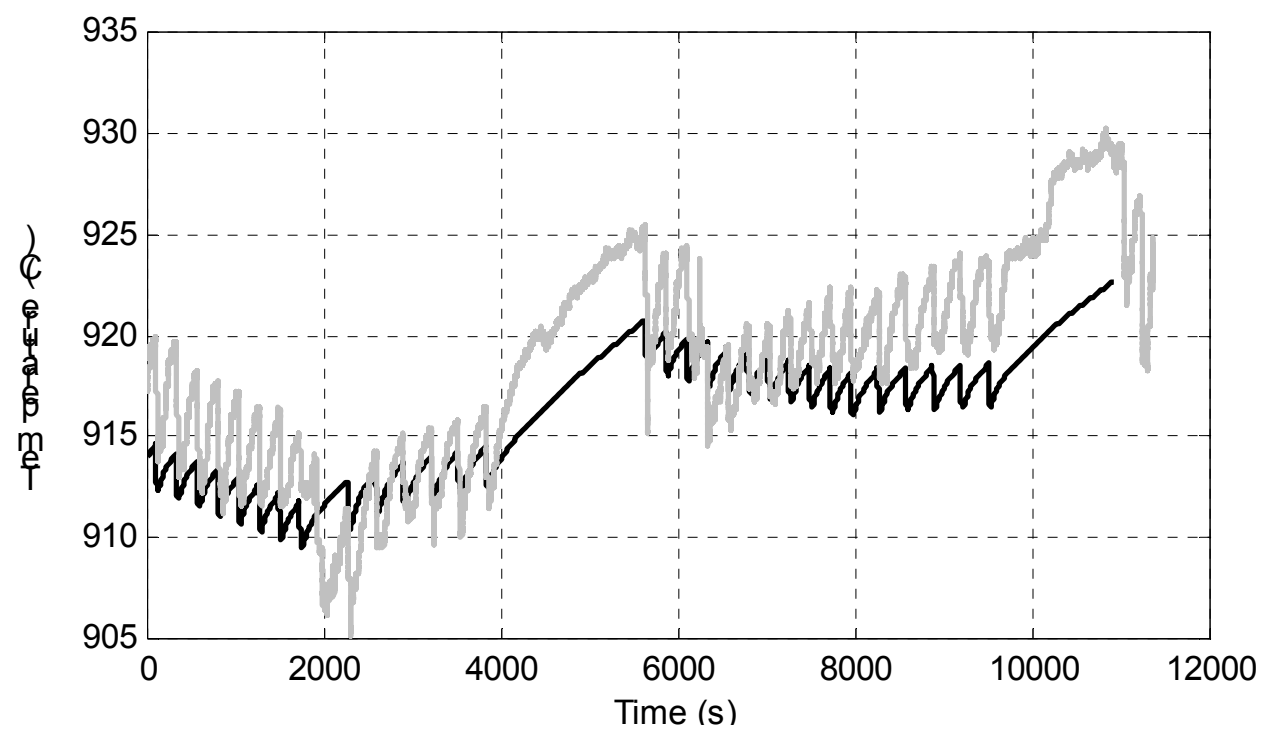

Figure 11.5: Comparison of bath temperature predictions and measured values following a step change in the voltage

\section{$\underline{11.3 \text { Estimator Results }}$}

In order to test the ability of the new model to predict the temperature and the ratio, the temperature and ratio were measured once a day for three consecutive days on 14 cells. The raw data is given in Appendix A. The model was then run starting one day before the first day the measurements were taken. The ratio at the beginning of the simulation was determined so that the actual ratio matched the estimated ratio at the time of the first measurement. This gave an estimated bath temperature, which was compared to the actual bath temperature. An adjusted ratio was then computed which would cause the actual and estimated bath temperatures to match. The cell was then run until the next sample period starting at the adjusted ratio. This produced the estimated bath temperature and the initial ratio estimate. From these values, the adjusted ratio was computed. This process was then repeated for the third set of measurements.

The average bath temperature was $938^{\circ} \mathrm{C}$, and the standard deviation was $13.03^{\circ} \mathrm{C}$. The average ratio was 1.051 with a standard deviation of 0.055 . The average estimated 
temperature was $933^{\circ} \mathrm{C}$, and the standard deviation was $14.34^{\circ} \mathrm{C}$. The average error between the estimated and measured bath temperature was $-5.38^{\circ} \mathrm{C}$ with a standard deviation of $12.84^{\circ} \mathrm{C}$. Figure 11.6 shows the estimated temperature versus the actual temperature. The average adjusted ratio was 1.053 and the standard deviation was 0.048 . The average error between the measured ratio and the adjusted ratio was 0.002 and the standard deviation was 0.032 . Figure 11.7 shows the adjusted ratio versus the actual ratio. A table showing the estimated and actual temperatures and ratios is given in Appendix A. These results indicate that the estimator does not have much success predicting changes in the temperature. However, adjusting the initial ratio estimate based on the difference between the estimated and measured temperature produces ratio estimates that are reasonably accurate. The error between the adjusted and measured ratio is only slightly greater than the uncertainty in the ratio measurement ratio. Thus, if daily temperature measurements are available, an accurate estimate of the ratio can be made. Making corrective bath additions based on these estimates should make it possible to significantly reduce the amount of variability currently observed in the ratio measurements. 


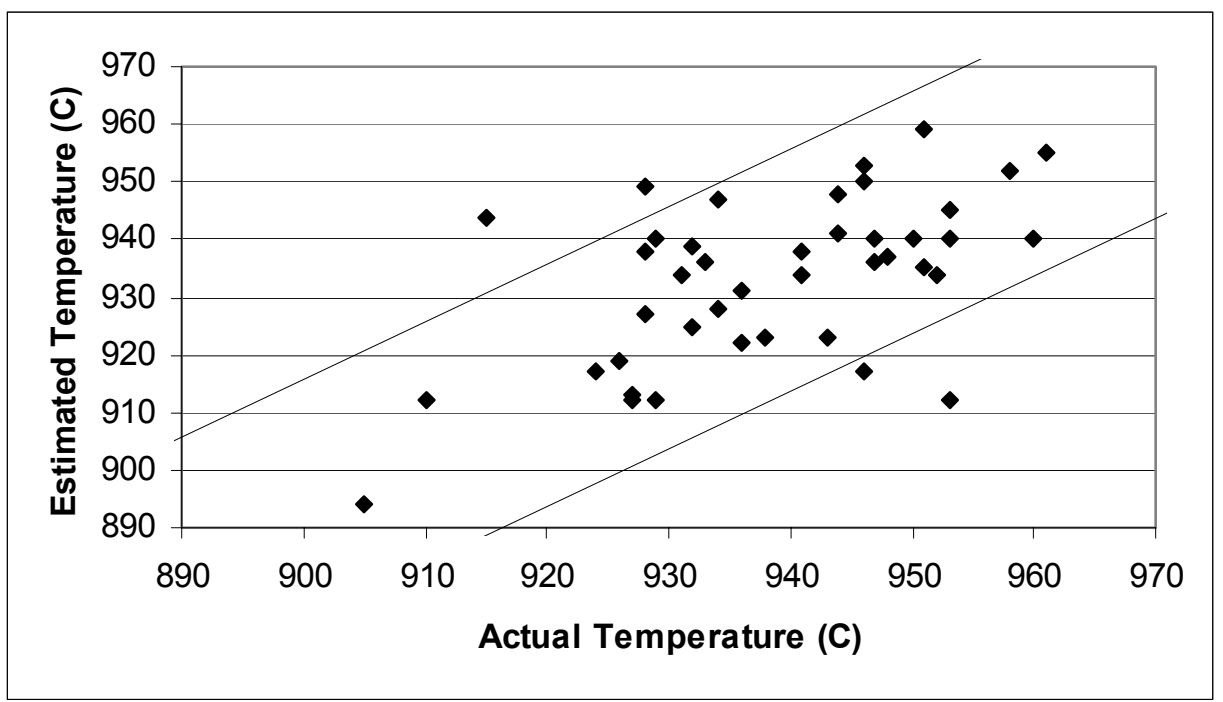

Figure 11.6: Estimated temperature versus actual temperature

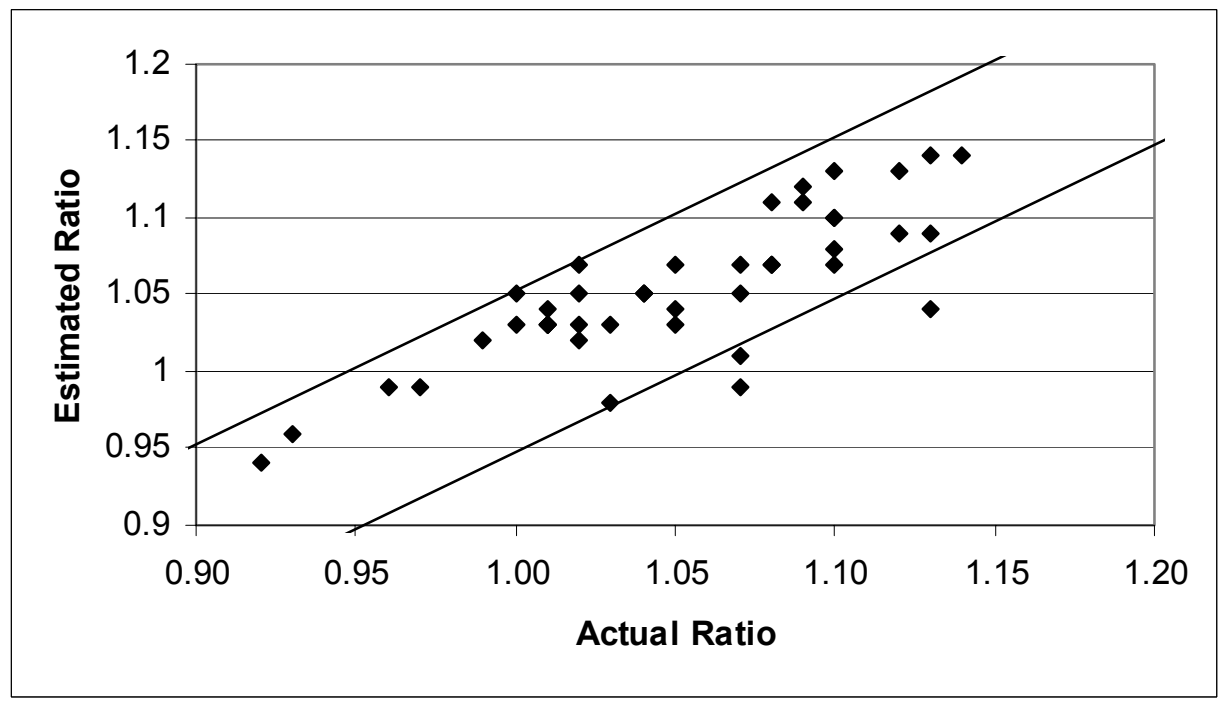

Figure 11.7: Estimated ratio versus actual ratio 


\section{Chapter 12: Conclusions and Future Work}

In this research, three models were developed for simulating the physical phenomena inherent to the aluminum reduction process. The first model was a finite element model that included the electrical, thermal, and chemical processes. The voltage model was used to study the effects of changes in the applied current density on the alumina concentration at which anode effect occurs. As the current density was increased, the anode effect occurred at higher alumina concentrations. A low bath depth is generally viewed in the industry as a trigger for an increase in the number of anode effects. However, the model suggests that only when the bath depth is extremely low would the alumina concentration at which anode effect occurs be changed by an appreciable amount. The effect of having anodes set too high or too low was also studied. When anodes are misset, the current density differences between anodes at different heights can lead to operational problems. A chart was developed which shows how far each anode should be moved to correct any imbalance.

The combined electrical, thermal, and chemical model was used to study the reaction of the system to various changes in process variables, such as the cell voltage, the bath ratio, the alumina concentration, the metal pad depth. Variations in these variables had a profound impact on the heat balance of the cell. Because many changes in the process variable levels are temporary, these effects need to be accounted for when making corrective bath additions. Furthermore, it was shown that changes in the cell voltage should not be made in an effort to correct a cell heat imbalance, but instead appropriate chemical additions should be made. A chemical correction will result in a permanent adjustment to the bath ratio, rather than one that is only temporary, and will also avoid 
putting the cell in a potentially catastrophic position. Changes in the length of time between each metal tapping event were also studied. A 48-hour tapping schedule results in larger ratio fluctuations than a 24-hour tapping schedule. However, the ratio fluctuations are probably not sufficient to warrant the increased cost associated with decreasing the time between each tapping event. Current modulation was shown to have a significant impact on the heat balance of the cell. This highlights the importance of proper planning and the study of available options when power modulation is necessary.

The finite element model is a useful tool for studying potential changes in the operation of a cell. The model would be helpful in identifying potential problems with a new operational strategy and could be used to provide a pathway for moving from the current operating regime to a new operating regime. With slight modifications in the geometry and material properties, the model could also be used to simulate other cell technologies.

Based on the knowledge that was gained developing the finite element model, two simplified models were developed. The first simplified model was used to estimate the alumina concentration in the bath. It included the chemical model and a scalar version of the electrical model. This estimator predicts occurrences of high and low alumina concentrations at the end of the overfeed period with a high level of accuracy. In its current form, the estimator could be used to adjust the feed rate during the normal period to bring the alumina concentration closer to the target level. Additional testing should be conducted to determine whether accurate estimates can be obtained at the end of the search period, in addition to the end of the overfeed period. Improved estimates would also be possible if the data obtained from the controller was accurate to $0.001 \mathrm{~V}$ rather 
than the current accuracy of $0.01 \mathrm{~V}$. The controller reports data accurate to $0.001 \mathrm{~V}$ on screen, but the data stored in the data files is only accurate to $0.01 \mathrm{~V}$. Thus, more accurate data should be available if the estimator were integrated into the feed control system. The estimator should also be tested in cells using different control algorithms to determine how well it works under different circumstances.

The second simplified model was developed to estimate the bath temperature and the ratio. It includes the chemical model, a scalar version of the electrical model, and a thermal model that is made up of 30 one-dimensional elements. The model does not appear to predict fluctuations in the temperature with a high degree of accuracy. However, using daily temperature measurements, the model is capable of accurately predicting the bath ratio. These ratio predictions could be used to make corrective bath additions on a daily basis, which should result in lower ratio variability and improved operational results. Additional work should be directed at improving the ability of the estimator to more accurately predict temperature fluctuations.

In conclusion, the finite element model provides a useful tool for studying various process interactions and the alumina concentration and ratio estimators provide the ability to reduce variability in these two important process variables. 
Appendix A: Data from the Verification of the Alumina Concentration

Estimator, and the Temperature and Ratio Estimator 
Raw Alumina Concentration Data

\begin{tabular}{|c|c|c|c|}
\hline Pot \# & Date & Time & Al2O3 \\
\hline 3B29 & $12 / 17 / 02$ & $7: 37$ & 2.57 \\
\hline 3B29 & $12 / 17 / 02$ & $9: 00$ & 2.51 \\
\hline 3B29 & $12 / 17 / 02$ & $10: 19$ & 2.53 \\
\hline 3B29 & $12 / 17 / 02$ & $11: 30$ & 2.87 \\
\hline 3B29 & $12 / 17 / 02$ & $12: 49$ & 2.61 \\
\hline 3B29 & $12 / 18 / 02$ & $1: 01$ & 3.21 \\
\hline 3B29 & $12 / 18 / 02$ & $7: 07$ & 2.93 \\
\hline 3B29 & $12 / 18 / 02$ & $9: 42$ & 3.42 \\
\hline 3B29 & $12 / 18 / 02$ & $11: 30$ & 3.04 \\
\hline 3B29 & $12 / 19 / 02$ & $6: 43$ & 3.00 \\
\hline 3B29 & $12 / 19 / 02$ & $8: 07$ & 3.06 \\
\hline 3B29 & $12 / 19 / 02$ & $9: 31$ & 3.76 \\
\hline 3B29 & $12 / 19 / 02$ & $11: 18$ & 5.57 \\
\hline 3B29 & $12 / 19 / 02$ & $12: 55$ & 2.78 \\
\hline
\end{tabular}

\begin{tabular}{|c|c|c|c|}
\hline Pot \# & Date & \multicolumn{1}{l|}{ Time } & Al2O3 \\
\hline 3B30 & $12 / 17 / 02$ & $9: 06$ & 2.70 \\
\hline 3B30 & $12 / 17 / 02$ & $10: 31$ & 2.97 \\
\hline 3B30 & $12 / 17 / 02$ & $12: 13$ & 2.87 \\
\hline 3B30 & $12 / 18 / 02$ & $7: 25$ & 3.95 \\
\hline 3B30 & $12 / 18 / 02$ & $9: 13$ & 3.38 \\
\hline 3B30 & $12 / 18 / 02$ & $11: 07$ & 3.74 \\
\hline 3B30 & $12 / 19 / 02$ & $1: 12$ & 2.34 \\
\hline 3B30 & $12 / 19 / 02$ & $6: 49$ & 3.76 \\
\hline 3B30 & $12 / 19 / 02$ & $8: 42$ & 2.91 \\
\hline 3B30 & $12 / 19 / 02$ & $10: 12$ & 3.40 \\
\hline 3B30 & $12 / 19 / 02$ & $12: 19$ & 4.40 \\
\hline
\end{tabular}

\begin{tabular}{|c|c|c|c|}
\hline Pot \# & \multicolumn{1}{|l|}{ Date } & \multicolumn{1}{l|}{ Time } & Al2O3 \\
\hline 3B31 & $12 / 17 / 02$ & $6: 43$ & 3.51 \\
\hline 3B31 & $12 / 17 / 02$ & $9: 37$ & 3.91 \\
\hline 3B31 & $12 / 17 / 02$ & $11: 25$ & 4.74 \\
\hline 3B31 & $12 / 18 / 02$ & $7: 19$ & 4.63 \\
\hline 3B31 & $12 / 18 / 02$ & $9: 00$ & 4.82 \\
\hline 3B31 & $12 / 18 / 02$ & $10: 49$ & 5.20 \\
\hline 3B31 & $12 / 18 / 02$ & $12: 31$ & 5.16 \\
\hline 3B31 & $12 / 19 / 02$ & $6: 25$ & 4.80 \\
\hline 3B31 & $12 / 19 / 02$ & $8: 07$ & 4.42 \\
\hline 3B31 & $12 / 19 / 02$ & $9: 54$ & 5.08 \\
\hline 3B31 & $12 / 19 / 02$ & $12: 01$ & 5.82 \\
\hline
\end{tabular}

\begin{tabular}{|c|c|c|c|}
\hline Pot \# & Date & Time & Al2O3 \\
\hline 3B32 & $12 / 17 / 02$ & $7: 13$ & 2.59 \\
\hline 3B32 & $12 / 17 / 02$ & $8: 55$ & 2.87 \\
\hline 3B32 & $12 / 17 / 02$ & $10: 13$ & 2.70 \\
\hline 3B32 & $12 / 17 / 02$ & $11: 49$ & 3.51 \\
\hline 3B32 & $12 / 17 / 02$ & $1: 07$ & 3.08 \\
\hline 3B32 & $12 / 18 / 02$ & $1: 07$ & 2.32 \\
\hline 3B32 & $12 / 18 / 02$ & $7: 55$ & 3.08 \\
\hline 3B32 & $12 / 18 / 02$ & $10: 00$ & 2.44 \\
\hline 3B32 & $12 / 18 / 02$ & $11: 37$ & 2.19 \\
\hline 3B32 & $12 / 19 / 02$ & $8: 31$ & 2.70 \\
\hline 3B32 & $12 / 19 / 02$ & $10: 12$ & 3.04 \\
\hline 3B32 & $12 / 19 / 02$ & $12: 07$ & 2.95 \\
\hline
\end{tabular}

\begin{tabular}{|c|c|c|c|}
\hline Pot \# & Date & \multicolumn{1}{l|}{ Time } & Al2O3 \\
\hline 3B33 & $12 / 17 / 02$ & $9: 55$ & 3.84 \\
\hline 3B33 & $12 / 17 / 02$ & $12: 43$ & 3.63 \\
\hline 3B33 & $12 / 18 / 02$ & $7: 55$ & 2.72 \\
\hline 3B33 & $12 / 18 / 02$ & $9: 55$ & 3.17 \\
\hline 3B33 & $12 / 18 / 02$ & $11: 49$ & 3.17 \\
\hline 3B33 & $12 / 19 / 02$ & $6: 30$ & 2.80 \\
\hline 3B33 & $12 / 19 / 02$ & $8: 13$ & 2.70 \\
\hline 3B33 & $12 / 19 / 02$ & $9: 43$ & 3.19 \\
\hline 3B33 & $12 / 19 / 02$ & $11: 49$ & 2.72 \\
\hline 3B33 & $12 / 19 / 02$ & $1: 24$ & 2.45 \\
\hline
\end{tabular}

\begin{tabular}{|c|c|c|c|}
\hline Pot \# & Date & \multicolumn{1}{l|}{ Time } & Al2O3 \\
\hline 3B34 & $12 / 17 / 02$ & $6: 55$ & 2.91 \\
\hline 3B34 & $12 / 17 / 02$ & $8: 42$ & 2.97 \\
\hline 3B34 & $12 / 17 / 02$ & $10: 06$ & 3.10 \\
\hline 3B34 & $12 / 17 / 02$ & $11: 37$ & 2.63 \\
\hline 3B34 & $12 / 18 / 02$ & $6: 42$ & 5.40 \\
\hline 3B34 & $12 / 18 / 02$ & $8: 42$ & 3.65 \\
\hline 3B34 & $12 / 18 / 02$ & $10: 43$ & 4.10 \\
\hline 3B34 & $12 / 19 / 02$ & $7: 25$ & 3.89 \\
\hline 3B34 & $12 / 19 / 02$ & $12: 13$ & 3.40 \\
\hline
\end{tabular}




\begin{tabular}{|c|c|c|c|}
\hline Pot \# & Date & Time & Al2O3 \\
\hline 3B35 & $12 / 17 / 02$ & $6: 19$ & 3.68 \\
\hline 3B35 & $12 / 17 / 02$ & $8: 07$ & 6.03 \\
\hline 3B35 & $12 / 17 / 02$ & $10: 01$ & 3.55 \\
\hline 3B35 & $12 / 17 / 02$ & $12: 25$ & 3.27 \\
\hline 3B35 & $12 / 18 / 02$ & $6: 49$ & 3.53 \\
\hline 3B35 & $12 / 18 / 02$ & $8: 31$ & 3.00 \\
\hline 3B35 & $12 / 18 / 02$ & $10: 07$ & 4.14 \\
\hline 3B35 & $12 / 18 / 02$ & $12: 25$ & 2.93 \\
\hline 3B35 & $12 / 19 / 02$ & $7: 01$ & 2.70 \\
\hline 3B35 & $12 / 19 / 02$ & $8: 37$ & 3.74 \\
\hline 3B35 & $12 / 19 / 02$ & $10: 12$ & 4.72 \\
\hline 3B35 & $12 / 19 / 02$ & $11: 49$ & 3.42 \\
\hline
\end{tabular}

\begin{tabular}{|c|c|c|c|}
\hline Pot \# & Date & Time & Al2O3 \\
\hline 3B36 & $12 / 17 / 02$ & $1: 07$ & 4.35 \\
\hline 3B36 & $12 / 17 / 02$ & $6: 25$ & 3.93 \\
\hline 3B36 & $12 / 17 / 02$ & $7: 43$ & 3.55 \\
\hline 3B36 & $12 / 17 / 02$ & $9: 13$ & 3.95 \\
\hline 3B36 & $12 / 17 / 02$ & $11: 14$ & 4.52 \\
\hline 3B36 & $12 / 18 / 02$ & $1: 07$ & 2.44 \\
\hline 3B36 & $12 / 18 / 02$ & $7: 25$ & 4.40 \\
\hline 3B36 & $12 / 18 / 02$ & $9: 19$ & 5.33 \\
\hline 3B36 & $12 / 18 / 02$ & $11: 30$ & 3.48 \\
\hline 3B36 & $12 / 19 / 02$ & $7: 13$ & 4.10 \\
\hline 3B36 & $12 / 19 / 02$ & $9: 12$ & 3.99 \\
\hline 3B36 & $12 / 19 / 02$ & $11: 25$ & 3.74 \\
\hline
\end{tabular}

\begin{tabular}{|c|c|c|c|}
\hline Pot \# & Date & Time & Al2O3 \\
\hline 3B37 & $12 / 17 / 02$ & $1: 01$ & 3.19 \\
\hline 3B37 & $12 / 18 / 02$ & $7: 19$ & 4.80 \\
\hline 3B37 & $12 / 18 / 02$ & $9: 00$ & 4.48 \\
\hline 3B37 & $12 / 18 / 02$ & $10: 31$ & 4.10 \\
\hline 3B37 & $12 / 18 / 02$ & $12: 25$ & 4.69 \\
\hline 3B37 & $12 / 19 / 02$ & $10: 54$ & 13.55 \\
\hline 3B37 & $12 / 19 / 02$ & $12: 13$ & 14.36 \\
\hline
\end{tabular}


Estimated and Actual Alumina Concentrations

\begin{tabular}{|c|c|c|c|c|c|c|c|}
\hline Pot \# & Date & Time & $\begin{array}{c}\text { Estimated } \\
\text { Alumina }\end{array}$ & $\begin{array}{c}\text { Actual } \\
\text { Alumina }\end{array}$ & $\begin{array}{c}\text { Approx. } \\
\text { ACD }\end{array}$ & $\begin{array}{c}\text { Tracking } \\
\text { Error }\end{array}$ & $\begin{array}{c}\text { Conc. } \\
\text { Error }\end{array}$ \\
\hline 3B29 & $12 / 17 / 02$ & $7: 37$ & 2.95 & 2.57 & 3.179 & $1.09 \mathrm{E}-02$ & 0.38 \\
\hline 3B29 & $12 / 17 / 02$ & $9: 00$ & 2.8 & 2.51 & 3.13 & $4.36 \mathrm{E}-03$ & 0.29 \\
\hline 3B29 & $12 / 17 / 02$ & $10: 19$ & 2.7 & 2.75 & 3.184 & $6.27 \mathrm{E}-03$ & 0.05 \\
\hline 3B29 & $12 / 17 / 02$ & $11: 30$ & 2.5 & 2.87 & 3.153 & $7.87 \mathrm{E}-03$ & 0.37 \\
\hline 3B29 & $12 / 17 / 02$ & $12: 49$ & 2.9 & 2.61 & 3.24 & $1.11 \mathrm{E}-02$ & 0.29 \\
\hline 3B29 & $12 / 18 / 02$ & $1: 01$ & 2.65 & 2.93 & 3.652 & $8.44 \mathrm{E}-03$ & 0.28 \\
\hline 3B29 & $12 / 18 / 02$ & $7: 07$ & 3.45 & 3.42 & 3.22 & $1.46 \mathrm{E}-02$ & 0.03 \\
\hline 3B29 & $12 / 18 / 02$ & $9: 42$ & 3.45 & 3.04 & 3.228 & $9.47 \mathrm{E}-03$ & 0.41 \\
\hline 3B29 & $12 / 18 / 02$ & $11: 30$ & 3.45 & 3.21 & 3.239 & $6.04 \mathrm{E}-03$ & 0.24 \\
\hline 3B29 & $12 / 19 / 02$ & $6: 43$ & 3 & 3 & 3.284 & $1.16 \mathrm{E}-02$ & 0 \\
\hline 3B29 & $12 / 19 / 02$ & $8: 07$ & 2.75 & 3.06 & 3.291 & $7.53 \mathrm{E}-03$ & 0.31 \\
\hline 3B29 & $12 / 19 / 02$ & $9: 31$ & 2.65 & 3.5 & 3.289 & $4.82 \mathrm{E}-03$ & 0.85 \\
\hline 3B29 & $12 / 19 / 02$ & $11: 18$ & 2.75 & 3.5 & 3.184 & $6.46 \mathrm{E}-03$ & 0.75 \\
\hline 3B29 & $12 / 19 / 02$ & $12: 55$ & 2.7 & 2.78 & 3.194 & $4.14 \mathrm{E}-03$ & 0.08 \\
\hline
\end{tabular}

\begin{tabular}{|c|c|c|c|c|c|c|c|}
\hline Pot \# & Date & Time & $\begin{array}{c}\text { Estimated } \\
\text { Alumina }\end{array}$ & $\begin{array}{c}\text { Actual } \\
\text { Alumina }\end{array}$ & $\begin{array}{c}\text { Approx. } \\
\text { ACD }\end{array}$ & $\begin{array}{c}\text { Tracking } \\
\text { Error }\end{array}$ & $\begin{array}{c}\text { Conc. } \\
\text { Error }\end{array}$ \\
\hline 3B30 & $12 / 17 / 02$ & $9: 06$ & 2.65 & 2.7 & 4.106 & $9.09 \mathrm{E}-03$ & 0.05 \\
\hline 3B30 & $12 / 17 / 02$ & $10: 31$ & 2.8 & 2.97 & 3.824 & $1.42 \mathrm{E}-02$ & 0.17 \\
\hline 3B30 & $12 / 17 / 02$ & $12: 13$ & 2.85 & 2.87 & 3.988 & $7.88 \mathrm{E}-03$ & 0.02 \\
\hline 3B30 & $12 / 18 / 02$ & $7: 25$ & 3.5 & 3.5 & 3.551 & $1.07 \mathrm{E}-02$ & 0 \\
\hline 3B30 & $12 / 18 / 02$ & $9: 13$ & 3.5 & 3.38 & 3.577 & $8.91 \mathrm{E}-03$ & 0.12 \\
\hline 3B30 & $12 / 18 / 02$ & $11: 07$ & 3.5 & 3.5 & 3.588 & $1.28 \mathrm{E}-02$ & 0 \\
\hline 3B30 & $12 / 19 / 02$ & $1: 12$ & 3.3 & 3.5 & 3.895 & $8.57 \mathrm{E}-03$ & 0.2 \\
\hline 3B30 & $12 / 19 / 02$ & $8: 42$ & 3.35 & 2.91 & 4.16 & $4.44 \mathrm{E}-03$ & 0.44 \\
\hline 3B30 & $12 / 19 / 02$ & $10: 12$ & 3.5 & 3.4 & 3.964 & $8.00 \mathrm{E}-03$ & 0.1 \\
\hline 3B30 & $12 / 19 / 02$ & $12: 19$ & 3.5 & 3.5 & 3.741 & $6.11 \mathrm{E}-03$ & 0 \\
\hline
\end{tabular}

\begin{tabular}{|c|c|c|c|c|c|c|c|}
\hline Pot \# & Date & Time & $\begin{array}{c}\text { Estimated } \\
\text { Alumina }\end{array}$ & $\begin{array}{c}\text { Actual } \\
\text { Alumina }\end{array}$ & $\begin{array}{c}\text { Approx. } \\
\text { ACD }\end{array}$ & $\begin{array}{c}\text { Tracking } \\
\text { Error }\end{array}$ & $\begin{array}{c}\text { Conc. } \\
\text { Error }\end{array}$ \\
\hline 3B31 & $12 / 17 / 02$ & $6: 43$ & 2.75 & 3.5 & 3.193 & $4.92 \mathrm{E}-02$ & 0.75 \\
\hline 3B31 & $12 / 17 / 02$ & $9: 37$ & 2.5 & 3.5 & 3.72 & $3.28 \mathrm{E}-02$ & 1 \\
\hline 3B31 & $12 / 17 / 02$ & $11: 25$ & 2.85 & 3.5 & 3.642 & $1.87 \mathrm{E}-02$ & 0.65 \\
\hline 3B31 & $12 / 18 / 02$ & $7: 19$ & 3.5 & 3.5 & 3.043 & $1.14 \mathrm{E}-02$ & 0 \\
\hline 3B31 & $12 / 18 / 02$ & $9: 00$ & 3.5 & 3.5 & 2.988 & $2.18 \mathrm{E}-02$ & 0 \\
\hline 3B31 & $12 / 18 / 02$ & $10: 49$ & 3.5 & 3.5 & 3.002 & $9.00 \mathrm{E}-03$ & 0 \\
\hline 3B31 & $12 / 18 / 02$ & $12: 31$ & 3.5 & 3.5 & 3.019 & $1.12 \mathrm{E}-02$ & 0 \\
\hline 3B31 & $12 / 19 / 02$ & $6: 25$ & 3.5 & 3.5 & 3.051 & $8.53 \mathrm{E}-03$ & 0 \\
\hline 3B31 & $12 / 19 / 02$ & $8: 07$ & 3.5 & 3.5 & 3.051 & $8.53 \mathrm{E}-03$ & 0 \\
\hline 3B31 & $12 / 19 / 02$ & $9: 54$ & 3.5 & 3.5 & 3.047 & $8.77 \mathrm{E}-03$ & 0 \\
\hline 3B31 & $12 / 19 / 02$ & $12: 01$ & 3.5 & 3.5 & 3.125 & $2.49 \mathrm{E}-02$ & 0 \\
\hline
\end{tabular}




\begin{tabular}{|c|c|c|c|c|c|c|c|}
\hline Pot \# & Date & Time & $\begin{array}{c}\text { Estimated } \\
\text { Alumina }\end{array}$ & $\begin{array}{c}\text { Actual } \\
\text { Alumina }\end{array}$ & $\begin{array}{c}\text { Approx. } \\
\text { ACD }\end{array}$ & $\begin{array}{c}\text { Tracking } \\
\text { Error }\end{array}$ & $\begin{array}{c}\text { Conc. } \\
\text { Error }\end{array}$ \\
\hline 3B32 & $12 / 17 / 02$ & $7: 13$ & 3.35 & 2.59 & 3.261 & $6.82 \mathrm{E}-03$ & 0.76 \\
\hline 3B32 & $12 / 17 / 02$ & $8: 55$ & 3.05 & 2.87 & 3.263 & $1.03 \mathrm{E}-02$ & 0.18 \\
\hline 3B32 & $12 / 17 / 02$ & $10: 13$ & 3.45 & 2.7 & 3.268 & $1.58 \mathrm{E}-02$ & 0.75 \\
\hline 3B32 & $12 / 17 / 02$ & $11: 49$ & 3 & 3.5 & 3.252 & $7.71 \mathrm{E}-03$ & 0.5 \\
\hline 3B32 & $12 / 17 / 02$ & $1: 07$ & 2.75 & 3.08 & 3.304 & $1.46 \mathrm{E}-02$ & 0.33 \\
\hline 3B32 & $12 / 18 / 02$ & $1: 07$ & 3.5 & 3.08 & 3.336 & $1.30 \mathrm{E}-02$ & 0.42 \\
\hline 3B32 & $12 / 18 / 02$ & $7: 55$ & 3.5 & 2.5 & 3.337 & $1.37 \mathrm{E}-02$ & 1 \\
\hline 3B32 & $12 / 18 / 02$ & $10: 00$ & 3.25 & 2.5 & 3.343 & $1.79 \mathrm{E}-02$ & 0.75 \\
\hline 3B32 & $12 / 18 / 02$ & $11: 37$ & 3.05 & 2.5 & 3.294 & $8.79 \mathrm{E}-03$ & 0.55 \\
\hline 3B32 & $12 / 19 / 02$ & $8: 31$ & 3.5 & 2.7 & 3.36 & $1.44 \mathrm{E}-02$ & 0.8 \\
\hline 3B32 & $12 / 19 / 02$ & $10: 12$ & 3.45 & 3.04 & 3.423 & $1.20 \mathrm{E}-02$ & 0.41 \\
\hline 3B32 & $12 / 19 / 02$ & $12: 07$ & 3.2 & 2.95 & 3.233 & $1.14 \mathrm{E}-02$ & 0.25 \\
\hline
\end{tabular}

\begin{tabular}{|c|c|c|c|c|c|c|c|}
\hline Pot \# & Date & Time & $\begin{array}{c}\text { Estimated } \\
\text { Alumina }\end{array}$ & $\begin{array}{c}\text { Actual } \\
\text { Alumina }\end{array}$ & $\begin{array}{c}\text { Approx. } \\
\text { ACD }\end{array}$ & $\begin{array}{c}\text { Tracking } \\
\text { Error }\end{array}$ & $\begin{array}{c}\text { Conc. } \\
\text { Error }\end{array}$ \\
\hline 3B33 & $12 / 17 / 02$ & $9: 55$ & 2.5 & 3.5 & 3.599 & $1.29 \mathrm{E}-02$ & 1 \\
\hline 3B33 & $12 / 17 / 02$ & $12: 43$ & 3.25 & 3.5 & 4.581 & $1.62 \mathrm{E}-02$ & 0.25 \\
\hline 3B33 & $12 / 18 / 02$ & $7: 55$ & 3.45 & 2.72 & 3.155 & $8.87 \mathrm{E}-03$ & 0.73 \\
\hline 3B33 & $12 / 18 / 02$ & $9: 55$ & 3.5 & 3.17 & 3.171 & $8.90 \mathrm{E}-03$ & 0.33 \\
\hline 3B33 & $12 / 18 / 02$ & $11: 49$ & 3.25 & 3.17 & 3.073 & $7.23 \mathrm{E}-03$ & 0.08 \\
\hline 3B33 & $12 / 19 / 02$ & $6: 30$ & 2.8 & 2.8 & 3.042 & $9.20 \mathrm{E}-03$ & 0 \\
\hline 3B33 & $12 / 19 / 02$ & $8: 13$ & 2.6 & 2.7 & 3.067 & $5.35 \mathrm{E}-03$ & 0.1 \\
\hline 3B33 & $12 / 19 / 02$ & $9: 43$ & 2.75 & 3.19 & 3.112 & $5.46 \mathrm{E}-03$ & 0.44 \\
\hline 3B33 & $12 / 19 / 02$ & $11: 49$ & 3.05 & 2.72 & 3.08 & $7.10 \mathrm{E}-03$ & 0.33 \\
\hline 3B33 & $12 / 19 / 02$ & $1: 24$ & 2.8 & 2.5 & 3.179 & $3.70 \mathrm{E}-03$ & 0.3 \\
\hline
\end{tabular}

\begin{tabular}{|c|c|c|c|c|c|c|c|}
\hline Pot \# & Date & Time & $\begin{array}{c}\text { Estimated } \\
\text { Alumina }\end{array}$ & $\begin{array}{c}\text { Actual } \\
\text { Alumina }\end{array}$ & $\begin{array}{c}\text { Approx. } \\
\text { ACD }\end{array}$ & $\begin{array}{c}\text { Tracking } \\
\text { Error }\end{array}$ & $\begin{array}{c}\text { Conc. } \\
\text { Error }\end{array}$ \\
\hline 3B34 & $12 / 17 / 02$ & $6: 55$ & 3.45 & 2.91 & 3.045 & $1.52 \mathrm{E}-02$ & 0.54 \\
\hline 3B34 & $12 / 17 / 02$ & $8: 42$ & 3.45 & 2.97 & 3.136 & $1.91 \mathrm{E}-02$ & 0.48 \\
\hline 3B34 & $12 / 17 / 02$ & $10: 06$ & 3.5 & 3.1 & 3.141 & $1.29 \mathrm{E}-02$ & 0.4 \\
\hline 3B34 & $12 / 17 / 02$ & $11: 37$ & 3.5 & 2.63 & 3.145 & $1.48 \mathrm{E}-02$ & 0.87 \\
\hline 3B34 & $12 / 18 / 02$ & $6: 42$ & 3.3 & 3.5 & 3.14 & $1.70 \mathrm{E}-02$ & 0.2 \\
\hline 3B34 & $12 / 18 / 02$ & $8: 42$ & 3.5 & 3.5 & 3.067 & $1.94 \mathrm{E}-02$ & 0 \\
\hline 3B34 & $12 / 18 / 02$ & $10: 43$ & 3.5 & 3.5 & 3.403 & $1.43 \mathrm{E}-02$ & 0 \\
\hline 3B34 & $12 / 19 / 02$ & $7: 25$ & 3.05 & 3.5 & 3.845 & $2.15 \mathrm{E}-02$ & 0.45 \\
\hline 3B34 & $12 / 19 / 02$ & $12: 13$ & 3.5 & 3.4 & 4.352 & $2.92 \mathrm{E}-02$ & 0.1 \\
\hline
\end{tabular}




\begin{tabular}{|c|c|c|c|c|c|c|c|}
\hline Pot \# & Date & Time & $\begin{array}{c}\text { Estimated } \\
\text { Alumina }\end{array}$ & $\begin{array}{c}\text { Actual } \\
\text { Alumina }\end{array}$ & $\begin{array}{c}\text { Approx. } \\
\text { ACD }\end{array}$ & $\begin{array}{c}\text { Tracking } \\
\text { Error }\end{array}$ & $\begin{array}{c}\text { Conc. } \\
\text { Error }\end{array}$ \\
\hline 3B35 & $12 / 17 / 02$ & $6: 19$ & 3.3 & 3.5 & 3.087 & $1.21 \mathrm{E}-02$ & 0.2 \\
\hline 3B35 & $12 / 17 / 02$ & $8: 07$ & 3.05 & 3.5 & 3.041 & $6.19 \mathrm{E}-03$ & 0.45 \\
\hline 3B35 & $12 / 17 / 02$ & $10: 01$ & 3.1 & 3.5 & 2.97 & $1.02 \mathrm{E}-02$ & 0.4 \\
\hline 3B35 & $12 / 17 / 02$ & $12: 25$ & 3.45 & 3.27 & 3.023 & $1.04 \mathrm{E}-02$ & 0.18 \\
\hline 3B35 & $12 / 18 / 02$ & $6: 49$ & 2.9 & 3.5 & 3.033 & $5.37 \mathrm{E}-03$ & 0.6 \\
\hline 3B35 & $12 / 18 / 02$ & $8: 31$ & 2.8 & 3 & 3.01 & $6.06 \mathrm{E}-03$ & 0.2 \\
\hline 3B35 & $12 / 18 / 02$ & $10: 07$ & 3.5 & 3.5 & 2.974 & $1.37 \mathrm{E}-02$ & 0 \\
\hline 3B35 & $12 / 18 / 02$ & $12: 25$ & 3.2 & 2.93 & 3.082 & $7.50 \mathrm{E}-03$ & 0.27 \\
\hline 3B35 & $12 / 19 / 02$ & $7: 01$ & 2.65 & 2.7 & 3.03 & $1.05 \mathrm{E}-02$ & 0.05 \\
\hline 3B35 & $12 / 19 / 02$ & $8: 37$ & 2.9 & 3.5 & 3.069 & $6.83 \mathrm{E}-03$ & 0.6 \\
\hline 3B35 & $12 / 19 / 02$ & $10: 12$ & 2.75 & 3.5 & 3.095 & $8.36 \mathrm{E}-03$ & 0.75 \\
\hline 3B35 & $12 / 19 / 02$ & $11: 49$ & 2.8 & 3.42 & 3.076 & $4.20 \mathrm{E}-03$ & 0.62 \\
\hline
\end{tabular}

\begin{tabular}{|c|c|c|c|c|c|c|c|}
\hline Pot \# & Date & Time & $\begin{array}{c}\text { Estimated } \\
\text { Alumina }\end{array}$ & $\begin{array}{c}\text { Actual } \\
\text { Alumina }\end{array}$ & $\begin{array}{c}\text { Approx. } \\
\text { ACD }\end{array}$ & $\begin{array}{c}\text { Tracking } \\
\text { Error }\end{array}$ & $\begin{array}{c}\text { Conc. } \\
\text { Error }\end{array}$ \\
\hline 3B36 & $12 / 17 / 02$ & $1: 07$ & 2.75 & 3.5 & 3.246 & $1.51 \mathrm{E}-02$ & 0.75 \\
\hline 3B36 & $12 / 17 / 02$ & $6: 25$ & 2.55 & 3.5 & 3.306 & $1.25 \mathrm{E}-02$ & 0.95 \\
\hline 3B36 & $12 / 17 / 02$ & $7: 43$ & 3.5 & 3.5 & 3.384 & $2.00 \mathrm{E}-02$ & 0 \\
\hline 3B36 & $12 / 17 / 02$ & $9: 13$ & 3.35 & 3.5 & 3.263 & $1.04 \mathrm{E}-02$ & 0.15 \\
\hline 3B36 & $12 / 17 / 02$ & $11: 14$ & 3.5 & 3.5 & 3.301 & $4.11 \mathrm{E}-02$ & 0 \\
\hline 3B36 & $12 / 18 / 02$ & $1: 07$ & 3.5 & 3.5 & 3.161 & $8.62 \mathrm{E}-03$ & 0 \\
\hline 3B36 & $12 / 18 / 02$ & $7: 25$ & 3.05 & 3.5 & 3.168 & $9.20 \mathrm{E}-03$ & 0.45 \\
\hline 3B36 & $12 / 18 / 02$ & $9: 19$ & 3.35 & 3.48 & 3.17 & $6.42 \mathrm{E}-03$ & 0.13 \\
\hline 3B36 & $12 / 18 / 02$ & $11: 30$ & 3.5 & 2.5 & 3.172 & $2.30 \mathrm{E}-02$ & 1 \\
\hline 3B36 & $12 / 19 / 02$ & $7: 13$ & 3.35 & 3.5 & 3.252 & $8.53 \mathrm{E}-03$ & 0.15 \\
\hline 3B36 & $12 / 19 / 02$ & $9: 12$ & 3.45 & 3.5 & 3.151 & $1.48 \mathrm{E}-02$ & 0.05 \\
\hline 3B36 & $12 / 19 / 02$ & $11: 25$ & 3.5 & 3.5 & 3.122 & $1.05 \mathrm{E}-02$ & 0 \\
\hline
\end{tabular}

\begin{tabular}{|c|c|c|c|c|c|c|c|}
\hline Pot \# & Date & Time & $\begin{array}{c}\text { Estimated } \\
\text { Alumina }\end{array}$ & $\begin{array}{c}\text { Actual } \\
\text { Alumina }\end{array}$ & $\begin{array}{c}\text { Approx. } \\
\text { ACD }\end{array}$ & $\begin{array}{c}\text { Tracking } \\
\text { Error }\end{array}$ & $\begin{array}{c}\text { Conc. } \\
\text { Error }\end{array}$ \\
\hline 3B37 & $12 / 17 / 02$ & $1: 01$ & 2.75 & 3.19 & 4.478 & $1.16 \mathrm{E}-02$ & 0.44 \\
\hline 3B37 & $12 / 18 / 02$ & $7: 19$ & 3.3 & 3.5 & 3.489 & $7.48 \mathrm{E}-03$ & 0.2 \\
\hline 3B37 & $12 / 18 / 02$ & $9: 00$ & 3.5 & 3.5 & 3.395 & $8.91 \mathrm{E}-03$ & 0 \\
\hline 3B37 & $12 / 18 / 02$ & $10: 31$ & 2.9 & 3.5 & 3.395 & $4.82 \mathrm{E}-03$ & 0.6 \\
\hline 3B37 & $12 / 18 / 02$ & $12: 25$ & 3.2 & 3.5 & 3.263 & $1.26 \mathrm{E}-02$ & 0.3 \\
\hline 3B37 & $12 / 19 / 02$ & $10: 54$ & 3.5 & 3.5 & 3.419 & $1.94 \mathrm{E}-02$ & 0 \\
\hline 3B37 & $12 / 19 / 02$ & $12: 13$ & 2.7 & 3.5 & 3.492 & $1.04 \mathrm{E}-02$ & 0.8 \\
\hline
\end{tabular}


$\underline{\text { Raw Temperature and Ratio Data }}$

\begin{tabular}{|c|c|c|c|c|c|}
\hline Date & Pot & xs AIF3 & Ratio & Spar & Temp \\
\hline $12 / 17 / 2002$ & 3B29 & 16.4 & 1.01 & 4.40 & 938 \\
\hline $12 / 17 / 2002$ & 3B30 & 13.4 & 1.08 & 4.39 & 946 \\
\hline $12 / 17 / 2002$ & 3B31 & 16.1 & 1.01 & 4.38 & 932 \\
\hline $12 / 17 / 2002$ & 3B32 & 15.2 & 1.04 & 4.17 & 941 \\
\hline $12 / 17 / 2002$ & 3B33 & 15.7 & 1.02 & 4.47 & 928 \\
\hline $12 / 17 / 2002$ & 3B34 & 20.2 & 0.92 & 4.15 & 905 \\
\hline $12 / 17 / 2002$ & 3B35 & 12.8 & 1.10 & 4.34 & 953 \\
\hline $12 / 17 / 2002$ & 3B36 & 15.4 & 1.03 & 4.09 & 931 \\
\hline $12 / 17 / 2002$ & 3B37 & 15.3 & 1.03 & 4.24 & 915 \\
\hline $12 / 17 / 2002$ & 3B38 & 17.0 & 0.99 & 4.40 & 927 \\
\hline $12 / 17 / 2002$ & 3B39 & 17.8 & 0.97 & 4.38 & 927 \\
\hline $12 / 17 / 2002$ & 3B40 & 15.6 & 1.02 & 4.58 & 936 \\
\hline $12 / 17 / 2002$ & 3B41 & 14.6 & 1.05 & 4.21 & 928 \\
\hline $12 / 17 / 2002$ & 3B42 & 13.5 & 1.08 & 4.40 & 944 \\
\hline
\end{tabular}

\begin{tabular}{|l|l|l|l|l|l|}
\hline $12 / 18 / 2002$ & 3B29 & 14.7 & 1.05 & 4.25 & 950 \\
\hline $12 / 18 / 2002$ & 3B30 & 12.0 & 1.12 & 4.18 & 947 \\
\hline $12 / 18 / 2002$ & 3B31 & 11.6 & 1.13 & 4.09 & 960 \\
\hline $12 / 18 / 2002$ & 3B32 & 16.5 & 1.00 & 4.11 & 928 \\
\hline $12 / 18 / 2002$ & 3B33 & 12.7 & 1.10 & 4.27 & 947 \\
\hline $12 / 18 / 2002$ & 3B34 & 19.6 & 0.93 & 3.96 & 910 \\
\hline $12 / 18 / 2002$ & 3B35 & 13.6 & 1.08 & 3.87 & 946 \\
\hline $12 / 18 / 2002$ & 3B36 & 15.0 & 1.04 & 3.99 & 932 \\
\hline $12 / 18 / 2002$ & 3B37 & 11.7 & 1.13 & 3.81 & 953 \\
\hline $12 / 18 / 2002$ & 3B38 & 13.8 & 1.07 & 4.19 & 943 \\
\hline $12 / 18 / 2002$ & 3B39 & 13.7 & 1.07 & 3.97 & 929 \\
\hline $12 / 18 / 2002$ & 3B40 & 13.8 & 1.07 & 4.22 & 946 \\
\hline $12 / 18 / 2002$ & 3B41 & 16.1 & 1.01 & 4.20 & 934 \\
\hline $12 / 18 / 2002$ & 3B42 & 13.2 & 1.09 & 4.44 & 953 \\
\hline
\end{tabular}

\begin{tabular}{|l|l|l|l|l|l|}
\hline $12 / 19 / 2002$ & 3B29 & 16.7 & 1.00 & 4.36 & 934 \\
\hline $12 / 19 / 2002$ & 3B30 & 11.9 & 1.12 & 4.26 & 958 \\
\hline $12 / 19 / 2002$ & 3B31 & 11.3 & 1.14 & 4.15 & 961 \\
\hline $12 / 19 / 2002$ & 3B32 & 15.7 & 1.02 & 4.27 & 929 \\
\hline $12 / 19 / 2002$ & 3B33 & 14.8 & 1.05 & 4.62 & 936 \\
\hline $12 / 19 / 2002$ & 3B34 & 18.2 & 0.96 & 4.20 & 926 \\
\hline $12 / 19 / 2002$ & 3B35 & 12.8 & 1.10 & 4.26 & 944 \\
\hline $12 / 19 / 2002$ & 3B36 & 16.2 & 1.01 & 4.23 & 933 \\
\hline $12 / 19 / 2002$ & 3B37 & 14.0 & 1.07 & 4.28 & 924 \\
\hline $12 / 19 / 2002$ & 3B38 & 13.0 & 1.09 & 4.49 & 948 \\
\hline $12 / 19 / 2002$ & 3B39 & 12.6 & 1.10 & 4.31 & 952 \\
\hline $12 / 19 / 2002$ & 3B40 & 12.6 & 1.10 & 4.44 & 951 \\
\hline $12 / 19 / 2002$ & 3B41 & 15.9 & 1.02 & 4.22 & 941 \\
\hline $12 / 19 / 2002$ & 3B42 & 11.4 & 1.13 & 4.40 & 951 \\
\hline
\end{tabular}


Temperature Estimator Results

\begin{tabular}{|c|c|c|c|c|c|c|c|c|}
\hline Date & Pot & $\begin{array}{c}\text { Estimated } \\
\text { Temp. }\end{array}$ & $\begin{array}{l}\text { Actual } \\
\text { Temp. }\end{array}$ & Error & $\begin{array}{l}\text { Initial } \\
\text { Ratio }\end{array}$ & $\begin{array}{c}\text { Adjusted } \\
\text { Ratio }\end{array}$ & $\begin{array}{l}\text { Actual } \\
\text { Ratio }\end{array}$ & Error \\
\hline $12 / 17 / 2002$ & $3 B 29$ & 923 & 938 & -15 & 1.01 & 1.04 & 1.01 & 0.03 \\
\hline $12 / 17 / 2002$ & $3 B 30$ & 950 & 946 & 4 & 1.08 & 1.07 & 1.08 & -0.01 \\
\hline $12 / 17 / 2002$ & 3B31 & 925 & 932 & -7 & 1.01 & 1.03 & 1.01 & 0.02 \\
\hline $12 / 17 / 2002$ & 3B32 & 938 & 941 & -3 & 1.04 & 1.05 & 1.04 & 0.01 \\
\hline $12 / 17 / 2002$ & 3B33 & 927 & 928 & -1 & 1.02 & 1.02 & 1.02 & 0.00 \\
\hline $12 / 17 / 2002$ & 3B34 & 894 & 905 & -11 & 0.92 & 0.94 & 0.92 & 0.02 \\
\hline $12 / 17 / 2002$ & $3 B 35$ & 945 & 953 & -8 & 1.10 & 1.13 & 1.10 & 0.03 \\
\hline $12 / 17 / 2002$ & 3B36 & 934 & 931 & 3 & 1.03 & 1.03 & 1.03 & 0.00 \\
\hline $12 / 17 / 2002$ & 3B37 & 944 & 915 & 29 & 1.03 & 0.98 & 1.03 & -0.05 \\
\hline $12 / 17 / 2002$ & 3B38 & 912 & 927 & -15 & 0.99 & 1.02 & 0.99 & 0.03 \\
\hline $12 / 17 / 2002$ & 3B39 & 913 & 927 & -14 & 0.97 & 0.99 & 0.97 & 0.02 \\
\hline $12 / 17 / 2002$ & $3 B 40$ & 922 & 936 & -14 & 1.02 & 1.05 & 1.02 & 0.03 \\
\hline $12 / 17 / 2002$ & 3B41 & 938 & 928 & 10 & 1.05 & 1.03 & 1.05 & -0.02 \\
\hline $12 / 17 / 2002$ & 3B42 & 948 & 944 & 4 & 1.08 & 1.07 & 1.08 & -0.01 \\
\hline $12 / 18 / 2002$ & 3B29 & 940 & 950 & -10 & 1.05 & 1.07 & 1.05 & 0.02 \\
\hline $12 / 18 / 2002$ & $3 \mathrm{~B} 30$ & 940 & 947 & -7 & 1.07 & 1.09 & 1.12 & -0.03 \\
\hline $12 / 18 / 2002$ & 3B31 & 940 & 960 & -20 & 1.08 & 1.14 & 1.13 & 0.01 \\
\hline $12 / 18 / 2002$ & 3B32 & 949 & 928 & 21 & 1.08 & 1.03 & 1.00 & 0.03 \\
\hline $12 / 18 / 2002$ & 3B33 & 936 & 947 & -11 & 1.05 & 1.07 & 1.10 & -0.03 \\
\hline $12 / 18 / 2002$ & 3B34 & 912 & 910 & 2 & 0.97 & 0.96 & 0.93 & 0.03 \\
\hline $12 / 18 / 2002$ & $3 B 35$ & 953 & 946 & 7 & 1.13 & 1.11 & 1.08 & 0.03 \\
\hline $12 / 18 / 2002$ & 3B36 & 939 & 932 & 7 & 1.06 & 1.05 & 1.04 & 0.01 \\
\hline $12 / 18 / 2002$ & 3B37 & 912 & 953 & -41 & 0.96 & 1.04 & 1.13 & -0.09 \\
\hline $12 / 18 / 2002$ & 3B38 & 923 & 943 & -20 & 1.01 & 1.05 & 1.07 & -0.02 \\
\hline $12 / 18 / 2002$ & 3B39 & 912 & 929 & -17 & 0.98 & 1.01 & 1.07 & -0.06 \\
\hline $12 / 18 / 2002$ & $3 \mathrm{~B} 40$ & 917 & 946 & -29 & 1.01 & 1.07 & 1.07 & 0.00 \\
\hline $12 / 18 / 2002$ & $3 B 41$ & 928 & 934 & -6 & 1.02 & 1.03 & 1.01 & 0.02 \\
\hline $12 / 18 / 2002$ & 3B42 & 940 & 953 & -13 & 1.07 & 1.11 & 1.09 & 0.02 \\
\hline $12 / 19 / 2002$ & 3B29 & 947 & 934 & 13 & 1.08 & 1.05 & 1.00 & 0.05 \\
\hline $12 / 19 / 2002$ & $3 \mathrm{~B} 30$ & 952 & 958 & -6 & 1.10 & 1.13 & 1.12 & 0.01 \\
\hline $12 / 19 / 2002$ & 3B31 & 955 & 961 & -6 & 1.12 & 1.14 & 1.14 & 0.00 \\
\hline $12 / 19 / 2002$ & 3B32 & 940 & 929 & 11 & 1.06 & 1.03 & 1.02 & 0.01 \\
\hline $12 / 19 / 2002$ & 3B33 & 931 & 936 & -5 & 1.02 & 1.04 & 1.05 & -0.01 \\
\hline $12 / 19 / 2002$ & 3B34 & 919 & 926 & -7 & 0.98 & 0.99 & 0.96 & 0.03 \\
\hline $12 / 19 / 2002$ & 3B35 & 941 & 944 & -3 & 1.09 & 1.10 & 1.10 & 0.00 \\
\hline $12 / 19 / 2002$ & $3 \mathrm{~B} 36$ & 936 & 933 & 3 & 1.03 & 1.03 & 1.01 & 0.02 \\
\hline $12 / 19 / 2002$ & 3B37 & 917 & 924 & -7 & 0.98 & 0.99 & 1.07 & -0.08 \\
\hline $12 / 19 / 2002$ & 3B38 & 937 & 948 & -11 & 1.09 & 1.12 & 1.09 & 0.03 \\
\hline $12 / 19 / 2002$ & 3B39 & 934 & 952 & -18 & 1.04 & 1.08 & 1.10 & -0.02 \\
\hline $12 / 19 / 2002$ & $3 \mathrm{~B} 40$ & 935 & 951 & -16 & 1.06 & 1.10 & 1.10 & 0.00 \\
\hline $12 / 19 / 2002$ & 3B41 & 934 & 941 & -7 & 1.06 & 1.07 & 1.02 & 0.05 \\
\hline $12 / 19 / 2002$ & $3 B 42$ & 959 & 951 & 8 & 1.11 & 1.09 & 1.13 & -0.04 \\
\hline
\end{tabular}

\begin{tabular}{|l|r|r|r|r|r|r|r|}
\hline Average & 933.12 & 938.50 & -5.38 & 1.041 & 1.053 & 1.051 & 0.002 \\
\hline Standard Dev. & 14.34 & 13.03 & 12.88 & 0.048 & 0.048 & 0.055 & 0.032 \\
\hline
\end{tabular}

